Facultad de Ciencias Naturales y Museo

Universidad Nacional de La Plata

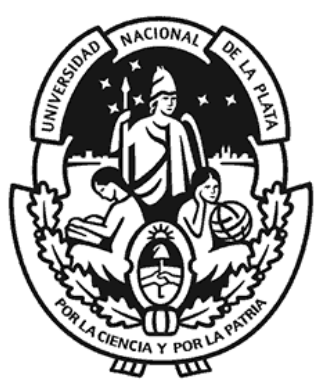

\title{
Vegetación y ambientes del Holoceno en el sector continental de la Bahía Samborombón, provincia de Buenos Aires: cambios del nivel del mar
}

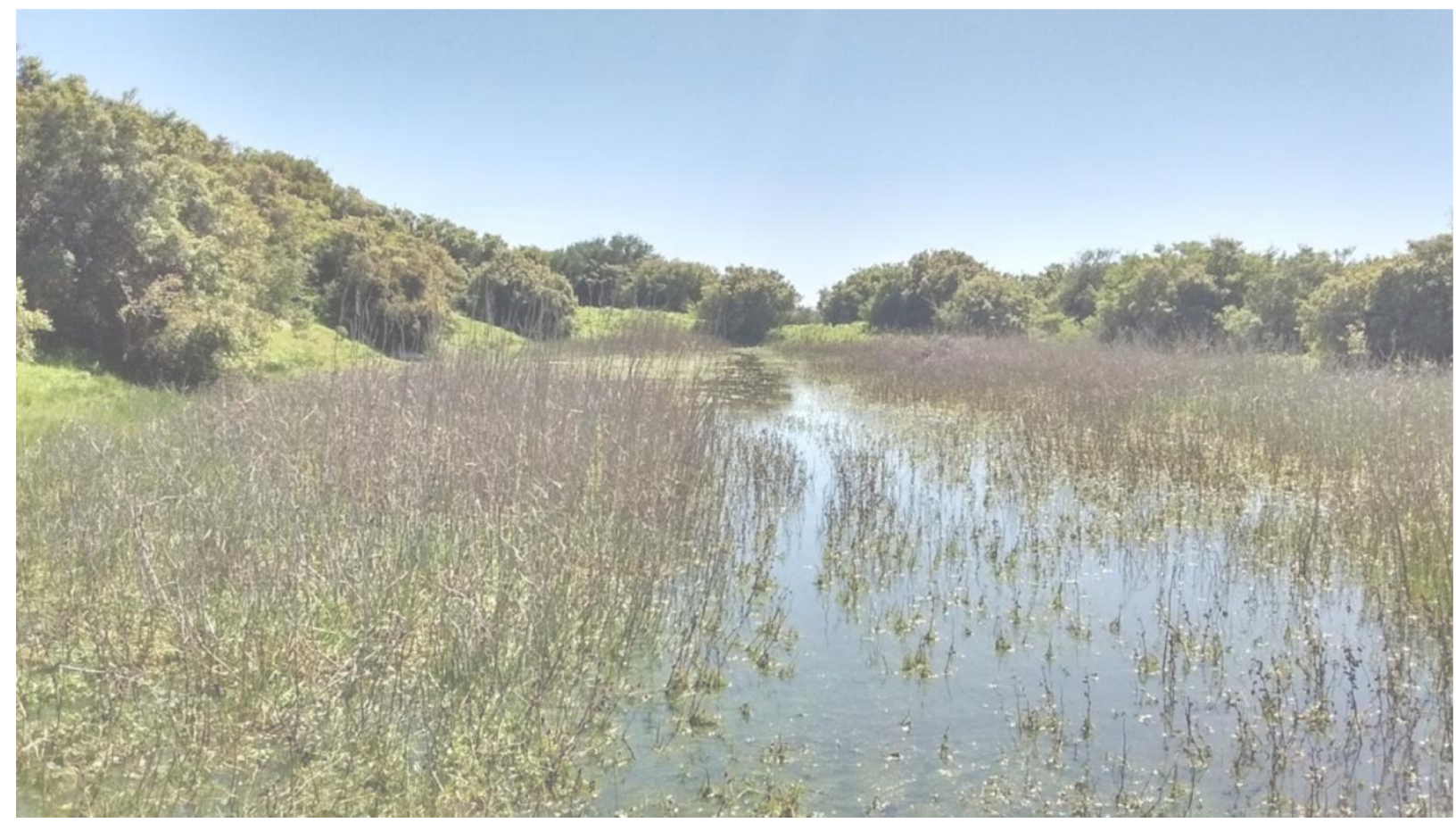

\section{Mariel Samanta Luengo}

Director: Dr. Enrique Eduardo Fucks

Directora: Dra. Isabel Vilanova

Tesis presentada para optar por el título de Doctora en Ciencias Naturales

(2019) 


\section{Agradecimientos}

Quiero agradecer en primer lugar a mis directores Isabel y Enrique por su infinita paciencia, dedicación y por tanto cariño.

A mis amigas, compañeras Flor, Gaby, Nicky y Ceci, que las adoro tanto y admiro más. Gracias por tanto cariño y apoyo sobre todo en los últimos meses.

A Lucho, que me ayuda a crecer día a día y que me banca en todo. Gracias por la paciencia y apoyo incondicional.

A Sonia Fontana gracias por lo brindado, y por el cariño. A todos los integrantes del Cisaua, gracias por brindarme un lugarcito del que me adueñé. Gracias por tanto cariño y por hacerme sentir como una más de su grupo. Gracias por la generosidad de todos y buena onda.

A todo el equipo de la Cátedra de palinología de la FCNyM; Marta, Ceci, Cosme , Agustina, Raquel, Daniela, Leo, Marce. Gracias por darme un lugar en

el labo 20, por las charlas, el apoyo y por tanto cariño, y por las charlas y fuerzas que me dieron en los últimos meses.

A graciela Salinas de Salmuni de CONAE gracias por su paciencia y dedicación. A Emiliana Bernasconi y Angélica Ballesteros, gracias por el aguante desde Bariloche, por las charlas, las campañas compartidas, por más trabajo juntas.

A Patricio Moreno y Simón, por la ayuda brindada con los análisis estadísticos

A los integrantes actuales y pasados de la cátedra Geología del Cuaternario Yamile, Flor, Marco, Mariana, Vicky, Marta, Betina, Nicky gracias por el aguante, un placer compartir los Lunes con ustedes.

A a Nico y al Tano por el aguante y cariño. 
Un especial agradecimiento a mi familia, mis papás Mirta y Daniel por creer siempre en mi y apoyarme en esta locura desde siempre. A mis hermanos Martín y Daniela que son todo para mí.

A mi hermana del alma Juliana, a quien admiro tanto y quien que brindó tanto apoyo y cariño. Incondicional.

A mis queridas y adoradas abuelas Haydeé y Delia, mis tías Miriam, Mari, Tati, Ana y mis tíos Osmar, Negro, Jorge y Martín. Y a toda la banda de primos.

A mis amigos del alma Juli, Seba, Gra, Rocío, Egly, Guada, Mili, Tere, Eve, Lu, Vale, Sabri, Laura,

A mis amigas linqueñas Roma y Orne, gracias por estar a la distancia. 


\section{ÍNDICE GENERAL}

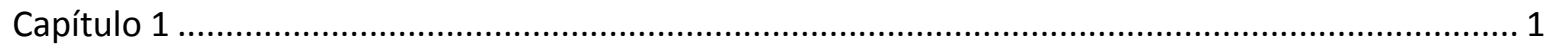

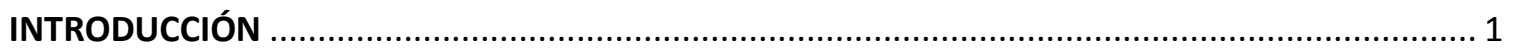

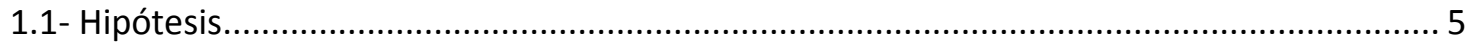

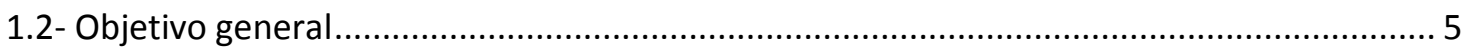

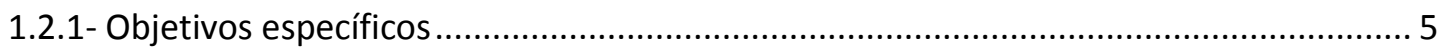

1.3- Características generales del área del estudio y antecedentes ....................................... 6

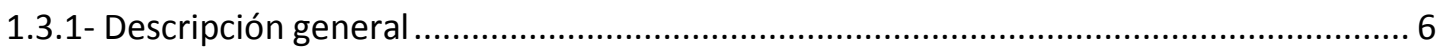

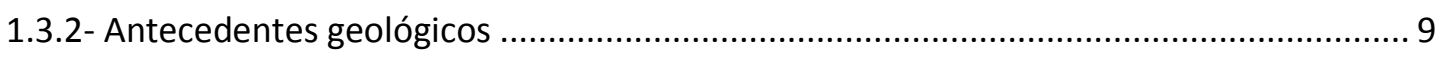

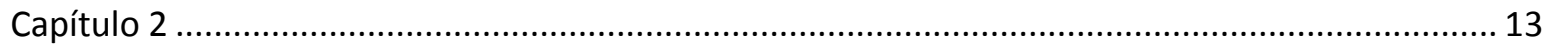

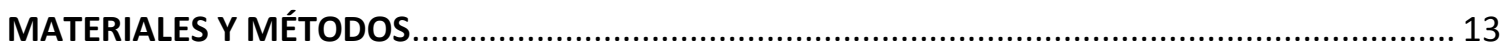

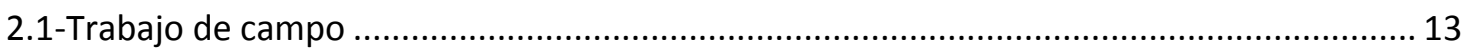

2.1.1 Recolección de muestras de sedimento superficial ................................................... 13

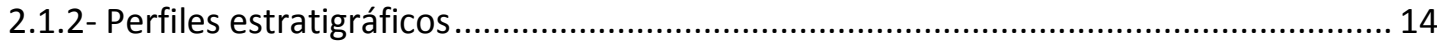

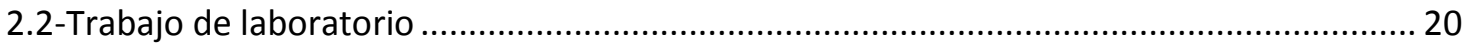

2.2.1- Submuestreo del sedimento de las secuencias fósiles ............................................... 20

2.2.2-Procesamiento físico y químico para la extracción del contenido palinológico de los



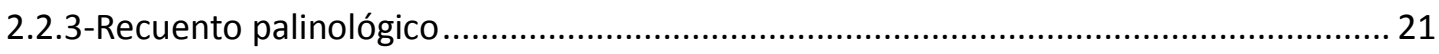

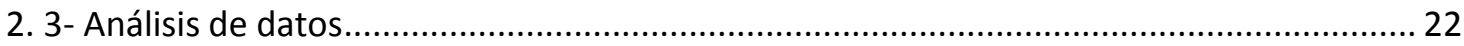

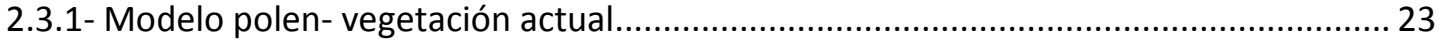

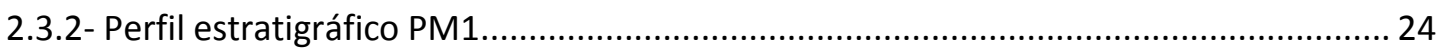

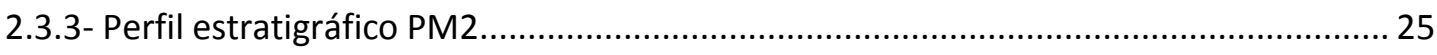

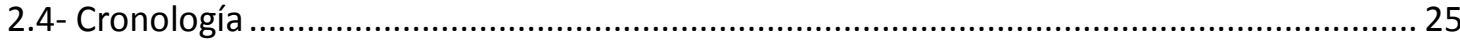

2.5- Uso de Sensores Remotos para el reconocimiento y análisis geomorfológico ................. 27

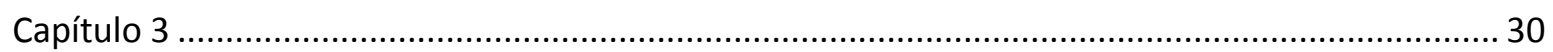

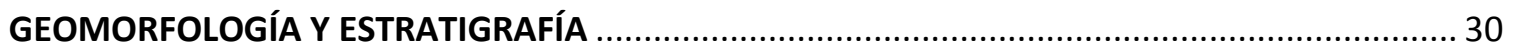

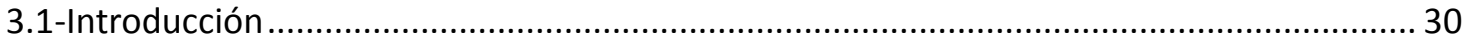

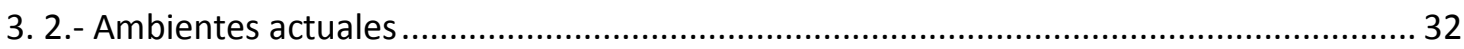




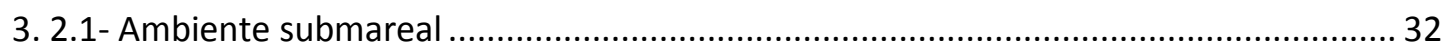

3. 2.2.- Ambiente intermareal o llanuras de mareas.............................................................. 32

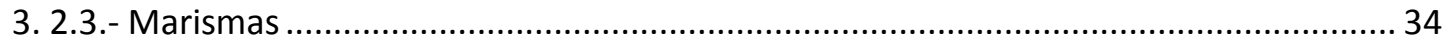

3.3.- Geoformas asociadas a paleoambientes litorales ...................................................... 36

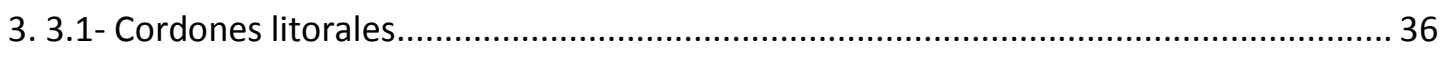

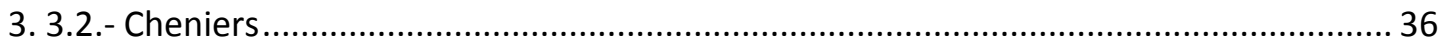

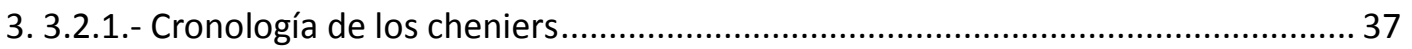

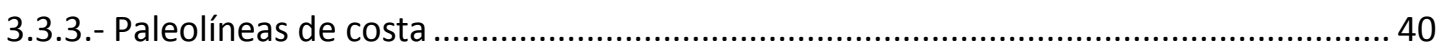

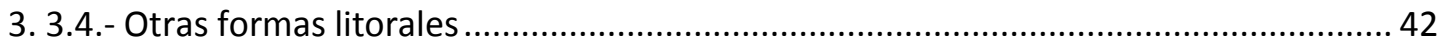

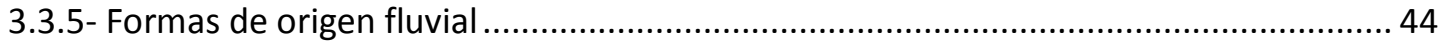

3. 4.- Perfiles representativos de las unidades reconocidas. ................................................. 50

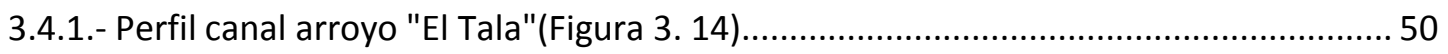

3.4.2.- PM 1 (355' $\left.14.86^{\prime \prime} \mathrm{S} / 57^{\circ} 24^{\prime} 49.72^{\prime \prime} \mathrm{O}\right)$, (Figura 3.15) ................................................. 51

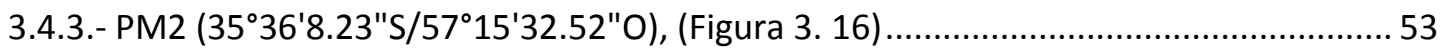

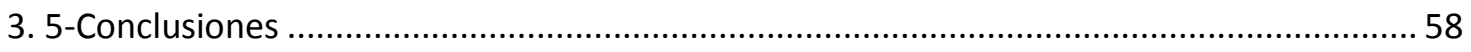

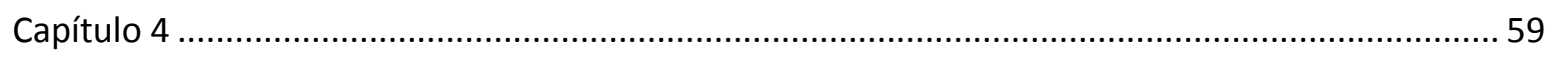

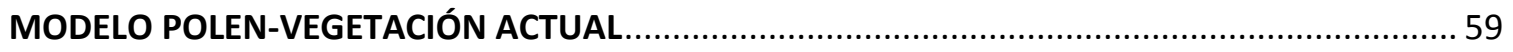

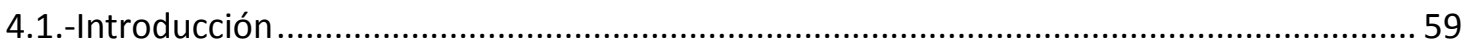

4.2.-Características de la vegetación actual de la Bahía Samborombón ................................ 62

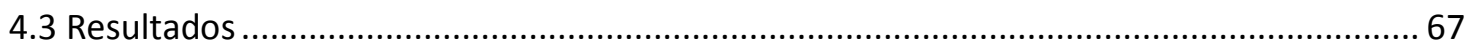

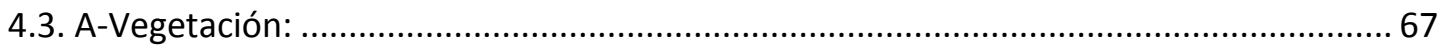

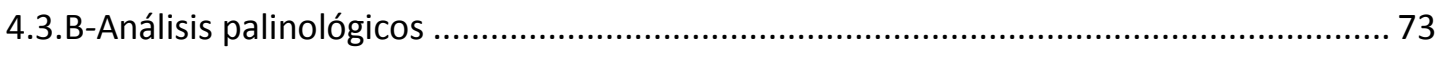

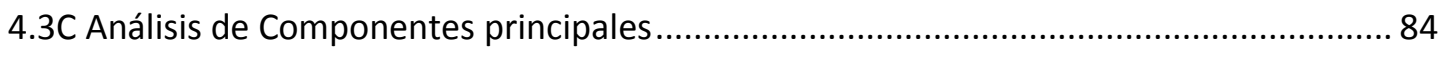

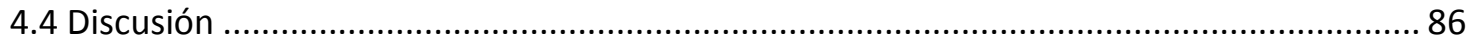

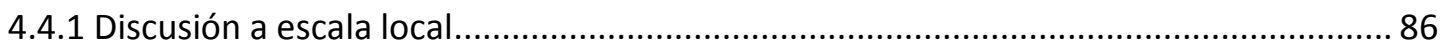

4.4.2- Discusión a escala regional (sector centro-norte de Bahía Samborombón) ................. 90

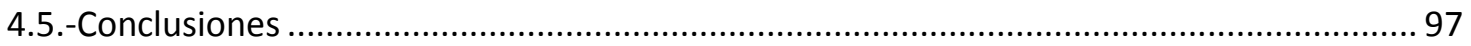

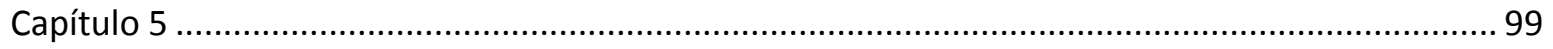

CAMBIOS AMBIENTALES EN EL SECTOR CENTRAL DE BAHÍA SAMBOROMBÓN DESDE EL

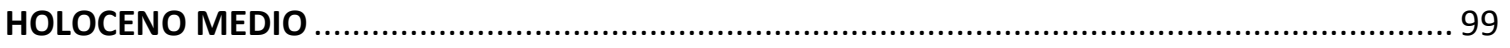

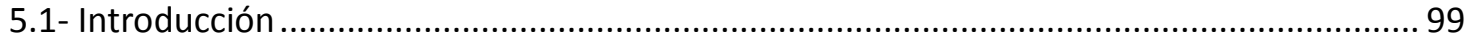


5.2-PM2. Cambios ambientales durante el evento transgresivo entre 6800 y 5500 años cal AP en el sector central de la Bahía Samborombón........................................................... 101

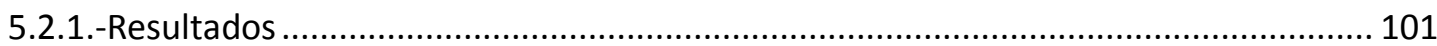

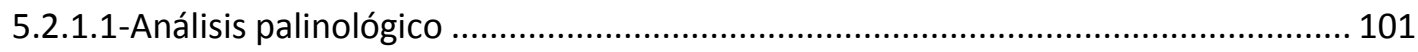

5.2.1.2- Cronología de la secuencia sedimentaria.......................................................... 105

5.2.1.3.-Análisis de Correspondencia sin tendencia (DCA) ............................................. 107



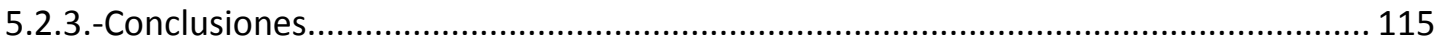

5. 3.-PM1. Cambios ambientales durante los últimos 2700 años $A P$ en la franja costera del sector central de la Bahía Samborombón....................................................................... 116

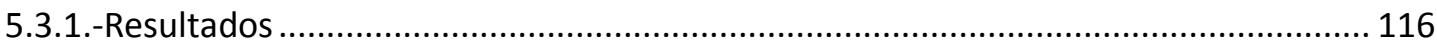

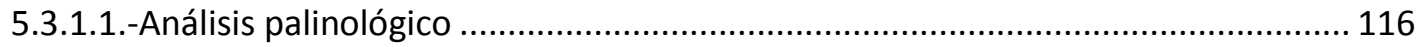

5.3.1.1.-Cronología de la secuencia sedimentaria PM1. ............................................... 121

5.3.1.3.-Análisis de Correspondencia sin tendencia (DCA) ........................................... 122

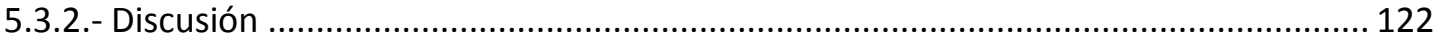

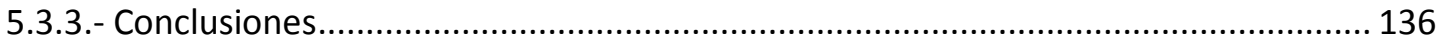

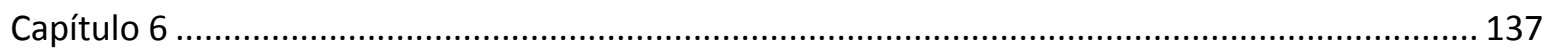

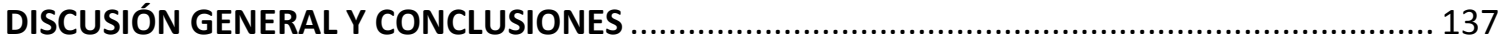

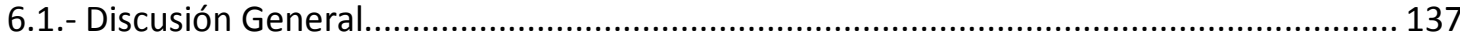

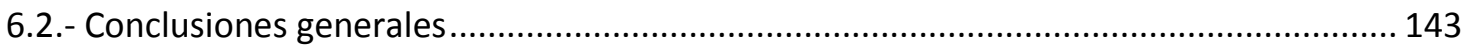

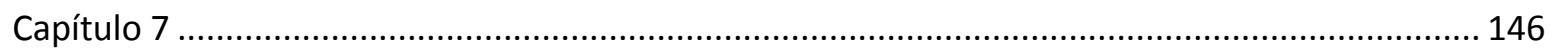

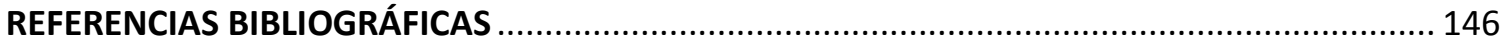




\section{ÍNDICE DE FIGURAS}

Figura 1.1. Mapa de ubicación del área de estudio indicada sobre imagen Landsat 7 del sector costero, NE de la provincia de Buenos Aires.

Figura 1.2. Curvas de variaciones relativas del nivel del mar según Cavallotto et al. (2004), en azul, y según Prieto et al. (2017), en rojo. Modificado de Mourelle et al. (2015).

Figura 1.3. Imagen ALOS Global Digital Surface Model "ALOS World 3D-30 m (AW3D30)" 9

Figura 1.4. Esquema de los diferentes miembros de la formación Las Escobas (Fucks et al., 2010). El gráfico es tomado de Richiano et al. (2012), y corresponde a una representación de los depósitos Holocenos de origen litoral, expuestos en la localidad de Cerro de la Gloria por el canal artificial №15.

Figura 1.5. Esquema estratigráfico de los depósitos marino-litorales de la Bahía Samborombón, modificado de Fucks et al., 2010. MIS: Marine Isotope Stages.

Figura 2.1. Área de estudio. Localización de los sitios estudiados en este trabajo de tesis: en amarillo los sitios donde se colectó material para dataciones y análisis geomorfológico (Capítulo 3); en rojo los sitios donde se tomaron las muestras para la realización del modelo polen-vegetación actual (Capítulo 4); y con asterisco rosa las secuencias sedimentarias fósiles analizadas palinológicamente (Capítulo 5).

Figura 3.1. Mapa geomorfológico regional donde se muestra la llanura costera y área de estudio. Modificado de Cavallotto, 2002.

Figura 3. 2. A- Esquema modificado de Davidson-Arnott, R. (2010), en donde se representa la morfología de la costa de tipo microacantilada. B- Foto de la línea de costa de la zona Norte de Bahía Samborombón ( $35^{\circ} 33^{\prime} 51.56^{\prime \prime S}$, 57¹3'19.37"O) en donde se observa la morfología de la costa de tipo microacantilada.

Figura 3.3. Cronología de los cheniers reconocidos en el área de la desembocadura de los ríos Salado y Samborombón.

Figura 3.4. A-Vista en planta de los depósitos de conchilla vinculados a un canal artificial (35 $58^{\prime} 9.70^{\prime \prime}$, $\left.57^{\circ} 23^{\prime} 15.90^{\prime \prime O}\right)$. B- Foto del lugar.

Figura 3.5. Recorte de la banda pancromática del producto Spot 6 en donde se visualizan los efectos de dos filtros "Mediana" y (especificar.). 
Figura 3.6. A- Spot 6 como imagen de base sobre la que se mapearon las paleo líneas de costa reconocidas (amarillo) y el cordón de conchillas principal, Mb Cerro de la Gloria (verde). Con asterisco se indica la ubicación de PM1. El punto rojo indica el sitio en el que se reconoció el depósito de chenier que se indica en las fotos B Y C, coincidiendo con la paleolínea de costa reconocida. La escala representa $1 \mathrm{~m}$.

Figura 3.7. Imagen Spot 6 de la zona costera de Bahía Samborombón a $11 \mathrm{~km}$ al $\mathrm{N}$ de Canal 15 $\left(35^{\circ} 51^{\prime} 49.33^{\prime \prime} / 57^{\circ} 26^{\prime} 52.76^{\prime \prime O}\right)$ en donde se pueden observar desde $\mathrm{O}$ a $\mathrm{E}$ diferentes geoformas preservadas en el terreno; paleodesembocadura, paleoespigas, cordones conchiles, y ambiente de marisma con cheniers.

Figura 3.8. A- Recorte de la imagen original de un sector del río Samborombón. B- se visualiza el mismo recorte pero con filtro direccional, kernel 3x3, ángulo 180 . Con flechas blancas se indica los point bars. C- Recorte de la imagen original de una sección del río Samborombón donde se encuentran numerosos meandros abandonados. D- Imagen con filtro kernel $3 \times 3$, 30 ‥

Figura 3.9.A- Recorte de la imagen original en donde de muestra un paleocauce. B- filtro de realce "Mediana". C- "Filtro direccional", 3×3, 45‥ D- Aplicación del "Filtro Sobel".

Figura 3.10. Resultado de tratamiento de combinación de bandas 431. A: detalle de cordones. B: cheniers en zona de marisma. C: alineamiento de la vegetación en relación a las geoformas litorales.

Figura 3.11. Digitalización de los ríos Salado y Samborombón en la zona de su desembocadura. Se observan morfologías de origen fluvial y costeras de edad holocena; cordones litorales. 1: Detalle de tramo del río Samborombón donde se indican depósitos de barras de meandros (point bars) y meandros abandonados. Con flechas naranjas se indica el sentido de escurrimiento de ambos ríos.

Figura 3.12. Tramo final del río Samborombón. En las fotos $A$ y $B$ se muestra, en línea de puntos, el cauce abandonado por avulsión del río Samborombón. En las fotos $C$ y E se evidencia el anegamiento del paleocauce. En D se muestra el desnivel del mismo.

Figura 3.13. Tramo final del río Salado donde se observa, arriba indicado con flecha un antiguo cauce. En la foto A se indica en línea de puntos el paleocauce y se muestra el desnivel del mismo.

Figura 3.14.A- Imagen satelital QuickBird, Google Earth de Agosto 2017. B- El arroyo canal "El Tala" corta de manera transversal a los cheniers, dejando un perfil expuesto. C- Perfil expuesto en donde se observan capas/estratos compuestos casi exclusivamente por conchillas, alternando con capas de arena. Estos depósitos gruesos que yacen sobre fango. DPerfil estratigráfico estudiado.

Figura 3.15. Perfil estratigráfico PM1. 56

Figura 3.16. Perfil estratigráfico PM2. 57 
Figura 4.1. Área de estudio. A- Imagen Landsat 7 del sector costero al NE de la provincia de Buenos Aires en donde se muestra la ubicación de las transectas estudiadas, a lo largo de la franja costera de Bahía Samborombón (T1 a T4) y de la transecta Río Salado (TRS) (Vilanova y Prieto, 2012).B- Transecta 1; en naranja de delimita el chenier. C- Transecta 2. D- Transecta Río Salado. E- Transectas 3 y 4, F- fotografía del ambiente de marisma.

Figura 4.2. Diagrama polínico en porcentaje y concentración polínica total (granos/cm3) de la Transecta.

Figura 4.3. Diagrama polínico en porcentaje y concentración polínica total (granos/cm3) de la Transecta 2.

Figura 4.4. Diagrama polínico en porcentaje y concentración polínica total (granos/cm3) de la Transecta 3.

Figura 4.5. Diagrama polínico en porcentaje y concentración polínica total (granos/cm3) de la Transecta 4.

Figura 4.6. Gráfico bidimensional de ordenación de las 40 muestras de superficie de la franja costera de Bahía Samborombón. Los ejes 1 y 2 representan los dos primeros componentes principales. Este análisis fue realizado en base a 9 taxa (Poaceae, Chenopodiaceae, Limonium brasiliense, Cyperaceae, Typha sp, Asteraceae, Ambrosia spp, Solanaceae, Pediastrum spp). Los círculos alrededor de las muestras agrupan las diferentes zonas de la marisma.

Figura 4.7. Diagrama palinológico en porcentaje (resumido) de las 40 muestras de superficie de la zona centro-norte de Bahía Samborombón (T1, T2, TRS, T3 Y T4). Asteraceae incluye los tipos Baccaris, Senecio y Cichorioideae. Otras hierbas: Brassicaceae, Convolvulaceae, Euphorbiaceae, Geraniaceae, Gomphrena, Malvaceae, Onagraceae, Oxalis, Plantago, Ranunculaceae, Alternanthera, Tipo Plumbago, Polygonum, Verbenaceae. Otros árboles y arbustos: Acacia, Ephedra tweediana, Fabaceae (Caesalpinioidae y Papilionoideae), Jodina rhombifolia, Salix, Sambucus, Schinus, Solanaceae, Rhamnaceae. Extraregionales: Alnus, Betula Myrtaceae, Nothofagus, Pinaceae/Podocarpaceae. Algas coloniales: Botryococcus, Gloeotrichia, Pediastrum, Scenedesmus, Zignemataceae. Impacto: Tipo Carduus y Rumex. Briofitas: Ricciaceae, Phaeoceros tenuis, P. bulbiculosus y Anthoceros. Hongos: Glomus y esporas undiff.

Figura 5. 1. Mapa geomorfológico regional y de ubicación de las secuencias sedimentarias PM1 y PM2 (modificado de Cavallotto, 2002).

Figura 5.2. Diagrama polínico en porcentaje, concentración polínica total (granos/cm3) y análisis de agrupamiento (CA) de PM2. Perfil estratigráfico y edades radiocarbónicas de la secuencia sedimentaria PM2, ubicada en Canal 15, Bahía Samborombón

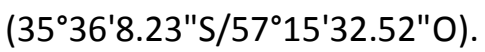

Figura 5.3. Diagrama polínico en porcentaje, concentración polínica total (granos/cm3) resumido y análisis de agrupamiento (CA) de PM2. Perfil estratigráfico y edades radiocarbónicas de la secuencia sedimentaria PM2. Asteraceae incluye los tipos Baccaris, 
Senecio y Cichorioideae. Otras hierbas: Lamiaceae, Brassicaceae, Convolvulaceae, Geraniaceae, Malvaceae, Alternanthera. Arbustos árboles: Acacia, Ephedra tweediana, Fabaceae (Caesalpinioideae y Papilionoideae), Schinus, Celtis y Phytolacca. Algas coloniales: Botryococcus y Zignemataceae. Briofitas: Ricciaceae, Phaeoceros tenuis, P. bulbiculosus y Anthoceros. Hongos: Glomus y esporas undiff.

Figura 5.4. DCA de las muestras palinológicas de 40 muestras de superficie y 20 muestras fósiles de la secuencia PM1. Ordenamiento espacial de los 13 tipos palinológicos considerados para el análisis, a lo largo de los dos primeros ejes de ordenación. Referencias: Poa: Poaceae, Cheno: Chenopodiaceae, Limo: Limonium brasiliense, Cyp: Cyperaceae, Typ: Typha, Ast: Asteraceae, Amb: Ambrosia, Sol: Solanaceae, Pha: Phaeoceros, Ricc: Ricciaceae, Oper: Operculodinium spp., Spi: Spiniferites spp., Azo: Azolla filiculoides. 109

Figura 5.5. Diagrama polínico en porcentaje y concentración polínica total (granos/cm3) de las muestras LEM 1 Y 2.

Figura 5.6. Diagrama polínico en porcentaje, concentración polínica total (granos/cm3) y análisis de agrupamiento (CA) de PM1. Perfil estratigráfico y edades radiocarbónicas de la secuencia sedimentaria PM1, ubicada en Canal 15, Bahía Samborombón (35 $\left.58^{\prime} 14.86^{\prime \prime} \mathrm{S} / 57^{\circ} 24^{\prime} 49.72^{\prime \prime} \mathrm{O}\right)$.

Figura 5. 7. Modelo de edad-profundidad de la secuencia PM1 realizado con el programa Bacon. Los paneles superiores representan las iteraciones de Markov Chain Monte Carlo (MCMC) (izquierda), anteriores (curvas verdes) y posteriores (histogramas grises) distribuciones de tasa de acumulación (panel central) y memoria $\mathrm{R}$ (panel derecho). El panel inferior muestra el modelo de profundidad de edad (gris) y las fechas calibradas 14C (azul). Las líneas grises despojadas indican los intervalos de confianza del 95\%; la curva roja muestra el "mejor" ajuste en función de la edad promedio ponderada para cada profundidad. 121

Figura 5.8. A- DCA de las muestras palinológicas de 40 muestras de superficie y 38 muestras fósiles de la secuencia PM1. B- Ordenamiento espacial de los 15 tipos palinológicos considerados para el análisis, a lo largo de los dos primeros ejes de ordenación. Referencias: Poa: Poaceae, Cheno: Chenopodiaceae, Limo: Limonium brasiliense, Cyp: Cyperaceae, Typ: Typha, Ast: Asteraceae, Amb: Ambrosia, Sol: Solanaceae, Ped: Pediastrum, Pha: Phaeoceros, Ricc: Riccia, Botr: Botriococcus, Oper: Operculodinium spp., Spi: Spiniferites spp., Azo: Azolla filiculoides.

Figura 5.9. Secuencia evolutiva de la planicie costera de la zona central de Bahía Samborombón construida mediante el mapeo de las geoformas reconocidas mediante sensores remotos y marco cronológico basado en dataciones de secuencias sedimentarias y de depósitos de cheniers.

Figura 5.10. Distribución de las especies de foraminíferos de la sección PM1, Canal 15, Bahía Samborombón, con al menos $1 \%$ de abundancia relativa.

Figura 5.11. Resumen de zonas micropaleontológicas y paleoambientes inferidos a partir del análisis de la secuencia PM1. 
Figura 5. 12. Datos estandarizados de diferentes proxies analizados provenientes de la secuencia estratigráfica PM1.

Figura 5.13. Modelo de evolución geomorfológica. Esquema de la progradación costera con formación de cheniers, posterior al máximo transgresivo.

Figura 6. 1. Mapa de ubicación. Mapa geomorfológico regional, modificado de Cavallotto (2002), en donde se muestra la ubicación de las secuencias sedimentarias PM1 y PM2 (asteriscos rojos). Además, se señala la ubicación de otros sitios previamente estudiados por otros autores, en la llanura costera, y que se mencionan en la presente Tesis (círculos rojos): 1. Sitio RS (Vilanova y Prieto,2012); 2. Sitio Los Molles (Aldazabal,2002); 3. Sitio Ea. Rincón Grande, (Figini,1992); 4. Sitio Puesto Berrondo (Fucks, et al., 2007).

\section{ÍNDICE DE TABLAS}

Tabla 2.1. Ubicación geográfica de las muestras de superficie.

Tabla 2.2. Rangos espectrales de la imagen SPOT 6.

Tabla 3.1. Edades radiocarbónicas de diferentes ambientes de la planicie costera NE de Buenos Aires.

Tabla 3.2. Descripción sedimentaria y fosilífera de PM1.

Tabla 3.3. Edades radiocarbónicas de diferentes ambientes de la planicie costera NE de Buenos Aires.

Tabla 4.1. Comunidades vegetales de la llanura costera (Pampa Deprimida), (Vervoorst, 1967; Cabrera, 1976; León, 1991; Stutz y Prieto, 2003).

Tabla 4.2. Tipos polínicos y PNPs indentificados.

\section{ÍNDICE DE FOTOS}

Foto 2.1. Selección y extracción de muestras de sedimentos de los ambientes mareales de Bahía Samborombón.

Foto 2.2. Metodología de muestreo de testigos continuos mediante el uso de tubos PVC. 18 
Foto 2.3. Metodología de muestreo de material para datar proveniente de depósitos de cordón litoral.

Fot 4.1. A y B- Límite entre los ambientes intemareal alto y marisma baja. C- Marisma alta con mosaico de las hidrófitas tales como X. strumarium L. y S. glaucophylum (duraznillar), y el pasto salado del género Distichlis.

Foto 4.2. A- Costa con depósitos de tormenta B- Schoenoplectus californicus dispuestas en parches circundados por S. densiflorus en una marisma media-alta. C- Marisma media-alta con comunidades de juncales-espartillares. D- Schoenoplectus californicus en el ambiente de marisma.

Foto 4.3. A- Poblaciones de S. densiflorus en el límite del albardón sobre la desembocadura del canal 15. B- Parches ("abras") de S. perennis en una zona de marisma media. C- Juncales en un terreno deprimido bordeado por S. densiflorus en una zona de marisma media. 


\section{RESUMEN}

En esta tesis se realizó el análisis palinológico fósil contenido en depósitos sedimentarios de perfiles estratigráficos expuestos sobre las márgenes del Canal 15 en el sector central de la Bahía Samborombón. Además, se realizó el análisis de unidades geomorfológicas y de los sedimentos, incluyendo la tafonomía de moluscos presentes en dichos depósitos; por lo cual la investigación desarrollada se basa en el análisis de múltiples indicadores ambientales (o análisis multi-proxy). La integración de las interpretaciones a partir de cada indicador permitió reconstruir la evolución paleoambiental y los cambios de las comunidades vegetales en relación con las fluctuaciones del nivel del mar y a la variabilidad climática, desde la etapa final de la transgresión Holocena (MIS 1). El análisis geomorfológico se realizó mediante el uso de imágenes satelitales de alta resolución espacial, y la aplicación de filtros y realces que permitió identificar y mapear diferentes geoformas tales como: paleolíneas de costa, cheniers, paleocanales de marea vinculadas principalmente a la fase regresiva del nivel del mar durante el Holoceno tardío. Por otro lado, con el objetivo de generar un modelo de la relación polen-vegetación actual y utilizarlo como análogo moderno en la interpretación de los registros polínicos fósiles, se analizaron 23 muestras superficiales de sedimento provenientes de los distintos ambientes mareales desarrollados en la franja costera de la zona centro-norte de Bahía Samborombón (intermareal, marisma baja, marisma media y marisma alta). Los análisis estadísticos empleados permitieron diferenciar grupos polínicos que se correspondieron con: (1) la marisma baja-intermareal, (2) la marisma media, (3) la marisma alta. Además, palinomorfos no polínicos como: Operculodinium spp. y Spiniferites spp., microforaminíferos y hongos, junto con la concentración polínica total contribuyeron en la diferenciación de los ambientes mareales en particular vinculado a la señal de la influencia de las mareas. Este modelo palinológico reflejó la sucesión lateral de los ambientes mareales de Bahía Samborombón constituyendo un buen análogo para interpretar secuencias polínicas fósiles de ambientes costeros cuya evolución está vinculada a los cambios del nivel del mar. Para realizar las reconstrucciones paleoambientales y de la historia de la vegetación se seleccionaron dos perfiles estratigráficos PM1 


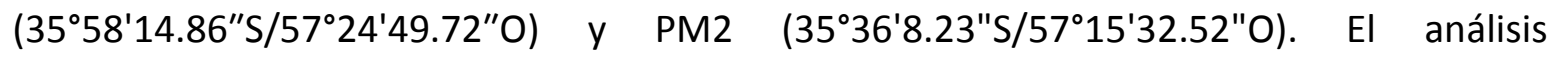
palinológico de PM2 permitió establecer la evolución paleoambiental y la historia de la vegetación en respuesta al aumento del nivel del mar durante el Holoceno Medio. Desde 7000-6670 años cal AP prevalecieron comunidades halófitas de marisma media-alta en un ambiente de extensas Ilanuras de marea abierto a $\sim 10 \mathrm{~km}$ de la costa actual. Entre 6670- 6535 años cal AP ocurre un cambio en las comunidades vegetales pasando de marisma media-alta a una marisma baja que se relaciona con un nivel del mar en ascenso evidenciado por el gradual incremento de los dinoquistes Operculodinium spp. y Spiniferites spp. Durante la fase transgresiva. Desde 6535-6453 años cal AP continúa el predominio de una vegetación de marisma que coexiste con comunidades de agua dulce bajo significativa y creciente influencia marina. A partir de 6453 años cal AP, el registro palinológico es limitado sin embargo asociaciones autóctonas de Tagelus plebeius indican condiciones estables coincidiendo con el periodo de estabilidad del nivel del mar. Por otro lado, durante los últimos 3000 años cal AP, el análisis multi-proxy de la secuencia PM1 permitió inferir la evolución paleoambiental desde un ambiente submareal-intermareal, es decir, bajo una influencia significativa de las mareas, a un ambiente supramareal con influencia de aguas salobres a dulces en relación al descenso del nivel del mar durante Holoceno tardío. Entre 2700-1660 años cal AP se desarrolló una vegetación halófita de marisma en las cercanías a un ambiente depositacional submareal-intermareal a $\sim 5,7 \mathrm{~km}$ de la costa actual. A partir de 2050 años cal AP esta situación cambia muy gradualmente a condiciones con parcial exposición aérea vinculado a una menor influencia mareal por el retiro paulatino del mar, con el desarrollo de comunidades vegetales de una marisma media-alta, similares a las comunidades actuales, evidenciado por el registro de Limonium brasiliense y la disminución de los dinoquistes y foraminíferos. Entre 1660-950 cal AP se establece una marisma madura y estable y se evidencia un cambio gradual en las condiciones ambientales que van de ambientes intermareales a un ambiente supramareal con el desarrollo de cuerpos de agua someros inferido por el incremento gradual de Azolla filiculoides y Ricciaceae. Estos cambios ambientales responden a la progradación costera que implicó el desarrollo de nuevas posiciones de la línea de costa hacia el este que, junto 
con el desarrollo de cheniers fueron aislando ambientes de la influencia de las mareas. Desde los 950 años cal AP hasta el presente continúa el predominio de una vegetación de marisma aunque coexisten con comunidades de agua dulce desarrolladas en pequeños cuerpos de agua con rara a nula frecuencia de las mareas. La señal climática pudo visualizarse en el registro dado el cese de la superposición de la influencia mareal en PM1 lo que permitió inferir un mayor régimen de precipitaciones por el aumento de los componentes acuáticos de agua dulce.

\begin{abstract}
In this thesis, the analysis of palynological fossil content fromsedimentary deposits found instratigraphic outcrops were carried out. These outcrops are located on the margins of Channel 15 at the central sector of Bahía Samborombón. Also, the analyses of geomorphological units and sediments, along with the taphonomy of mollusks contained in the same deposits were performed. Therefore, the investigation is based on a multiproxy analysis, which integrates the paleoenvironmental information from each proxy in order to get a more precise reconstruction of the paleo-environmental evolution and vegetation changes related to sea-level fluctuations and climatic variability during the final stage of the sea-level transgression phase (isotopic state MIS 1). The geomorphological analysis was carried out by the use of satellite images of high spatial resolution, appliying filters and enhancement processes; which give the tools for the identification and mapping of different geoforms such as coastal paleoshorelines, cheniers, tidal paleochannels linked to the sea-level regressive phase during the late Holocene. On the other hand, with the aim of produce a model of the modern pollen-vegetation relationship to be used as a modern analogue for the interpretation of the fossil pollen record, there was performed the palynological analysis of 23 surface sediments samples taken from the different tidal environments that develop in the coastal fringe at the central sector of Bahía Samborombón (intertidal, low, middle and high saltmarsh zones The statistical analyses applied to the data produced the ordination in groups: (1)
\end{abstract}


intertidal-low marsh, (2) middle marsh, (3) high marsh. Besides, non-pollen palynomorphs such as Operculodinium spp. andSpiniferites spp., microforaminífers and fungi; along with total pollen concentration contributed to the recognition of the different tidal environments related to the marine influence. This palynological model reflected a lateral succession of the tidal environments and constitutes a good analogue for the interpretation of fossil pollen records from coastal environments whose evolution is related to sea-level variations. There were selected 2 sedimentary sequences PM1

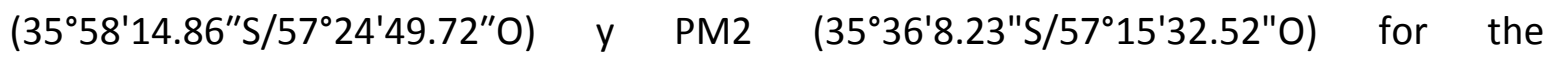
reconstruction of paleoenvironmental evolution and vegetation changes. The PM2 analysis shows this paleoenvironmental evolution in response to the sea-level increase during the Mid-Holocene. During the interval $7000-6670$ cal $\mathrm{yr}$ BP, halophytic communities prevailed in a middle-high marsh in an environment of extensive tidal plains and open sea, which was located at $\sim 10 \mathrm{~km}$ from the present coastline. Then, between 6670 and $6535 \mathrm{cal}$ yr BP vegetation of the middle-high marsh was replaced by that vegetation communities corresponding to the low marsh; which is related with the increasing sea-level during this period and evidenced by the gradual increase of the dinocysts Operculodinium spp. y Spiniferites spp during its transgression phase. From 6535 to $6453 \mathrm{cal}$ yr BP, continues the predominance of marsh vegetation in coexistence with freshwater vegetation under increasing marine influence. From 6453 cal yr BP, the palynological record is scarce; nevertheless autochthon populations of Tagelus plebeiusindicate a stabilized period of the sea-level. During the last 3000 cal yrs BP, the multi-proxy analysis of PM1 showed the paleoenvironmental evolution from a subtidalintertidal environment under significant tidal influence, to a supratidal environment with brackish-freshwater influence related to the sea-level decrease during this time. During the period $\sim 2700-1660$ cal yr BP, halophytic vegetation from a marsh developed in the vicinity of a subtidal-intertidal depositional environment at $\sim 5.7 \mathrm{~km}$ from the present coastline. Within this period, at 2050 cal yr. BP a gradual and partial aerial exposition occurred in relation to a lower tidal influence due to the sea-level steady fall; along with the development of middle-high marsh vegetation, similar to the present vegetation of 
this transitional zone, evidenced by the presence of Limonium brasiliense and the decrease of dinocysts and foraminifers abundance.Between 1660 and 950 cal yr. BP a stable mature saltmarsh established in environments that change from those of intertidal conditions to supratidal conditions with shallow water bodies developed as reflected by gradial increase of Azolla filiculoides and Ricciaceae. This change of environments is linked to the coastal progradation, implying successive paleo-shorelines and chenier deposits toward the East that isolated the environments left behind. The last period, from $\sim 950 \mathrm{cal}$ $\mathrm{yr} \mathrm{BP}$ to the present, the predominance of marsh vegetation continues although accompanied by freshwater vegetation developed in small water bodies with rare or null tidal influence. The climatic signal was possible to infer due to the cessation of the overlap between the tidal influence related to the sea level fall; which was characterized by a greater precipitation regime as suggested by the high increase of the freshwater components. 


\section{Capítulo 1}

INTRODUCCIÓN

Esta Tesis Doctoral consiste en investigaciones microfosilíferas y geomorfológicas en el ámbito continental costero de la Bahía Samborombón, Buenos Aires, Argentina. En particular, deambientes marino- litorales del Holoceno cuya génesis está vinculada a las variaciones del nivel del mar durante el ciclo transgresivo-regresivo a partir de la terminación del Último Máximo Glacial (estadío isotópico "MIS 1") y la variabilidad climática Las planicies costeras del estuario del Río de la Plata y zonas adyacentes del NE de la provincia de Buenos Aires se desarrollaron durante el Cuaternario respondiendo a periodos de ascenso y descenso del nivel del mar (Figura 1.1). Las secuencias sedimentarias a lo largo de estas llanuras presentan continuidad estratigráfica y una alta riqueza fosilífera a partir de las cuales se ha podido establecer el desarrollo de ambientes de barreras litorales, cordones de playa, llanuras de marea y lagunas costeras; permitiendo reconstruir la historia geomorfológica y ambiental en relación con las variaciones eustáticas del nivel del mar y la variabilidad climática durante el Cuaternario tardío (Fidalgo et al., 1973; 1981; Aguirre, 1993; Codignotto y Aguirre, 1993; Aguirre y Whatley, 1995; Colado et al., 1995; Violante y Parker, 2000; Violante et al., 2001; Laprida y Bertels-Psotka, 2003; Violante y Parker, 2004; Cavallotto et al., 2004; Schnack et al., 2005; Laprida et al., 2007; Fucks et al., 2007; 2010; Prieto et al., 2017; Luengo et al., 2018, entre otros). 


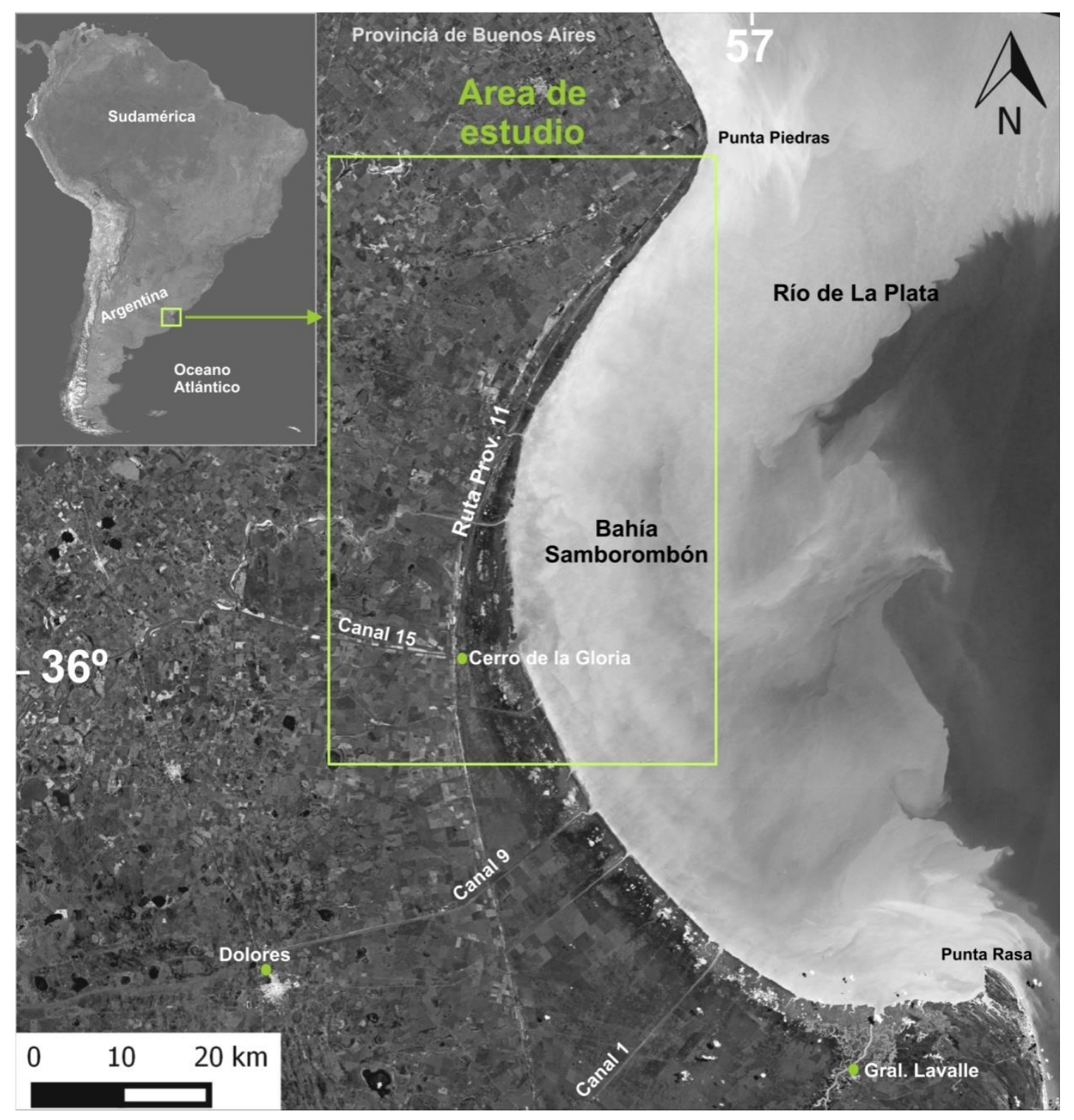

Figura 1.1 Mapa de ubicación del área de estudio indicada sobre imagen Landsat 7 del sector costero, NE de la provincia de Buenos Aires.

Las distintas reconstrucciones ambientales obtenidas hasta el momento, desde diferentes disciplinas, se han desarrollado de manera exitosa al reflejar la evolución ambiental a partir del indicador utilizado. Sin embargo, existen pocos estudios que analicen múltiples indicadores y realicen una reconstrucción integral de dicha evolución.

El análisis de registros palinológicos ha sido una herramienta útil para reconstruir la historia de la vegetación en la costa de la provincia de Buenos Aires. Por esta razón, si 
se considera que los cambios en los procesos de sedimentación relacionados con las variaciones del nivel del mar tienen consecuencias en la vegetación, la cual debe adaptarse a los distintos ambientes sedimentarios, entonces, el análisis de registros palinológicos fósiles puede compararse e integrarse con modelos sedimentarios y geomorfológicos del área para reconstruir en forma detallada y precisa las condiciones paleoambientales e interpretar la historia de la vegetación. Además, los patrones de distribución espacial de la vegetación actual están relacionados con la evolución geomorfológica y la topografía del área, la salinidad del suelo, los nutrientes y el drenaje (Cagnoni, 1999), por lo cual es de esperarse que los cambios potenciales que se pueden encontrar en los espectros polínicos fósiles permitan inferir las modificaciones de estas variables ambientales que se mencionan.

Sin embargo, hasta el momento se ha desarrollado solo un estudio palinológico fósil en el área de la Bahía Samborombón, el cual ha mostrado los cambios en las comunidades vegetales en relación con la influencia marina y fluvial desde 8800 años cal. AP (Vilanova y Prieto, 2012); período durante el cual el nivel del mar alcanza el máximo transgresivo, seguido de la fase regresiva hasta llegar al nivel actual. Este análisis palinológico permitió inferir la ocurrencia de eventos de inundación y de evaporación, erosión y/o acumulación, e inferir las zonas baja, media y alta de una marisma a partir de la comparación del espectro fósil con espectros palinológicos modernos obtenidos de las diferentes zonas de la marisma actual de la bahía, cercana a la desembocadura del Río Salado.

Asimismo, tampoco existen estudios de tipo multi-proxy, es decir estudios que integren la información paleoecológica proveniente de distintos indicadores como palinológicos y biológicos y geológicos tales como litología, composición de sedimentos, isótopos estables $(\mathrm{C}, \mathrm{O}, \mathrm{N})$ y tafonomía de distintas poblaciones de moluscos; lo cual puede proveer información más precisa sobre la evolución ambiental del área. Resultados preliminares en muestras actuales y fósiles de la Bahía Samborombón permiten considerarlos como potenciales herramientas para comenzar a resolver las interrogantes 
planteadas respecto a la distinción de los efectos de cada forzante: la influencia marina durante las fluctuaciones del nivel del mar y la variabilidad climática.

Por otra parte, son varias las curvas del nivel del mar que han sido propuestas para el estuario del Río de la Plata y planicies costeras adyacentes para el Holoceno (e.g. Isla, 1989; Aguirre y Whatley, 1995; Cavallotto, 1995; Cavallotto et al., 2004; Prieto et al. (2017).

En base a dataciones radiocarbónicas provenientes de diferentes ambientes depositacionales en el ámbito del "Río de la Plata", varios autores establecieron que partiendo de los 18/20 mil años AP, el nivel de mar se encontraba en su posición más baja (alrededor de los -110 m) en la plataforma continental Argentina (Guilderson et al., 2000) para a partir de allí comenzar un rápido ascenso acompañando la deglaciación a una velocidad aproximada de 12 mm/año (Violante y Parker, 2004) hasta los 8600 años AP, cuando la velocidad de ascenso desciende a los 9,4 mm/año, pasando por la posición semejante a la actual línea de costa a los 7000 años AP y alcanzando el máximo transgresivo, en la cota de $+6,5 \mathrm{~m}$ a los 6000 años AP (Cavallotto et al., 2004. Figura 1.2), aunque otros autores consideran que el máximo nivel alcanzado no llegó a esos valores (Schnack et al., 2005; Fucks et al., 2010). La fase regresiva ocurrió de manera discontinua hasta su posición actual, fundamentalmente en dos etapas (Cavallotto et al., 2004).

Prieto et al. (2017) propusieron una curva del nivel del mar para esta misma región basándose en una amplia base de datos, provenientes de la recopilación de 80 dataciones radiocarbónicas obtenidas de diferentes trabajos publicados a partir de 1980 en adelante (Figura 1.2). Este estudio reveló que durante la fase transgresiva, el nivel del mar aumentó hasta alcanzar el nivel actual cerca o antes de $\sim 7000$ cal AP, con el máximo transgresivo entre los 6000 y 5500 cal AP alcanzando la altura de casi +4 m (dependiendo este valor del método estadístico usado) o a los 7000 cal AP según el modelo ICE-6G. Posterior a estas edades comenzó un descenso gradual y continuó hasta su posición actual (Prieto et al., 2017). 


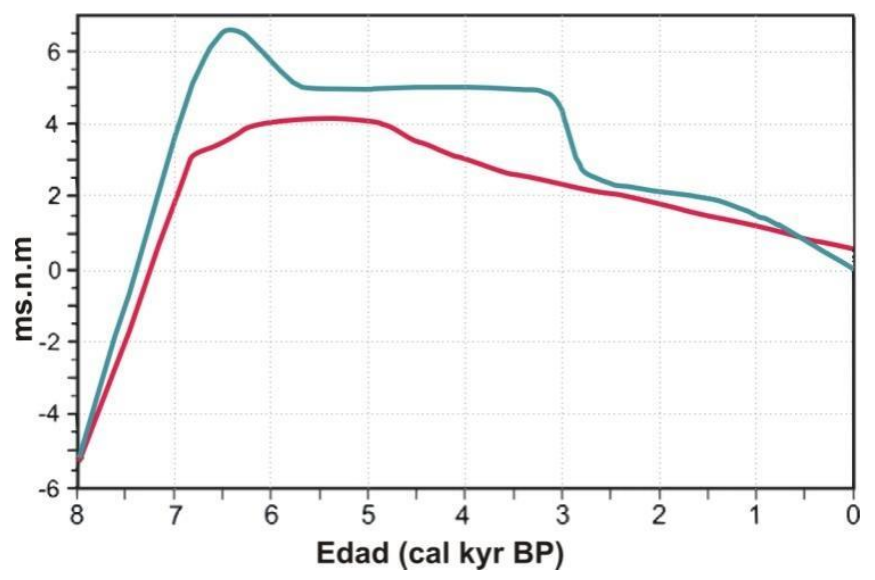

Figura 1.2. Curvas de variaciones relativas del nivel del mar según Cavallotto et al. (2004), en azul, y según Prieto et al. (2017), en rojo. Modificado de Mourelle et al. (2015).

\section{1- Hipótesis}

Los cambios en la vegetación están determinados por la evolución geomorfológica ocurrida durante el Holoceno, la cual, a su vez, responde a cambios climáticos globales y/o locales que originan entre otros fenómenos, las variaciones del nivel del mar. En función de esto, las comunidades vegetales de los distintos ambientes se modificaron en el tiempo y en el espacio en concordancia con las distintas posiciones del nivel del mar

\section{2- Objetivo general}

Reconstruir la evolución paleoambiental en la llanura costera de la Bahía Samborombón a partir de la etapa final de la transgresión Holocena mediante estudios palinológicos, sedimentarios y geomorfológicos y su relación con la variabilidad climática.

\subsection{1- Objetivos específicos}

- Estudiar secuencias sedimentarias y unidades geomorfológicas con una cronología detallada y precisa a lo largo de una transecta perpendicular a la costa, mediante análisis litoestratigráfico y de registros palinológicos fósiles obtenidos de los sedimentos de dichas secuencias. 
- Interpretar los cambios de la vegetación y las condiciones ambientales en relación con la evolución geomorfológica, influencia marina y condiciones climáticas de los últimos 7000 años ${ }^{14} \mathrm{C}$ AP.

- Realizar un modelo de la relación polen-vegetación actual y utilizarlo como un análogo moderno para interpretar los registros polínicos fósiles.

- Integrar los resultados fósiles obtenidos con los existentes en el área central de la bahía y correlacionar estratigráficamente las secuencias sedimentarias para una reconstrucción regional de la historia de la vegetación y los ambientes de la bahía.

- Reconstruir las variaciones de salinidad y las condiciones paleoambientales a partir de los registros palinológicos y geomorfológicos y de la información proveniente de estudios de otros indicadores ecológicos (moluscos, ostrácodos y foraminíferos) disponibles para el área de la bahía.

\section{3- Características generales del área del estudio y antecedentes}

\subsection{1- Descripción general}

La Bahía Samborombón, donde se encuentra el área de estudio de la presente Tesis, se ubica en la zona costera al Noreste de la Provincia de Buenos Aires, Argentina.

La misma se localiza sobre el margen Sudoeste del denominado "Río de La Plata Exterior" y constituye la zona costera de la llamada depresión del Salado (Bértola, 1994). Se trata de una amplia bahía con una línea de costa de cerca de $150 \mathrm{~km}$, que se extiende desde Punta Piedras $\left(35^{\circ} 27^{\prime \prime} \mathrm{S} / 56^{\circ} 45^{\prime \prime} \mathrm{W}\right)$ a Punta Rasa $\left(36^{\circ} 17^{\prime \prime} \mathrm{S} / 56^{\circ} 46^{\prime \prime} \mathrm{W}\right)$. Es una zona de escasa pendiente, lo cual permitió/ condicionó en parte su génesis y evolución en relación a variaciones del nivel del mar durante el Cuaternario (Fig. 1.2).

La bahía posee características propias (geomorfología, biota, dinámica, evolución geológica, etc.) que la diferencian de las costas ubicadas al Norte de Punta Piedras y al Sur de Punta Rasa. Esto se debe a la interacción entre la dinámica del Río de La Plata y del Océano Atlántico, además de la acción de las mareas y los vientos que completan los factores físicos que moldelan sus ambientes (Bértola, 1994). 
Las planicies de la Bahía Samborombón forman parte de la llanura costera Ajó, superficie de un relieve llano con pocas irregularidades y de muy baja pendiente $(0,01 \%)$ que se desarrolla al pie de la llanura pampeana y presenta cotas que promedian los 2-3 m s.n.m (Figura 1.3). Esta llanura, junto con otras del Este bonaerense (Mar Chiquita y del margen Sur del Río de La Plata) comparten su origen y están formadas por depósitos marinos holocenos producto del último ciclo transgresivo- regresivo del nivel relativo del mar (Violante et al., 2001).

El rango mareal de la Bahía Samborombón es de escasa amplitud, es decir, de tipo micromareal $(0,46 / 0,52)$ (Servicio de Hidrografía Naval, 2002). El gradiente horizontal de distribución de la salinidad es de 5 ups en Punta Piedras hasta 20-25 ups en Punta Rasa (Guerrero et al., 1997). El régimen de precipitaciones, el aporte de agua dulce por parte de los ríos y otros cursos de agua, el proceso de evaporación, entre otros, determinan la hidroquímica y la composición isotópica de las aguas subterráneas para la región (Carol et al., 2013). Desde la costa hacia el interior del continente, se pueden reconocer varios ambientes, como llanuras de mareas, marismas y llanura pampeana (Bértola et al., 1998).

El clima en la Bahía Samborombón es templado subhúmedo a húmedo con influencia de oceanidad decreciendo al Oeste y Sudoeste. La temperatura media anual es de $16^{\circ} \mathrm{C}$ y la precipitación media anual es de $950 \mathrm{~mm}$. La mayores precipitaciones ocurren durante el verano, aunque con gran variabilidad interanual (Barros et al., 2000), lo cual se relaciona con la influencia del Sistema Monsónico Sudamericano (SAMS por sus siglas en inglés) y por el centro de alta presión semi-permanente del Atlántico Sur (Garreaud et al., 2009). Los vientos más representativos para la región son aquellos provenientes del Norte, Noreste, Este y Sudeste (Servicio Meteorológico Nacional, 1986). Un fenómeno que afecta al Río de La Plata así como a la Bahía Samborombón es el de la "sudestada", evento de anomalía climática caracterizado por vientos fuertes provenientes del sector sureste, acompañados o no por precipitaciones y descensos de temperatura. Este fenómeno tiene su origen en la acción combinada de dos sistemas de circulación atmosférica; uno de alta presión sobre la región patagónica y otro (aunque no siempre) de baja presión sobre el 
Litoral (Servicio Meteorológico Nacional, 1989). Estos eventos episódicos afectan la región costera Argentina provocando severas inundaciones (D'Onofrio et al., 2008).

Otro fenómeno que influye sobre las precipitaciones en la región, a una escala decadal e incluso multidecadal es el fenómeno de El Niño -Oscilación del Sur (ENOS). Este evento de variabilidad interanual del clima está asociado a condiciones anómalas de humedad en el sureste de América del Sur (Garreaud et al., 2009).

En la Bahía Samborombón desembocan tres ríos principales: Salado, Samborombón y Ajó. Además, a principios del siglo 20, se canalizaron diferentes cursos de agua de la región los cuales transportan grandes volúmenes de agua dulce a alta velocidad y que han modificado el régimen / caudal original de los ríos mencionados. Estos canales desembocan en la franja costera, destacándose el Canal 15 (en las proximidades a la localidad de Cerro de la Gloria), el Canal 9, el Canal 1 (en las proximidades de la localidad de Conesa) y el Canal 2 (que desemboca en las proximidades de General Lavalle) (Volpedo et al., 2005), (Figura 1.1 y Figura 1.3). En determinados sitios estos canales artificiales han dejado expuestas secciones enteras de depósitos cuya génesis está vinculada a las fluctuaciones del nivel del mar correspondientes al MIS (Marine Isotopic Stage) 1. 


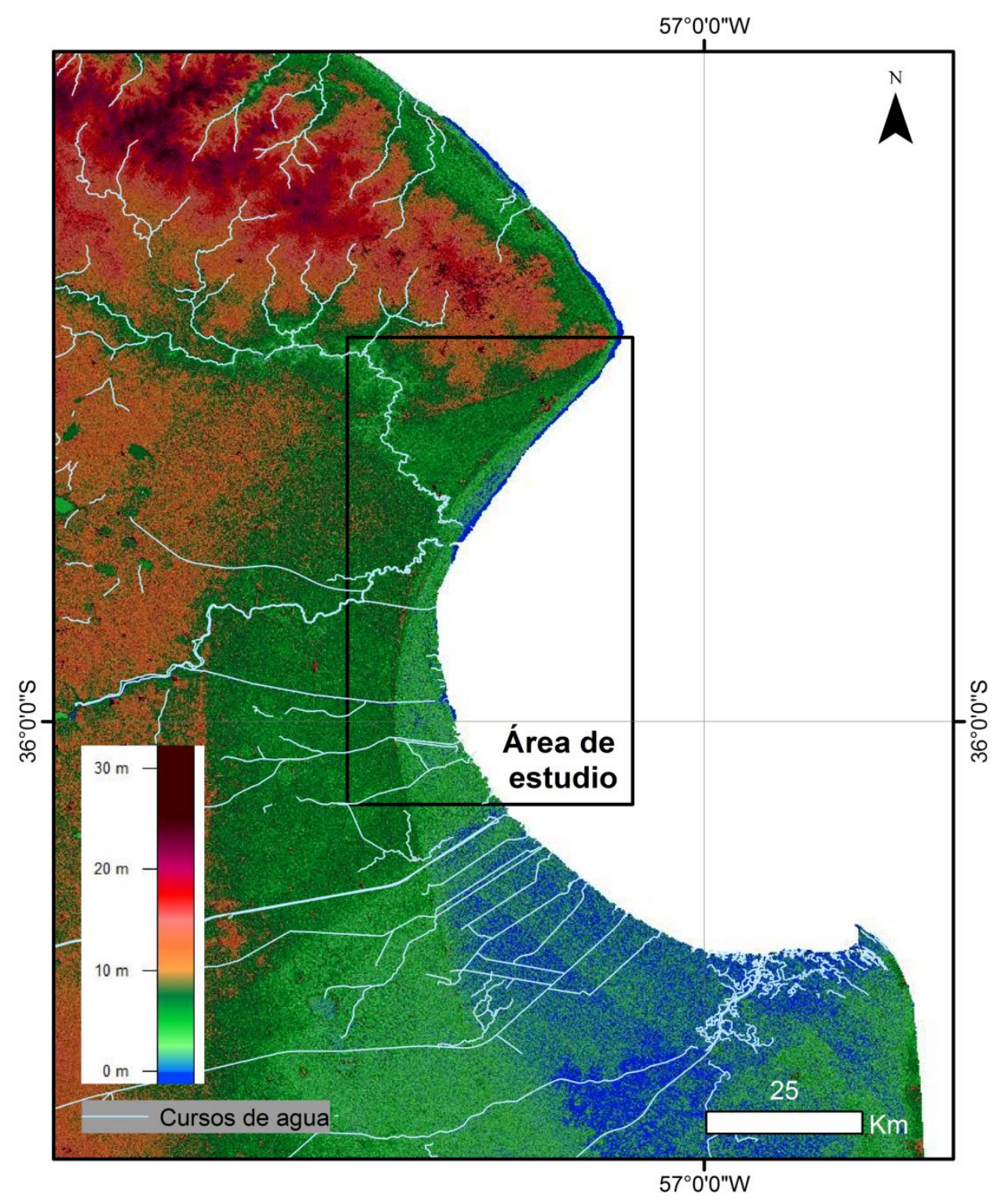

Figura 1.3. Modelo digital de elevación ALOS Global Digital Surface Model "ALOS World 3D-30 m (AW3D30)"

\subsection{2- Antecedentes geológicos}

Los registros palinológicos fósiles que se analizan en esta Tesis, así como las geoformas analizadas, provienen de secuencias sedimentarias y ambientes 
depositacionales de edad holocena, que se agrupan bajo la unidad litoestratigráfica denominada Formación Canal de las Escobas (Fidalgo et al., 1973; Fucks et al., 2010).

La Bahía Samborombón forma parte del sector oriental de la denominada Pampa Deprimida (Frenguelli, 1950) ubicada en la Provincia de Buenos Aires, representando el sector costero de la misma, la cual ha sido modelada por sucesivos ciclos transgresivosregresivos desde al menos el Pleistoceno tardío. Estos ciclos fueron el producto de fluctuaciones marcadas del nivel del mar en respuesta a las forzantes climáticas.

Como resultado de las variaciones eustáticas del nivel del mar en el ámbito continental de la Bahía Samborombón ocurre el depósito de paquetes sedimentarios (Fucks et al., 2010), los cuales constituyen un archivo fundamental de los eventos transgresivos-regresivos del nivel del mar, y que han sido el objeto de estudios geológicos, estratigráficos y paleontológicos.

Las primeras observaciones y descripciones de estos depósitos, junto con su contenido faunístico (principalmente malacofauna), se remonta al siglo XIX cuando importantes naturalistas como d'Orbigny (1842), Darwin (1846), Bravard (1857), Doering (1882), Ameghino (1889). Posteriormente Frenguelli (1950; 1957), Tricart (1973), Fidalgo et al. (1973) hacen sus primeras investigaciones mencionando en sus trabajos las diferentes unidades marinas del noreste de la Provincia de Buenos Aires.

Sin embargo, Fidalgo et al. (1973) realizan el primer estudio litoestratigráfico del paquete sedimentario para la región, agrupando los depósitos en tres unidades o Formaciones (Fm.) atribuidas, cada una, a una ingresión marina distinta; Fm. Pascua, Fm. Destacamento Río Salado y Fm. Las Escobas. A las dos primeras les adjudicó una edad pleistocena (Pleistoceno Superior), mientras que a la Fm. Las Escobas, le adjudicó una edad holocena. Años más tarde, Fidalgo (1979) reinterpreta a la Fm. Destacamento Río Salado como generada en una laguna costera asociada a la ingresion holocena. Posteriormente, autores como Violante et al., 2001; Violante y Parker 2004; Parker et al., 2008, hicieron una primera reinterpretación de la estratigrafía de Fidalgo utilizando por primera vez para la región costera del Este bonaerense, incluyendo Bahía Samborombón, unidades Aloestratigráfcas, sismoestratigráficas y la nomenclatura de secuencias y 
sistemas depositacionales. Por último, Fucks et al. (2010), agrupan las secuencias marinas y rasgos geomorfológicos del sector terminal de las cuencas de drenaje de los ríos Salado y Samborombón en dos unidades litoestratigráficas distintas, correspondiéndose a dos eventos transgresivo-regresivos del Pleistoceno tardío y Holoceno: Fm. Pascua (MIS 5e) y Fm. Canal de Las Escobas (MIS 1) (Figura 1.4 y 1.5). En particular, la Fm. Canal de Las Escobas abarca los depósitos que corresponden a las fases transgresiva, regresiva y de nivel alto de la última ingresión marina, (MIS 1), comprendiendo 4 miembros: Destacamento Río Salado, Canal 18, Cerro de la Gloria y Canal 15 (Fucks et al., 2010).

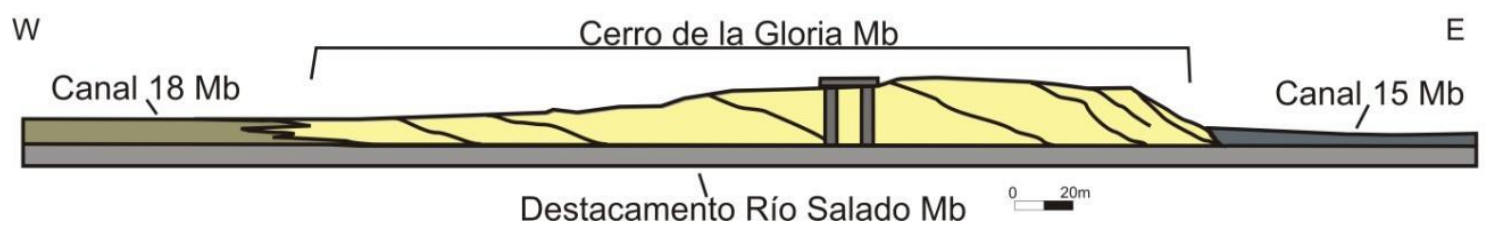

Figura 1.4. Esquema de los diferentes miembros de la formación Las Escobas (Fucks et al., 2010). El gráfico es tomado de Richiano et al. (2012), y corresponde a una representación de los depósitos Holocenos de origen litoral, expuestos en la localidad de Cerro de la Gloria por el canal artificial №15.

Durante la etapa transgresiva hasta su estabilización, se produce la depositación de Miembro Destacamento Río Salado, compuesto por fangos con estratificación flaser y ondulosa de ambientes sub a intermareales. Luego de la depositación de esta unidad se inicia un proceso de caída del nivel relativo del mar con la formación de cordones litorales conformando el Miembro Cerro de la Gloria, compuesto por arenas y material orgánico y representando ambientes de playa. La formación de los cordones interrumpe la llegada de las mareas a importantes sectores situados a sus espaldas, generándose pantanos y lagunas costeras cuyos depósitos se agrupan como Miembro Canal 18. Hacia el este de los cordones, en la etapa regresiva se deposita Miembro Canal 15 representando ambientes de llanuras de mareas que gradan a marismas (Fucks et al., 2010, Richiano et al., 2010). 


\begin{tabular}{|c|c|c|c|c|}
\hline MIS & Edad & \multicolumn{2}{|c|}{$\begin{array}{l}\text { Unidades Litoestratigráficas } \\
\text { marinas }\end{array}$} & $\begin{array}{c}\text { Elevación } \\
\text { máxima } \\
\text { del n.m.m. }\end{array}$ \\
\hline 1 & Holoceno & 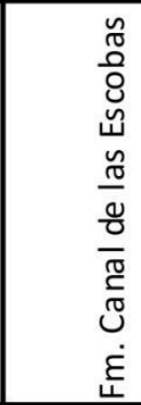 & $\begin{array}{l}\text { Mb. Canal } 15 \\
\text { Mb.Cerro de la Gloria } \\
\text { Mb.Canal } 18 \\
\text { Mb. Destacamento Río } \\
\text { Salado }\end{array}$ & 3-4 m \\
\hline $5 e ?$ & $\begin{array}{l}\text { Pleis toceno } \\
\text { tardío }\end{array}$ & \multicolumn{2}{|c|}{ Fm. Puente de Pascua } & $6-8 \mathrm{~m}$ \\
\hline
\end{tabular}

Figura 1.5. Esquema estratigráfico de los depósitos marino-litorales de la Bahía Samborombón, modificado de Fucks et al., 2010. MIS: Marine Isotope Stages. 


\section{Capítulo 2}

\section{MATERIALES Y MÉTODOS}

\section{1-Trabajo de campo}

\subsubsection{Recolección de muestras de sedimento superficial}

Con el objetivo de construir un modelo de la relación polen-vegetación actual para la franja costera del sector centro-norte de la Bahía Samborombón, se tomaron 23 muestras de sedimento superficial $(\sim 3-5 \mathrm{~cm}$ superiores del suelo actual) mediante la técnica de sub-muestreos múltiples (Adam y Mehringer, 1975) entre abril de 2014 y diciembre de 2016 (Figura 2.1). Estas muestras fueron tomadas en 3 transectas perpendiculares a la costa; dos de estas transectas (T1 y T2) se realizaron en la zona norte de la bahía y siguen una dirección NE-SE, cada una con una longitud de 360 y 440 m, respectivamente. La tercer transecta (T3) se realizó en el sector central de la bahía siguiendo una dirección E-O, paralela a Canal 15 y de 3400 m de longitud. Una cuarta serie de muestras se tomó en los alrededores de un canal de marea activo (T4), abarcando las distintas comunidades vegetales y microambientes observados durante el trabajo de campo (Foto 2.1). En cada transecta se realizó un relevamiento cualitativo de la vegetación con el fin de lograr interpretación precisa del registro polínico. La numeración del total de muestras desde T1 a T4 responde a su ubicación Norte - Sur, es decir, la primera muestra en T1 y la última en T4. Este diseño de muestreo se realizó con el objetivo de observar si existen cambios en las comunidades vegetales a lo largo de un gradiente desde la línea de costa hacia sectores continentales y también para detectar las posibles variaciones en un gradiente latitudinal NE-SO (Tabla 2.1, Figura 2.1).

En la selección de los sitios de muestreo se tuvieron en cuenta los diferentes ambientes mareales de la franja costera de Bahía Samborombón siguiendo un mapa 
geomorfológico de la zona (Bértola, 1994); así como también un mapa de clasificación supervisada de la vegetación de marisma a través de una imagen Landsat 5 (Isacch et al., 2006), patrones de distribución de la vegetación para la cuenca del Salado (Vervoorst, 1967) e imágenes satelitales Spot 5 y 6 y QuickBird.

Adicionalmente, se tomaron dos muestras de sedimento del fondo de un cuerpo de agua somero cercano a la Laguna El Manchado (LEM 1 Y 2, Figura 2.1, Tabla 2.1) con el fin de obtener un registro palinológico moderno correspondiente a un ambiente depositacional lacustre caracterizado por helechos acuáticos formando una carpeta sobre la superficie de dicho cuerpo de agua. Esta metodología y muestreo complementarios se realizaron para poder comparar el registro fósil con su contraparte moderna y, de esta forma, reconstruir las condiciones paleoambientales.

\subsection{2- Perfiles estratigráficos}

Se tomaron muestras de dos secuencias sedimentarias continuas y expuestas sobre las márgenes del Canal 15 (PM1 Y PM2), sector central de la Bahía Samborombón (Figura 2.1), este canal es una obra de ingeniería que representa una extraordinaria oportunidad para reconocer las diferentes secuencias del ciclo transgresivo-regresivo del nivel del mar, correspondiente al MIS1, siguiendo una dirección E-O; es decir, desde las costa hacia elinterior continental pampeano. Las secuencias están constituidas por depósitos que corresponden al momento de la última transgresión marina que representan los diferentes ambientes sedimentarios/geomorfológicos (Violante et al., 2001; Fucks et al., 2010; entre otros) (Capítulo 5).

El muestreo de las secuencias fósiles se llevó a cabo entre 2014 y 2015 . En el campo se realizó el reconocimiento de unidades litoestratigráficas que componen los diferentes miembros de la unidad Fm. Canal de las Escobas descripta por Fidalgo et al., 1973 y Fucks et al., 2010 (Capítulo 3). A partir de dicho reconocimiento, se realizó la descripción de estructuras sedimentarias según Carter y Woodroffe (1994), Corrales Zarauza et al. (1977) y Spalletti (1981); la presencia de estructuras biogénicas y 
macrorestos (conchillas de moluscos), color (con ayuda de la tabla Munsell) y textura de los sedimentos, presencia de concreciones y contactos, entre otros.

Para la realización del muestreo se utilizaron tubos PVC cortados longitudinalmente de 2 y $3 "$, de longitudes variables de acuerdo a las características del sedimento y para facilitar su transporte al laboratorio. El tubo se hincó verticalmente sobre la secuencia sedimentaria, con previa limpieza de la superficie expuesta, a fin de evitar posibles contaminaciones; a continuación se extrajo el tubo conteniendo el segmento seccionado envolviendolo en film para inmovilizarlo y prevenir que se disturbe la estratigrafía, y rotulándolo. Finalmente, una vez obtenidos todos los segmentos, se trasladaron al laboratorio para la recuperación del contenido palinológico, otros microfósiles y macrofósiles y descripción de las características sedimentarias (Foto 2.2). 


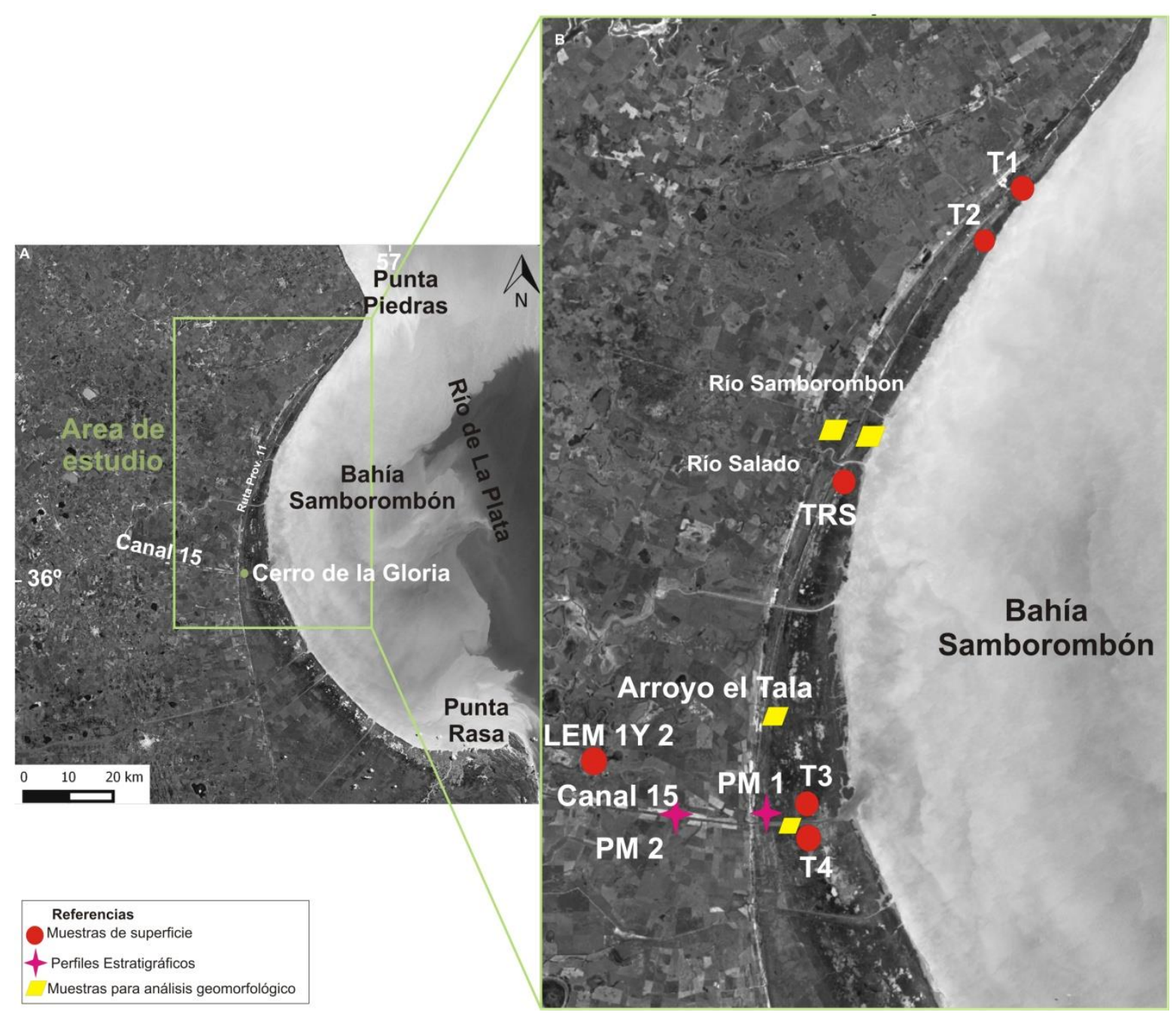

Figura 2.1. Área de estudio. Localización de los sitios estudiados en este trabajo de tesis: en amarillo los sitios donde se colectó material para dataciones y análisis geomorfológico (Capítulo 3 ); en rojo los sitios donde se tomaron las muestras para la realización del modelo polenvegetación actual (Capítulo 4); y con asterisco rosa las secuencias sedimentarias fósiles analizadas palinológicamente (Capítulo 5). 

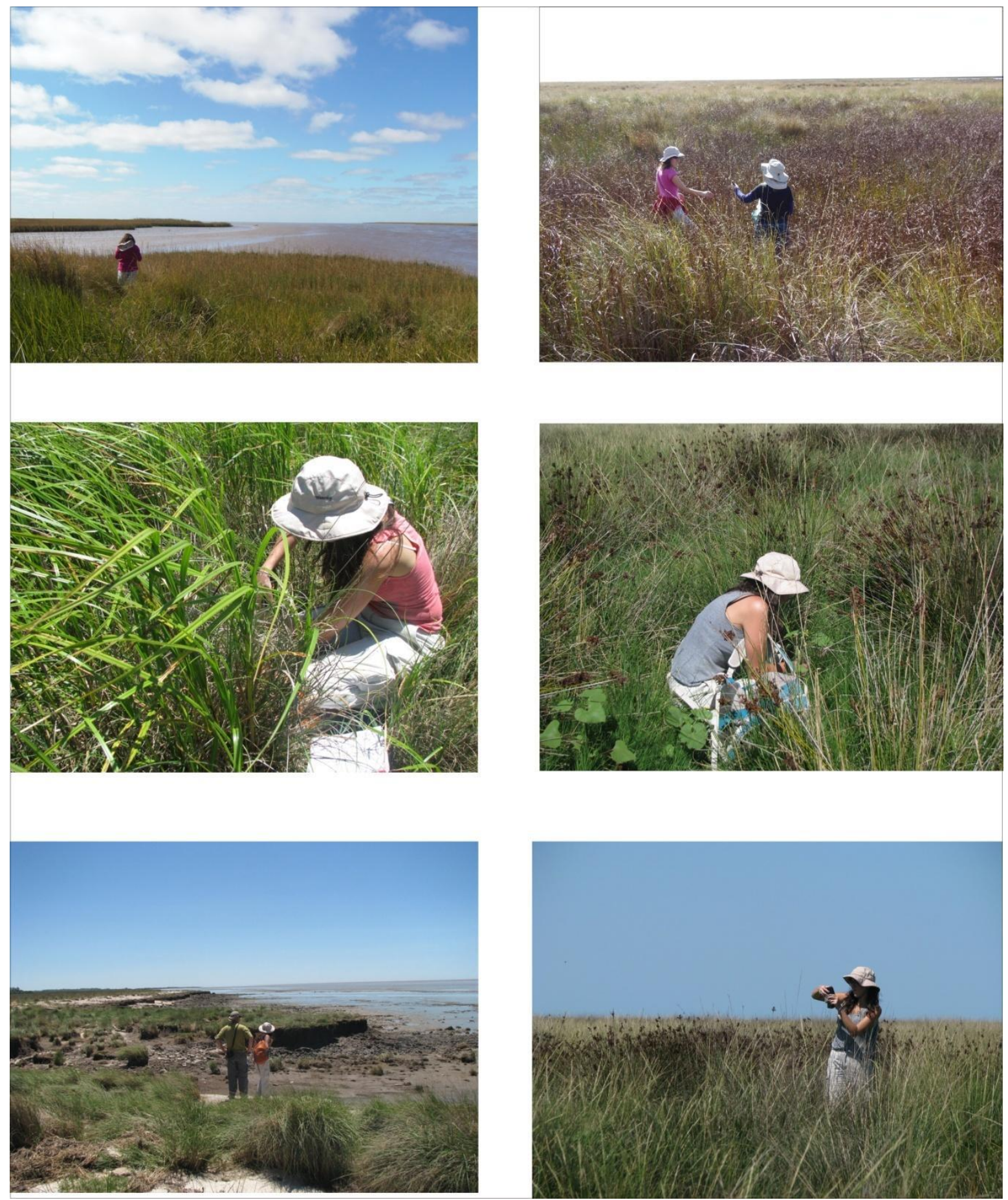

Foto 2.1. Selección y extracción de muestras de sedimentos de los ambientes mareales de Bahía Samborombón. 

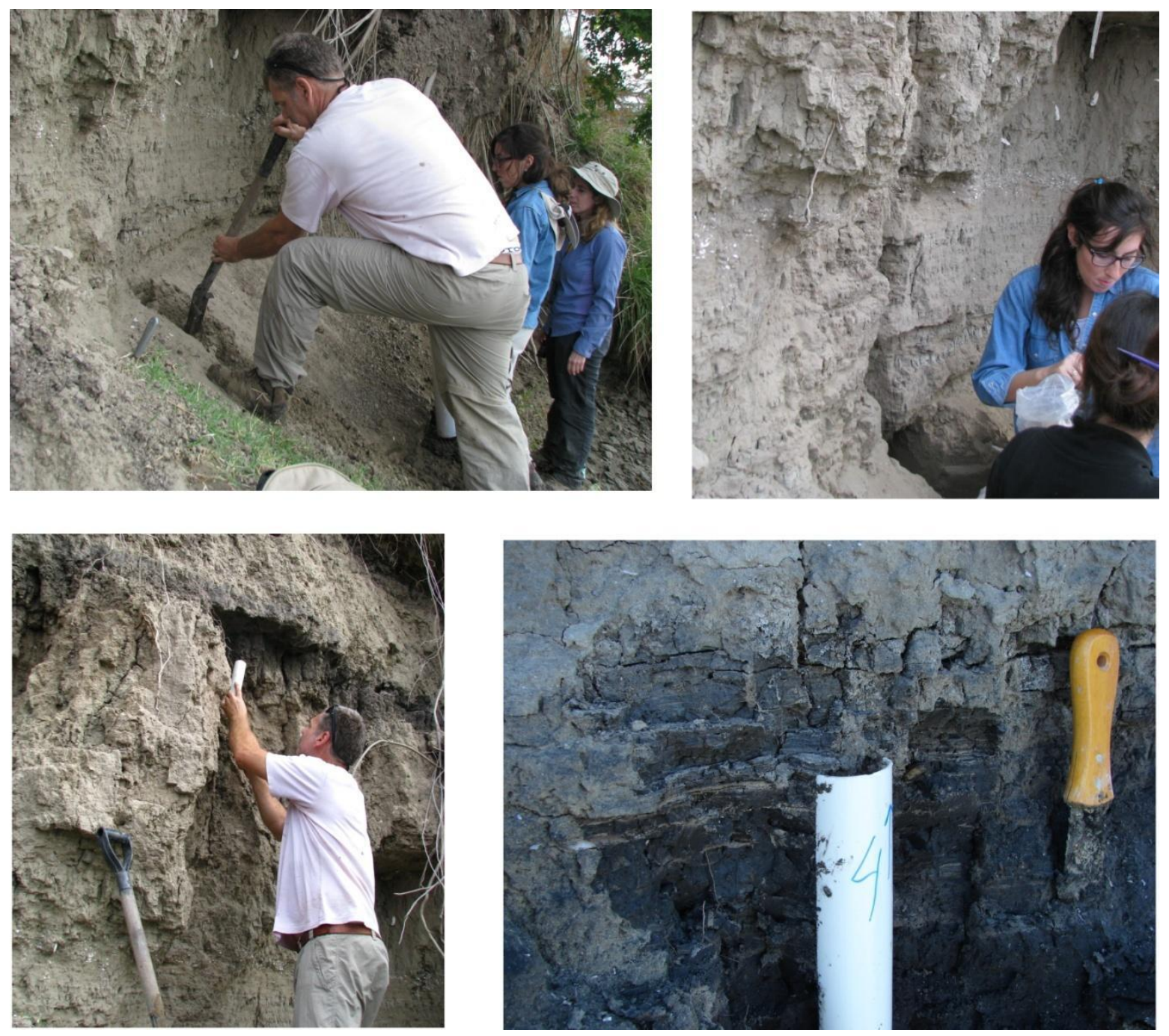

Foto 2.2. Metodología de muestreo de testigos continuos mediante el uso de tubos PVC. 
Tabla 2.1. Ubicación geográfica de las muestras de superficie.

\begin{tabular}{|c|c|c|c|c|}
\hline Muestra & $\begin{array}{c}\text { Código de } \\
\text { muestra }\end{array}$ & Coordenadas geográficas & Partido & Observaciones \\
\hline \multicolumn{5}{|c|}{ Transecta 1} \\
\hline 1 & MS_T 01 & $35^{\circ} 33^{\prime} 51.56^{\prime \prime S}, 57^{\circ} 13^{\prime} 19.37^{\prime \prime O}$ & Punta Indio & \multirow{8}{*}{$\begin{array}{l}\text { Transecta Norte de la } \\
\text { Bahía Samborombón. }\end{array}$} \\
\hline 2 & MS_T 02 & $35^{\circ} 33^{\prime} 51.29 " \mathrm{~S}, 57^{\circ} 13^{\prime} 18.97^{\prime \prime O}$ & Punta Indio & \\
\hline 3 & MS_T 03 & $35^{\circ} 33^{\prime} 50.01^{\prime \prime} \mathrm{S}, 57^{\circ} 13^{\prime} 20.40^{\prime \prime} \mathrm{O}$ & Punta Indio & \\
\hline 4 & MS_T 04 & $35^{\circ} 33^{\prime} 50.01^{\prime \prime} \mathrm{S}, 57^{\circ} 13^{\prime} 20.82^{\prime \prime} \mathrm{O}$ & Punta Indio & \\
\hline 5 & MS_T 05 & $35^{\circ} 33^{\prime} 48.65^{\prime \prime S}, 57^{\circ} 13^{\prime} 22.67^{\prime \prime O}$ & Punta Indio & \\
\hline 6 & MS_T06 & $35^{\circ} 33^{\prime} 47.38^{\prime \prime S}, 57^{\circ} 13^{\prime} 25.32^{\prime \prime O}$ & Punta Indio & \\
\hline 7 & MS_T 07 & $35^{\circ} 33^{\prime} 45.83^{\prime \prime S}, 57^{\circ} 13^{\prime} 27.10^{\prime \prime O}$ & Punta Indio & \\
\hline 8 & MS_T 08 & $35^{\circ} 33^{\prime} 43.90^{\prime \prime} \mathrm{S}, 57^{\circ} 13^{\prime} 30.29^{\prime \prime} \mathrm{O}$ & Punta Indio & \\
\hline \multicolumn{5}{|c|}{ Transecta 2} \\
\hline 9 & MS_R36 01 & $35^{\circ} 36^{\prime} 8.23^{\prime \prime S}, 57^{\circ} 15^{\prime} 32.52^{\prime \prime O}$ & Punta Indio & \multirow{5}{*}{$\begin{array}{c}\text { Sitio continuación } \\
\text { Ruta Provincial №36 }\end{array}$} \\
\hline 10 & MS_R36 02 & $35^{\circ} 36^{\prime} 6.77^{\prime \prime S}, 57^{\circ} 15^{\prime} 33.93^{\prime \prime O}$ & Punta Indio & \\
\hline 11 & MS_R36 03 & $35^{\circ} 36^{\prime} 2.75^{\prime \prime S}, 57^{\circ} 15^{\prime} 36.56^{\prime \prime O}$ & Punta Indio & \\
\hline 12 & MS_R36 04 & $35^{\circ} 36^{\prime} 0.54^{\prime \prime S}, 57^{\circ} 15^{\prime} 38.96^{\prime \prime O}$ & Punta Indio & \\
\hline 13 & MS_R36 05 & $35^{\circ} 35^{\prime} 57.85^{\prime \prime S}, 57^{\circ} 15^{\prime} 40.69^{\prime \prime O}$ & Punta Indio & \\
\hline \multicolumn{5}{|c|}{ Transecta 3} \\
\hline 14 & MS_C15A 01 & $35^{\circ} 58^{\prime} 9.70^{\prime \prime} \mathrm{S}, 57^{\circ} 23^{\prime} 15.90^{\prime \prime} \mathrm{O}$ & Castelli & \multirow{5}{*}{$\begin{array}{c}\text { Transecta paralela a } \\
\text { Canal } 15\end{array}$} \\
\hline 15 & MS_C15A 02 & $35^{\circ} 58^{\prime} 11.60^{\prime \prime} \mathrm{S}, 57^{\circ} 23^{\prime} 24.60^{\prime \prime} \mathrm{O}$ & Castelli & \\
\hline 16 & MS_C15A 03 & $35^{\circ} 58^{\prime} 12.50^{\prime \prime} \mathrm{S}, 57^{\circ} 24^{\prime} 15.60^{\prime \prime} \mathrm{O}$ & Castelli & \\
\hline 17 & MS_C15A 04 & $35^{\circ} 58^{\prime} 13.10^{\prime \prime S}, 57^{\circ} 24^{\prime} 30.20^{\prime \prime O}$ & Castelli & \\
\hline 18 & MS_C15A 05 & $35^{\circ} 58^{\prime} 13.20^{\prime \prime} \mathrm{S}, 57^{\circ} 24^{\prime} 51.00^{\prime \prime} \mathrm{O}$ & Castelli & \\
\hline \multicolumn{5}{|c|}{ Transecta 4} \\
\hline 19 & MS_C15B 01 & $35^{\circ} 58^{\prime} 20.90^{\prime \prime} \mathrm{S}, 57^{\circ} 23^{\prime} 22.00^{\prime \prime} \mathrm{O}$ & Castelli & \multirow{5}{*}{$\begin{array}{l}\text { Muestras tomadas en } \\
\text { los alrededores de un } \\
\text { canal de marea activo }\end{array}$} \\
\hline 20 & MS_C15B 02 & $35^{\circ} 58^{\prime} 21.40^{\prime \prime} \mathrm{S}, 57^{\circ} 23^{\prime} 23.00^{\prime \prime} \mathrm{O}$ & Castelli & \\
\hline 21 & MS_C15B 03 & $35^{\circ} 58^{\prime} 22.00^{\prime \prime S}, 57^{\circ} 23^{\prime} 23.60^{\prime \prime} \mathrm{O}$ & Castelli & \\
\hline 22 & MS_C15B 04 & $35^{\circ} 58^{\prime} 21.50^{\prime \prime} \mathrm{S}, 57^{\circ} 23^{\prime} 28.40^{\prime \prime} \mathrm{O}$ & Castelli & \\
\hline 23 & MS_C15B 05 & $35^{\circ} 58^{\prime} 21.80^{\prime \prime} \mathrm{S}, 57^{\circ} 23^{\prime} 34.30^{\prime \prime} \mathrm{O}$ & Castelli & \\
\hline \multicolumn{5}{|c|}{ Sitio Laguna el Manchado } \\
\hline 1 & LEM_1 & $35^{\circ} 56^{\prime} 16.93^{\prime \prime S}, 57^{\circ} 36^{\prime} 7.65^{\prime \prime O}$ & Castelli & \multirow{2}{*}{$\begin{array}{c}\text { Colectadas en cuerpo } \\
\text { de agua somero }\end{array}$} \\
\hline 2 & LEM_2 & $35^{\circ} 56^{\prime} 18.30^{\prime \prime} \mathrm{S}, 57^{\circ} 36^{\prime} 8.7^{\prime \prime O}$ & Castelli & \\
\hline
\end{tabular}




\section{2-Trabajo de laboratorio}

\subsection{1- Submuestreo del sedimento de las secuencias fósiles}

En el laboratorio se realizó el submuestreo de los testigos el que consistió en seccionarlos cada un centímetro $(1 \mathrm{~cm})$ con la ayuda de espátulas y almacenado el material en bolsas rotuladas. Este material fue separado una parte para ser tratada mediante procesos físicos y químicos para la obtención del polen, esporas y otros palinomorfos y otra para datar (sedimento y/o conchillas).

\subsection{2-Procesamiento físico y químico para la extracción del contenido palinológico de los sedimentos modernos y fósiles}

Para la recuperación del contenido palinológico (polen, esporas, y otros) del sedimento actual y fósil, se procesó un volumen de 1 a $2 \mathrm{~cm}^{3}$ por muestra, tamizando el material utilizando mallas de 150 y 250 micrones para remover las partículas gruesas. A continuación se emplearon técnicas físico-químicas estándar propuestas por Faegri e Iversen (1989) y Mudie y Harland (1996). Previo al tratamiento físico-químico se agregaron en cada muestra 1 o 2 tabletas de Lycopodium clavatum (taxón foráneo al área de estudio), para luego realizar cálculos de concentración polínica en granos por centímetro cúbico (Stockmarr, 1971).

El procesamiento físico-químico incluyó: hidróxido de potasio $(\mathrm{KOH}) 10 \%$ para la defloculación y neutralización de los ácidos húmicos; eliminación de carbonatos con ácido clorhídrico (HCL) 10\%, eliminación de silicatos con ácido fluorhídrico (HF) 48\% en caliente, ácido clorhídrico $25 \%$ en caliente para eliminar el gel de silicato producto del paso anterior y acetólisis para eliminar restos orgánicos. Finalmente, el material resultante se conserva en glicerina fenicada pura y se almacena en tubos Kahn. Luego, se realiza el montaje del material para ser observado al microscopio óptico mediante la colocación de una alícuota del residuo en un portaobjetos y se sella con parafina.

Este etapa del estudio comenzó llevándose a cabo en el laboratorio de Palinología del Cuaternario del Museo de Ciencias Naturales "Bernardino Rivadavia" y continuó en el 
Instituto de Geomorfología y Suelos (IGS)- Centro de Investigaciones en Suelos y Agua de uso agropecuario (CISAUA) de la Facultad de Ciencias Naturales y Museo, Universidad Nacional de La Plata (convenio CEIDE-IGS).

\subsection{3-Recuento palinológico}

La determinación y el recuento palinológico fueron realizados mediante microscopía óptica y con un aumento final de 1000x. Se contaron al menos 300 granos de polen por muestra, registrándose también esporas y otros palinomorfos no polínicos (PNP) tales como algas, quistes de dinoflagelados (dinoquistes) y hongos durante dicho recuento. La determinación taxonómica de los mismos se realizó en base a características morfológicas, estructurales y morfogeométricas de los elementos; utilizando las palinotecas de referencia de la Cátedra de Palinología de la Facultad de Ciencias Naturales y Museo de la Universidad Nacional de La Plata (Yáñes et al., 2014) y de la colección de Actuopalinología del Museo de Ciencias Naturales "Bernardino Rivadavia" de Buenos Aires; además de consultar las descripciones e imágenes de diversas publicaciones y atlas (Heusser, 1971; Markgraf y D`Antoni, 1978; Prieto y Quattrocchio, 1993, Mourelle y Prieto, 2016).

La nomenclatura de polen y esporas fue realizada siguiendo las recomendaciones de Birks y Birks (1980), a nivel de familia (ej. Chenopodiaceae), de género (ej. Ambrosia) y de especie (ej. Limonium brasiliense). En el caso de un tipo polínico con una morfología que es común a varios taxa, pero que no pueden ser distinguidos en base a dicha morfología, se le agregó el prefijo "Tipo" al nombre taxonómico (ej. Tipo Baccharis).

Adicionalmente; se identificaron estructuras de PNP de algas y cianobacterias como Gloeotrichia (vainas), Pediastrum, Scenedesmus y Botryococcus (coloniales); Debaryia, Mougeotia y Tipo Zignema (zigosporas), estas últimas agrupadas como Zignemataceae. También se reconocieron y registraron las especies de dinoquistes como Operculodinium centrocarpum (Deflandre y Cookson) sensu Wall 1967, y Operculodinium centrocarpum (Deflandre y Cookson) sensu Wall 1967 de procesos cortos, agrupados en este trabajo como Operculodinium spp. y Spiniferites bentorii (Rossignol) Wall y Dale, 
junto con Spiniferites bulloideus (Deflandre y Cookson) Sarjeant agrupados como Spiniferites spp. Se reconocieron hongos (Glomus, conidios de Tetraploa y cuerpos fructíferos de Microthirium y esporas Undiff.) y microforaminíferos. Estos PNP se determinaron siguiendo a Van Geel (2002); Borel et al. (2003) y Borel (2007), entre otros. Otros PNP identificados fueron las esporas de briofitas Anthoceros, Phaeocerostenuis, Phaeocerosbulbiculosus, Ricciaceae y Riella (Prieto y Quattrocchio, 1993) junto con gloquidios y másulas del helecho acuático Azolla filiculoides. Los porcentajes de granos de polen fueron calculados en base a la suma total de polen, mientras que los porcentajes de dinoquistes, esporas, algas y hongos fueron calculados de la suma total. Adicionalmente, se identificaron y contaron los agregados de dos o más granos de polen de un mismo tipo o de varios, a los que se denomina como "clumps"; sin embargo, dada su escasa representación no se consideraron en la suma polínica ni tampoco se calculó su valor en porcentaje.

\section{3- Análisis de datos}

Los resultados de los recuentos se expresan en porcentaje y concentración polínica total $\left(\right.$ granos $/ \mathrm{cm}^{3}$ ) y se grafican en diagramas palinológicos realizados mediante el programa TGView2.0.4 (Grimm, 2004). Además, los datos se analizan mediante técnicas de análisis multivariados tanto de agrupamiento o "Cluster Analysis" (CA) como de ordenación: Análisis de Componentes Principales (ACP) y Análisis de Correspondencia destendenciado (ACD). Los tipos polínicos (variables) seleccionados para estos análisis fueron aquellos que presentaron valores medios de al menos $1 \%$ o cuyos valores máximos fueron $5 \%$ o mayores.

Para estos análisis, los programas/softwares estadísticos que se emplearon son: 'PAST' (Hammer et al., 2001), TGView2.0.4 (Grimm, 2004) y R studio (R Core Team, 2013).

El Cluster Analysis (CA) tiene como objetivo agrupar las unidades de estudio (sitios y niveles en este caso) generando gráficos donde éstas se relacionan en una estructura jerárquica ramificada, obtenidos a partir de una matriz de similitud entre dichas unidades; 
puede realizarse restringido, es decir, respetando el orden estratigráfico o no restringido, sin respetar dicho orden.

El Análisis de Componentes Principales (ACP) tiene como objetivo generar el ordenamiento de las unidades de estudio (sitios de muestreo y niveles) en grupos definidos por variables "tipos polínicos" y establecer qué variables contribuyen a la diferenciación entre sitios. Esta técnica de ordenación calcula las distancias entre muestras de la manera más euclidiana posible en el espacio multidimensional (Lamb, 1984). Además, esta herramienta posibilita reducir la variabilidad de los datos con la menor pérdida de la información posible, al transformar las variables originales en componentes principales. Este análisis genera como resultado, gráficos bidimensionales de las muestras a lo largo de los primeros dos componentes principales (ejes). A su vez, los diagramas de ACP revelan la importancia de los diversos taxones utilizados en los cálculos en términos de vectores en el espacio de muestra, lo que implica llegar a determinar aquellos taxa polínicos más importantes en la clasificación y ordenación de los diferentes sitios de muestreo que caracterizan, ambientes/zonación de la vegetación. El análisis de correspondencia sin tendencia "Detrended correspondence analysis" (DCA) es una técnica de reducción de dimensiones.. El CA se realizó en todos los conjuntos polínicos, tanto actuales como fósiles y sus correspondientes dendrogramas se los encuentra en el sector derecho de todos los diagramas palinológicos. El ACP se realizó sobre el conjunto polínico actual con el objetivo de establecer aquellas variables que determinan la distribución espacial del conjunto de muestras en las dos primeras componentes del análisis (ejes 1 y 2). El DCA se realizó entre el conjunto polínico actual y cada uno de los conjuntos fósiles por separado para establecer la similitud entre el modelo actual y el registro fósil

\subsection{1- Modelo polen- vegetación actual}

Fueron analizados un total de 25 muestras de superficie ( 23 provenientes de la franja costera del área de estudio y 2 provenientes de un ambiente de laguna somera a ca. $20 \mathrm{~km}$ de la costa). Las zonas polínicas fueron determinadas mediante CA de tipo 
restringido para $\mathrm{T} 1, \mathrm{~T} 2$ Y T3, es decir, respetando la posición de las muestras a lo largo de la transecta y su distancia a la costa; y CA no restringido para T4 (canal de mareas), ya que la disposición de las muestras no se relacionó con la distancia a la costa. Con el objetivo de realizar un modelo representativo e integral para el área de estudio, se incorporaron 17 muestras de superficie ya analizadas por Vilanova y Prieto (2012), tomadas a lo largo de una de la transecta E-O que se encuentra en el área de estudio, específicamente en el tramo inferior del Río Salado sobre su desembocadura en la Bahía Samborombón (transecta TRS, Figura 4.1.D, Capítulo 4). Se realizó un ACP para el total de las muestras mencionadas, constituyendo una matriz de 40 muestras por 9 variables, estas últimas fueron; Poaceae, Chenopodiaceae, Limonium brasiliense, Cyperaceae, Typha, Asteraceae, Ambrosia, Solanaceae, Pediastrum. Por último, se realizó un diagrama palinológico en porcentaje resumido para el total de las muestras de la franja costera de sector centronorte de la Bahía Samborombón. Estos datos se analizan en el Capítulo 4.

\subsection{2- Perfil estratigráfico PM1}

Fueron seleccionados, procesados y analizados 39 niveles a lo largo del afloramiento (intervalo cada tres $\mathrm{cm}$ ). La muestra correspondiente al nivel PM1-29 cm no fue considerada. Las zonas polínicas fueron determinadas mediante CA de tipo restringido, es decir, respetando el orden estratigráfico de los niveles seleccionados (Grimm, 2004).

La comparación entre las muestras polínicas de superficie (incluyendo las muestras LEM 1 y LEM 2) con las muestras sub-fósiles se realizó mediante DCA quedando constituida una matriz de 78 muestras y 15 variables, estas últimas fueron: Poaceae, Chenopodiaceae, Limonium brasiliense, Cyperaceae, Typha, Asteraceae, Ambrosia, Solanaceae, Pediastrum, Phaeoceros, Riccia, Botriococcus, Operculodinium, Spiniferites, Azollafiliculoides.

A excepción de la comparación del espectro fósil con el análogo moderno mediante el análisis de DCA y las muestras obtenidas de sedimentos de cuerpo de agua 
someros, la mayor parte de este capítulo se encuentra publicado por Luengo et al. (2018) en donde se desarrolló el análisis de foraminíferos fósiles contenidos en los sedimentos del PM1, llevado a cabo por Emiliana Bernasconi.

\subsection{3- Perfil estratigráfico PM2}

Para llevar adelante los objetivos de este capítulo se procesaron 55 muestras provenientes del perfil sedimentario PM2 (35 resultaron estériles). Las muestras del perfil que no resultaron estériles, provienen de la parte basal de la secuencia (Figura .2, Capítulo 5). Además, se emplearon las 42 muestras del modelo polen-vegetación actual (representando la vegetación y los ambientes mareales de la franja costera de Bahía Samborombón) para interpretar la vegetación y las condiciones ambientales del Holoceno medio, representado por las muestras fósiles de este perfil PM2. También, se incluyeron las muestras de sedimento superficial de un cuerpo de agua somero tapizado por la proliferación del helecho acuático Azolla. filiculoides.

La comparación entre el análogo moderno (incluyendo las muestras LEM 1 y LEM 2) con las muestras fósiles se realizó mediante DCA quedando constituida una matriz de 62 muestras y 13 variables, estas últimas fueron: Poaceae, Chenopodiaceae, Limonium brasiliense, Cyperaceae, Typha, Asteraceae, Ambrosia, Solanaceae, Phaeoceros, Riccia, Operculodinium, Spiniferites, Azolla filiculoides.

\section{4- Cronología}

Para establecer un marco temporal preciso de los cambios de la vegetación y ambientales durante el Holoceno medio y tardío, se obtuvieron un total de 12 dataciones

radiocarbónicas $\left(\mathrm{C}^{14}\right)$ (AMS y convencional) sobre material proveniente de depósitos de cordones de conchillas y de niveles específicos de los perfiles estratigráficos (materia orgánica y conchillas). Los cordones conchiles muestreados para establecer su cronología 
numérica, se ubican en la zona de las desembocaduras de los ríos Salado y Samborombón (Figura 2.1). La selección del sitio de muestreo de cheniers fue en base a la accesibilidad al área, previo reconocimiento aéreo en imágenes satelitales o QuickBird y además por su descripción previa (Bértola, 1994). El muestreo consistió en recolectar muestras de sediemnto de los primeros $50 \mathrm{~cm}$ superficiales sobre el depósito (Foto 2.3) para luego separar conchillas. El molusco seleccionado para estas dataciones fue el bivalvo Mactra isabelleana d'Orbigny, 1846, debido a su gran abundancia en los depósitos holocenos, ya que representa casi el 90 \% del material biogénico extraído de dichos depósitos en el área de estudio (Aguirre y Whatley, 1995).

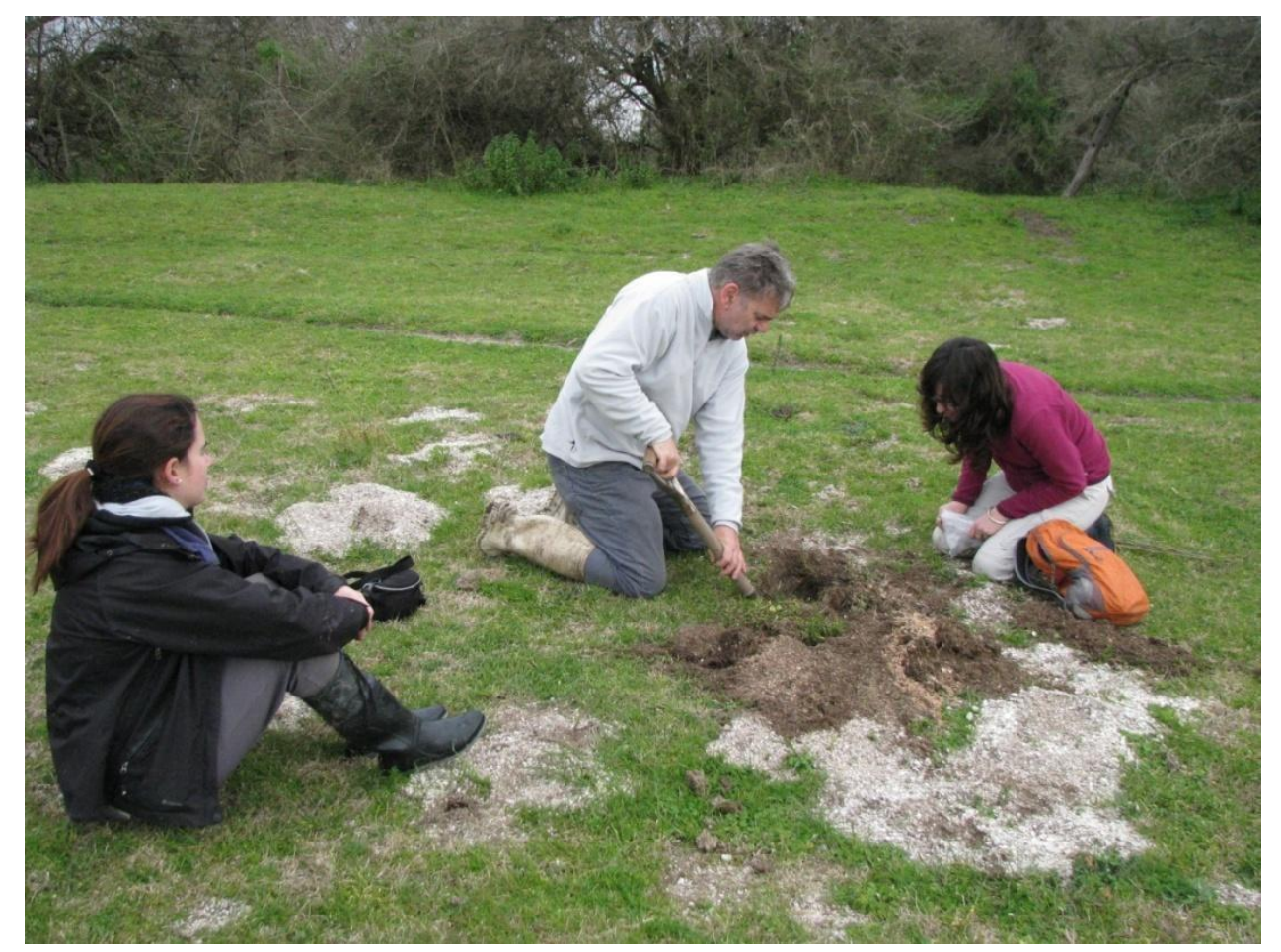

Foto 2.3. Metodología de muestreo de material para datar proveniente de depósitos de cordón litoral.

Estas muestras fueron tamizadas en laboratorio con mallas de 2,80 mm, 1,40 mm y 0,354 $\mathrm{mm}$ para separar las diferentes fracciones e incluso lavar la matriz generalmente arenosa y luego se separaron aquellas valvas mejor preservadas, según resultara de la evaluación de los atributos tafonómicos (análisis y descripción de: articulación, 
fragmentación, abrasión, corrosión y bioerosión). Finalmente fueron elegidas aquellas conchillas que evidenciaron un menor grado de retrabajo y transporte para la realización del fechado absoluto.

Las dataciones se realizaron en el LATYR (CIG-CONICET) en La Plata, Argentina y en el laboratorio Direct AMS en Seatle, EEUU. Los fechados fueron calibrados usando el programa Calib Rev. 7.0.2 (Stuiver y Reimer, 1993) utilizando las curvas de calibración SHCal13 (Hogg et al., 2013) y Marine13 (Reimer et al., 2013).

El control cronológico de la secuencia PM1 se obtuvo mediante tres dataciones radiocarbónicas (una AMS y dos convencionales). Se realizó un modelo de edadprofundidad (Capítulo 5) usando el programa Bacon (Blaauw y Christen, 2011). Para la secuencia PM2 se obtuvieron tres dataciones radiocarbónicas (una AMS y dos convencionales), y el modelo de edad se realizó con el software TGView2.0.4 (Grimm, 2004).

Por último, para completar y mejorar el encuadre temporal de los resultados de la presente tesis, se suman edades previamente publicadas para la zona de estudio, las mismas fueron calibradas mediante el programa Calib antes mencionado.

\section{5- Uso de Sensores Remotos para el reconocimiento y análisis geomorfológico}

Las imágenes satelitales empleadas para el reconocimiento y análisis de las geoformas de origen litoral y fluvial fueron provistas por la Comisión Nacional de Actividades Espaciales (CONAE), provenientes del Satélite SPOT 6 (4 bandas espectrales de resolución espacial 6,0 m, a excepción de la banda pancromática con resolución de 1,5 m) con una resolución espectral descripta en la Tabla 2.2. La imagen seleccionada correspondió a la del 14 de septiembre del Año 2015 del Sensor SPOT 6. 
Tabla 2.2. Rangos espectrales de la imagen SPOT 6.

\begin{tabular}{ll}
\hline Pancromática & $0,450-0,745 \mu \mathrm{m}$ \\
Azul & $0,450-0,520 \mu \mathrm{m}$ \\
Verde & $0,530-0,590 \mu \mathrm{m}$ \\
Rojo & $0,625-0,695 \mu \mathrm{m}$ \\
Infrarrojo cercano & $0,760-0,890 \mu \mathrm{m}$ \\
\hline
\end{tabular}

Para el reconocimiento de morfologías de origen litoral-costero y fluvial, la mejor información la proporcionó la banda pancromática de la imagen Spot 6. El preprocesamiento consistió en la corrección radiométrica de los datos y luego se realizaron operaciones espaciales denominadas "filtros" que tienen la finalidad de eliminar la variabilidad de una imagen al calcular un nuevo valor de cada pixel o celda (nivel digital) a través de determinadas funciones que se aplican sobre los valores de los pixeles contiguos dando como resultado, algún tipo de promedio ponderado (Conolly y Lake, 2009). La aplicación del filtro se llevó a cabo por medio de un núcleo o matriz numérica cuadrada que se desplaza a través de la imagen modificando los valores de los niveles digitales centrales originales. Los filtros utilizados son los denominados filtros de convolución. Este proceso espacial utiliza un promedio ponderado del pixel de entrada y de sus vecinos inmediatos para calcular el valor de brillo del pixel de salida. El grupo de pixeles utilizados en el cálculo del promedio ponderado se conoce como núcleo (kernel) (Aldalur y Santamaría, 2002); variantes de este filtro y aplicados en este trabajo son: el "filtro direccional" que actúa en el realce de bordes que poseen componentes específicos de dirección (gradientes) que pueden ir de $0^{\circ}$ a $360^{\circ}$. El "filtro Sobel" es comúnmente utilizado para la detección de bordes al igual que el "filtro laplaciano" aunque si bien este último fue implementado, no fue considerado para este trabajo. Por último, otro de los filtros es el "Mediano" aunque no es función lineal de los valores de brillo de los pixeles de 
una imagen. Los filtros se aplicaron a la banda pancromática de la imagen SPOT 6 utilizando el Software Envi 5.1. (Exelis, 2013).

Por otro lado, para reconocimiento y mapeo de paleocauces y cordones litorales, se aplicaron realces espectrales que resaltaron los cambios en la vegetación y humedad. Para ello se trabajó con los siguientes procesos: combinación de bandas 431. Todas estas operaciones permiten mejorar la calidad visual de una imagen; su aplicación como paso previo a otras técnicas de procesamiento digital es necesaria para explorar y detectar los distintos rasgos presentes en la imagen.

Por último, la técnica usada en este trabajo para el mapeo de los rasgos del paisaje fue la digitalización manual. Para ello se crearon capas de datos vectoriales, es decir, se generaron polígonos y/o líneas de diferentes colores para diferenciar las geoformas fluviales, litorales, cursos actuales, rutas y otras obras antrópicas, entre los más importantes mediante el software QGIS 2.2.0.

Además, fue necesario realizar trabajo de campo para corroborar las morfologías reconocidas y para la descripción de secciones expuestas tanto en canteras de explotación de conchillas como en canales artificiales producto de obras hidráulicas. La integración de resultados obtenidos a partir de los análisis de imágenes satelitales de alta resolución (empleo de filtros y realces), junto con los estudios en campo y las dataciones obtenidas se presentan en el Capítulo 3.

Para realizar un mapa detallado de los paleocauces, se tuvo en cuenta la cobertura de los pastizales y arbustales-pastizales. Para ello se trabajó adoptándose el siguiente proceso: Combinaciones de bandas "Falso Color 431 (RGB)". 


\section{Capítulo 3}

\section{GEOMORFOLOGÍA Y ESTRATIGRAFÍA}

\section{1-Introducción}

Los procesos geomorfológicos litorales generan modificaciones permanentes en las zonas costeras, ya sea a través de procesos de acumulación o erosión. En particular, la Bahía Samborombón muestra cómo los procesos geomorfológicos litorales, asociados a los cambios del nivel del mar y en consecuencia de las oscilaciones climáticas ocurridas durante el Cuaternario, han moldeado y generado diferentes morfologías al menos desde el Pleistoceno tardío (Fidalgo et al., 1973; Violante et al., 1992; Codignotto y Aguirre, 1993; Cavallotto, 1995; Violante y Parker, 2000; Violante et al., 2001; Schnack et al., 2005; Fucks et al., 2010).

Estos episodios transgresivos/regresivos permitieron la generación de importantes depósitos y geoformas como cordones litorales, paleocanales de marea, paleocauces, entre otros han quedado preservadas en todo el ámbito continental de la bahía, en particular aquellas más modernas, correspondientes al MIS 1, y cuyo análisis puede contribuir al entendimiento de las condiciones paleoambientales que le dieron origen.

La Ilanura costera del NE de la provincia de Buenos Aires comprende la franja costera que se extiende entre la cota de $5 \mathrm{~m}$ hasta la presente línea de costa (Bértola, 1994; Cavallotto, 1995; entre otros). Abarca el ámbito que se desarrolla al pie de la llanura pampeana y está constituida por la cuña sedimentaria costera del Holoceno (Violante et al., 2001) incluyendo tanto ambientes fósiles como aquellos que se encuentran actualmente activos. Los ambientes litorales identificados en la llanura costera del área de estudio presentan características muy diferentes, cuya génesis está vinculada a los últimos 
episodios transgresivos/regresivos en general, y a una serie de factores evolutivos climáticos, geológicos, biológicos, físicos, en particular.

El objetivo del presente capítulo es identificar, mapear y caracterizar los diferentes rasgos geomorfológicos como paleolíneas de costa, cheniers, paleocanales de marea, ubicados en la zona costera de Bahía Samborombón mediante el uso de sensores remotos y afloramientos naturales y artificiales, para luego generar un modelo de evolución geomorfológica de la región durante el Holoceno medio - tardío.

En este trabajo de Tesis se adopta la descripción de los ambientes geomorfológicos actuales, principalmente los ambientes mareales definidos por Bértola (1994) para la Bahía Samborombón. Este autor, individualiza los ambientes en submareal, intermareal bajo, intermareal alto, marisma baja y alta. Para el ambiente de marisma, se tiene en cuenta además, la determinación y descripción de Cagnoni (1999).

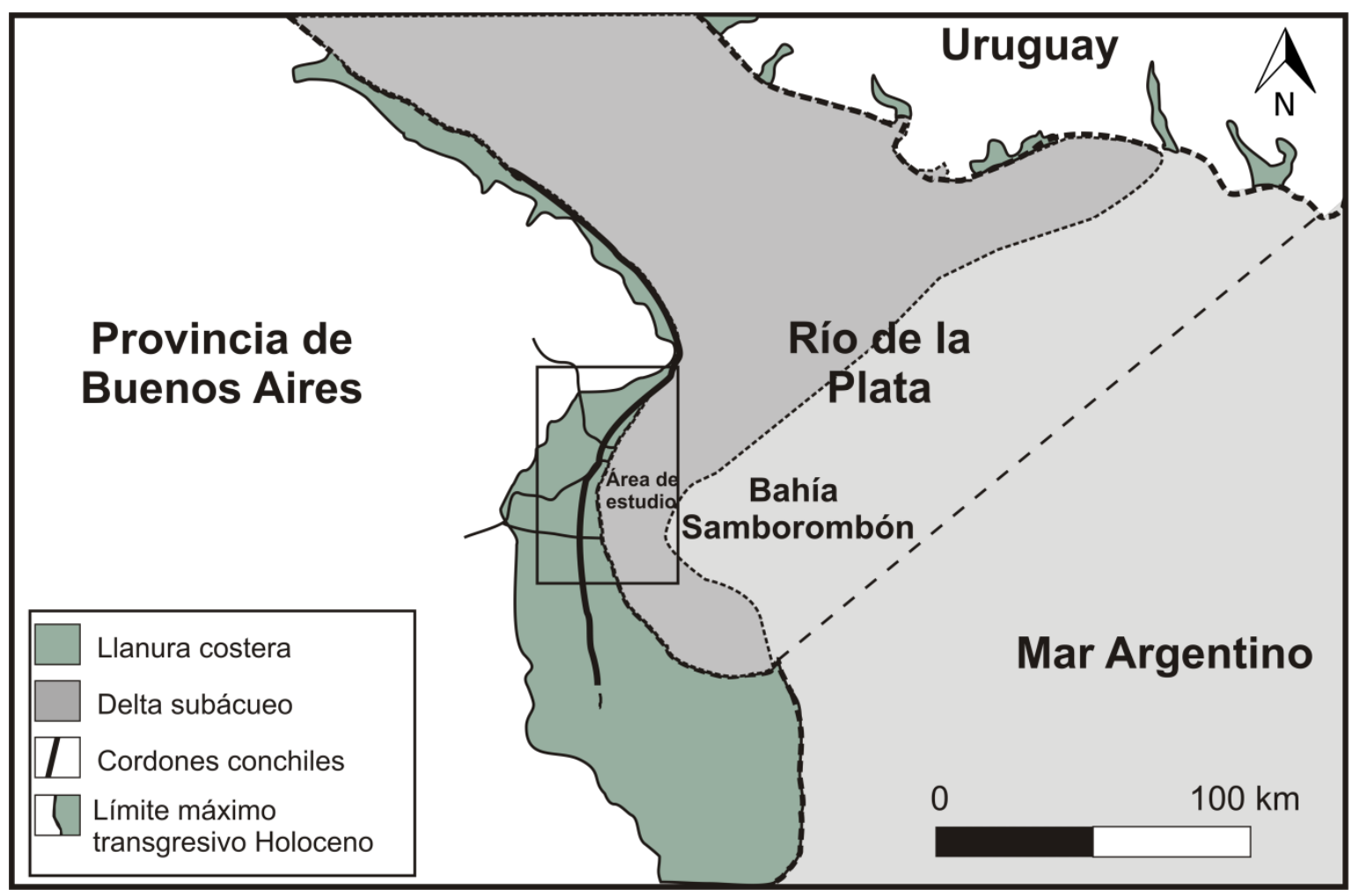

Figura 3.1. Mapa geomorfológico regional donde se muestra la llanura costera y área de estudio. Modificado de Cavallotto, 2002. 


\section{2.- Ambientes actuales}

\section{2.1- Ambiente submareal}

El ambiente submareal se caracteriza por estructuras sedimentarias y características dinámicas que responden a la influencia de corrientes de marea y olas. Este ambiente, dentro de la Bahía Samborombón, tiene sus límites entre la isobata de $10 \mathrm{~m}$ y el nivel de bajamares de sicigia (Guerrero et al., 1989; Bértola, 1994). Los sedimentos de esta zona, que se encuentra siempre sumergida, son principalmente pelíticos (limos y arcillas), mostrando un aumento granulométrico desde la costa hacia el mar y son muy pobremente seleccionados a lo largo de la bahía. Las estructuras sedimentarias corresponden a formas de fondo en surcos longitudinales y a óndulas menores de diferentes longitudes de onda según si se originaron por corrientes de marea o por olas (Bértola, 1994). En cuanto a su morfología, el fondo de la Bahía Samborombón es plano, con una suave pendiente hacia el mar.

\section{2.2.- Ambiente intermareal o llanuras de mareas}

Este ambiente presenta una pendiente que varía entre 0,03 y $1 \%$ y una zonación textural (granulométrica) producto de la pérdida de capacidad de transporte de las olas al recorrer grandes distancias en una costa baja. En condiciones normales los sedimentos más pesados son depositados primero mientras que los sedimentos finos recorren mayor distancia en suspensión y son depositados en zonas topográficamente más elevadas (Bértola, 1994).

Los límites de este ambiente están dados por el nivel de bajamares de sicigias al nivel de pleamares de sicigia; y además, fue dividido en base a la granulometría y exposición en: 1 intermareal bajo, que se extiende desde el nivel de bajamares de sicigias al de pleamares de cuadratura, quedando sumergido diariamente con una exposición parcial. 2 intermareal alto, caracterizado por una granulometría levemente mayor que el anterior. Este ambiente se extiende desde el nivel de pleamares de cuadraturas al de pleamares de sicigia quedando sumergido pocos días al mes y puede ser invadido por 
vegetación halófita como Sporobolus spp. indicando un avance de la marisma por sobre el ambiente intermareal alto (Bértola, 1994). Este autor identifica además, en la llanura de mareas, depósitos de material grueso cordoniformes (cheniers) cuya formación la atribuye a la acción de las olas (durante eventos de tormenta y altas mareas de sicigia) que pueden tener la capacidad de llevar material grueso hasta niveles en donde sólo llega material pelítico en condiciones de sedimentación normal. A su vez, reconoce la formación de estas geoformas a lo largo de toda la bahía pero en particular en bocas de canales y ríos indicando la influencia de estos en su formación o génesis. Estos depósitos, se encuentran en ambientes de marismas, en una posición topográfica más elevada evidenciando su formación en el pasado y sobre los cuales se desarrolla vegetación que favorece su estabilización y preservación del registro estratigráfico. Por esta razón, los cheniers pueden ser utilizados como proxy ambiental y como indicadores de la posición de antiguas líneas de costa.

De acuerdo con la clasificación de Allen (1993), la transición o contacto entre el ambiente intermareal y la marisma en el área de estudio, es de tipo microacantilada (Figura 3. A y B). 


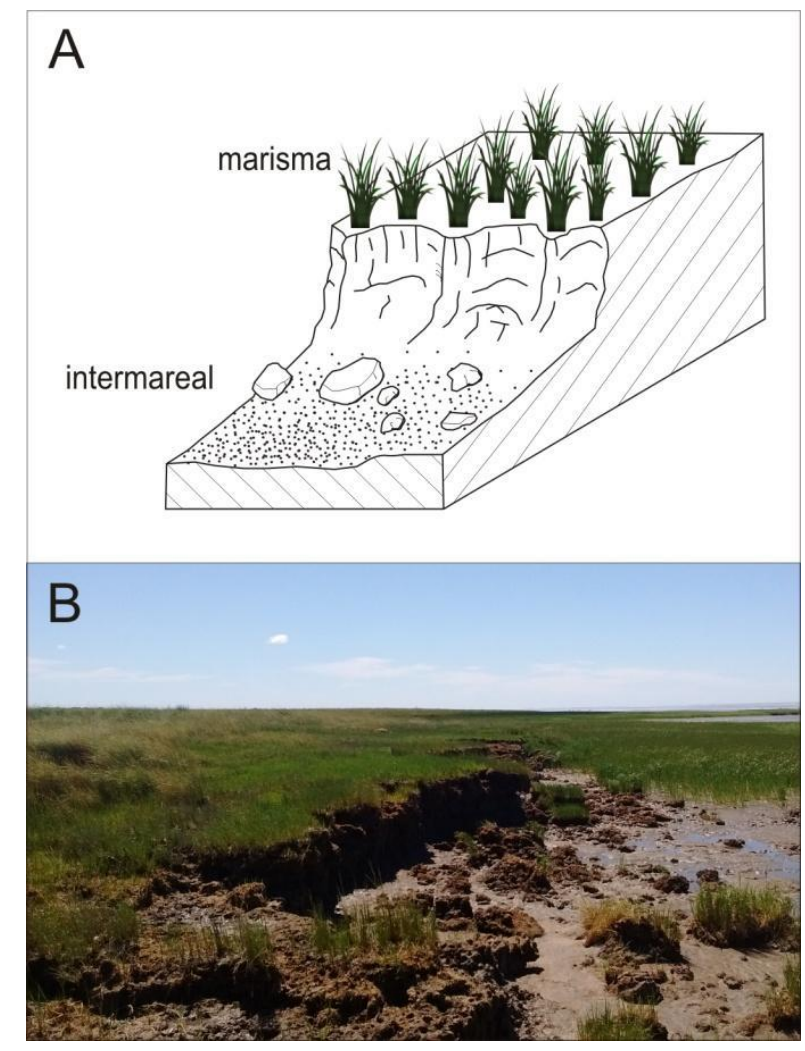

Figura 3. 2. A- Esquema modificado de Davidson-Arnott, R. (2010), en donde se representa la morfología de la costa de tipo microacantilada. B- Foto de la línea de costa de la zona Norte de

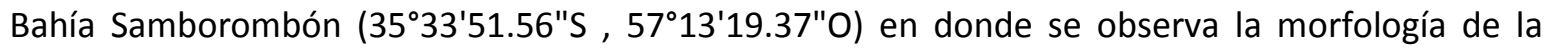
costa de tipo microacantilada.

\section{2.3.- Marismas}

Las marismas son ambientes altamente dinámicos formados por la interacción del agua, el sedimento y la vegetación. Se desarrollan en sitios protegidos como desembocaduras de ríos, bahías, lagunas costeras, entre otros, donde la energía de las olas es baja y por lo tanto la granulometría es generalmente fina (Allen, 2000; Adam, 2002). Los límites de este ambiente están dados por el nivel medio de mareas altas ordinarias y el nivel medio de mareas altas extraordinarias. En el ambiente de marisma, el transporte de sedimentos se da por medio de agentes eólicos y ácueos (pluvial, fluvial y de oleaje en pleamares máximas) (Bértola, 1994). Las comunidades asociadas a este tipo de ambientes están constituidas por especies altamente especializadas y en general están caracterizadas por una baja diversidad (Cagnoni, 1999). 
La marisma se divide en dos zonas principales, una baja y una alta, en base a: las características topográficas del terreno y la magnitud, duración y alcance de las inundaciones por las mareas, sedimentología y contenido florístico (Bértola, 1994; Cagnoni, 1999). La zona baja (marisma baja) está sujeta a tres o cuatro inundaciones por mes, y su extensión está acotada a los límites de la influencia del régimen de inundación de las mareas diarias. Los sedimentos son más finos que en la alta y la vegetación, en general, está comprendida por más del 50\% de Sporobolus spp. La zona alta (marisma alta) es inundada irregularmente (no más de cuatro o cinco inundaciones por año al menos) y su límite superior está condicionado al alcance de la inundación producida por las mareas altas extremas y sudestadas. La granulometría de este sector es mayor que la baja y la vegetación generalmente está compuesta en más del 50\% por Sarcocornia perennis (Bértola, 1994; Cagnoni, 1999).

Los principales factores que controlan el tipo de vegetación a lo largo de la marisma son: el grado de exposición, la salinidad, la temperatura, el tipo de sedimentos y el régimen de mareas.

Los canales de marea constituyen una geoforma importante en el intercambio de agua salada desde el sistema estuárico al de llanura de mareas y marisma, produciéndose el intercambio en dos sentidos: el ingreso de agua salada por efectos de la marea en forma de manto y su egreso canalizado, y de agua de lluvia que cae sobre las planicies mareales y marismas, encauzándose por los canales y desaguando en el mar (Bértola, 1994). Además, los canales de marea pueden alterar este patrón de zonación de la vegetación (Zedler et al., 1999).

Bértola (1994) destaca que estos tres ambientes mareales descriptos en la bahía se vinculan genéticamente a través de un proceso de progradación costera, en donde ocurre la migración de los ambientes por encima de los que van quedando lejos de la costa actual conforme ésta progradó durante el Holoceno tardío, es decir, la actual zona supramareal se desarrolla en zonas donde antiguamente existían ambientes intermareales y submareales. 


\section{3.- Geoformas asociadas a paleoambientes litorales}

\section{3.1- Cordones litorales}

Los cordones o crestas litorales (beach ridges) son rasgos lineares, relictuales del paisaje, paralelos a semi-paralelos a la costa actual. Se originan tanto en el intermareal como en el supramareal por acción conjunta de las mareas y el viento y se componen principalmente por material grueso (arena, gravas y/o bioclastos) (Otvos, 2000). En el área de estudio los cordones litorales constituyen el rasgo más característico de la llanura costera y han sido agrupados litoestratigráficamente como Miembro Cerro de la Gloria de la Formación Canal de Las Escobas (Fidalgo et al., 1973 y Fucks et al., 2010). En particular, en el sector central de la bahía, estos cordones constituyen un cuerpo único de alrededor de $500 \mathrm{~m}$ de extensión lateral (ancho) y $5 \mathrm{~m}$ de espesor, y están compuestos casi exclusivamente por concentraciones esqueletales de moluscos enteros o fragmentados, rodados de tosca y en forma subordinada arena (Fidalgo et al., 1973; Fucks et al., 2010; Richiano et al., 2012). Estos depósitos han sido interpretados como ambientes de playa de alta energía con evidencia de eventos de tormentas (Fucks et al., 2010). Dataciones radiocarbónicas realizadas sobre conchillas dan cuenta de que su formación ocurrió durante el intervalo que va de los 5294-4843 a los 4613-3979 cal AP (Tabla 3.1).

\section{3.2.- Cheniers}

Los cheniers son un tipo de cordón litoral que se encuentran separados entre sí por material fangoso progradacional (Otvos y Price, 1979; Rodhes, 1982; Otvos, 2000). Aquellos ambientes constituidos por la alternancia de fangos, donde se establece vegetación de marisma, con cheniers se los denominó llanura de cheniers (chenier plain) (Otvos, 2000) la cual debe estar formada por dos o más complejos de cheniers (McBride et al., 2007). 
Estas geoformas se desarrollan a lo largo de costas que reciben un gran volumen de sedimento fino por parte de los ríos (Otvos, 2000) y su evolución está influenciada por el aporte sedimentario de tipo episódico, es decir, la tasa de progradación costera está controlada por el aporte sedimentario fangoso que, cuando éste se interrumpe, ocurre la depositación de material grueso, por acción de las olas y de eventos de tormenta (Dougherty y Dickson, 2012 y referencias allí citadas). Por esto, los cheniers representan antiguas posiciones de la línea de costa y además pueden proporcionar un registro sensible de los cambios ambientales como por ejemplo: aporte sedimentario, eventos catastróficos (depositacionales y erosivos), nivel del mar, entre otros (Augustinus, 1989).

\section{3.2.1.- Cronología de los cheniers}

Las cronología de los cheniers se realizó en la zona de la desembocadura de los ríos Salado y Samborombón y se basan en edades radiocarbónicas de material biogénico (principalmente conchillas de moluscos bivalvos de la especie Mactra Isabelleana) componentes principales de estos rasgos geomorfológicos. 
Tabla 3.1. Edades radiocarbónicas de diferentes ambientes de la planicie costera NE de Buenos Aires.

\begin{tabular}{|c|c|c|c|c|c|c|c|}
\hline Muestra & Edad ${ }^{14} \mathrm{CAP}$ & Edad cal AP & $\begin{array}{l}\text { Código de } \\
\text { muestra }\end{array}$ & $\begin{array}{l}\text { Coordenadas } \\
\text { geográficas }\end{array}$ & Material & $\begin{array}{c}\text { Ambiente } \\
\text { depositacional }\end{array}$ & Ref. \\
\hline $\mathrm{C} 01$ & $2590 \pm 80$ & $2344-2146$ & LP-3297 & $\begin{array}{l}35^{\circ} 44^{\prime} 7.790 " \mathrm{~S}, \\
57^{\circ} 21^{\prime} 31.26^{\prime \prime} \mathrm{O}\end{array}$ & Mactra isabelleana & \multirow{4}{*}{$\begin{array}{l}\text { Depósitos de } \\
\text { chenier(Mb. } \\
\text { Canal 15) }\end{array}$} & \multirow{4}{*}{ Esta tesis } \\
\hline $\mathrm{CO3}$ & $3050 \pm 100$ & $2941-2726$ & LP-3300 & $\begin{array}{l}35^{\circ} 44^{\prime} 9.18^{\prime \prime} \mathrm{S} \\
57^{\circ} 21^{\prime} 54.600\end{array}$ & Mactra isabelleana & & \\
\hline $\mathrm{CO5}$ & $3570 \pm 110$ & $3600-3338$ & LP-3321 & $\begin{array}{l}35^{\circ} 44^{\prime} 12.56^{\prime \prime S}, \\
57^{\circ} 22^{\prime} 8.74^{\prime \prime O} \\
\end{array}$ & Mactra isabelleana & & \\
\hline C01_2T & $2860 \pm 90$ & $2724-2493$ & LP-3523 & $\begin{array}{l}35^{\circ} 44^{\prime} 36.20^{\prime \prime} \mathrm{S} \\
57^{\circ} 22^{\prime} 49.90^{\prime \prime} \mathrm{O}\end{array}$ & Mactra isabelleana & & \\
\hline 1 & $4800 \pm 90$ & $5294-4843$ & LP 108 & $\begin{array}{l}35^{\circ} 58^{\prime} 24^{\prime \prime S}, \\
57^{\circ} 27^{\prime} 07^{\prime \prime O}\end{array}$ & Mactra isabelleana & \multirow{2}{*}{$\begin{array}{l}\text { Cordón de } \\
\text { conchillas (Mb. } \\
\text { Cerro de La } \\
\text { Gloria) }\end{array}$} & Gomez , 1988 \\
\hline 2 & $4220 \pm 110$ & $4613-3979$ & LP-147 & $\begin{array}{l}35^{\circ} 58^{\prime} 24^{\prime \prime S}, \\
57^{\circ} 27^{\prime} 07^{\prime \prime O}\end{array}$ & Mactra isabelleana & & Gomez,1988 \\
\hline 3 & $6180 \pm 100$ & $6730-6491$ & LP1580 & $\begin{array}{l}35^{\circ} 51^{\prime} 12^{\prime \prime S}, \\
57^{\circ} 33^{\prime} 41^{\prime \prime O}\end{array}$ & Tagelus plebeius & \multirow{5}{*}{$\begin{array}{l}\text { Llanura de } \\
\text { mareas } \\
\text { (Mb. Canal 18) }\end{array}$} & $\begin{array}{l}\text { Fucks et al., } \\
2007\end{array}$ \\
\hline 4 & $5490 \pm 40$ & $5927-5825$ & KIA 33510 & $\begin{array}{l}35^{\circ} 58^{\prime} 16^{\prime \prime S}, \\
57^{\circ} 29^{\prime} 02^{\prime \prime} \mathrm{O}\end{array}$ & Tagelus plebeius & & \begin{tabular}{|l|} 
Fucks et al., \\
2010 \\
\end{tabular} \\
\hline 5 & $6150 \pm 190$ & $6803-6372$ & LP 50 & $\begin{array}{l}35^{\circ} 58^{\prime} 21 " \mathrm{~S}, \\
57^{\circ} 29^{\prime} 16^{\prime \prime} \mathrm{O}\end{array}$ & Tagelus plebeius & & \begin{tabular}{|l} 
Fidalgo et al., \\
1981 \\
\end{tabular} \\
\hline 6 & $6489 \pm 232$ & $7239-6728$ & LP 66a & $\begin{array}{l}35^{\circ} 58^{\prime} 21^{\prime \prime} \mathrm{S} \\
57^{\circ} 29^{\prime} 16^{\prime \prime} \mathrm{O}\end{array}$ & Tagelus plebeius & & \begin{tabular}{|l|} 
Fidalgo et al., \\
1981 \\
\end{tabular} \\
\hline 7 & $6764 \pm 195$ & 7473-7077 & LP 66b & $\begin{array}{l}35^{\circ} 58^{\prime} 21^{\prime \prime S}, \\
57^{\circ} 29^{\prime} 16^{\prime \prime O}\end{array}$ & Tagelus plebeius & & $\begin{array}{l}\text { Fidalgo et al., } \\
1981\end{array}$ \\
\hline
\end{tabular}

Se obtuvo el fechado radiocarbónico de tres cheniers, de un total de cinco reconocidos en las cercanías a la desembocadura del río Salado, ubicados al E del cordón principal, cuyas edades se muestran en la Figura 3.4. Las distancias a la línea de costa de cada chenier datado son: $C 01=260 \mathrm{~m} ; \mathrm{CO3}=670 \mathrm{~m} ; \mathrm{CO5}=860 \mathrm{~m}$ (Tabla 3.1, Figura 3. 3).

La composición litológica de un chenier se analiza más abajo. 


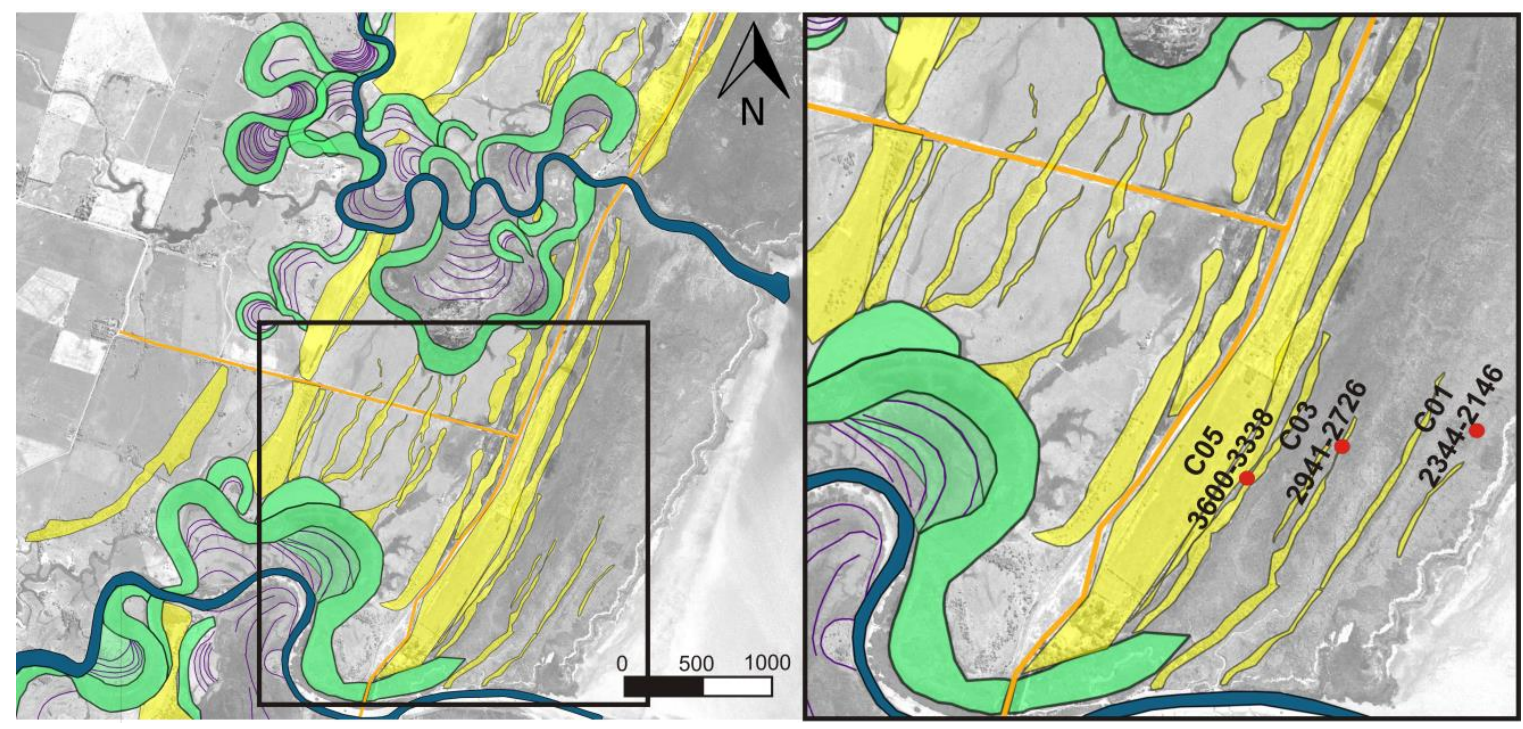

Figura 3.3. Cronología de los cheniers reconocidos en el área de la desembocadura de los ríos Salado y Samborombón. En amarillo se marcan los depósitos bioclásticos, en verde los paleocauces y en azul los cursos de agua.

La respuesta de la costa actual a los procesos litorales dominantes puede ofrecer una aproximación para entender la distribución espacial de las geoformas relictuales (Mc Bride et al., 2007). Aunque este enfoque no esté contemplado dentro de los objetivos de este trabajo de Tesis, trabajos de campo han permitido observar que en la actualidad no se produce la formación de este tipo de depósitos de conchilla debido a la no disponibilidad de estos elementos en el sistema actual. Sin embargo, en ciertos lugares, afectados por la actividad antrópica, se han generado depósitos de material grueso de origen artificial (cubiertas, botellas, bolsas, vegetación, maderas, cajas de plásticos, conchillas, etc). Por lo tanto, esto sugiere que los procesos que dan lugar a su formación, están vigentes en la actualidad (Figura 3.4 A y B). 

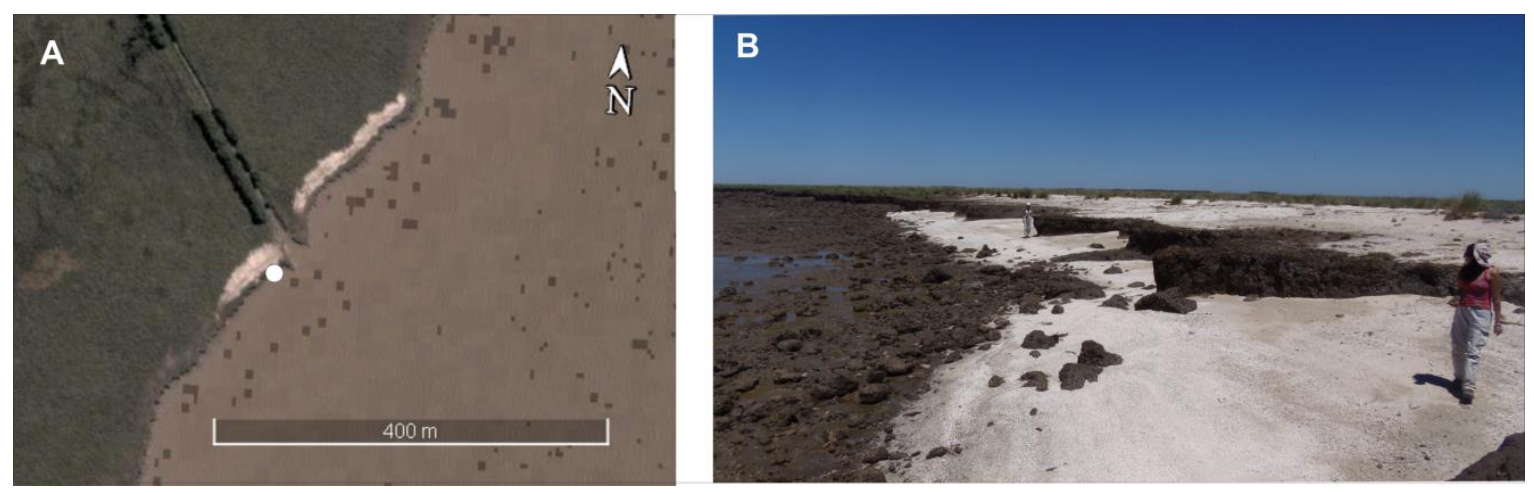

Figura 3.4. A-vista en planta de los depósitos de conchilla vinculados a un canal artificial (3558'9.70"S, 57²3'15.90"O). B- Foto del lugar.

\subsection{3.- Paleolíneas de costa}

El reconocimiento y la reconstrucción de las paleolíneas de costa se llevaron a cabo mediante el reconocimiento de geoformas a través del tratamiento de imágenes satelitales de alta resolución (Figura 3.5) y de inspecciones en el campo.
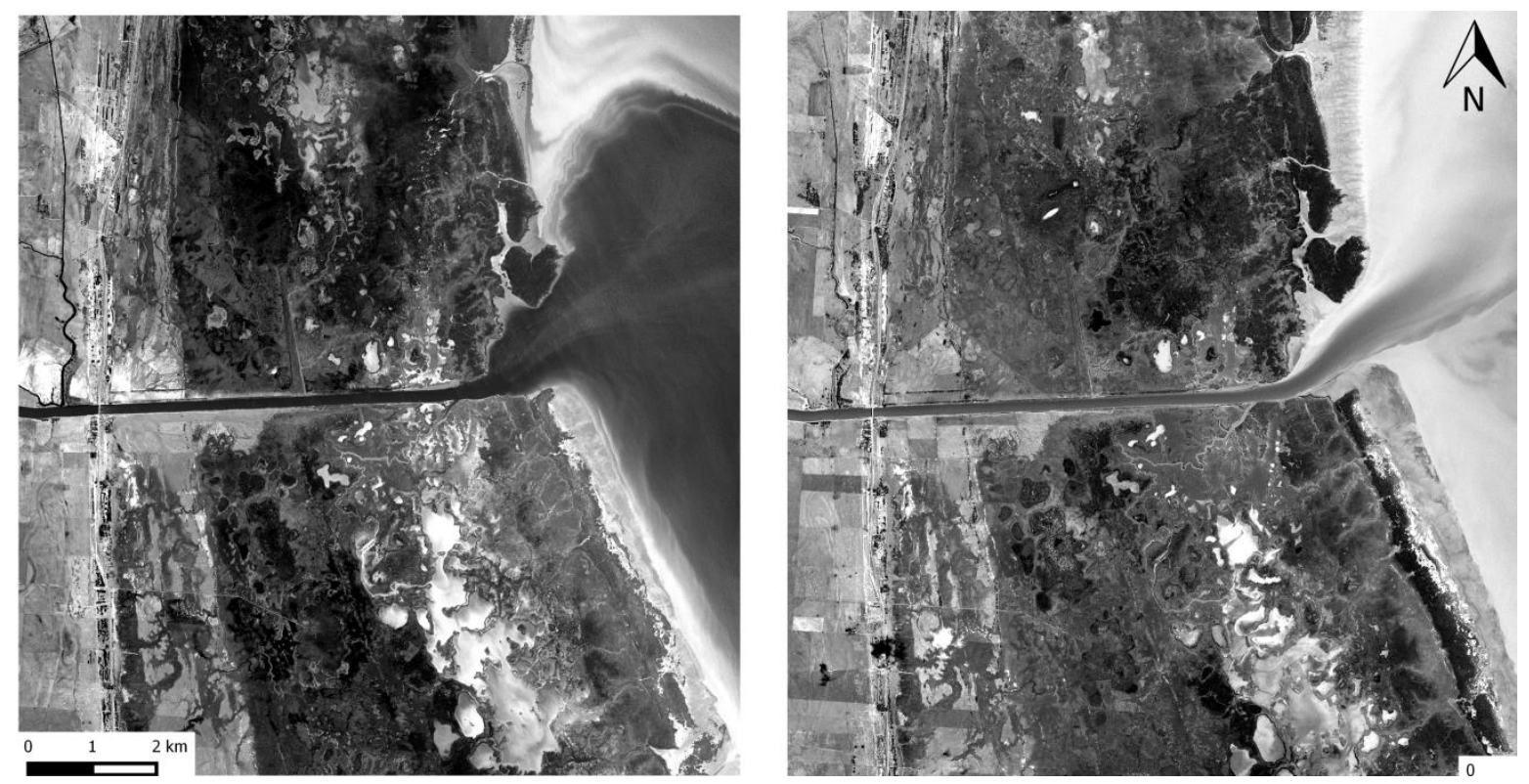

Figura 3.5- Recorte de la banda pancromática del producto Spot 6 en donde se visualizan los efectos de filtros "Mediana".

Un total de 9-10 paleolíneas de costa fueron reconocidas y mapeadas en la zona central de la Bahía Samborombón (sin incluir la actual), específicamente en la franja costera que abarca unos $\sim 7 \mathrm{~km}$ desde los cordones principales (Mb. Cerro de la Gloria) 
hasta la línea de costa actual (en una transecta en dirección O-E, Figura 3.6.A). Las paleolíneas de costa presentan características variables en cuanto a su forma y relación, presentándose formas lineales casi rectilíneas o con leve curvatura, paralelas a subparalelas, pudiéndose contactar unas con otras quedando prácticamente amalgamadas o bifurcarse (Figura 3.6.A). Estas morfologías relictas son acompañadas por otras formas litorales como: 1) depósitos de cheniers, 2) cuerpos de agua alineados, 3) paleocanales de mareas consecutivos, los que en conjunto permiten la identificación de estas paleocostas. Además, otras características como: pequeños cambios en la topografía y modificaciones en la cobertura vegetal, han contribuido en la identificación de dichas paleolíneas.

El espaciamiento de las paleolíneas varía a lo largo de la transecta O-E. Al oeste, en proximidad a Mb. Cerro de la Gloria, se hallan espaciadas entre sí a una distancia que va desde los 150 hasta los 500 m, produciéndose la divergencia de ellas hacia el Sur. Hacia el este se dificulta el reconocimiento de las líneas de costa ya que no se observa la formación de las geoformas que las acompañan y pierden definición los canales de marea, entonces la delimitación puede realizarse en base a la disposición de cuerpos de agua de manera alineada, producidas por la generación de barras progradantes.

Estas paleolíneas se pueden continuar a lo largo de varios kilómetros y son cortadas transversalmente por canales artificiales que suelen dejar expuestas secciones transversales de estos rasgos (e.g. cheniers) facilitando su estudio (Figuras 3.6. B Y C).

Todas estas morfologías se encuentran topográficamente a una altura inferior a la del cordón principal (Fucks et al., 2010), ubicado a aproximadamente 6,5 km de la costa actual y se desarrollan en un paleoambiente de llanuras de mareas que gradan a marismas reunidas bajo la unidad litoestratigráfica denominada Miembro Canal 15 de la Formación Canal de Las Escobas (Fidalgo et al., 1973; Fucks et al., 2010), y que además incluye las llanuras mareales y marismas actuales. 

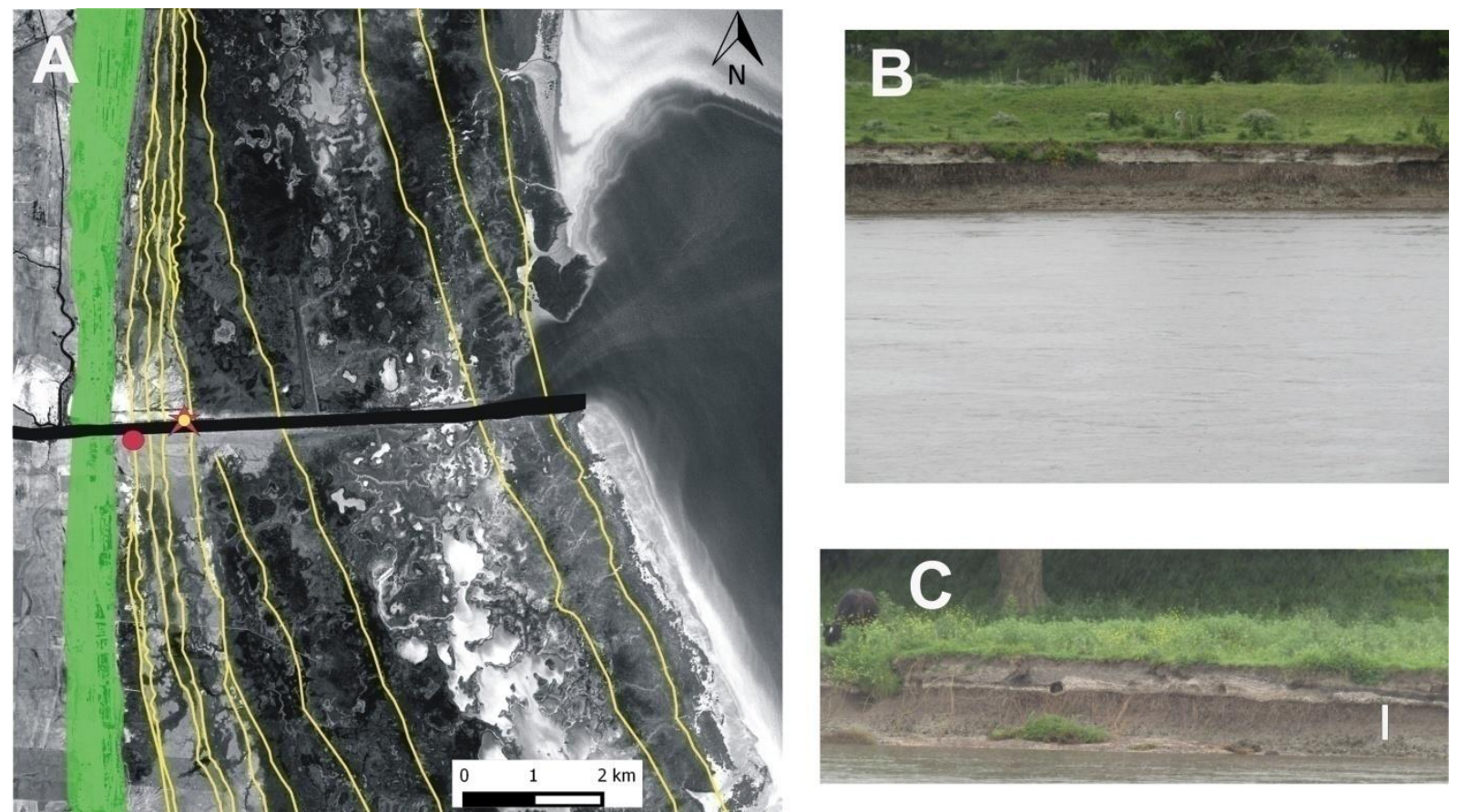

Figura 3.6. A- Spot 6 como imagen de base sobre la que se mapearon las paleo líneas de costa reconocidas (amarillo) y el cordón de conchillas principal, Mb Cerro de la Gloria (verde). Con asterisco se indica la ubicación de PM1. El punto rojo indica el sitio en el que se reconoció el depósito de chenier que se indica en las fotos B Y C, coincidiendo con la paleolínea de costa reconocida. La escala representa $1 \mathrm{~m}$.

\section{3.4.- Otras formas litorales}

Otras formas litorales que se reconocieron en el área de estudio son el conjunto de flechas/paleoespigas en gancho ubicadas al oeste del cordón principal sobre el que se desarrolla la ruta 11 (Figura 3.7) y se los puede observar por varios kilómetros a lo largo de la bahía (siguiendo una dirección paralela a la costa). Estas formas varían en tamaño y ancho a lo largo de la paleocosta y su morfología o inflexiones hacia el continente indicaría un ambiente abierto, muy probablemente lacustre. 


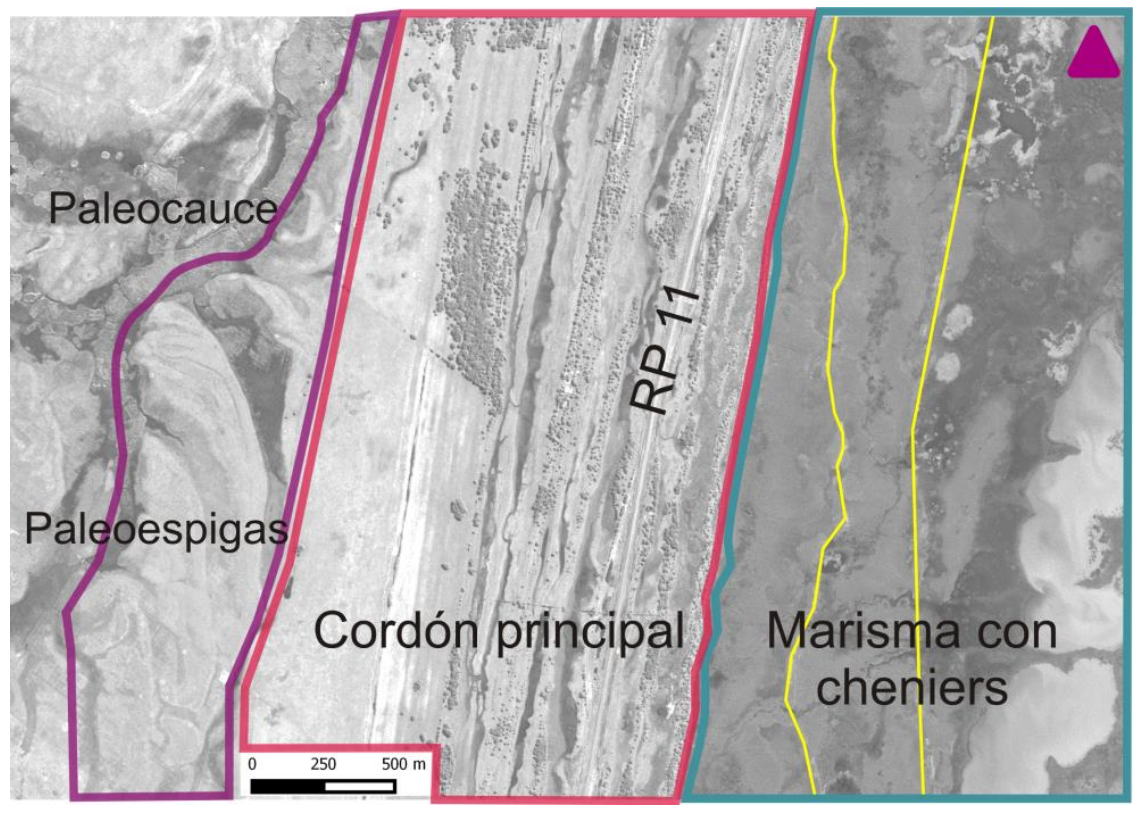

Figura 3.7. Imagen Spot 6 de la zona costera de Bahía Samborombón a $11 \mathrm{~km}$ al N de Canal 15 $\left(35^{\circ} 51^{\prime} 49.33^{\prime \prime} / 57^{\circ} 26^{\prime} 52.76^{\prime \prime} \mathrm{O}\right)$ en donde se pueden observar desde $\mathrm{O}$ a $\mathrm{E}$ diferentes geoformas preservadas en el terreno; paleodesembocadura, paleoespigas, cordones conchiles, y ambiente de marisma con cheniers.

Por otro lado, se reconocieron y mapearon paleocanales de marea. Los antiguos canales de marea son aquellos que van quedando inactivos al producirse un cambio en la posición de la línea de costa por progradación costera, pudiendo preservarse en el terreno y constituir líneas de drenaje actuales. Los paleocanales se encuentran labrados sobre sedimentos finos de llanuras de marea tanto en Mb. Canal 18 como Mb. Canal 15 (Fucks et al., 2010) y suelen acompañar las paleolíneas de costa. Estas geoformas, se preservan en el terreno y suelen estar ocupadas por comunidades vegetales edáficas como juncales, totorales, espadañales (Vervoorst, 1967) lo que facilita su reconocimiento.

Todas estas morfologías reconocidas analizadas, se utilizan aquí como proxies ambientales y de nivel del mar y serán empleadas junto con los análisis micropaleontológicos en la reconstrucción paleoambiental integral que se discutirá en el Capítulo 6. 


\subsection{5- Formas de origen fluvial}

Como resultado de la aplicación de filtros a la banda pancromática del producto Spot 6 se obtuvieron imágenes que facilitaron el reconocimiento de paleocauces, meandros abandonados, point bars (depósitos de barras de meandros) y cordones conchiles. Por un lado, el filtro direccional kernel 3×3, ángulo 180 permitió la visualización de point bars en zonas con una densa cobertura vegetal de tipo arbórea (Figura 3.8.A y B). Para el caso de los meandros abandonados, debido a que las morfologías a resaltar presentan diferentes orientaciones dadas por la propia dinámica de migración del río, se buscó un filtro direccional que resaltara cada tramo. Del total de filtros direccionales aplicados, sólo se exhibe la imagen con filtro kernel 3×3, 30 (Figura 3.8.C y D).
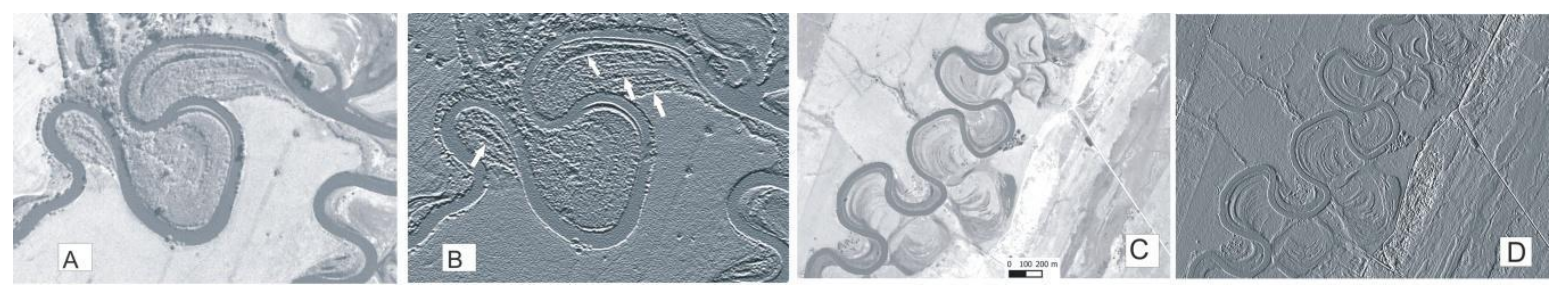

Figura 3.8. A- Recorte de la imagen original de un sector del río Samborombón. B- se visualiza el mismo recorte pero con filtro direccional, kernel $3 \times 3$, ángulo 180 ․ Con flechas blancas se indica los point bars. C- Recorte de la imagen original de una sección del río Samborombón donde se encuentran numerosos meandros abandonados. D- Imagen con filtro kernel $3 \times 3,30$ ․

En la Figura 3.9 se observa de forma comparativa una imagen con la morfología correspondiente a un paleocauce a la que se le aplicó tres filtros diferentes, filtro de realce "Mediana" (Figura 3.9.B) dando como resultado una imagen con marcado contraste la que fuera usada como fondo durante la digitalización de pantalla para el mapeo de las geoformas; "filtro direccional", 3×3, 45 (Figura 3.9.C) y aplicación del "Filtro Sobel" que favorece la identificación de cordones conchiles (Figura 3.9.D). 

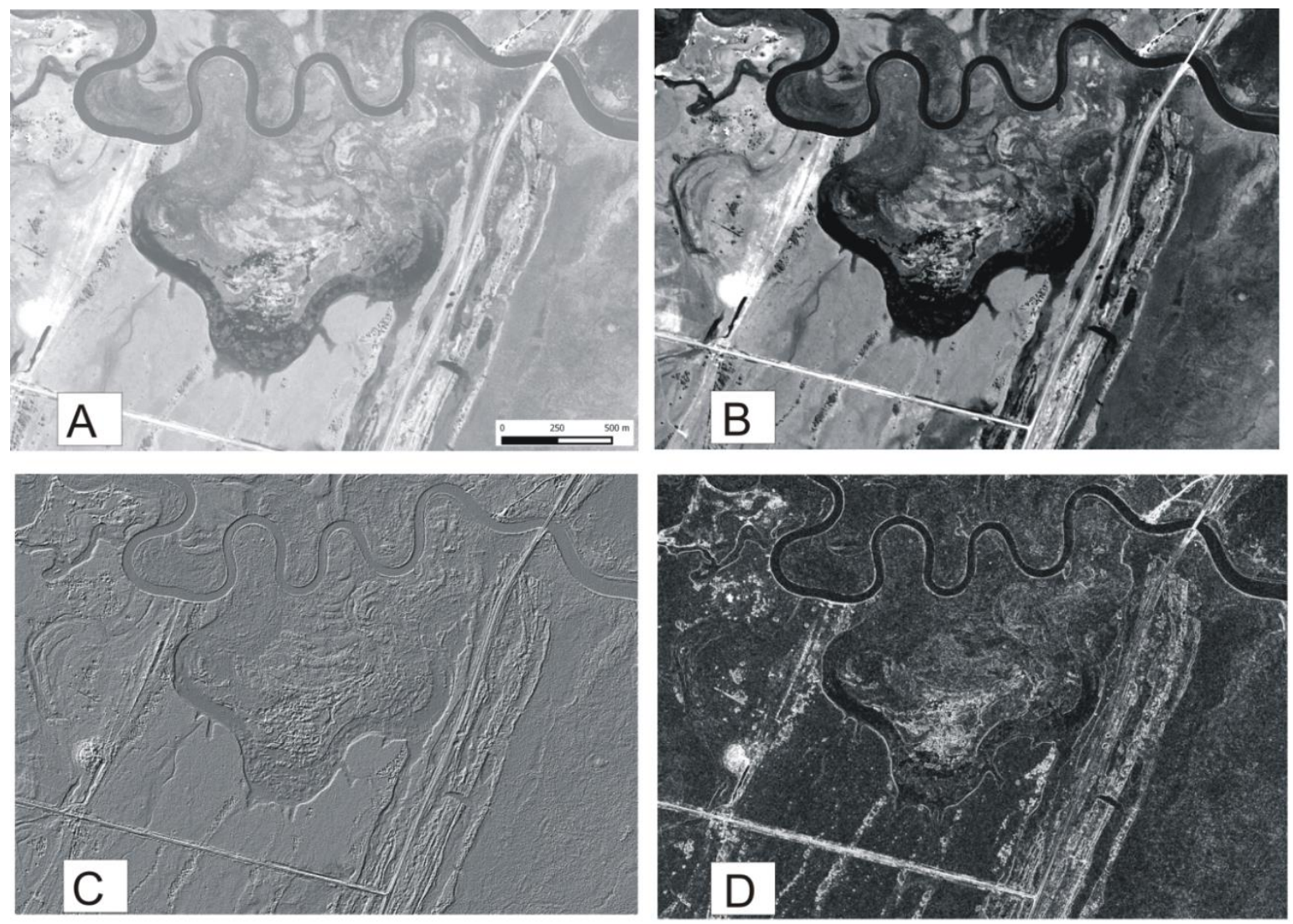

Figura 3.9.A- Recorte de la imagen original en donde de muestra un paleocauce. B- filtro de realce "Mediana". C- "Filtro direccional", 3×3, 45‥ D- Aplicación del "Filtro Sobel".

Además, el resultado del tratamiento de combinación de bandas "Falso Color 431 (RGB)" se muestra en la figura 3.10 y se puede observar que se destacan: 1- los talares (comunidades de Celtis sp.) en colores magenta (Figura 3.10.A-C); 2-los pastizales en colores rojizos a rosados, 3-campos de cultivos que se distinguen por los colores rojos fuertes (además de la clara disposición en parcelas); 4- suelo desnudo en color celeste grisáceo; humedales, en colores verdosos a grisáceos oscuros, como la zona de marisma, y zonas de paleocauces. De colores oscuros, se identifican cuerpos de agua, lagunas de aguas limpias, principalmente en ciertos sectores de cauces abandonados, y cursos menores. Colores verdes a celestes claros, muestran agua con alto contenido de sedimento en suspensión (Figura 3.10).

El mapeo de los rasgos geomorfológicos se realizó en la zona de desembocaduras de los ríos Salado y Samborombón de rasgos fluviales y litorales (Figura 3.11). 

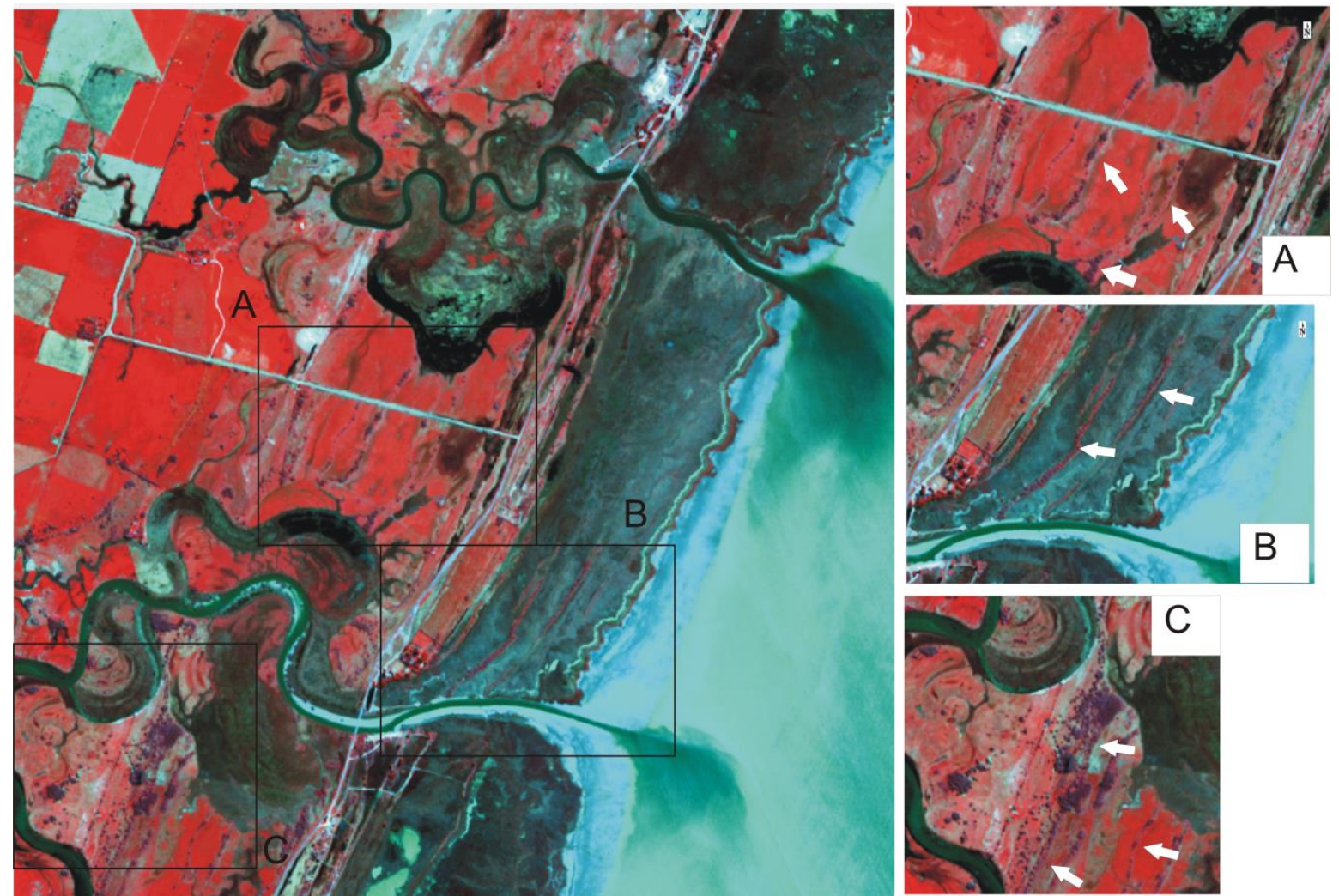

Figura 3.10. Resultado de tratamiento de combinación de bandas 431. A: detalle de cordones. B: cheniers en zona de marisma. C: alineamiento de la vegetación en relación a las geoformas litorales. 


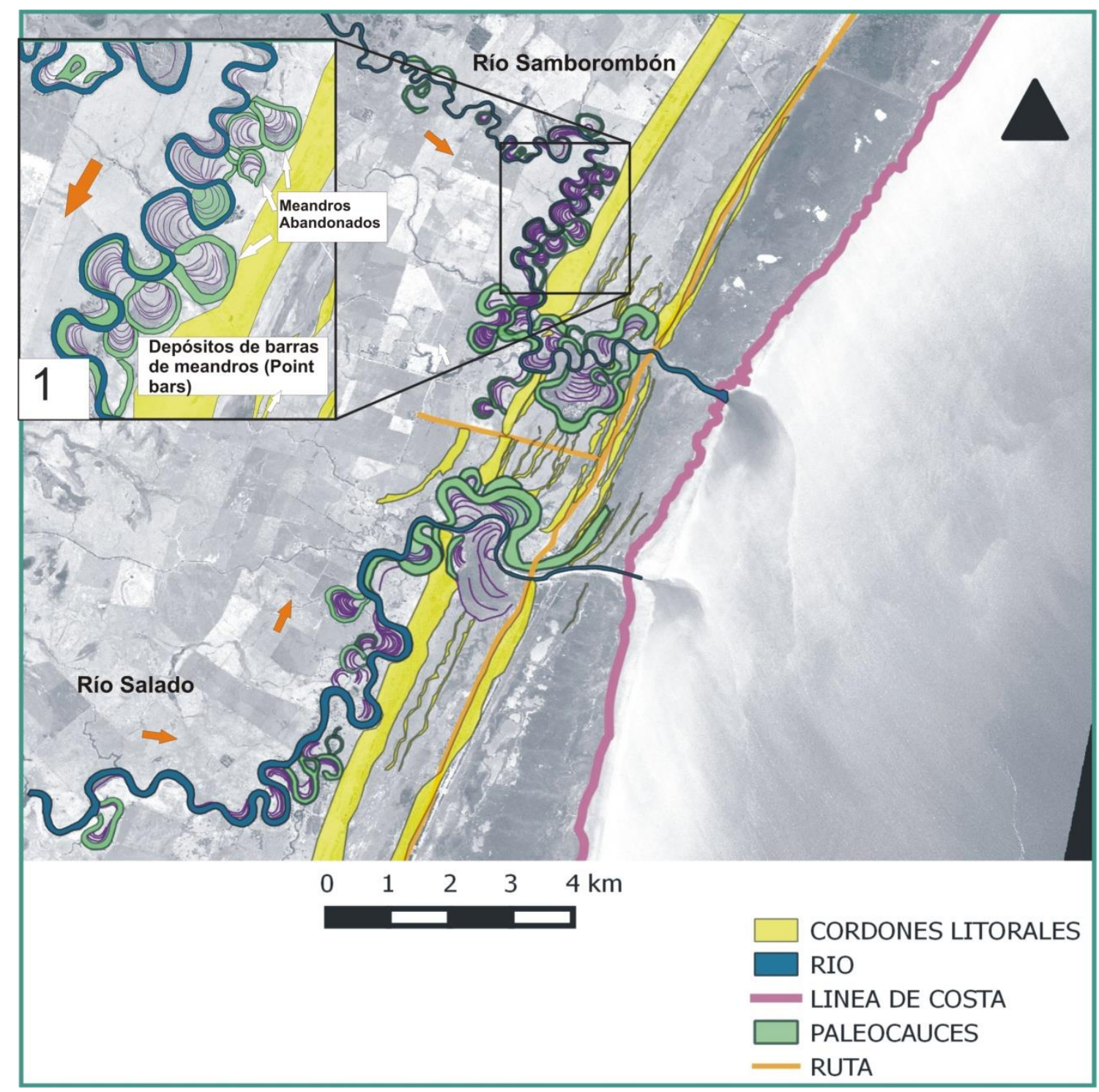

Figura 3.11. Digitalización de los ríos Salado y Samborombón en la zona de su desembocadura. Se observan morfologías de origen fluvial y costeras de edad holocena; cordones litorales. 1: Detalle de tramo del río Samborombón donde se indican depósitos de barras de meandros (point bars) y meandros abandonados. Con flechas naranjas se indica el sentido de escurrimiento de ambos ríos.

El río Samborombón tiene un recorrido en dirección NO-SE, desarrollado en su parte superior y media sobre la Llanura Pampeana y su tramo inferior sobre la llanura costera, reconociéndose barras en espolón y meandros abandonados, que están permanente o transitoriamente anegados y con vegetación hidrófila. Luego el curso se ve obstaculizado por los cordones litorales y cambia a dirección NE-SO, escurriendo paralelo al cordón por aproximadamente una extensión de 4 kilómetros, donde se visualizan la 
mayor cantidad de meandros abandonados (Figura 3.11.1), algunos de difícil reconocimiento, por las obras de construcción. Cuando el meandro abandonado atraviesa el cordón, es allí donde se evidencian 2 cauces abandonados por corte y avulsión. En el último tramo, el curso retoma la dirección de flujo regional (NO-SE), presentando esencialmente 2 canales abandonados por avulsión (Figura 3.12), éstos últimos fácilmente distinguibles en las imágenes y en el campo (Figura 3.12. A y B). En el punto

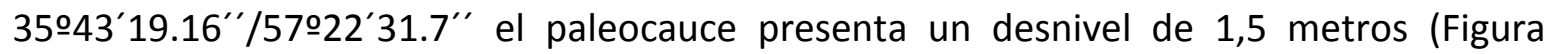
3.12.D), y constituye un cuerpo de agua con vegetación de tipo hidrófita (Figura 3.12.C y

E.)




Figura 3.12. Tramo final del río Samborombón. En las fotos A y B se muestra, en línea de puntos, el cauce abandonado por avulsión del río Samborombón. En las fotos C y E se evidencia el anegamiento del paleocauce. En $\mathrm{D}$ se muestra el desnivel del mismo.

El tramo final del río Salado también cambia su dirección de escurrimiento (SO-NE, sentido hacia el NE) al encontrar los depósitos litorales como obstáculo, escurriendo en forma paralela a éstos, con presencia de numerosos meandros abandonados (Figura. 3.13). Finalmente, el curso toma una dirección perpendicular a las formas holocenas, y es allí donde se puede observar un importante paleocauce producto del proceso de avulsión (Figura 3.13 indicado con flecha) a un lado del curso principal. Al otro lado, se observa un cuerpo homogéneo (en el cual se reconocieron lineamientos, pero no se logró establecer un patrón determinado) el que podría haber representado un antiguo cuerpo lacustre, constituyendo actualmente un lugar deprimido y anegado con vegetación hidrófita según el análisis de su comportamiento espectral y reconocimientos de campo. En el punto 35년 $54.8^{\prime \prime} / 57023^{\prime} 07.8^{\prime \prime}$ el paleocauce presenta un desnivel de aproximadamente 1 metro (figura 3.13.A). 


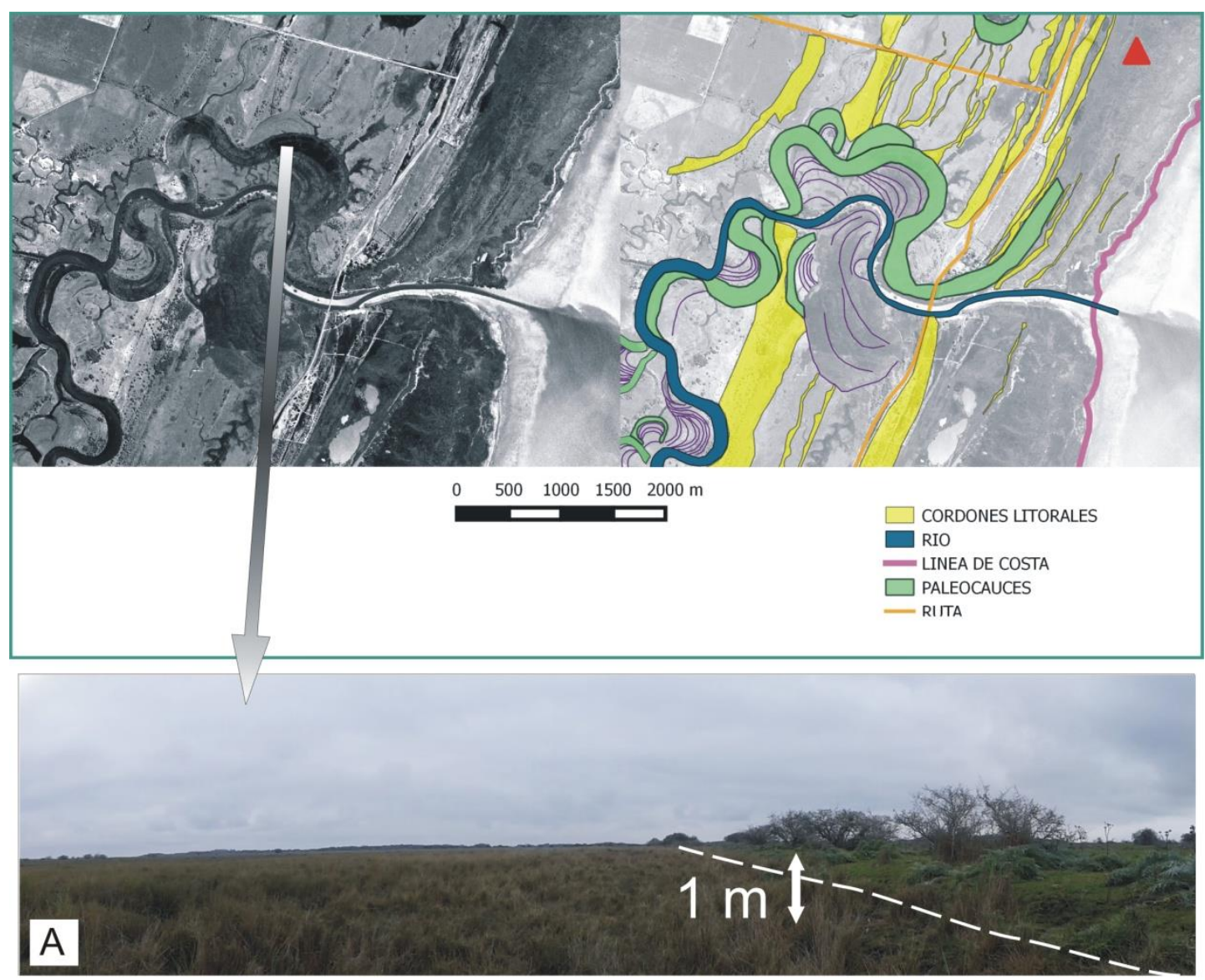

Figura 3.13. Tramo final del río Salado donde se observa, arriba indicado con flecha un antiguo cauce. En la foto A se indica en línea de puntos el paleocauce y se muestra el desnivel del mismo.

\section{4.- Perfiles representativos de las unidades reconocidas.}

En este apartado se realiza la descripción litológica de afloramientos de los ambientes y geoformas analizadas con particular énfasis en aquellos donde se realizó el análisis palinológico.

La descripción de las unidades litológicas, junto con la determinación de estructuras sedimentarias, textura, contactos, color y contenido macrofosilífero se realiza in situ en exposiciones artificiales.

\subsection{1.- Perfil canal arroyo "El Tala"(Figura 3. 14)}


El perfil presenta cerca de $210 \mathrm{~cm}$ de espesor (tomando como base la altura del pelo de agua) y se ubica a 500 m aguas abajo de la RP № 11 (Figura 14.A) sobre la margen izquierda del canal $\left(35^{\circ} 53^{\prime} 58.01^{\prime \prime} \mathrm{S} / 57^{\circ} 26^{\prime} 8.85^{\prime \prime} \mathrm{O}\right)$, en donde corta de manera perpendicular un conjunto de cheniers. La base está compuesta por 70 a $80 \mathrm{~cm}$ de sedimento arcillo-limoso a arcilloso, de color grisáceo a castaño oscuro y estructura laminar en la base haciéndose homogénea hacia el techo y con restos de conchillas (enteras y fragmentadas) diseminadas a lo largo de toda la unidad (Figura 3.14.D). Esta unidad corresponde a sedimentos arcillosos del Mb. Canal 15. Por encima de esta unidad y de forma discordante, apoyan depósitos gruesos de material bioclástico, es decir, concentraciones esqueletales de moluscos con arenas subordinadas de colores castaños oscuros, que se disponen en estratos de espesor y composición variables, desde inferiores a $20 \mathrm{~cm}$ hasta $100 \mathrm{~cm}$ (Figura 3.14.C-D). De los $80 \mathrm{~cm}$ a $135 \mathrm{~cm}$, se observa una alternancia de estratos compuestos principalmente por bioclastos enteros a poco fragmentados y por valvas dispuestas con la concavidad hacia abajo (imbricadas); otros estratos compuestos por valvas sin orientación distinguible (caóticas), y estratos compuestos por arenas y en menor proporción valvas (Figura 3.14.C-D). Hacia el tope de la secuencia se observa el depósito de bioclastos dispuestos de manera caótica con arenas muy subordinadas evidenciando eventos de depositación abrupta causando posiblemente mortandad masiva. Estos estratos presentan una leve inclinación hacia el este. Por encima de toda la secuencia se verifica una capa uniforme compuesta por material de destape (Figura 3. 14.D). Dentro de esta secuencia se pueden observar raíces de gran porte, leñosas, las cuales posiblemente correspondan a la vegetación arbórea que se desarrolla actualmente por encima del chenier (Figura 3.14. D).

\subsection{2.- PM 1 (35 $\left.58^{\prime} 14.86^{\prime \prime} \mathrm{S} / 57^{\circ} 24^{\prime} 49.72^{\prime \prime} \mathrm{O}\right)$, (Figura 3.15)}

Este perfil está ubicado sobre la margen izquierda del Canal 15, cuya unidad estratigráfica corresponde a sedimentos arcillosos de colores oscuros del Mb. Canal 15 y se encuentra a $\sim 5.700 \mathrm{~m}$ de la costa actual. La secuencia sedimentaria es de textura 
fangosa, y en su base presenta una estructura laminar heterolítica (arcillas y limos/arena fina) que se hace progresivamente homogénea hacia el techo. La secuencia también contiene restos de conchillas enteras o fragmentadas dispersas a lo largo de todo el perfil, aunque también se hallan concentradas constituyendo niveles continuos (Figura 3.15). Se describe a la secuencia en base a su color, estructuras, características pedogenéticas y macrofósiles (Tabla 3.2). Por encima, se encuentra una capa uniforme compuesta por material de destape, producto de la realización del canal artificial №15 en 1910 (Min. de Obras Públicas de la Provincia de Buenos Aires, 1911).

Tabla 3.2. Descripción sedimentaria y fosilífera de PM1

\begin{tabular}{|l|l|}
\hline $\begin{array}{c}\text { Profundidad } \\
(\mathrm{cm})\end{array}$ & $\begin{array}{l}\text { Textura, estructuras, características pedogenéticas y macrorestos } \\
\text { fósiles. }\end{array}$ \\
\hline $0-20 \mathrm{~cm}$ & $\begin{array}{l}\text { Se desarrolla un suelo arcillo limoso, plástico y adhesivo, muy } \\
\text { estructurado en prismas, de color castaño oscuro (2,5 YR 3/2), con } \\
\text { raíces y abundante contenido en materia orgánica. }\end{array}$ \\
\hline $20-90 \mathrm{~cm}$ & $\begin{array}{l}\text { Sedimento fangoso de color castaño rojizo (10YR 5/2), (presencia de } \\
\text { materia orgánica y óxidos de hierro). Estructura masiva (ver en texto } \\
\text { abajo). Conchillas enteras para el nivel 22-23 cm. Por encima, } \\
\text { fragmentos bioclásticos y gatrópodos del género Heleobia sp. aislados } \\
\text { y presencia de escasos restos biogénicos triturados, no identificables. }\end{array}$ \\
\hline $90-118 \mathrm{~cm}$ & $\begin{array}{l}\text { Color castaño grisáceo- verdoso (2,5YR 6/2) con presencia de una } \\
\text { laminación de arcillas y limos. El material es muy plástico y adhesivo. } \\
\text { Hacia los 108 cm hay un nivel fosilífero de pocos centímetros de } \\
\text { espesor con restos de moluscos (Mactra isabelleana d'Orbigny, 1846; } \\
\text { Heleobia australis (d'Orbigny, 1835), H. parchappii (d'Orbigny, 1835) y } \\
\text { Tagelus plebeius (Lightfoot, 1786)). }\end{array}$ \\
\hline
\end{tabular}


La cronología de esta secuencia está basada en tres dataciones radiocarbónicas (Tabla 3.3) e indica que la sección estudiada representa los últimos 2700 años cal. AP. Un modelo de edad profundidad para PM1 se muestra en el Capítulo 5.

En el paquete sedimentario de la parte superior del perfil, predominantemente fangoso, no se visualizan estructuras sedimentarias. Sin embargo, en el laboratorio y con la muestra seca, se observó la ruptura del material a lo largo de distintas superficies que indican la presencia de granos más gruesos (limo-arenosos) muy dispersos para constituir una lámina, similar a lo descripto por Evans (1965) para testigos fangosos de un ambiente sub-depositacional de marisma. Esto además evidencia eventos de tracción y suspensión por la acción de mareas, indicando la presencia de granos de mayor tamaño. El contenido palinológico de la secuencia se muestra en el Capítulo 5.

\subsection{3.- PM2 (3536' $\left.8.23^{\prime \prime} \mathrm{S} / 57^{\circ} 15^{\prime} 32.52^{\prime \prime} \mathrm{O}\right)$, (Figura 3. 16)}

El perfil analizado se encuentra a $10 \mathrm{Km}$ de la costa, sobre la margen derecha del Canal 15 (35 $\left.36^{\circ} 8.23^{\prime \prime} \mathrm{S} / 57^{\circ} 15^{\prime} 32.52^{\prime \prime} \mathrm{O}\right)$. La secuencia tiene una potencia de $261 \mathrm{~cm}$, cuyos sedimentos son de textura areno-limosa con alternancia de capas de arcilla que van desapareciendo hacia el techo. Se dispone sobre el Mb. Destacamento Río Salado por medio de un contacto transicional. En la base de la secuencia predomina la alternancia de capas de arcilla, de pocos centímetros de espesor, con capas de arena fina a limosa, de espesores que varían entre 2 y $10 \mathrm{~cm}$, con estratificación planar y colores castaños a castaños verdosos (10 YR 5/3). Cerca de la base, a $252 \mathrm{~cm}$ de profundidad, se observó un nivel de alta concentración de moluscos, valvas en su mayoría desarticuladas, con escasa participación de las articuladas, evidenciando poca energía en el medio de depositación y a su vez poco transporte y retrabajo. La edad del material de este nivel es 6641-6882 años cal AP (Tabla 3.3). Esta alternancia de capas finas y más gruesas se repite a lo largo de toda la secuencia, sin embargo a $160 \mathrm{~cm}$ se empieza a observar el predominio de capas areno-limosas de mayor espesor alternando con láminas de material arcilloso. Hacia el cm 128 , se presenta otra capa fosilífera o nivel de conchillas que tienen una edad de 6249- 
6503 años cal AP (Tabla 3.3). Además, se observan bivalvos de la especie T. plebeius en posición de vida a profundidades variables. Por encima de este nivel, se describe un paquete sedimentario de $\sim 65 \mathrm{~cm}$ de espesor, color castaño claro (2,5Y 6/2), areno-limoso, con fragmentos carbonáticos pequeños y diseminados a lo largo de la unidad y con gran abundancia de T. plebeius. Este taxón ha sido datado en trabajos previos resultando en edades que van desde 7077-7473 a 5825-5927 cal AP (Tabla 3.1). Desde el cm 79 hacia el techo se observa un sedimento limo-arenoso, pudiendo presentar capas de arcilla pero de escaso espesor y representación, de colores castaños claros $(2,5 Y 6 / 2)$ y sin presencia de moluscos. A los $72 \mathrm{~cm}$ de profundidad la edad radiocarbónica obtenida de materia orgánica es de 5432-5596 años cal AP (Tabla 3.3). La secuencia culmina con el desarrollo de un suelo estructurado, de color castaño oscuro, de unos 10 a $15 \mathrm{~cm}$ y por sobre el cual se destaca una capa homogénea de material de destape proveniente de la construcción del Canal 15.

Tabla 3.3. Edades radiocarbónicas de diferentes ambientes de la planicie costera, NE de Buenos Aires.

\begin{tabular}{|c|c|c|c|c|c|c|c|}
\hline & $\begin{array}{c}\text { Edad }{ }^{14} \mathrm{C} \\
\mathrm{AP}\end{array}$ & Edad cal AP & $\begin{array}{l}\text { Código de } \\
\text { muestra }\end{array}$ & $\begin{array}{c}\text { Coordenadas } \\
\text { geográficas }\end{array}$ & Material & $\begin{array}{c}\text { Ambiente } \\
\text { depositacional }\end{array}$ & Ref. \\
\hline \multicolumn{8}{|c|}{ PM 1 (Profundidad) } \\
\hline $42-43 \mathrm{~cm}$ & $1489 \pm 22$ & $1254-1218$ & D-AMS 016771 & $\begin{array}{l}35^{\circ} 58^{\prime} 14.86^{\prime \prime} \mathrm{S}, \\
57^{\circ} 24^{\prime} 49.72^{\prime \prime} \mathrm{O}\end{array}$ & Materia orgánica & \multirow{3}{*}{$\begin{array}{c}\text { Llanura de } \\
\text { mareas }\end{array}$} & \multirow{3}{*}{$\begin{array}{l}\text { Esta } \\
\text { tesis }\end{array}$} \\
\hline $85-86 \mathrm{~cm}$ & $1689 \pm 23$ & $1406-1343$ & D-AMS 016770 & $\begin{array}{l}35^{\circ} 58^{\prime} 14.86^{\prime \prime} \mathrm{S}, \\
57^{\circ} 24^{\prime} 49.72^{\prime \prime} \mathrm{O}\end{array}$ & $\begin{array}{c}\text { Mactra } \\
\text { isabelleana }\end{array}$ & & \\
\hline $\begin{array}{c}107-108 \\
\mathrm{~cm}\end{array}$ & $2640 \pm 80$ & 2444-2206 & LP-3129 & $\begin{array}{l}35^{\circ} 58^{\prime} 14.86^{\prime \prime} \mathrm{S}, \\
57^{\circ} 24^{\prime} 49.72^{\prime \prime} \mathrm{O}\end{array}$ & $\begin{array}{c}\text { Mactra } \\
\text { isabelleana }\end{array}$ & & \\
\hline \multicolumn{8}{|c|}{ PM 2 (Profundidad) } \\
\hline $\begin{array}{l}72-73 \\
\mathrm{Cm}\end{array}$ & $5153 \pm 40$ & $5596-5432$ & D-AMS 030366 & $\begin{array}{l}35^{\circ} 36^{\prime} 8.23^{\prime \prime S}, \\
57^{\circ} 15^{\prime} 32.52^{\prime \prime O}\end{array}$ & Materia orgánica & \multirow{3}{*}{$\begin{array}{c}\text { Llanura d } \\
\text { mareas/laguna } \\
\text { costera }\end{array}$} & \multirow{3}{*}{$\begin{array}{l}\text { Esta } \\
\text { tesis }\end{array}$} \\
\hline $\begin{array}{c}127-128 \\
\mathrm{~cm}\end{array}$ & $5950 \pm 120$ & $6503-6249$ & LP- 3275 & $\begin{array}{l}35^{\circ} 36^{\prime} 8.23^{\prime \prime} \mathrm{S}, \\
57^{\circ} 15^{\prime} 32.52^{\prime \prime} \mathrm{O}\end{array}$ & $\begin{array}{c}\text { Mactra } \\
\text { isabelleana }\end{array}$ & & \\
\hline $\begin{array}{c}251-252 \\
\mathrm{~cm}\end{array}$ & $6300 \pm 100$ & $6882-6641$ & LP- 3327 & $\begin{array}{l}35^{\circ} 36^{\prime} 8.23^{\prime \prime S}, \\
57^{\circ} 15^{\prime} 32.52^{\prime \prime} \mathrm{O}\end{array}$ & $\begin{array}{c}\text { Mactra } \\
\text { isabelleana }\end{array}$ & & \\
\hline
\end{tabular}




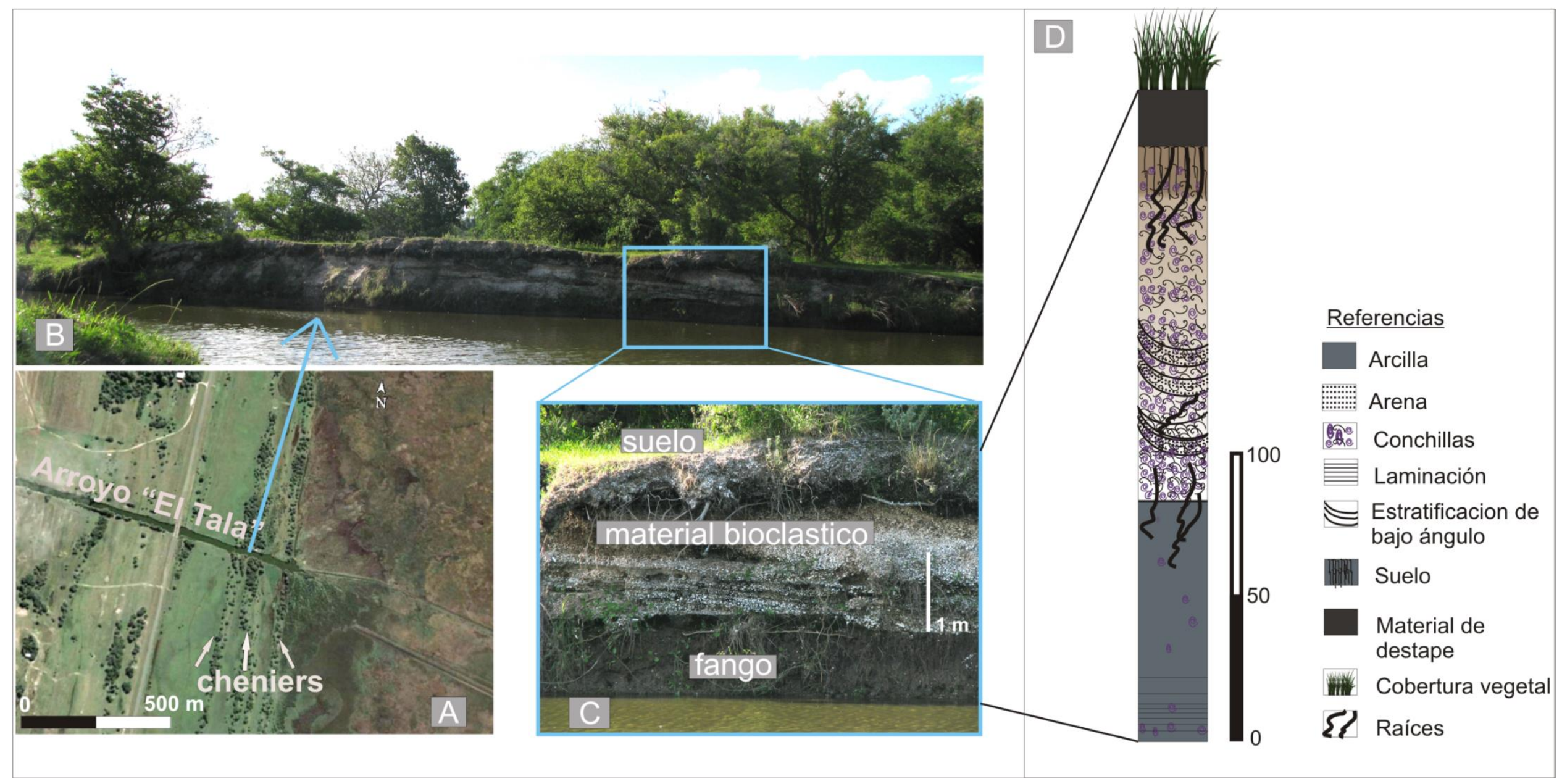

Figura 3.14.A- Imagen satelital QuickBird, Google Earth de Agosto 2017. B- El arroyo canal "El Tala" corta de manera transversal a los cheniers, dejando un perfil expuesto. C- Perfil expuesto en donde se observan capas/estratos compuestos casi exclusivamente por conchillas, alternando con capas de arena. Estos depósitos gruesos que yacen sobre fango. D- Perfil estratigráfico estudiado. 


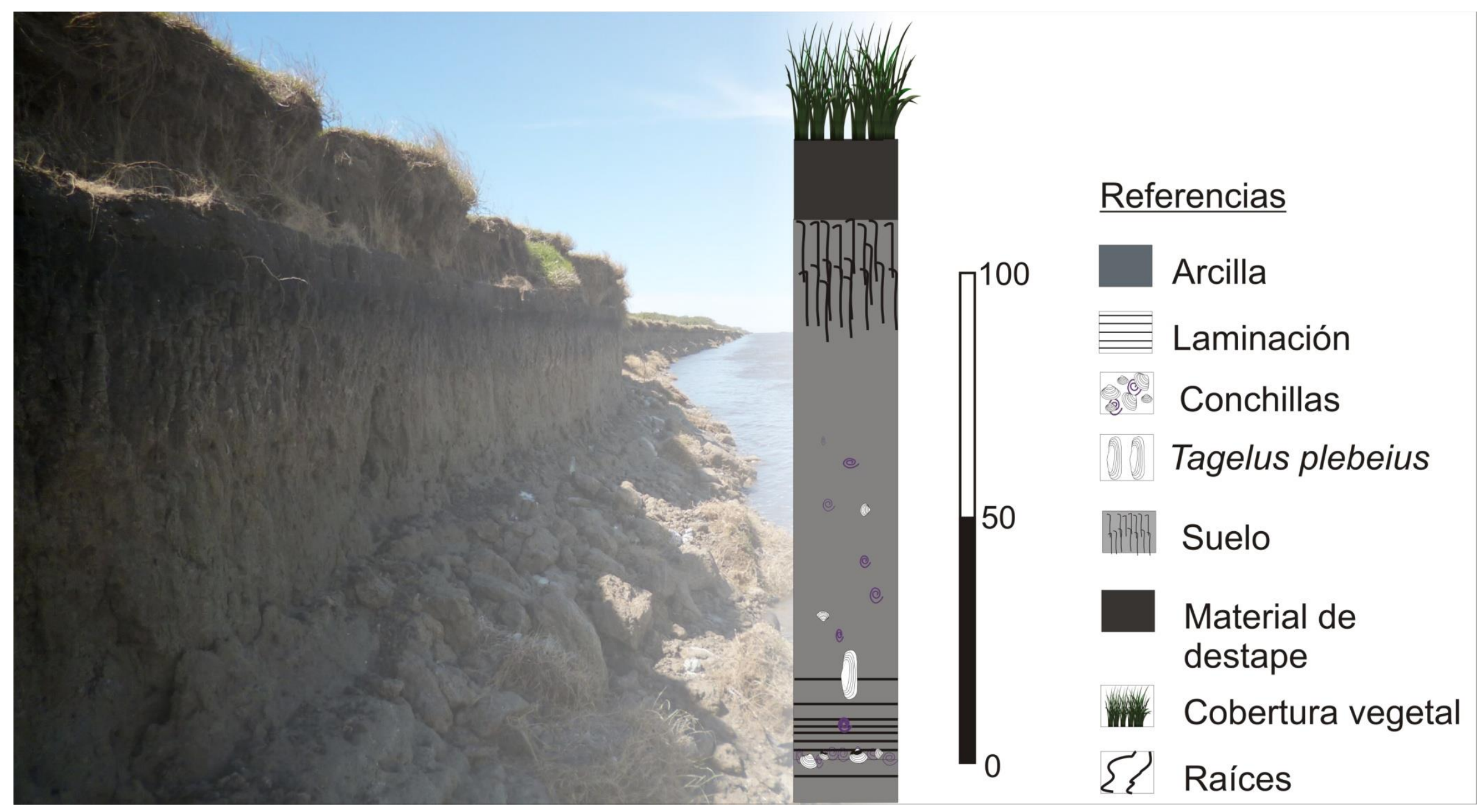

Figura 3.15. Perfil estratigráfico PM1. 


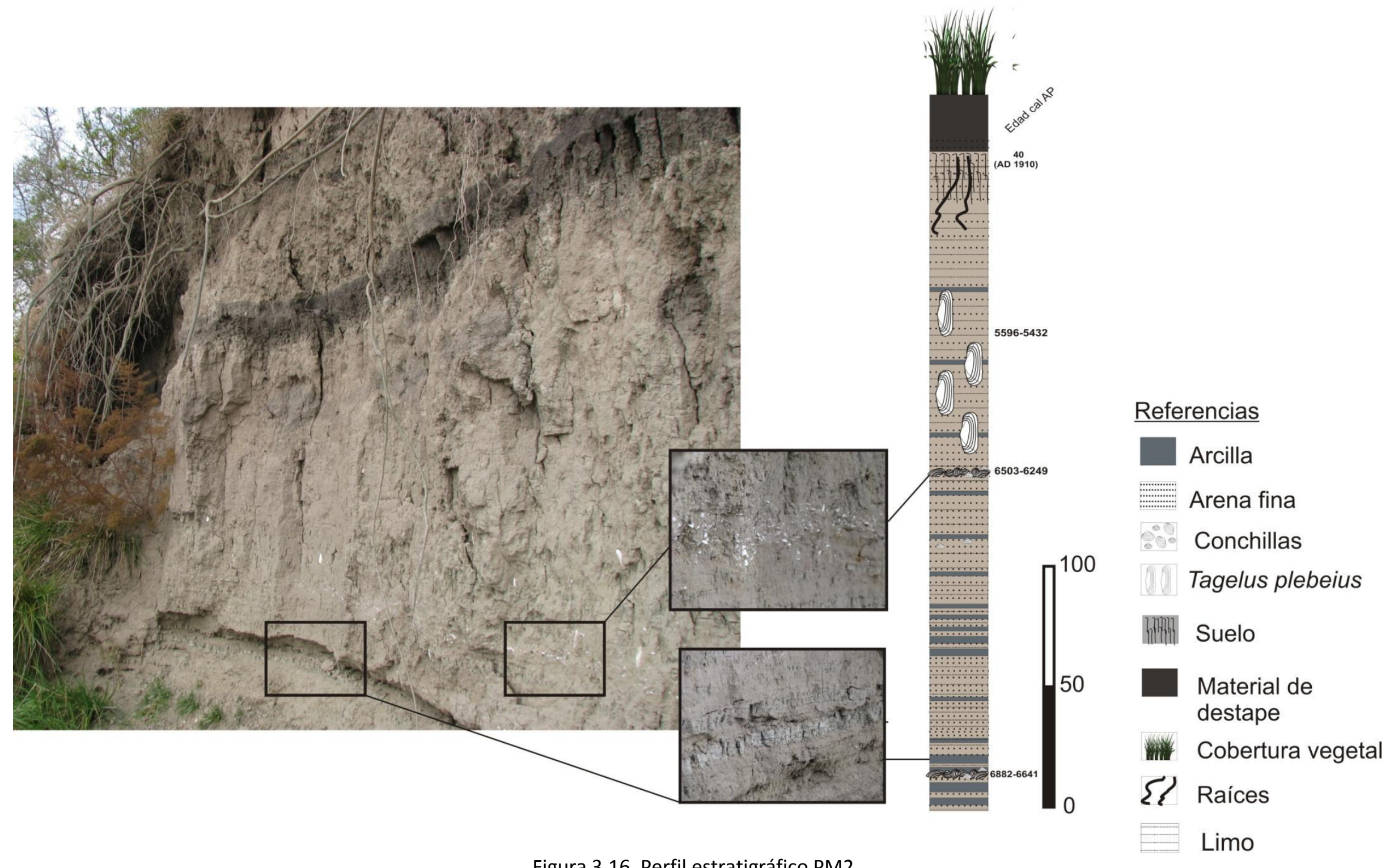

Figura 3.16. Perfil estratigráfico PM2. 


\section{5-Conclusiones}

El empleo de imágenes satelitales de alta definición permitió la identificación y el mapeo de geoformas preservadas a lo largo de la llanura costera de la zona Centro-Norte de Bahía Samborombón. Esta herramienta, junto con el análisis y empleo de filtros de realce permitió reconocer formas vinculadas a la dinámica costera como: paleolíneas de costa, cheniers, paleocanales de marea, paleoespigas, antiguos cuerpos de agua, y formas de origen fluvial: paleocauces, point bars, meandros abandonados asociados a los ríos Salado y Samborombón, todas estas geoformas mostraron distinto grado de preservación en el terreno. En la zona central de la bahía, se lograron identificar 9-10 paleolíneas de costa, cuyo espaciado aumentó hacia el E, hasta alcanzar la posición actual.

Además, el estudio de secuencias estratigráficas permitió confirmar la presencia de cheniers, cuyas edades radiocarbónicas apoyaron el caracter regresivo de estos depósitos. A su vez, la caracterización de las geoformas, junto con la caracterización litológica y cronológica, se pudo realizar el modelo de evolución geomorfológico que se empleará en el capítulo 5 integrado al análisis de otros proxies. 


\section{Capítulo 4}

\section{MODELO POLEN-VEGETACIÓN ACTUAL}

\section{1.-Introducción}

El modelo polen-vegetación actual es una herramienta fundamental para interpretar los conjuntos polínicos fósiles y establecer la vegetación del pasado; dicho modelo consiste en: (1) el análisis cuali-cuantitativo del conjunto polínico (tipos de polen y esporas) que se encuentra en sedimentos superficiales que representan un tiempo actual/reciente (e. g. sedimentos obtenidos de los 1-5 cm superiores del suelo o del fondo de lagos), y (2) el estudio de la composición florística y cobertura de la vegetación existente en el ambiente del cual provienen dichos sedimentos y su conjunto polínico. Este modelo puede considerarse un análogo moderno de la relación entre las especies presentes en la vegetación y su representación en el espectro polínico, que luego se compara con el espectro polínico fósil para determinar el tipo de vegetación del pasado y sus cambios en el tiempo vinculados con las condiciones paleoambientales y paleoclimáticas (e.g. Birks y Birks, 1980; Prieto, 1992; Medeanic et al., 2016).

En el desarrollo del análogo moderno se debe tener en cuenta la compleja interacción de factores que condicionan la representación de la vegetación en el conjunto polínico actual, entre los que se encuentran: (1) productividad polínica de las plantas en relación al tipo de polinización; (2) procesos de dispersión y transporte (aéreo, acuático fluvial-marino); (3) procesos de depositación y post-depositación como la re-suspensión y/o re-sedimentación (procesos bioestratinómicos) y el re-trabajo (proceso fósil diagenético) por parte de agentes eólicos y/o ácueos. Todos estos factores ocasionan la ausencia, sub-representación y/o sobre-representación de los tipos polínicos.

Además del contenido polínico, también se puede analizar el contenido de palinomorfos no polínicos (PNP); por lo cual, cuando se analizan ambos se trata de un 
análisis palinológico, el cual contribuye a interpretar las condiciones paleoambientales con mayor precisión, especialmente si se registran aquellos PNP indicadores de condiciones ecológicas específicas; por ejemplo, los quistes de dinoflagelados y colonias de algas cuyos cambios en abundancia se relacionan con la dinámica de los sistemas sedimentarios y las fluctuaciones del nivel del mar en ambientes litorales (Grindrod, 1988; Roe y van de Plassche, 2005; García-Moreiras et al., 2015 , entre otros).

En Argentina, desde 1980 se han desarrollado varios modelos polínicos y palinológicos, tanto continentales como costeros y a diferentes escalas espaciales, es decir, tanto a escala regional como local, demostrando su utilidad y validez. Entre los modelos pioneros se destacan Markgraf et al. (1981); Mancini (1989; 1993); Schäbitz (1989) y Prieto (1989; 1992; 1996). Entre los modelos más recientes se encuentran Páez et al. (2002); Stutz y Prieto (2003); Tonello y Prieto (2010); Marcos y Mancini (2012). Estos modelos incluyen distintas regiones de los pastizales pampeanos y de la Patagonia, con transectas que abarcan diferentes extensiones y unidades de vegetación.

En particular, en las llanuras costeras de Argentina, Uruguay y Brasil se desarrollaron varios modelos de la relación polen-vegetación actual que se utilizaron para establecer los cambios de la vegetación y de las condiciones paleoambientales en relación con las fluctuaciones del nivel del mar y variabilidad climática durante el Holoceno (e.g. Grill y Guerstein, 1995; Stutz y Prieto, 2003; Fontana, 2005; Medeanic, 2006; Vilanova y Prieto, 2012; Masciardi et al., 2013; Mourelle et al., 2015; Medeanic et al., 2016). Específicamente, el modelo desarrollado a partir de una transecta en el tramo inferior de la desembocadura del Río Salado (Figura 4.1.D) permitió identificar la dinámica de la zonación de las marismas en relación con las fluctuaciones del nivel del mar del Holoceno (Vilanova y Prieto, 2012).

De acuerdo con lo expuesto sobre la utilidad y validez del modelo de polenvegetación actual y la integración de los PNP para reconstruir las comunidades vegetales y condiciones ambientales del pasado, los objetivos de este capítulo son: 


\section{Objetivo general:}

Generar un modelo de polen -vegetación actual del sector centro-norte de Bahía Samborombón para ser utilizado como base para la interpretación de los conjuntos polínicos fósiles del área y, de esta forma, realizar la reconstrucción de los cambios de la vegetación y de las condiciones paleoambientales durante Holoceno medio-tardío.

\section{Objetivos específicos:}

- Establecer la relación entre las asociaciones de polen y esporas contenidas en sedimento superficial y la vegetación de las marismas de la zona centro-norte de Bahía Samborombón a lo largo de 5 transectas ubicadas en diferentes latitudes, y tomando en cuenta los procesos y factores que determinan la representación de la vegetación en el espectro polínico.

- Reconocer la distribución de los palinomorfos polínicos y no polínicos (e.g. esporas, quistes de dinoflagelados y algas coloniales) en cada transecta y para las distintas zonas de las marismas y microambientes generados por las variaciones en el micro-relieve.

- Definir los espectros palinológicos-patrón de las diferentes zonas de la marisma. 


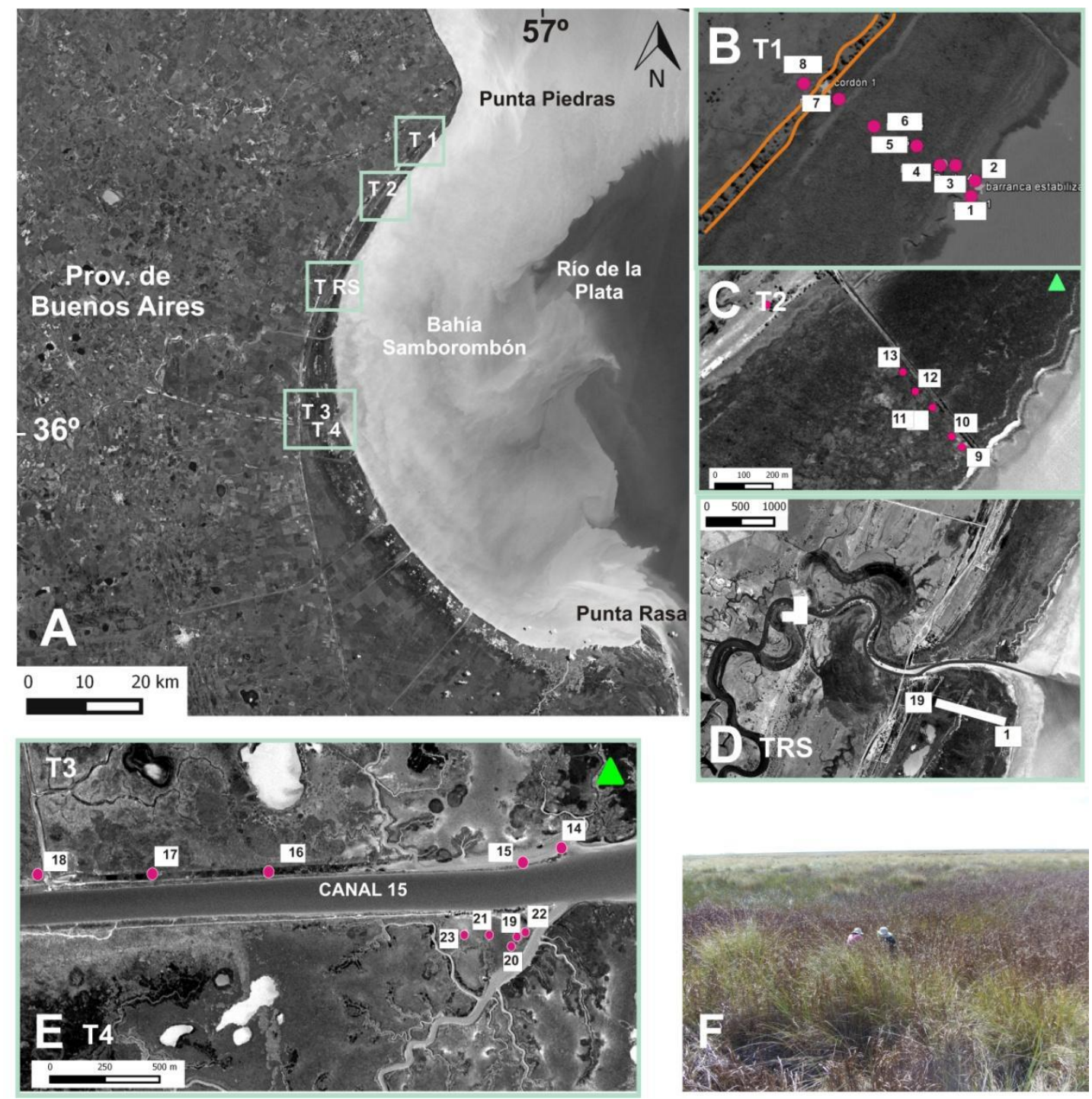

Figura 4.1. Área de estudio. A- Imagen Landsat 7 del sector costero al NE de la provincia de Buenos Aires en donde se muestra la ubicación de las transectas estudiadas, a lo largo de la franja costera de Bahía Samborombón (T1 a T4) y de la transecta Río Salado (TRS) (Vilanova y Prieto, 2012).BTransecta 1; en naranja de delimita el chenier. C- Transecta 2. D- Transecta Río Salado. ETransectas 3 y 4, F- fotografía del ambiente de marisma.

\section{2.-Características de la vegetación actual de la Bahía Samborombón}

A escala regional, la vegetación de las marismas de la costa sudamericana se caracteriza por los géneros halófitos Sporobolus y Sarcocornia, cuya cobertura vegetal constituye un $70 \%$ del total (Isacch et al., 2006). Específicamente, las marismas de la Bahía 
Samborombón se consideran entre las más importantes de Argentina junto con las de Bahía Blanca y Bahía Anegada y son las únicas con un aporte importante de agua dulce. De acuerdo con el inventario realizado en la Bahía Samborombón por Isacch et al. (2006), Sporobolus alterniflorus, Sporobolus densiflorus y Sarcocornia perennis tienen cobertura de 5060, 26314 y 8336 hectáreas ( $\mathrm{Ha}$ ) respectivamente; otras especies que se desarrollan en las marismas de condiciones salobres tienen una cobertura de $42345 \mathrm{Ha}$ y se encuentran relacionadas con una precipitación anual de 1220 mm/año (Isacch et al., 2006). Entre las especies de marismas salobres se encuentran Bolboschoenus maritimus, Juncus acutus y Cortaderia selloana; así como también otras especies con distinta tolerancia a la salinidad como Distichlis spicata, Cyclospermum leptophyllum y Apium sellowianum. Además, existen planicies de mareas sin vegetación que abarcan una superficie de 14046 Ha. Las marismas de la Bahía Samborombón pertenecen al grupo de las marismas que se desarrollan entre la Lagoa dos Patos y Laguna Mar Chiquita $\left(31^{\circ} 48^{\prime}-\right.$ $37^{\circ} 46^{\prime}$ S) caracterizadas por el dominio de Sporobolus densiflorus sobre el margen de la zona costera y por especies que habitan ambientes de condiciones salobres que se ubican sobre el límite continental (Isacch et al., 2006).

Las marismas o pantanos salados de zonas templadas se caracterizan por ser ambientes que presentan una baja riqueza y diversidad específicas (Cagnoni, 1999). Todas las especies se asocian en comunidades a lo largo de un gradiente, estableciéndose patrones de zonación de las marismas (baja, media, alta). Esta zonación se establece de acuerdo con la distancia de la línea de costa y la topografía, las cuales determinan el alcance y frecuencia de las mareas, la exposición aérea del sustrato y el aporte de agua continental; generándose en consecuencia un gradiente de salinidad. Por otra parte, el desarrollo y la zonación de la vegetación están relacionados con numerosos factores químicos, de los cuales los más importantes son: la salinidad del agua, la disponibilidad de nutrientes, en particular el nitrógeno, y el grado de anaerobiosis, el cual controla la tasa de descomposición y la disponibilidad de nutrientes (Cagnoni, 1999).

En general, Sporobolus alterniflorus se encuentra en poblaciones puras ubicadas entre el intermareal y la marisma baja, inundándose diariamente por la acción de las 
mareas, y con largos períodos de anegamiento. Por otro lado, Sporobolus densiflorus y Sarcocornia perennis se ubican generalmente a partir de unos pocos metros de la línea de costa hasta varios kilómetros hacia el interior de las marismas, es decir, en zonas un poco más elevadas y/o alejadas sujetas tanto a períodos de exposición como de anegamiento e inundándose solo por mareas altas durante la primavera como en las zonas media y alta de las marismas. De todas formas, S. densiflorus puede también ocupar sitios anegados de la zona de marisma baja, en condiciones de sumersión frecuente. Estas dos especies se encuentran formando tres patrones distintos: poblaciones puras de $S$. densiflorus, poblaciones puras de $S$. perennis y una mezcla de ambas. En estos tres patrones también se pueden encontrar las especies tolerantes a condiciones salobres, formando franjas de pocos metros de ancho (Isacch et al., 2006), especialmente en la zona de marisma alta donde existe mayor aporte de agua dulce.

Si bien la zona costera se caracteriza por tierras bajas con suelos salinos, sobre la costa del Río de la Plata, al norte de la Bahía Samborombón, existen áreas con influencia local de condiciones de aguadulce, lo cual produce un patrón inverso en la zonación de la vegetación, con comunidades de hidrófitas (Cyperaceae, Typha, entre otras) sumergidas por las mareas en la línea de costa y vegetación halófitas desarrollada en las zonas de mayor elevación y distancia de la línea de costa (Isacch et al., 2006).

Los distintos arreglos en mosaicos y/o en franjas de las comunidades vegetales, que incluyen otras especies de las marismas fueron descriptas por Vervoorst (1967) quien propuso que dichos arreglos en mosaicos responden a condiciones edáficas y topográficas (micro-ambientes/micro-relieve), es decir son comunidades azonales, tales como espartillar, hunquillar, duraznillar, pradera salada y pradera húmeda; cada una con composición florística distinta (Tabla 4.1). Estas comunidades junto con el flechillar (pastizales de Stipa) y el pajonal de Paspalum también se distribuyen en sectores continentales de la Depresión del Salado, excepto por los espartillares que sólo se los encuentra en las zonas bajas sobre la franja costera de la Bahía Samborombón.

Todas estas comunidades en mosaico se distribuyen en las distintas zonas de la marisma, modificándose rápidamente de acuerdo con los cambios ambientales, siendo 
especialmente dependientes de las variaciones en el microrelieve y la salinidad. Por ejemplo, al sur de la desembocadura del Río Salado, Vervoorst (1967) describió una zonación desde los talares, ubicados sobre cordones de conchillas en el extremo continental, hasta la línea de costa en el siguiente orden: -pradera húmeda con Eleocharis sp dominante, -cangrejal con Schoenoplectus americanus- zona con Distichlis spicata y Puccinellia glaucescens var. osteniana, Cotula coronopifolia, Sarcocornia ambigua, Triglochin striata - espejo de agua - espartillar y juncal (Scirpus olneyi y Solanum glaucophyllum). Además, también observó en las proximidades de la desembocadura del río Salado una vegetación caracterizada por poblaciones puras de Sarcocornia perennis. Otro ejemplo de los diferentes arreglos en mosaicos fue observado entre General Conesa y Canal 15 donde las praderas saladas se disponen al Este de la terraza formada por cordones de conchillas, alternando con el hunquillar y el espartillar.

Además, existe también una comunidad extrazonal representada bosques de Celtis spp ubicados especialmente sobre cordones de conchillas y cheniers. Entre las especies acompañantes arbóreas están Phytolacca dioica y Zanthoxylum fagara; en el estrato arbustivo se encuentran Jodina rhombifolia, Scutia buxifolia, Schinuslongifolius, Sambucus australis, Senna corymbosa, Cestrum parqui y Colletia spinosissima. Existen algunas enredaderas e.g Tropaeolum pentaphylum, Blumenbachia insignis y Clematis campestris. Entre las principales herbáceas se pueden encontrar Dichondra microcalyx, Bromus catharticus, Bowlesia incana y Sida rhombifolia. 
Tabla 4.1. Comunidades vegetales de la llanura costera (Pampa Deprimida), (Vervoorst, 1967; Cabrera, 1976; León, 1991; Stutz y Prieto, 2003).

\begin{tabular}{|c|c|c|}
\hline $\begin{array}{c}\text { Comunidades } \\
\text { Vegetales }\end{array}$ & Composición florística & $\begin{array}{c}\text { Ubicación en la } \\
\text { marisma }\end{array}$ \\
\hline Pradera húmeda & $\begin{array}{l}\text { Comunidades de suelos húmedos, terrenos bajos inundables } \\
\text { asociados a canales de desagüe y bordes de lagunas. Está } \\
\text { caracterizada por Carex, Elocharis, Cyperus, Stipa y Panicum. Entre } \\
\text { las especies presentes están: Paspalum vaginatum, Eryngium } \\
\text { echinatum, Phyla nodiflora, Centaurium pulchellum, Notica } \\
\text { strumdiffusum, Scutellaria racemosa, Trifolium polymorphum, } \\
\text { Melilotus indicus, Sisyrinchium laxum. }\end{array}$ & $\begin{array}{l}\text { marisma media- } \\
\qquad \text { alta } \\
\text { campos bajos } \\
\text { inundables }\end{array}$ \\
\hline Pradera salada & $\begin{array}{l}\text { Comunidad halófita de suelos y pantanos salados, caracterizada } \\
\text { principalmente por Distichlis spicata, D. scoparia y Sarcocornia } \\
\text { perennis. } \\
\text { Entre las especies acompañantes están las gramíneas como } \\
\text { Hordeum, Sporobolus, Puccinellia, entre otros; y por hierbas como } \\
\text { Malvella leprosa, Grindelia pulchellavar. discoidea, Plantago sp. } \\
\text { Sisyrinchium platense, Centaurium pulchellum, Eryngium spp, } \\
\text { Spergula villosa, Apium spp., Mentha pulegium. }\end{array}$ & $\begin{array}{l}\text { marisma alta y } \\
\text { sobre el río } \\
\text { Salado (en la } \\
\text { parte baja, en los } \\
\text { meandros) }\end{array}$ \\
\hline Hunquillar & $\begin{array}{l}\text { Comunidad halófita de suelos húmedos, salados y arenosos que } \\
\text { está dominada por Juncus acutus, en poblaciones puras, alternando } \\
\text { con las praderas y espartillares. Algunas de las especies } \\
\text { acompañantes son Limonium brasiliense, Sarcocornia perennis, } \\
\text { Hydrocotyle bonariensis, Androtrichum trigynum, Distichlis spicata }\end{array}$ & $\begin{array}{l}\text { marisma media- } \\
\text { alta en zonas de } \\
\text { de bajo } \\
\text { microrelieve }\end{array}$ \\
\hline Espartillar & $\begin{array}{l}\text { Comunidad halófita de suelos salados húmedos anegados } \\
\text { caracterizada por Sporobolus densiflora }{ }^{1} \text {, S.alterniflora*, Distichlis } \\
\text { spicata y Sarcocornia perennis. Otras acompañantes son } \\
\text { Schoenoplectus americanus*, Carex sp., Centariumpulchellum, } \\
\text { Scirpus spp, Ipomoea bonariensis, Atriplex sp., Alternanthera } \\
\text { phllloxeroides, Vicia gramínea, entre otras }\end{array}$ & $\begin{array}{l}\text { Marisma baja* } \\
\text { Marisma media- } \\
\qquad \text { alta }^{1}\end{array}$ \\
\hline $\begin{array}{c}\text { Juncales }{ }^{2}, \\
\text { Pajonales y } \\
\text { Duraznillares }\end{array}$ & $\begin{array}{l}\text { Comunidades hidrófitas caracterizadas por Cyperus spp, Carex spp, } \\
\text { Eleocharis spp. Schoenoplectu scalifornicus, Typha latifolia, T. } \\
\text { angustifolia, Eryngium sp. Solanum glaucophyllum,Mentha } \\
\text { pulegium, Rumex spp. }\end{array}$ & Marisma alta \\
\hline Talar & $\begin{array}{l}\text { Celtis ehrenbergiana, Jodina rhombifolia, Schinus longifolius, } \\
\text { Sambucus australis, Senna corymbosa, Bromus, Hordeum, Rumex, } \\
\text { Marrubium vulgare. Dichondra microcalyx, Urtica urens, entre } \\
\text { otras. }\end{array}$ & $\begin{array}{l}\text { Marisma media- } \\
\text { alta }\end{array}$ \\
\hline
\end{tabular}


${ }^{2}=$ sobre la línea de costa del río de La Plata (Punta Indio) y alrededores de la desembocadura del río Samborombón y río Salado

\subsection{Resultados}

\subsection{A-Vegetación:}

Durante el muestreo realizado en las transectas se observaron las comunidades y especies mencionadas por Vervoorst (1967), Cagnoni (1999) e Isacch et al., (2006). A continuación se describe la distribución de las comunidades vegetales registrada en cada transecta, desde la línea de costa hacia el interior del continente y con orientación SE-NO $(T 1, T 2)$ y $E-O(T 3, T 4)$, (Fig.4.1).

$\underline{\text { Transecta } 1} \sim 360 \mathrm{~m}$ de longitud $\left(35^{\circ} 33^{\prime} \mathrm{S}, 57^{\circ} 13^{\prime} \mathrm{O}\right)$

En la zona de planicie de mareas se observaron parches aislados de Sporobolus alterniflorus (Foto 4.1.A y B). A 50 m de la línea de costa, en la zona de marisma baja se encontró un mosaico de juncales de Carex spp. y Cyperus spp y espartillares de $S$. densiflorus y S. perennis, junto con la especie invasora Lotus sp. A $62 \mathrm{~m}$, existe un espartillar en mosaico compuesto por poblaciones puras de S. perennis rodeadas por $S$. densiflorus, y en menor proporción por Solanum glaucophyllum Desf, en un ambiente transicional entre las zonas de marisma media y alta. A 125 m, la vegetación se caracteriza por juncales de Carex spp., agrupados en parches y circundados por el espartillar de $S$. densiflorus. Entre 200-250 m de la línea de costa continúa el espartillar de S. densiflorus acompañado por algunos arbustos de S. glaucophylum (marisma media-alta). A 270 m de la línea de costa, se desarrollan poblaciones de Juncus acutus (Parl.) (hunquillar) en el borde de un chenier (Foto 4.2). Sobre este chenier, de $\sim 25 \mathrm{~m}$ de ancho (Fig. 4.1.B) se desarrollan árboles de Celtis sp (marisma alta). A 360 m, por detrás del chenier (marisma alta), existe un mosaico de las hidrófitas tales como Xanthium strumarium L. y $S$. glaucophylum (duraznillar), con parches aislados de Juncus acutus y de pasto salado del 
género Distichlis (pradera salada, foto 4.1.C). Otras especies observadas lo largo de toda la transecta son Conyza bonariensi y Carduus spp.
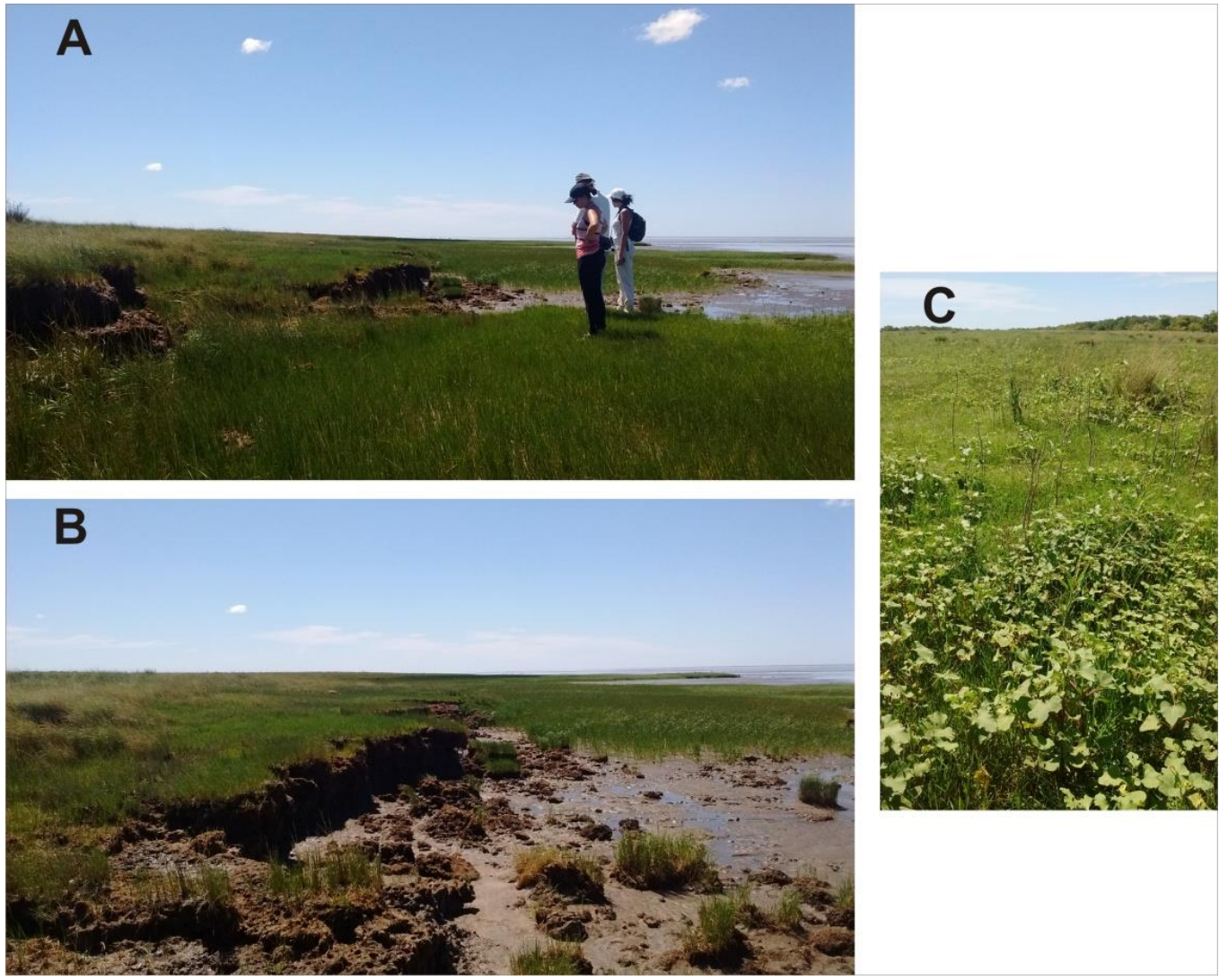

Foto 4.1. A y B- Límite entre los ambientes intemareal alto y marisma baja. C- Marisma alta con mosaico de las hidrófitas tales como X. strumarium L. y S. glaucophylum (duraznillar), y el pasto salado del género Distichlis.

$\underline{\text { Transecta } 2} \sim 440 \mathrm{~m}$ de longitud $\left(35^{\circ} 36^{\prime} \mathrm{S}, 57^{\circ} 15^{\prime} \mathrm{O}\right)$

La vegetación que correspondería al sector de la marisma baja fue destruida por la actividad antrópica y todo el paisaje de esa zona quedó disturbado con escombros de materiales depositados allí. A $92 \mathrm{~m}$ de la línea costa se observaron las comunidades de juncales-espartillares dominados por especies de Cyperaceae (Schoenoplectus 
americanusy Cyperus sp.) dispuestas en parches circundados por S. densiflorus en una marisma media-alta (Foto 4.2). A $145 \mathrm{~m}$ de la costa continúan estas comunidades observándose además S. perennis, que continúa hasta 255 m. A 400 m de la línea de costa, otro arreglo observado consiste en un mosaico caracterizado por S. perennis a modo de parches bordeados por S. densiflorus y arbustos aislados de S. glaucophylum. En el punto más interior de la transecta, a $440 \mathrm{~m}$ de la línea de costa, dominan los espartillares de $S$. densiflorus, con parches asociados de Cyperus sp en una marisma (Foto 4.2). 

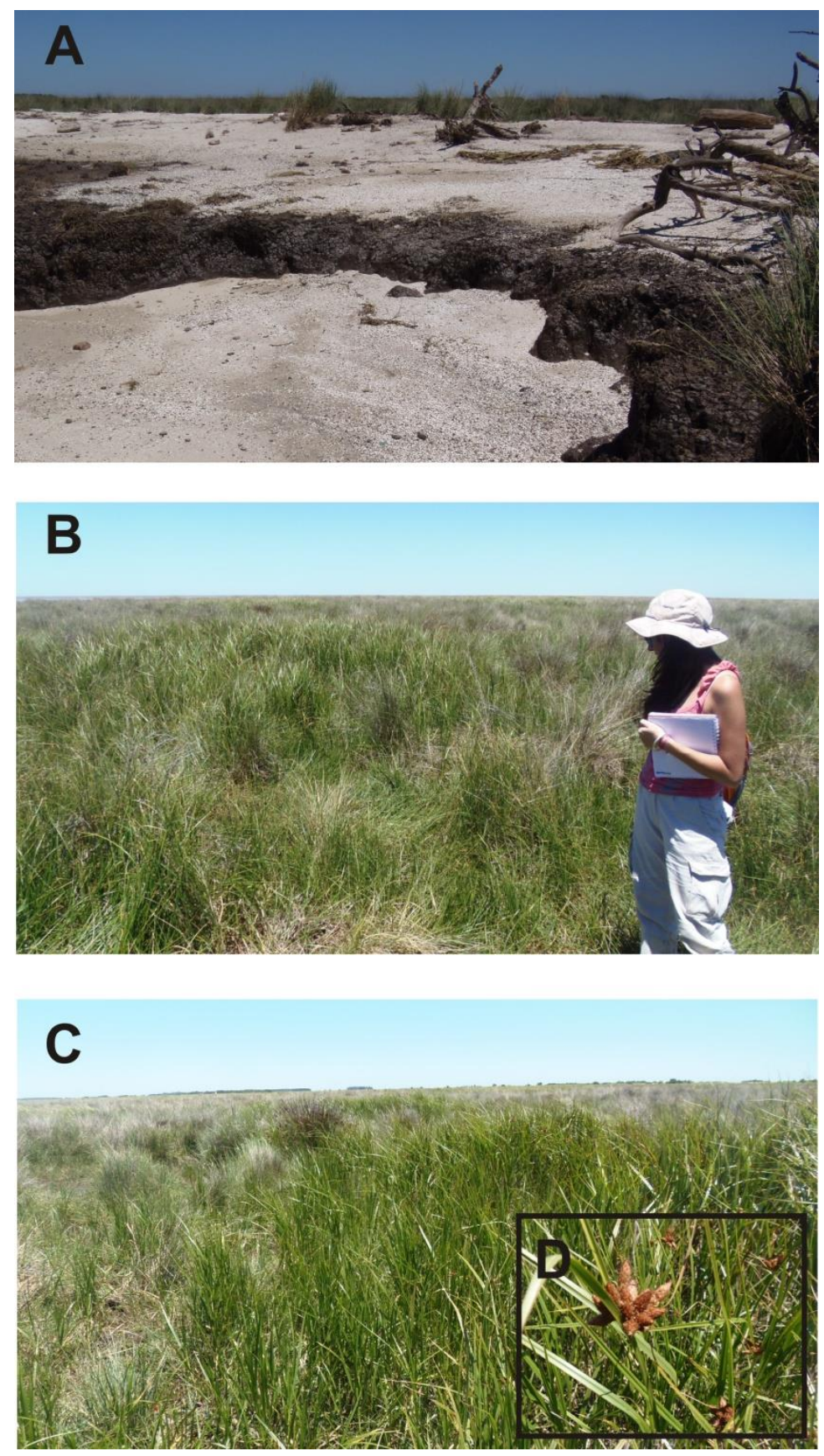

Foto 4.2. A- Costa con depósitos de tormenta B-Schoenoplectus americanus dispuestas en parches circundados por $S$. densiflorus en una marisma media-alta. C- Marisma media-alta con comunidades de juncales-espartillares. D- Schoenoplectus americanus en el ambiente de marisma. 
$\underline{\text { Transecta } 3} \sim 3400 \mathrm{~m}$ de longitud $\left(35^{\circ} 58^{\prime} \mathrm{S}, 57^{\circ} 23^{\prime} \mathrm{O}\right)$

Esta transecta comienza en las proximidades a la desembocadura del canal 15 (Figura 4.1E). En el límite del albardón sobre la desembocadura del canal 15 se observa una población pura de S. densiflorus (Foto 4.3.A). Esta vegetación corresponde a una situación particular probablemente originada por procesos de erosión y fragmentación de la marisma debido a la formación y dinámica de los canales de mareas y la descarga fluvial del canal 15. Por ese motivo, no están presentes ni el intermareal ni la marisma baja con poblaciones de S. alterniflorus. A 1000 m de la costa actual se observan parches ("abras") de S. perennis en una zona de marisma media (Foto 4.3.B). A $2350 \mathrm{~m}$ dominan juncales en un terreno deprimido bordeado por S. densiflorus en una zona de marisma media-alta (Figura 4.1.F y Foto 4.3.C). Además, se observaron especies introducidas que reflejan disturbio como Carduus sp. y Xanthium sp. A 2900 m de la línea de costa se encuentra el espartillar de S. densiflorus asociado con parches aislados de J. acutus en una zona de marisma media-alta. A 3400 m de la costa, en el extremo continental de la transecta, continúa el espartillar de $S$. densiflorus asociado con S. perennis en una marisma alta. 

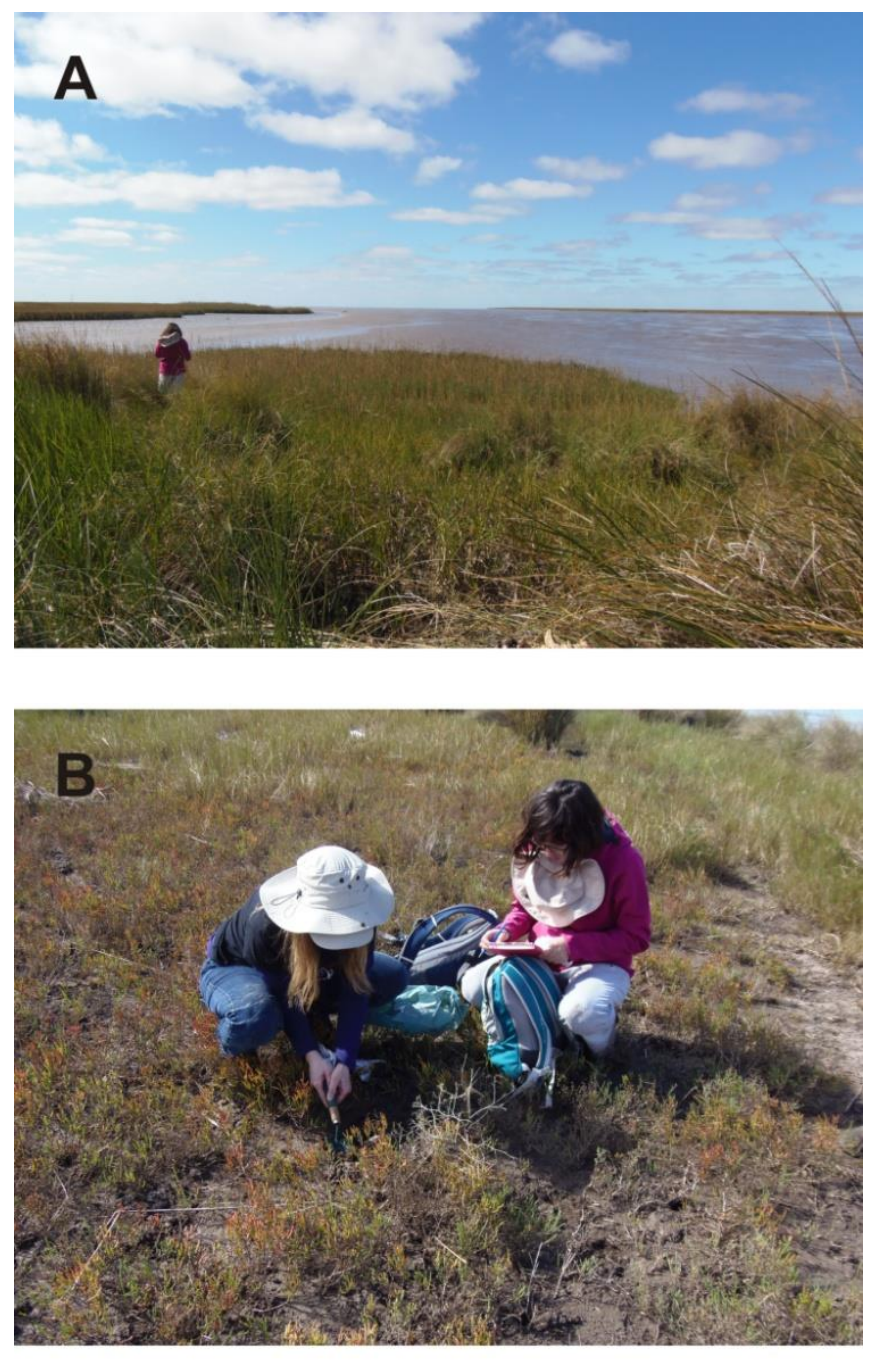

\section{C}

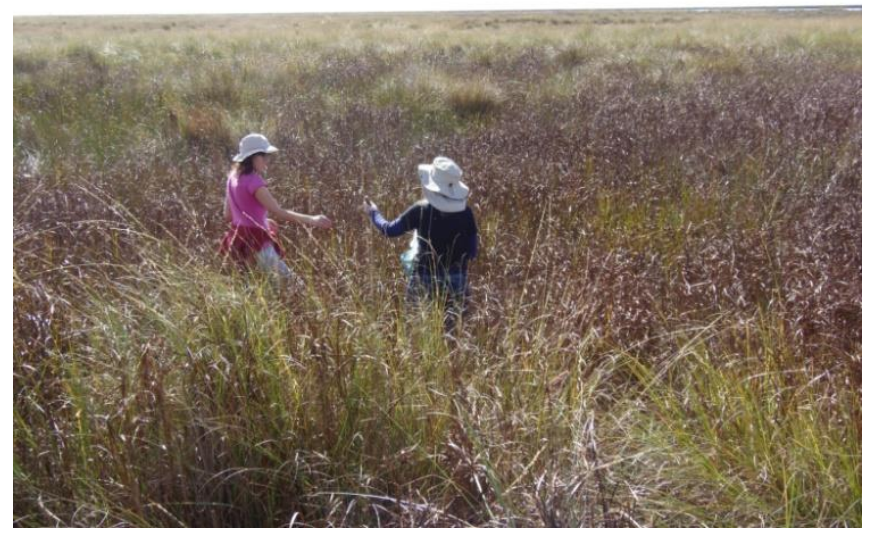

Foto 4.3. A- Poblaciones de Sporobolus densiflorus en el límite del albardón sobre la desembocadura del canal 15. B- Parches ("abras") de S. perennis en una zona de marisma media. C- Juncales en un terreno deprimido bordeado por $S$. densiflorus en una zona de marisma media. 
Transecta 4 alrededor de un canal del mareas conectado a la desembocadura del canal 15 $\left(35^{\circ} 58^{\prime} \mathrm{S}, 57^{\circ} 23^{\prime} \mathrm{O}\right)$

Este muestreo fue realizado en una depresión circundada por un canal de mareas activo conectado al margen derecho del canal 15 y ubicado a $1000 \mathrm{~m}$ de la línea de costa actual (Figura 4.1.E). Las comunidades vegetales se distribuyen de acuerdo a un microrelieve vinculado al canal de mareas activo. En las zonas elevadas sobre los bordes del canal de mareas se desarrollan los espartillares de ambas especies de Sporobolus junto con pequeños arbustos de Limonium brasiliense mientras que, en las zonas más deprimidas se desarrollan poblaciones puras de S. perennis sobre suelo con grietas de desecación en una marisma media.

\subsection{B-Análisis palinológicos}

Los resultados del análisis palinológico se presentan en gráficos de porcentaje y concentración polínica total (Figs. 4.2 a 4.5). Estos resultados se describen por transecta desde la T1 a la T4, cada una a partir de la línea de costa hacia el continente (Figura 4.1). T1 consta de 8 muestras, mientras que T2, T3 y T4 tienen 5 muestras c/u. En el total de las 23 muestras recolectadas se identificaron 54 tipos polínicos y 19 PNP (Tabla 4.2). La suma polínica varió entre 288 y 2972 granos de polen por muestra (Figuras 4.2 a 4.5).

Tabla 4.2. Tipos polínicos y PNPs indentificados

Poaceae

Chenopodiaceae

Cyperaceae

Limonium brasiliense (Plumbaginaceae)

Typha (Typhaceae)

Asteraceae

Tipo Carduus (Asteraceae)

\section{Dinoquistes}

Operculodinium spp.

Spiniferites spp.

Algascoloniales

Pediastrum

Botryococcus 
Tipo Baccharis (Asteraceae)

Tipo mutisiae (Asteraceae)

Ambrosia (Asteraceae)

Eryngium (Apiaceae)

Apiaceae

Tipo Hydrocotyle (Apiaceae)

Gomphrena (Amarantaceae)

Alternanthera (Amarantaceae)

Ranunculaceae

Myriophyllum (Haloragraceae)

Solanaceae

Brassicaceae

Convolvulaceae

Euphorbiaceae

Malvaceae

Verbenaceae

Onagraceae

Plantago (Plantaginaceae)

Geraniaceae

Cichorioideae

Tipo Cerastium (Caryophyllaceae)

Tipo Spergularia (Caryophyllaceae)

Plumbago (Plumbaginaceae)

Gentianaceae

Caesalpilonoideae

Papilionoideae

Monocotyledoneae

Polygonum (Polygonaceae)

Rumex (Polygonaceae)

Rhamnaceae

Rubiaceae

Celtis (Celtidaceae)

Schinus (Anacardiaceae)

Jodina rhombifolia (Santalaceae)

Sambucus (Caprifoliaceae)

Oxalis (Oxalidaceae)

Salix humboldtiana (Salicaceae)

Ephedra tweediana (Ephedraceae)

Prosopidastrum (Fabaceae

subf.Mimosoideae)

Acacia (Fabaceae subf.Mimosoideae)

Juglans (Jugladaceae)

Alnus (Betulaceae)
Gloetrichia

Scenedesmus

Zigosporas (Zignemataceae)

Debarya

Mougeotia

Tipo Zignema

Briofitas

Ricciaceae

Riella

Phaeoceros tenuis

Phaeoceros bulbiculosus

Anthoceros

Hongos

Esporas undiff.

Glomus

Helechos

Azolla filiculoides

Polypodiaceae undiff.

Cyatheaceae 
Pinaceae/Podocarpaceae

Myrtaceae

Nothofagus dombeyi (Fagaceae)

Betula (Ulmaceae)

\section{Transecta 1.(Figura 4.2)}

De acuerdo con el análisis de agrupamiento (CONISS) el espectro palinológico se divide en dos zonas T1-1 y T1-2 y tres subzonas T1-2a, T1-2b y T1-2c.

Zona T1.1 (sobre la línea de costa): el espectro palinológico está representado por Poaceae y Chenopodiaceae ( 30-40\%), Cyperaceae (17\%) y Asteraceae (10\%) junto con Ambrosia, Ranunculaceae y Celtis ( $\leq 5 \%)$. Operculodinium spp. y Spiniferites spp. presentan valores entre $25-40 \%$ y $\leq 5 \%$ respectivamente, registrándose también micro-foraminíferos de pared orgánica $\sim 5-6 \%$ y constituyen los valores más altos de la transecta. La concentración polínica es de 5278 y 17403 granos $/ \mathrm{cm}^{3}$. Se registran también conidios de Tetraploa y cuerpos fructíferos de Microthyrium.

\section{Zona T1.2}

Sub-Zona T1-2a (62-125 m de la línea de costa): el espectro se caracteriza por aumento de Chenopodiaceae (60-70\%), disminución de Poaceae (10-15\%), Cyperaceae (515\%), Asteraceae, Ambrosia, Typha y otras hierbas (Convolvulaceae, Brassicaceae, Euphorbiaceae, Malvaceae, Verbenaceae) presentan valores traza ( $\leq 5 \%)$. Operculodinium disminuye a valores entre 5 y $15 \%$ mientras que Spiniferites mantiene valores traza. La concentración polínica varía de 77357 a 31970 granos $/ \mathrm{cm}^{3}$. 
Sub-Zona T1-2b (200-268 m de la línea de costa): el espectro está caracterizado por el aumento de Poaceae (35-45\%) y la disminución de Chenopodiaceae (36-50\%); acompañan Cyperaceae, Asteraceae, Ambrosia, Apiaceae, Celtis con valores $\leq 5 \%$. Operculodinium spp. disminuye a $\sim 5 \%$ y Spiniferites spp. a trazas. Tanto los microforaminiferos como briofitas y gloquidios del helecho $A$. filiculoides están presentes con valores traza. Se registraron esporas de hongos indeterminados (30\%) y de Tetraploa (18\%) que son los valores más altos de la transecta. La concentración polínica varía de 33389 a 96758 granos $/ \mathrm{cm}^{3}$.

Sub-zona T1-2c ( 365 m de la línea de costa, detrás de un chenier): el espectro palinológico está representado por Poaceae ( 55\%), Cyperaceae (18\%), Apiaceae (10\%), acompañados por Chenopodiaceae (6\%), Asteraceae ( 5\%); Ambrosia, Celtis, Eryngium están presentes en trazas al igual que Operculodinium spp. La concentración polínica es de 243.019 granos $/ \mathrm{cm}^{3}$ y es la más alta de la transecta. Se registraron clumps polínicos de Poaceae y Cyperaceae. Los gloquidios A. filiculoides está presente como trazas. 
Transecta 1

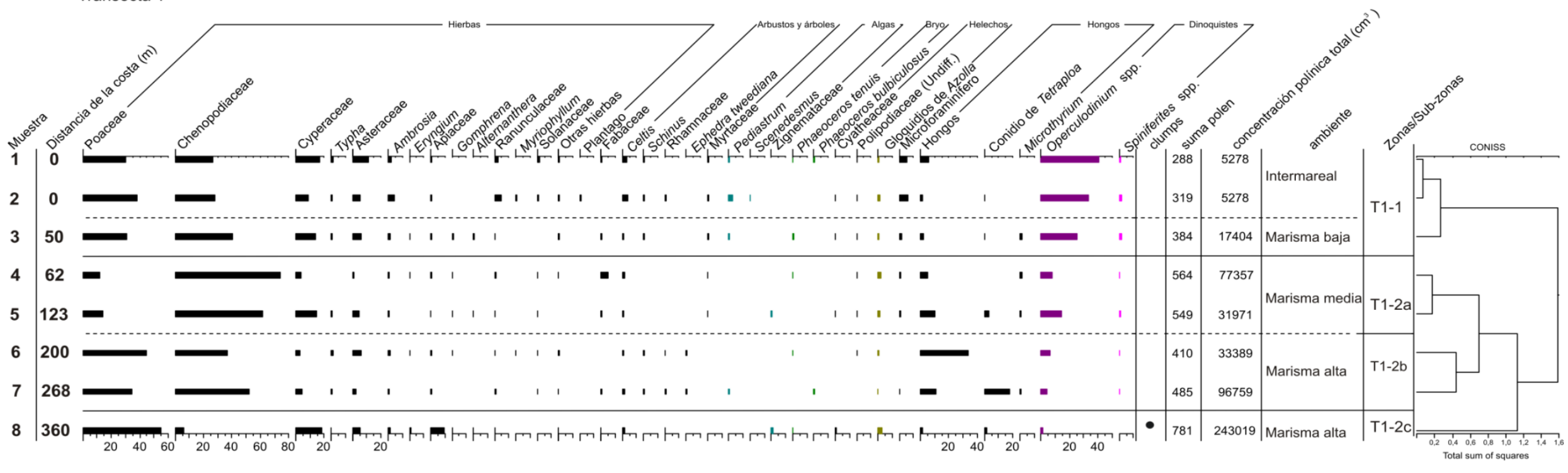

Figura 4.2. Diagrama polínico en porcentaje y concentración polínica total (granos/cm3) de la Transecta. 
Transecta 2. (Figura.4.3)

El CA divide al espectro en 2 zonas (T2-1 y T2-2) y 2 subzonas (T2-1a y T2-1b). Lasuma polínica varió entre 334 y 802 granos de polen por muestra.

Zona T2-1

Sub-Zona T2-1a ( 90-255 m de la línea de costa): El espectro palinológico se caracteriza por Cyperaceae (20-25\%) y Poaceae (24-35\%), acompañadas por Chenopodiaceae (15-35\%) junto con Typha y Asteraceae (5\%), Ambrosia ( $\leq 5 \%)$, Apiaceae, Eryngium y Plantago se registran en trazas, junto con Celtis spp y Schinus ( $\leq 5 \%)$. Entre los PNP, se registraron Phaeoceros spp. ( $\leq 5 \%)$, gloquidios A. filiculoides (5\%) Pediastrum y Zignemataceae (en trazas). Operculodinium spp. (22-24\%) y Spiniferites spp. ( $\leq 5 \%)$, alcanzan los valores más elevados de la transecta y los microforaminíferos de pared orgánica son registrados con valores de $5 \%$. Se encontraron 7 clumps de Chenopodiaceae. La concentración polínica aumenta hacia el interior del continente desde 18971 a 22716 granos $/ \mathrm{cm}^{3}$.

Sub-Zona T2-1b ( $\sim 00 \mathrm{~m}$ de la línea de costa): el espectro polínico muestra un incremento en Chenopodiaceae (hasta 90\%). Poaceae y Cyperaceae disminuyen a valores de $\leq 5 \%$ y la concentración polínica alcanza los 522503 granos $/ \mathrm{cm}^{3}$, el más alto de la transecta. Se registran siete clumps de Chenopodiaceae y Poaceae y trazas de Operculodinium y de gloquidios de Azolla filiculoides.

Zona T2-2 ( $440 \mathrm{~m}$ de la costa): el espectro está caracterizado por el dominio de Poaceae (alcanzando $60 \%$ ), el valor máximo a lo largo de la transecta; mientras que Chenopodiaceae y Cyperaceae tienen valores de 12 y $10 \%$, respectivamente. Acompañan Asteraceae (10\%) y Ambrosia (5\%). Operculodinium spp. y Spiniferites spp. disminuyen a valores de $10 \%$ y trazas, respectivamente al igual que los gloquidios de $A$. filiculoides. La concentración disminuye a 51190 granos $/ \mathrm{cm}^{3}$. 


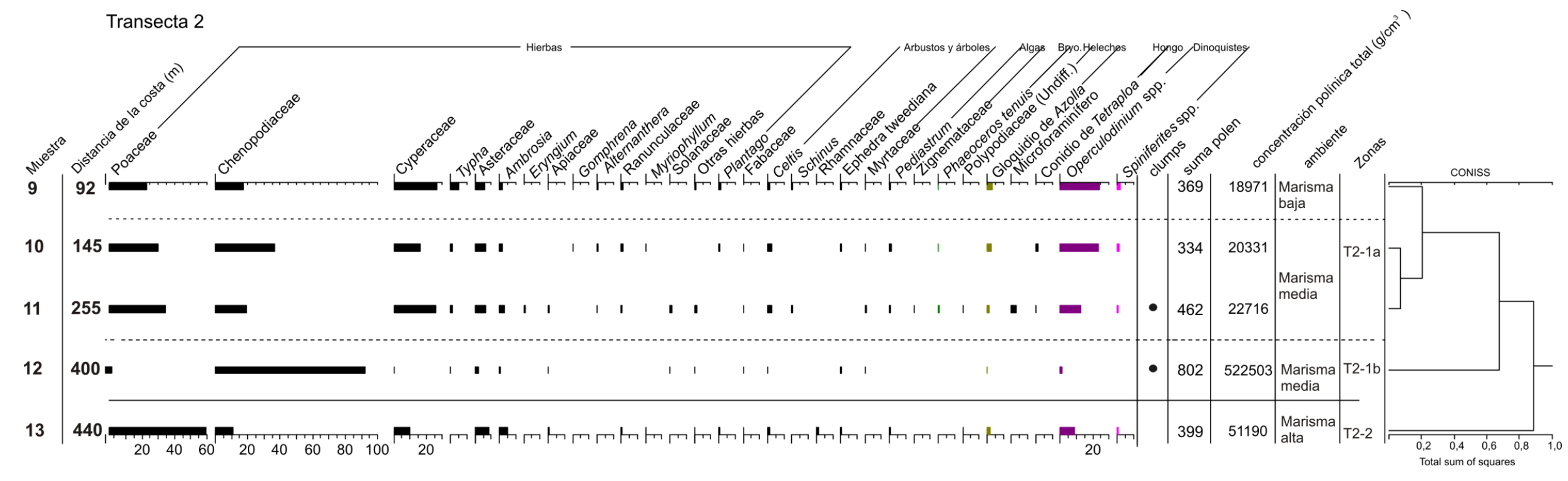

Figura 4.3. Diagrama polínico en porcentaje y concentración polínica total (granos $/ \mathrm{cm}^{3}$ ) de la Transecta 2 . 


\section{$\underline{\text { Transecta } 3 .}$}

\section{Transecta 3. (Figura 4.4)}

El CA divide al espectro en tres zonas: T3-1, T3-2 y T3-3. Las suma polínica varió entre 482 y 2972 granos de polen por muestra.

Zona T3-1 (1000 m de la línea de costa): el espectro se caracteriza por el dominio de Chenopodiaceae (64-80\%), Poaceae (15-19\%), acompañan Asteraceae (2-5\%), Cyperaceae, Ambrosia y Apiaceae con valores $\leq 5 \%$. Phaeoceros está presente como trazas al igual que $A$. filiculoides y Pediastrum ( $\leq 2 \%)$. Operculodinium spp. tiene valores de $10 \%$ y Spiniferites spp. valores traza. La concentración polínica es de 636509 a 179075 granos $/ \mathrm{cm}^{3}$.

Zona T3-2a (2350 m de la línea de costa): el espectro palinológico se caracteriza por valores mayores de Cyperaceae (hasta 20\%) y Poaceae (hasta 32\%), una disminución de Chenopodiaceae (36\%) y la presencia de trazas de Limonium brasiliense. Operculodinium spp. disminuye a $5 \%$ y Spiniferites spp. continúa con valores bajos. También, se registra $A$. filiculoides con valores traza (1\%) junto con Pediastrum, Botryococcus y Scenedesmus (trazas) y esporas de hongos (12\%). La concentración polínica es de 101994 granos $/ \mathrm{cm}^{3}$.

Zona T3-2b (2900-3400 m de la línea de costa): Está caracterizada por Chenopodiaceae (42-65\%), Poaceae (19-40\%), Cyperaceae (5-8 \%) y Ambrosia (6\%); junto Typha, Asteraceae y A. filiculoides ( $\leq 3 \%)$. Las esporas de hongos alcanzan los máximos valores de la transecta (25-30\%). La concentración polínica es de 218450- 115057 granos $/ \mathrm{cm}^{3}$. 


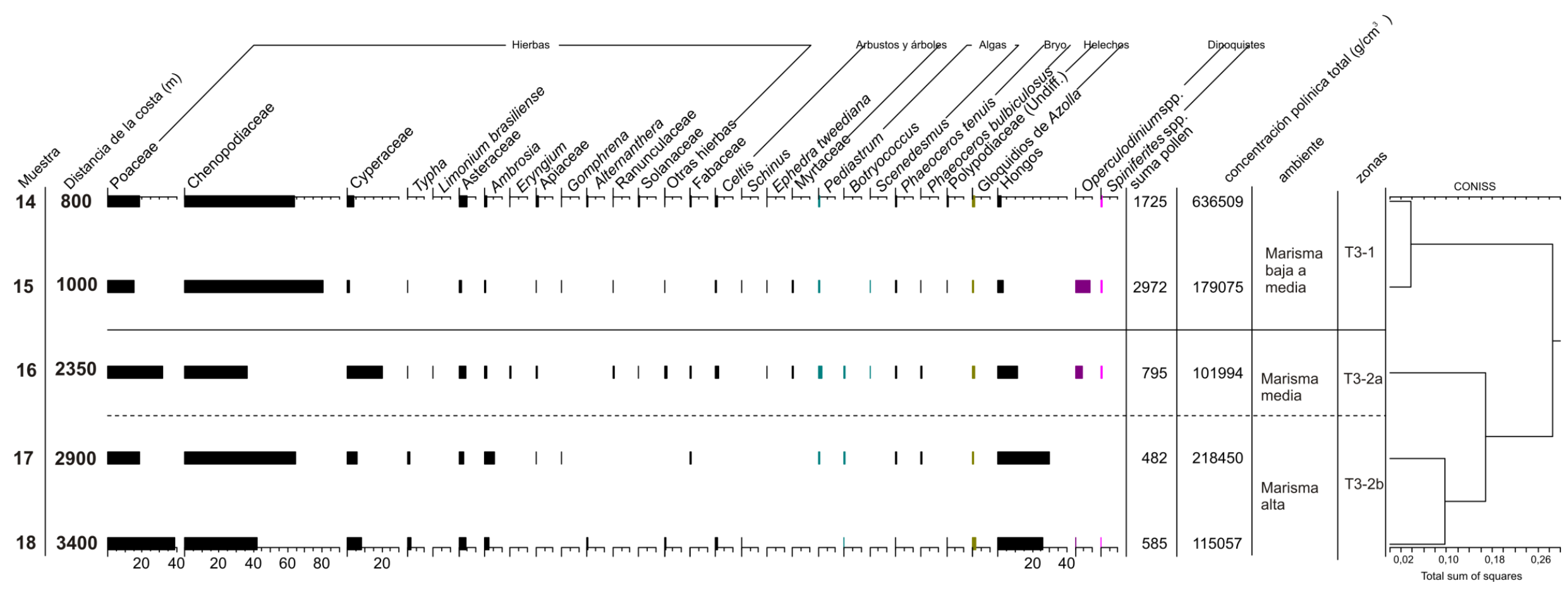

Figura 4.4. Diagrama polínico en porcentaje y concentración polínica total (granos/ $\mathrm{cm}^{3}$ ) de la Transecta 3. 
Transecta 4. (Figura 4.5)

El CA permitió diferenciar dos zonas (T4-1 y T4-2). Las suma polínica varió entre 414 y 583 granos de polen por muestra.

Zona T-4.1 ( 130 m de la boca del canal de marea): el espectro muestra Chenopodiaceae (70-73\%), Poaceae (12-15\%), Cyperaceae (4-6\%), Asteraceae, Ambrosia y Celtis ( $\leq 3 \%)$; y Limonium brasiliense $(\leq 2 \%)$. Operculodinium y Spiniferites presentan valores entre 10 y $17 \%$ mientras que $A$. filiculoides y microforaminíferos continúan como trazas. Se registran clumps de polen. La concentración polínica varía entre 35357 y 93856 granos $/ \mathrm{cm}^{3}$.

Zona T4-2: se caracteriza por: Chenopodiaceae ( 43\%), Poaceae (27-32\%) y Cyperaceae (8-15\%), acompañadas por Asteraceae, Ambrosia, Apiaceae, Eryngium, Typha y otras hierbas, todas con valores trazas $(\leq 5 \%)$. Operculodinium alcanza los mayores valores de la transecta ( 19-23\%) y Spiniferites solo está presente en trazas ( $\leq 2 \%)$. Pediastrum (4\%), Scenedesmus y Botryoccocus, junto con Zignemataceae, A. filiculoides, microforaminíferos y hongos, solo se encuentran en trazas. La concentración polínica es entre 17310 y 33453 granos $/ \mathrm{cm}^{3}$ (Fig. 4.5). 


\section{Transecta 4}

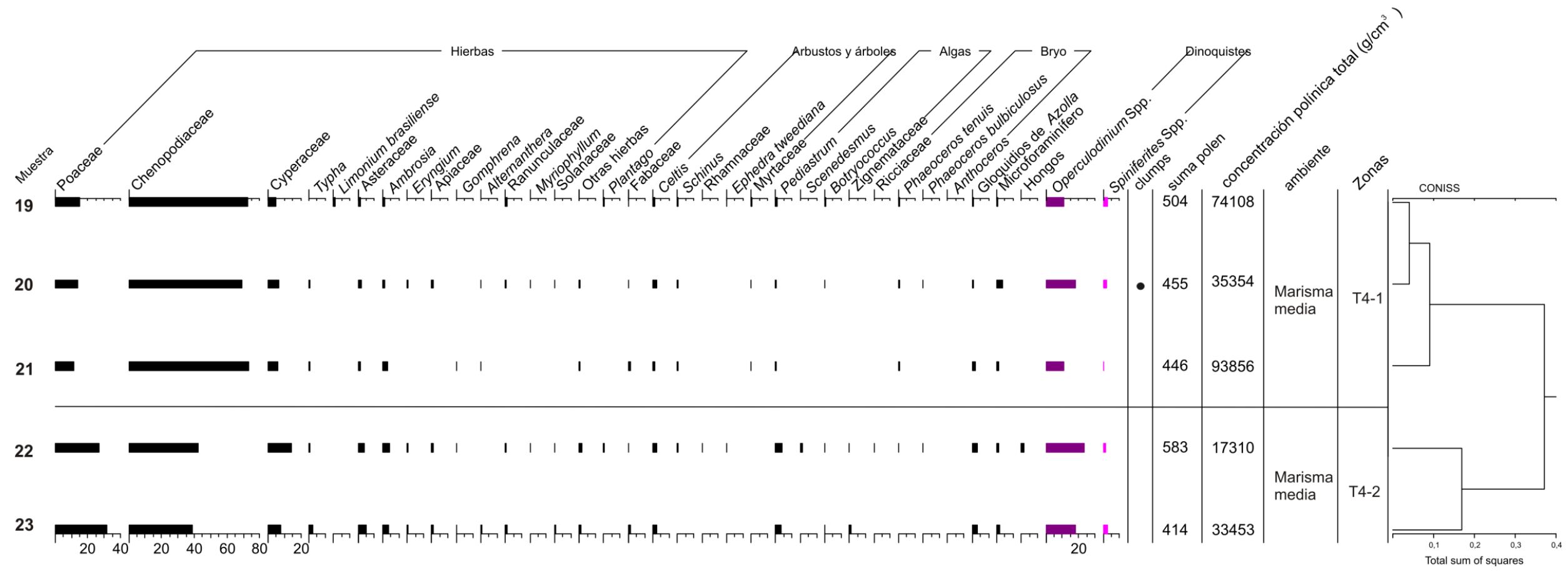

Figura 4.5. Diagrama polínico en porcentaje y concentración polínica total $\left(g r a n o s / \mathrm{cm}^{3}\right)$ de la Transecta 4. 


\subsection{Análisis de Componentes principales}

En este análisis se empleó una matriz formada por 42 muestras de superficie y 9 variables, y su resultado se muestra en un gráfico bidimensional (Figura. 4.6) considerando los dos primeros ejes o componentes principales (CPs), que en conjunto explicaron el $53,86 \%$ de la variación total de las muestras. El primer componente principal (CP 1) resumió un 38,57 \%, mientras que el segundo componente principal (CP 2) explicó un 15,29 \% de la variación total. EI CP 1 divide las muestras en tres grandes grupos de acuerdo a las proporciones de Chenopodiaceae y Limonium brasiliense por un lado y el resto de las variables por el otro. Las muestras provenientes de la marisma media, en su mayoría presentan valores negativos del primer componente, mientras que las de marisma baja presentan valores positivos en su mayoría, a excepción de las muestras 14 y 15 que presentaron valores negativos. Las muestras del ambiente intermareal y las de pradera salada presentaron valores positivos del primer componente y se ubicaron en el cuadrante inferior derecho (III). Sin embargo, no hay una separación bien definida entre la marisma media y alta ya que hay superposición en algunas muestras. A su vez, las muestras de la marisma alta se agruparon en el centro del gráfico, con valores tanto negativos como positivos. El CP 2 separa las muestras provenientes de cada zona de las marismas de aquellas del intermareal.

Chenopodiaceae y Limonium brasiliense son los que presentan los valores

negativos del componente principal 1 (CP1), mientras que, Poaceae, Asteraceae y Cyperaceae son las variables de mayor valor positivo del mismo eje. Esto estaría indicando que el componente principal 1 discrimina entre aquellas muestras con mayor porcentaje de Chenopodiaceae de aquellas con mayor porcentaje de Poaceae y Cyperaceae principalmente. 


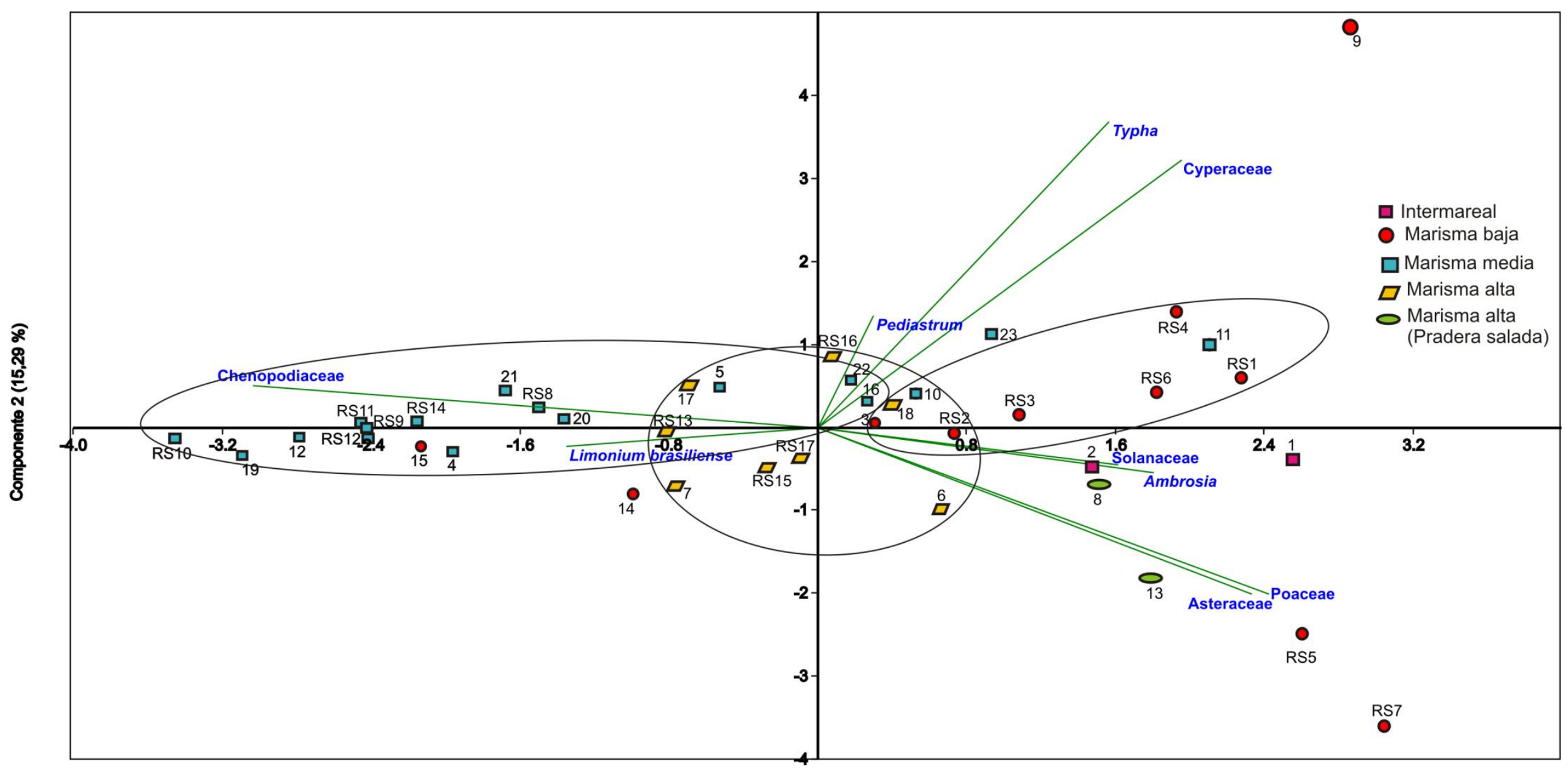

Componente 1 (38,57\%) 
Figura 4.6. Gráfico bidimensional de ordenación de las 40 muestras de superficie de la franja costera de Bahía Samborombón. Los ejes 1 y 2 representan los dos primeros componentes principales. Este análisis fue realizado en base a 9 taxa (Poaceae, Chenopodiaceae, Limonium brasiliense, Cyperaceae, Typha sp. Asteraceae, Ambrosia spp, Solanaceae, Pediastrum spp). Los círculos alrededor de las muestras agrupan las diferentes zonas de la marisma.

\subsection{Discusión}

\subsubsection{Discusión a escala local}

Transecta 1 (Fig. 4.2)

El espectro polínico proveniente del ambiente intermareal representa a los espartillares de S. alterniflorus y algunos parches de juncales de Cyperaceae que se desarrollan sobre la marisma adyacente y también en el sector intermareal, en éste último como parches aislados de esta vegetación. Este sector intermareal o de planicie de mareas permanece sumergido por completo unos pocos días al mes por lo que es considerado como un intermareal alto (Bértola, 1994). Este espectro polínico está compuesto tanto por polen de origen alóctono (representado por polen de Chenopodiaceae, Asteraceae y Celtis sp. transportado por la acción de las mareas desde la marisma adyacente hasta el intermareal) como de origen autóctono (representado por Poaceae y Cyperaceae cuya fuente es la vegetación encontrada in situ en dicho sector intermareal. Este ambiente intermareal se evidencia por los valores más elevados de dinoquistes y de microforaminiferos de toda la transecta (30-40\%) y en las características texturales arcillo areno-limoso de los sedimentos (Bértola, 1994). El grado de fragmentación de los granos de polen y esporas, junto con la presencia de restos de pared orgánica de Ammonia (Clase Foraminiferida) reflejan el retrabajo por transporte, la acción de las mareas y la mayor

energía del ambiente intermareal, ésta última responsable también de la baja concentración polínica. A pocos metros de la zona intermareal (50 m de la línea de costa) los espartillares y juncales están representados por un espectro polínico co-dominado por Poaceae, Chenopodiaceae y Cyperaceae. La disminución de Operculodinium spp. y restos 
de microforaminíferos, junto con el aumento de la concentración polínica a más del triple, indican una marisma baja y polen autóctono predominantemente por su mayor cercanía a la fuente emisora de polen (in situ), excepto por Chenopodiaceae que posiblemente provenga de las zonas adyacentes más elevadas. La mayor cobertura de la vegetación favorece las condiciones de entrampamiento del polen, lo cual incrementa la concentración polínica. Este espectro correspondería a un ambiente de transición entre marisma baja.

A mayor distancia de la línea de costa $(62-125 \mathrm{~m})$, el espectro palinológico se caracteriza por los mayores valores de Chenopodiaceae en relación con los de Poaceae y Cyperaceae. Este espectro representa una marisma media con espartillares de $S$. densiflorus y juncales de Cyperus sp. y Carex spp., pero dominada por Sarcocornia perennis Los altos valores de Chenopodiaceae (60-70\%) se deben a una sobre-representación de este taxón en relación con su mayor producción polínica en comparación con la de Poaceae y Cyperaceae, pero también con la menor dispersión anemófila de Chenopodiaceae por los efectos del canopeo de Poaceae por su mayor cobertura y altura (Stutz y Prieto, 2003; Vilanova y Prieto, 2012, entre otros). La disminución en las proporciones de dinoquistes sugiere una menor influencia de las mareas, mientras que el registro de elementos fúngicos (esporas de hongos, conidios de Tetraploa) puede estar relacionado con el desarrollo de suelos.

La disminución en Chenopodiaceae a 200 y 270 m de la costa, y el aumento en Poaceae (hasta 45\%) en el espectro polínico reflejan el espartillar de $S$. densiflorus de una marisma alta. El aumento de elementos fúngicos (hasta 40\%), incluyendo el registro de Tetraploa, sugiere una mayor estabilización del suelo y contenido de materia orgánica. El duraznillar y el hunquillar, presentes en la vegetación, no están representados en el espectro polínico; esta ausencia se relaciona con baja producción polínica (principalmente de Solanum glaucophyllum) y bajo potencial de preservación (Juncus acutus).

Al final de la transecta ( 360 m de la línea de costa), el espectro polínico muestra el dominio de Poaceae, el cual representa a las praderas saladas de Distichlis spp que se desarrollan por detrás de un chenier, en un ambiente estable y protegido de la acción 
marina directa, como lo sugiere la mayor concentración polínica de la transecta. Los valores de Cyperaceae reflejan los juncales que alternan con las comunidades de hunquillar y duraznillar, las dos últimas no reflejadas en este espectro.

\section{Transecta 2}

Entre 92 y 255 m de la línea de costa, el espectro polínico, caracterizado por Cyperaceae ( $25 \%$ ) y Poaceae (25-35\%) refleja los juncales y espartillares de S. densiflorus, los últimos circundando a los primeros en un ambiente con influencia de agua dulce asociado a un canal artificial de desagüe, que también se evidencia por el registro de Pediastrum y Zignemataceae. Por otro lado, los valores de Operculodinium spp. (que disminuyen progresivamente con la mayor distancia de la línea de costa) y la presencia de Spiniferites spp. reflejan la influencia de las mareas; probablemente esta zona sea transicional entre marisma baja y media, con condiciones más estables a los $255 \mathrm{~m}$ de distancia de la línea de la costa como lo sugiere el registro de granos de polen agrupados (clumps), que pueden haber sido depositados in situ.

A $400 \mathrm{~m}$, el incremento de Chenopodiaceae hasta el valor más alto de la transecta (90\%) refleja las poblaciones puras de Sarcocornia perennis en un ambiente de marisma media. La alta concentración polínica alcanzada en este sector podría deberse por la elevada producción polínica de S. perennis y su dispersión anemófila. (Stutz y Prieto, 2003; Vilanova y Prieto, 2012, entre otros). La presencia de clumps de Chenopodiaceae y Poaceae estaría vinculada con la cercanía a la fuente y con débil acción de un agente de transporte (vientos o mareas). A 440 m de la costa el predominio de Poaceae hasta 60\% en el espectro refleja el espartillar de $S$. densiflorus acompañado por juncales. El registro de Operculodinium spp. puede reflejar el transporte por mareas extraordinarias.

\section{Transecta 3}

Sobre la desembocadura del canal 15 el registro obtenido del borde de la marisma está caracterizado por altos valores de Chenopodiaceae que corresponderían a la zona 
media. Es posible que este sector haya sido erosionado y/o disturbado tanto por el desarrollo de canales de marea como por el aumento del caudal del Canal 15. A 2350 m de la costa, el espectro caracterizado por Cyperaceae (hasta 20\%), y Chenopodiaceae (que disminuye a $36 \%$ ) representa un sector bajo donde predomina el juncal. La disminución Operculodinium spp. y Spiniferites spp. refleja o se relaciona con una menor influencia mareal. Por otra parte, el aumento en el registro de elementos fúngicos sugiere condiciones estables y acumulación de materia orgánica.

A mayor distancia de la línea de costa (entre los 2900 y 3400 m) el espectro, caracterizado por Chenopodiaceae con valores entre 40 y $60 \%$ acompañado por Poaceae con valores entre 20 y 40\%, reflejan el espartillar de S. densiflorus con algunos parches de juncales sugeridos por Cyperaceae con valores entre 5 y 10\%, que se desarrollan en una zona de marisma alta con influencia de aguadulce. Otros géneros presentes en la vegetación son Ambrosia y Typha. La estabilidad de la marisma y las condiciones de humedad del suelo están indicadas por el registro de hongos hasta $20 \%$. En este sector de la transecta no se registraron dinoquistes lo cual está en relación con la mayor elevación del terreno, posiblemente relacionado con el relleno por material originado durante la construcción del canal 15, entre otros factores.

\section{Transecta 4 (Canal de mareas)}

El espectro polínico de las muestras tomadas en torno a un canal de mareas activo muestra variaciones que reflejan los diferentes arreglos de vegetación como respuesta a un microrelieve (microtopografía) dentro de un ambiente de marisma media. En albardones del curso principal y cursos menores, el espectro se caracteriza por la dominancia de Poaceae y Chenopodiaceae reflejando poblaciones del espartillar de $S$. densiflorus arregladas a modo de franja delimitando zonas deprimidas donde ocurren poblaciones puras de S. perennis, las cuales se reflejan en el espectro por Chenopodiaceae (hasta $\sim 80 \%$ ). El registro de Limonium brasiliense estaría apoyando un ambiente de marisma media. Los quistes de dinoflagelados muestran los valores más altos en los sitios más cercanos a la boca del canal de mareas evidenciando así la influencia mareal. 


\subsection{2- Discusión a escala regional (sector centro-norte de Bahía Samborombón)}

El conjunto de muestras de superficie del centro-norte de Bahía Samborombón, incluyendo también las analizadas por Vilanova y Prieto (2012), alcanzan un total de 40 muestras (figura 4.7). Estas muestras abarcan las 3 zonas de la marisma (baja, media y alta) y también ambientes particulares en torno a un canal de mareas (T4). El análisis de este conjunto de muestras indica que Chenopodiaceae, Poaceae, Cyperaceae y Asteraceae son los taxones polínicos dominantes de las marismas, al igual que ocurre en otras Ilanuras costeras de la región e.g. Mar Chiquita (Stutz y Prieto, 2003); SE costero bonaerense (Fontana, 2005); Arroyo Solís, Uruguay (Mourelle et al., 2016); Laguna costera Dos Patos, Brasil (Medeanic et al., 2016). A continuación se analizan los resultados del ACP y luego se discute el diagrama palinológico total con el objetivo de establecer la representación de la vegetación en el espectro palinológico para cada zona de las marismas.

\section{-Ordenamiento espacial a partir del análisis de componentes principales}

A partir del ACP se infiere que el CP1 (Figura 4.6) representa una gradiente de salinidad, con valores negativos para las muestras localizadas en ambientes con alta salinidad (Cs-Izqs), y con valores positivos aquellas muestras que provienen de ambientes de baja salinidad (Cs-Dchs). EI CP2 refleja un ordenamiento de acuerdo a un gradiente relacionado con el nivel de agua, desde un ambiente sumergido, esto es, muestras con valores positivos (Cs Sups) hasta un ambiente completamente terrestre, esto es, muestras con valores negativos (Cs-Infs).

Los grupos de muestras se distribuyen principalmente a lo largo del CP1, con lo cual se infiere que el gradiente de salinidad es el factor más influyente en arreglo de las comunidades vegetales. De todas formas, también el nivel de agua condiciona la distribución de la vegetación. Por ejemplo, el ACP ubica al ambiente intermareal en una transición entre condiciones acuáticas y terrestres; lo cual obedece al carácter 
principalmente alóctono del espectro polínico para este ambiente, compuesto por granos de polen de la vegetación de zonas cercanas que son transportados al sector intermareal (e.g. Poaceae, Chenopodiaceae, Cyperaceae, Asteraceae, Ambrosia, Ranunculaceae y Celtis).

El grupo que representa la zona de marisma baja tiene valores positivos en ambos componentes (CP1 y CP2) lo cual refleja condiciones de menor salinidad en comparación con marismas más alejadas de la línea de costa en un ambiente acuático a semi-acuático. Por un lado, la menor salinidad de la marisma responde a una mayor disolución del contenido de sales y a la mayor influencia de agua dulce-salobre proveniente del Río de La Plata y de los ríos Samborombón y Salado, y de los canales artificiales, en un ambiente sumergido diariamente. Por otro lado, las marismas más alejadas y con menor influencia de las mareas están sujetas a exposición aérea por tiempo prolongado y se ven afectadas por la consecuente desecación y concentración de sales. La marisma baja tiene un espectro polínico con taxones alóctonos transportados (Asteraceae, Ambrosia, Celtis y Chenopodiaceae) y autóctonos caracterizados por Poaceae, que representa al espartillar de S. alterniflorus.

El grupo de muestras que representa la zona de marisma media tiene valores negativos sobre el CP1, lo cual se relaciona con la más alta salinidad del suelo en un ambiente de condiciones principalmente terrestres pero con influencia esporádica de mareas y de agua proveniente de la lluvia o de canales de desagüe. El espectro polínico refleja claramente las poblaciones de Sarcocornia perennis y, también, un arbusto de la especie Limonium brasiliense asociado con el hunquillar, y que puede considerarse como un taxón indicador de marisma media-alta ya que la presencia de su grano de polen está sumamente vinculada con la cercanía a la fuente (in situ).

El grupo de muestras que representa la marisma alta se ubica en torno a la intersección de los componentes CP1 y CP2; por lo cual, representa un ambiente de condiciones intermedias, variables y mixtas (e.g. salinidad y nivel de agua, microrelieve, sustrato, etc.). El registro de Limonium brasiliense indica también las condiciones de marisma alta. 


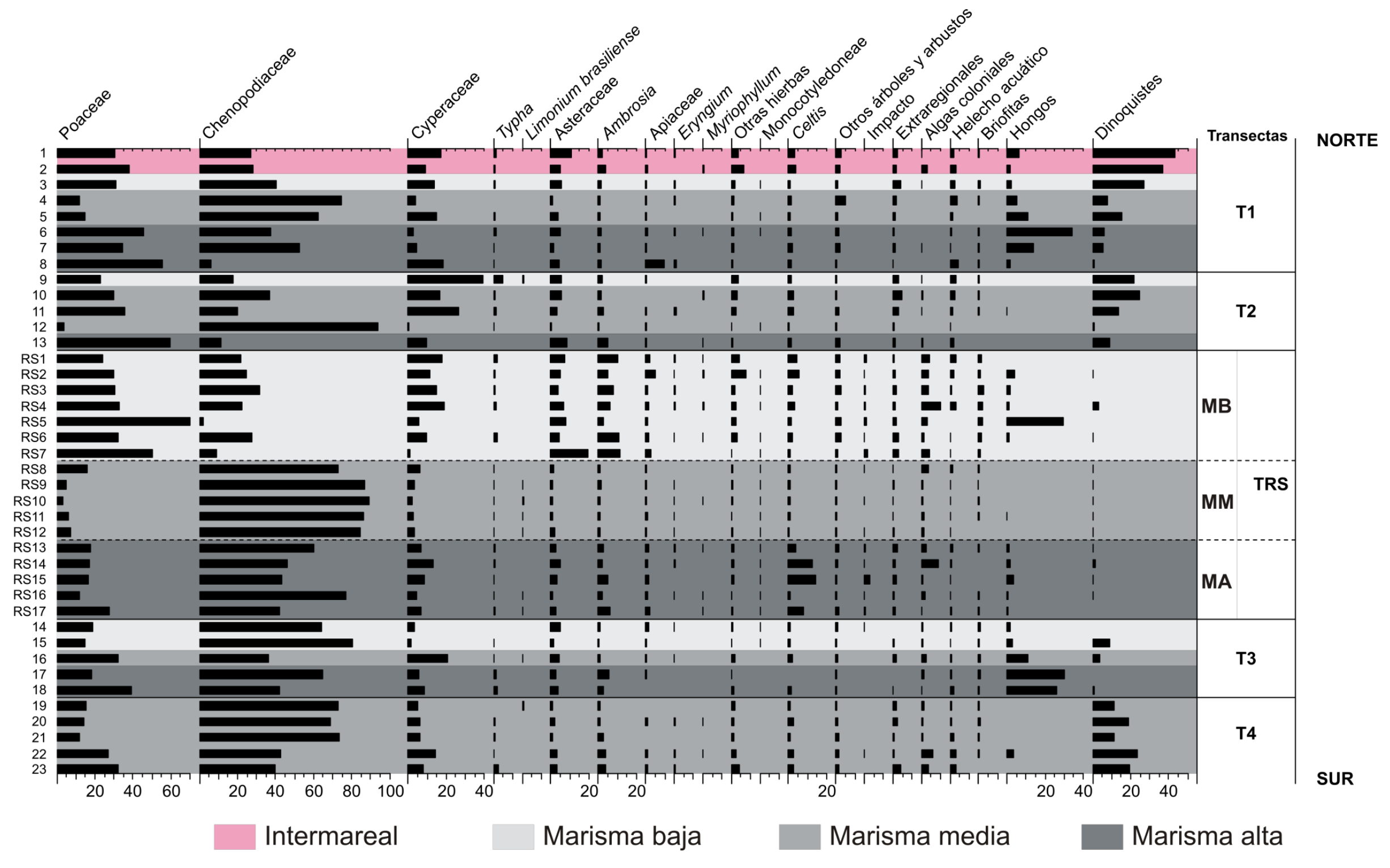


Figura 4.7. Diagrama palinológico en porcentaje (resumido) de las 40 muestras de superficie de la zona centro-norte de Bahía Samborombón (T1, T2, TRS, T3 Y T4). Asteraceae incluye los tipos Baccaris, Senecio y Cichorioideae. Otras hierbas: Brassicaceae, Convolvulaceae, Euphorbiaceae, Geraniaceae, Gomphrena, Malvaceae, Onagraceae, Oxalis, Plantago, Ranunculaceae, Alternanthera, Tipo Plumbago, Polygonum, Verbenaceae. Otros árboles y arbustos: Acacia, Ephedra tweediana, Fabaceae (Caesalpinioidae y Papilionoideae), Jodina rhombifolia, Salix, Sambucus, Schinus, Solanaceae, Rhamnaceae. Extraregionales: Alnus, Betula Myrtaceae, Nothofagus, Pinaceae/Podocarpaceae. Algas coloniales: Botryococcus, Gloeotrichia, Pediastrum, Scenedesmus, Zignemataceae. Impacto: Tipo Carduus y Rumex. Briofitas: Ricciaceae, Phaeoceros tenuis, P. bulbiculosus y Anthoceros. Hongos: Glomus y esporas undiff.

\section{-Análisis del espectro palinológico general}

El espectro polínico de muestras de superficie refleja la gran mayoría de las comunidades vegetales del sector centro-norte de la Bahía Samborombón (espartillares, juncales, pradera salada y bosques de Celtis sp); excepto por el hunquillar y duraznillares, caracterizado por el dominio de Juncus var. acutus cuyo grano de polen no se preserva por tener una pared muy débil con menor contenido de esporopolenina. El resto de las comunidades vegetales que se distribuyen en las diferentes zonas de las marismas (baja, media y alta) se encuentran representadas en todas las transectas. Además, en todas las transectas se reconocen, desde el espectro palinológico, las diferentes zonas de la marisma independientemente de la extensión que abarca cada una; dicha extensión depende de la topografía y pendiente del terreno, y es por eso que las marismas del norte de la bahía presentan zonas de menor extensión que en el sector central. Si bien la determinación e identificación de los tipos polínicos es por lo general de baja resolución (a

nivel de familia y género), las proporciones relativas de los taxones polínicos sumadas a taxones indicadores/ marcadores ecológicos y a PNP, complementan la información para inferir las diferentes zonas de la marisma.

\section{Marisma baja - intermareal}

En general, esta zona está representada en T1 y TRS por un espectro palinológico cuyo tipos polínicos indicadores con un rango de valores específico son: Cyperaceae, con 
valores representativos de 20-25\%; Poaceae, con valores que oscilan entre $30-70 \%$ y Chenopodiaceae, con valores menores entre 5-35\%. Este espectro pueden estar reflejando el patrón de zonación inverso de la vegetación que describieron Isacch et al. (2006) para el sector costero al norte de la Bahía Samborombón, y que es encontrado aquí, en el área de estudio de esta tesis. En general, valores de $25 \%$ de Cyperaceae estarían reflejando el patrón invertido con espartillares y juncales; mientras que, valores de Cyperaceae entre $10-15 \%$, podrían estar más relacionados con el transporte por las corrientes de marea y canales de desagüe. Este patrón invertido de la zonación de la vegetación a escala local, con juncales y espartillares semi-sumergidos se relaciona, en este caso, con la influencia del agua dulce-salobre del Río de la Plata, de los ríos Samborombón y Salado y de los canales artificiales de agua que desembocan en este sector de la bahía.

Complementariamente, el registro de valores altos de dinoquistes y la presencia de microforaminíferos podrían utilizarse como indicadores de la mayor influencia de mareas y los ambientes intermareal y marisma baja.

\section{Marisma media}

El espectro palinológico representativo o indicador de esta zona es el que refleja principalmente las poblaciones puras de Sarcocornia perennis rodeadas por el espartillar de S. densiflorus, el cual constituye uno de los 3 arreglos de estas dos especies encontrados en el inventario realizado por Isacch et al. (2006). Este espectro polínico se caracteriza por porcentajes de Chenopodiaceae entre 70 y 90\%. Otros tipos polínicos que componen el espectro son Poaceae 5-15\%, Cyperaceae, Asteraceae y Limonium brasiliense, todos estos con valores $\leq 5 \%$. En particular, Limonium brasiliense es un indicador de esta zona y suele localizarse en el borde o límite entre las poblaciones de S.perennis y $S$. densiflorus junto con algunos parches de Juncus acutus, éstos últimos, como ya se mencionó, sin representación en el espectro debido a la fragilidad y escasa preservación del polen (Peglar et al., 2001). 
Un arreglo particular de la vegetación encontrado en la marisma media de la transecta T2 entre 92 y 255 m de la línea de costa, es el de espartillares y juncales, con un espectro polínico similar al de la marisma baja. Probablemente el desarrollo de juncales obedece a canal artificial pequeño que atraviesa el sector. Por otro lado, este arreglo de la vegetación puede ser consecuencia del impacto antrópico ocurrido en los primeros $100 \mathrm{~m}$ desde la línea de costa que originaron un desplazamiento de la vegetación, encontrando condiciones propicias para su desarrollo; es decir, no sería representativo de esta zona en términos de frecuencia, comparando con la cobertura vegetal de $S$. perennis y de sus altos valores en este sector centro-norte de la bahía.

\section{Marisma alta}

Las dos características principales que pueden contribuir a diferenciar esta zona de las marismas son: 1- el mayor número de tipos polínicos que reflejan la mayor diversidad de las comunidades de espartillares y juncales que se desarrollan en la marisma alta, por ejemplo, aquellas ubicadas por detrás de los cheniers en dirección opuesta a la línea de costa. En este caso, valores de Celtis hasta $15 \%$ se relacionan con los árboles que se ubican sobre el chenier. En TRS la marisma alta se extiende entre los 800 y $1000 \mathrm{~m}$ de distancia de la línea de costa y posee una mayor diversidad de la vegetación que se refleja en el espectro polínico. Entre las especies registradas en esta zona se encuentran Solanum pseudocapsicum (Vell) (Solanaceae) y Eryngium sp. (Apiaceae). Otros taxones identificados en la marisma alta son Carex (Cyperaceae), Pseudognaphalium gaudichaudianum DC., Baccharis glutinosa DC., B. salicifolia (Ruiz y Pav.) Pers. (Asteraceae), Heliotropium curassavicum L. var. argentinum I.M. Johnst (Boraginaceae), Sesuvium portulacastrum (L.) L. (Aizoaceae), Centaurium pulchellum (Sw.) Druce (Gentianaceae), Euphorbia serpens Kunth (Euphorbiaceae), Oxybasis macrosperma (Hook.) subsp. macrospermum, Atriplex prostrata Boucher ex DC. (Chenopodiaceae), Polygonum aviculare L. (Polygonaceae), Phyla nodiflora (Kunth) Greene (Verbenaceae), Lotus tenuis (Mill).,Melilotus indicus L. All. (Fabaceae) y Paspalum vaginatum SW (Poaceae). 2- La concentración polínica ya que, en 
general es mayor a 100000 granos $/ \mathrm{cm}^{3}$, mientras que en la baja y en la media los valores no alcanzan ese rango.

El espectro polínico se caracteriza por el dominio de Poaceae (15-60\%) y Chenopodiaceae (5-40\%) junto con Cyperaceae (5-20\%), Asteraceae (5\%) y Celtis (hasta 15\%). Acompañan Asteraceae, Ambrosia, Eryngium y Apiaceae lo cual se relaciona con mayor diversidad de la vegetación, el espectro polínico es principalmente de origen autóctono.

Entre los PNP que podrían ayudar a diferenciar entre la marisma baja en relación con las zonas media y alta se encuentran los hongos, cuya proliferación en ambientes de marisma se da en condiciones de equilibrio entre los periodos de humedad y desecación, encontrándose una mayor diversidad en aquellas zonas sumergidas periódicamente a aquellas permanentemente sumergidas (Wong y Hyde, 2002). Estas condiciones son consistentes con la estabilidad de la superficie y por lo tanto con una mayor acumulación de materia orgánica (hojarasca). Específicamente, el registro de conidios de Tetraploa podría estar indicando la microbiota alcalino-tolerante descomponedora de restos del pasto salado Distichlis (Elíades et al., 2014), es decir, mediante la identificación de esta espora, es posible inferir la presencia del pasto salado que es indistinguible desde la morfología del polen del resto de las gramíneas.

Otros indicadores, que no son específicos de una zona de la marisma pero que aun así contribuyen a establecer las condiciones ambientales, son las algas coloniales como Pediastrum, Botryococcus, remanentes de cienobacterias, gloquídeos de Azolla que reflejan ambientes acuáticos (charcos, depresiones, lagunas temporarias, de aguas someras, etc.).

En síntesis, la similitud entre las transectas radica en que todas reflejan, desde el punto de vista palinológico, las zonas del ambiente de marisma de la Bahía Samborombón, y estas se extienden a lo largo de diferente magnitud (longitud) de las transectas lo que está estrechamente vinculado a la topografía, principalmente a un gradiente en la pendiente que varía de norte a sur. $\mathrm{Y}$ reflejan comunidades presentes en todas las transectas con diferentes arreglos, lo que se relaciona con una alta dinámica y 
una resiliencia de la vegetación de la marisma que les permite desplazarse de acuerdo a los cambios ambientales episódicos, abruptos, a diferentes escalas tanto espaciales como temporales; es así que frente a un evento erosivo, la vegetación de la zona baja se traslada al continente, desplazando todas las zonas en sentido tierra adentro.

\section{5.-Conclusiones}

El estudio de las asociaciones palinológicas de superficie permitió generar un análogo moderno para los ambientes litorales de Bahía Samborombón y además permitió diferenciar y caracterizar desde el punto de vista palinológico los ambientes mareales, incluyendo las distintas zonas de la marisma (baja, media y alta).

Los análisis estadísticos permitieron diferenciar grupos/unidades polínicos que se corresponden con; (1) la marisma baja-intermareal, (2) la marisma media, (3) la marisma alta. Es decir, estas unidades polínicas reflejan las unidades de vegetación y geomorfológicas de la franja costera de la zona centro-norte de Bahía Samborombón.

Mediante las conjuntos polínicos se pudieron reconocer dos gradientes ambientales; gradiente de salinidad y el gradiente de terrestrealidad (o nivel de agua).

Se pudo comprobar que pequeños cambios en el terreno (microrelieve) como canales de marea y depósitos asociados, cheniers, etc, modifican la vegetación local y por lo tanto condicionan la asociación polínica final.

Los dinoquistes junto con restos de microforaminíferos fueron de gran importancia en la determinación del ambiente intermareal, además de ser buenos indicadores de la influencia de las mareas. Además, los elementos fúngicos resultaron buenos indicadores de superficies estables con gran acumulación de materia orgánica.

La concentración polínica es otra característica de las asociaciones polínicas actuales que contribuyó a la diferenciación de los ambientes. 
Los espectros polínicos provenientes de las transectas ubicadas al Norte del área de estudio, reflejaron el patrón de zonación inverso de la vegetación descripto por Isacch et al., 2006.

El modelo polínico reflejó la sucesión lateral de los ambientes mareales de Bahía Samborombón a lo largo de anchos variables de la franja costera (desde 400 hasta 3000 m). Este modelo, en integración con los PNPs más indicadores, constituye un buen análogo para interpretar secuencias polínicas fósiles de ambientes costeros cuya evolución está vinculada a los cambios del nivel del mar.

Este modelo local, extra-local (superficie de estudio) contiene la representación polínica del total de las comunidades vegetales de la zona costera del centro-norte de Bahía Samborombón, que debería ser apropiado para la correcta interpretación de las asociaciones palinológicas fósiles. 


\section{Capítulo 5}

\section{CAMBIOS AMBIENTALES EN EL SECTOR CENTRAL DE BAHÍA SAMBOROMBÓN DESDE EL HOLOCENO MEDIO}

\section{1- Introducción}

Las llanuras costeras son importantes archivos de los cambios ambientales. En particular, sedimentos que contienen información acerca del desarrollo en el pasado de ambientes de marismas, han sido una importante herramienta en el estudio y comprensión de los cambios del nivel del mar durante el Holoceno.

Son pocos los estudios palinológicos llevados a cabo a partir de depósitos sedimentarios de la llanura costera de Bahía Samborombón, en donde las marismas costeras son el ecosistema más representativo. (Vilanova and Prieto, 2012). Además, son escasos los estudios que combinen o integren información paleoambiental, paleoecológica e incluso paleoclimática proveniente de diferentes indicadores (datos proxies) para el área del Río de la Plata y planicies adyacentes (e. g.: Mourelle et al., 2015; Prieto et al., 2017). Este tipo de estudios puede proporcionar la apreciación de las tasas de cambio ambiental y una perspectiva integral a largo plazo sobre cómo la vegetación y las condiciones ambientales han evolucionado hasta alcanzar su estado actual; lo cual puede contribuir a entender la variabilidad inherente, proporcionando un contexto para evaluar su futura respuesta. Esta información es relevante si se considera la importancia extrema de esta región en términos de su biodiversidad, uso de la tierra y servicios ecosistémicos que se brindan tanto a las sociedades locales como a las regionales.

Objetivos: en este capítulo se reconstruye la historia de la vegetación y de los cambios ambientales a partir del análisis micro y macropaleontológico (polen, esporas, 
dinoquistes, foraminíferos y restos de moluscos) a partir de dos secuencias sedimentarias expuestas sobre el canal 15, ubicadas a diferentes distancias de la línea de costa y abarcando distintas ventanas temporales; los nombres de las secuencias son PM1 y PM2.

El PM1 se encuentra en el área central de la franja costera de Bahía Samborombón a 5,7 km de la línea de costa actual y abarca los últimos 2700 años cal AP a una escala temporal milenial a centenal. La secuencia PM2 está ubicada a 10,3 km de la línea de costa actual y abarca un intervalo de tiempo entre 6800 y 5500 años cal. AP.

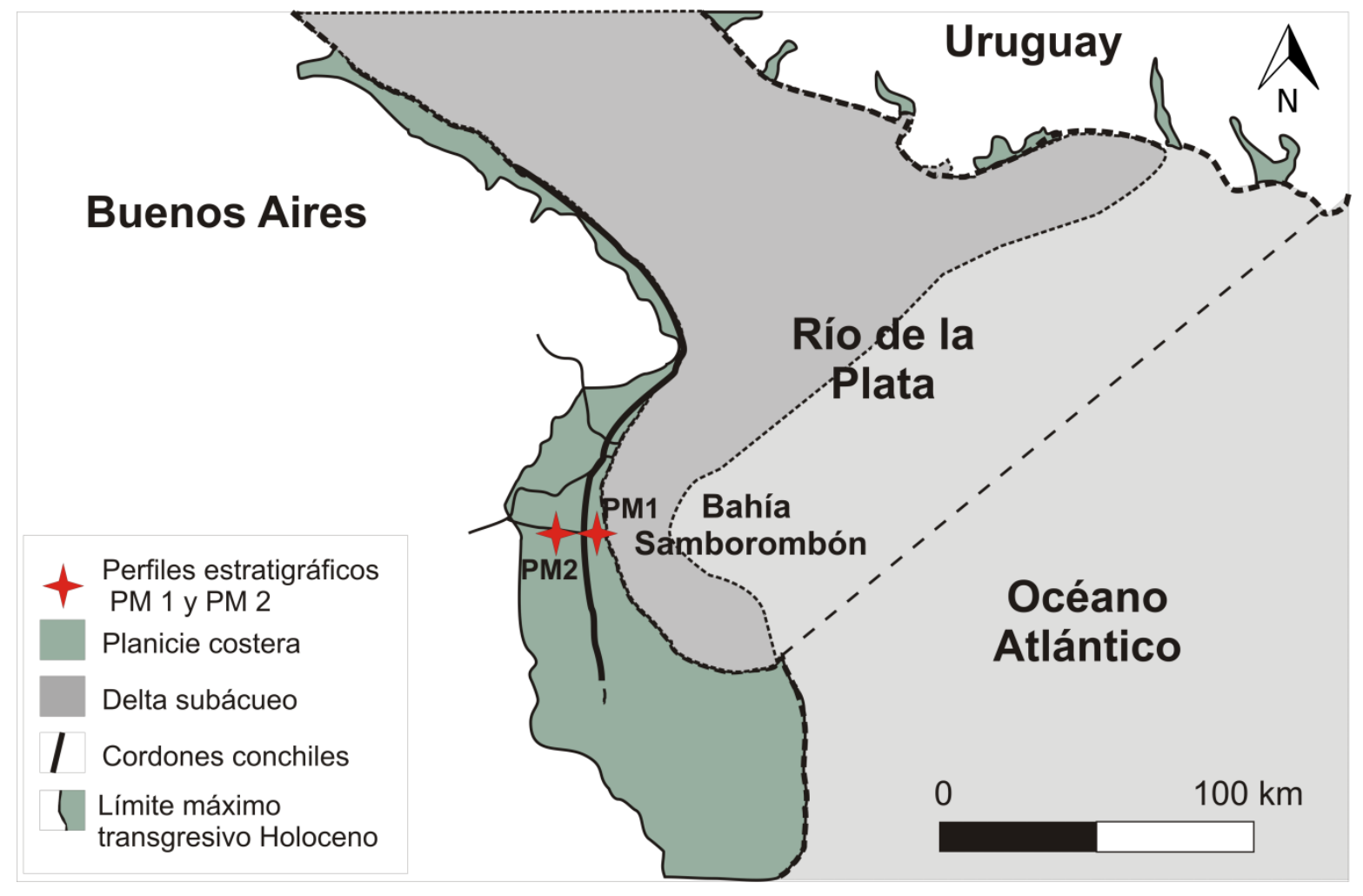

Figura 5. 1. Mapa geomorfológico regional y de ubicación de las secuencias sedimentarias PM1 y PM2 (modificado de Cavallotto, 2002) 


\section{2-PM2. Cambios ambientales durante el evento transgresivo entre 6800 y 5500 años cal AP en el sector central de la Bahía Samborombón.}

\subsection{1.-Resultados}

\subsubsection{1-Análisis palinológico}

Los resultados del análisis palinológico se presentan en gráficos de porcentaje y concentración polínica total (Figura 5.1). Las sumas palinológicas totales variaron entre 403 y 1105 palinomorfos por muestra y las sumas polínicas entre 226 y 405 granos de polen por muestra. La concentración polínica total (granos $/ \mathrm{cm}^{3}$ ) es muy baja a lo largo de la secuencia variando desde 923 a 7058 (Figura 5.2 y 5.3).

El diagrama polínico mostró que las familias Chenopodiaceae y Poaceae son los taxones dominantes del registro alcanzando valores de $75 \%$ y $43 \%$ respectivamente. Acompañan a estos taxones, polen de las familias Ranunculaceae con valores de hasta $18 \%$ y Asteraceae con valores de $4 \%$, junto con Celtis sp. que alcanza valores de $10 \%$. En cuanto a los quistes de dinoflagelados, Operculodinium spp. presenta los valores más altos hacia el techo de la secuencia sedimentaria con valores de $\sim 58 \%$; mientras que, Spiniferites spp. muestra valores fluctuantes entre $\sim 2 \%$ y $11 \%$ hacia la mitad de la secuencia (Figura 5.1).

De acuerdo con el análisis de agrupamiento (CA) el espectro palinológico se divide en dos zonas PM2-P1 y PM2-P2 y dos sub-zonas PM2-P1.1, PM2-P1.2 (Figura 5.1 y 5.2), las cuales se describen a continuación:

Zona PM2-P1 $(261-181 \mathrm{~cm})$

Sub-zona PM2-P1.1 (261-231 cm): el espectro está caracterizado por el dominio de Chenopodiaceae (52-75\%) y Poaceae (12-26\%), acompañados por Ranunculaceae (hasta 13\%), Asteraceae, Cyperaceae y Typha ( $\leq 3 \%)$. Limonium brasiliense se registra casi a lo largo toda la sub-zona y presenta valores traza ( $\leq 2 \%)$. Celtis alcanza valores de $6 \%$, mientras que Schinus y Ephedra tweediana presentan valores traza $(\leq 5 \%)$. Se registran las briofitas Phaeoceros spp. ( $5 \%$ ) y Ricciaceae ( $\leq 1 \%$ ). Los dinoquistes Operculodinium spp. y 
Spiniferites spp. presentan valores fluctuantes a lo largo de la sub-zona (entre 11-33\% y entre $3-10 \%$, respectivamente). Operculodinium spp. registra los valores más bajos de todo el perfil. Acritarcos presentan valores traza aunque alcanzan un pico de $15 \%$. La concentración polínica total es baja a muy baja y varía entre 949 a 7058 granos $/ \mathrm{cm}^{3}$. Se registró un clump polínico de Gomphrena.

Sub-zona PM2-P1.2 (226-181 cm): el espectro está caracterizado por valores fluctuantes de Chenopodiaceae y Poaceae ( $20-64 \%$ y $19-43 \%$ respectivamente), acompañados por Ranunculaceae (2-18\%), Asteraceae, Cyperaceae y Typha (3\%) y Celtis, Schinus, Ephedra tweediana y otros árboles y arbustos con valores traza ( $\leq 5 \%)$. Limonium brasiliense se registra en un sólo nivel de la sub-zona, con valores traza $(\leq 1 \%)$. Se hace presente en esta sub-zona el helecho acuático Azolla filiculoides (fragmentos de másulas), Myriophyllum, ambos con valores traza ( $\leq 5 \%)$ y las algas Botryococcus y Zignemataceae con valores traza. Se registran Phaeoceros spp. (3-8\%), Anthoceros y Ricciaceae como trazas ( $\leq 2 \%)$. En esta sub-zona ocurre un gradual y notable aumento hacia el tope en las proporciones de Operculodinium spp., que varían entre 22-60\%: mientras que, Spiniferites spp. fluctúa entre valores que van de 2 a 11\%. Se registran clumps polínicos de Poaceae y Asteraceae (Tipo Baccharis). La concentración polínica varía de 923 a 3885 granos $/ \mathrm{cm}^{3}$ alcanzando valores máximos de 6685 granos $/ \mathrm{cm}^{3}$ (Figura 5.1).

Zona PM2.P2 (176-156 cm): el espectro está caracterizado por valores fluctuantes de Chenopodiaceae (6-64\%) y Poaceae (10-27\%), acompañados por Caryophyllaceae (12$10 \%)$ Ranunculaceae (7-35\%) y que alcanza los valores máximos a lo largo de la secuencia, Cyperaceae incrementa ligeramente $(\sim 4 \%)$, Asteraceae y Typha presentan valores traza ( 3\%). Celtis aumenta a $\sim 9 \%$, Schinus, Ephedra tweediana y otros árboles y arbustos continúan con valores traza ( $\leq 5 \%)$. Limonium brasiliense, Azolla filiculoides (fragmentos de másulas) y las algas Botryococcus y Zignemataceae presentan valores traza $(\leq 1)$. Phaeoceros spp. presenta valores $\leq 5 \%$, Anthoceros y Ricciaceae registran valores traza. En esta zona continúa un gradual y constante aumento en las proporciones de Operculodinium spp., que alcanza los mayores valores de toda la secuencia (hasta $58 \%$ ): 
mientras que las proporciones de Spiniferites spp. disminuyen considerablemente ( $4 \%)$. La concentración polínica total disminuye valores de $\sim 3400$ y $\sim 1000$ granos $/ \mathrm{cm}^{3}$. Se registraron clumps polínicos Poaceae y Ranunculaceae. 


\section{PM 2}

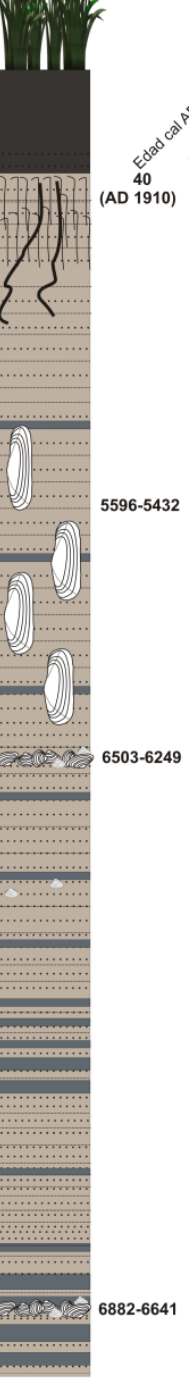

Arcilla

ESTÉRIL

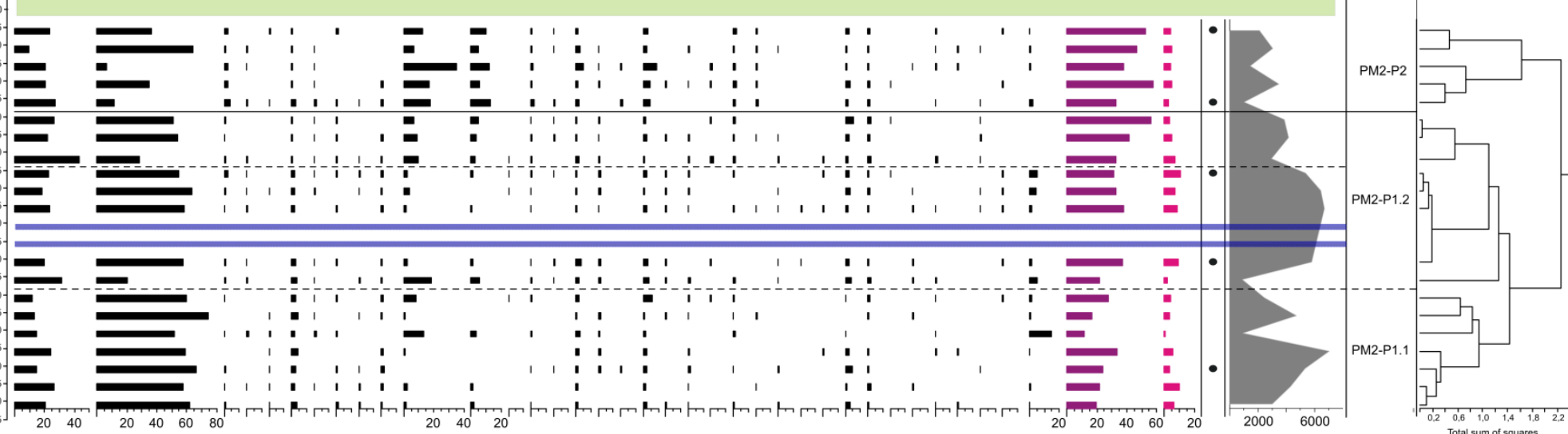


Figura 5.2. Diagrama polínico en porcentaje, concentración polínica total (granos $/ \mathrm{cm}^{3}$ ) y análisis de agrupamiento (CA) de PM2. Perfil estratigráfico y edades radiocarbónicas de la secuencia sedimentaria PM2, ubicada en Canal 15, Bahía Samborombón (35³6'8.23"S/57²15'32.52"O).

\subsubsection{2- Cronología de la secuencia sedimentaria.}

La cronología de la secuencia está basada en tres dataciones radiocarbónicas, dos sobre Mactra isabelleana y una sobre materia orgánica (Tabla 3.3, Capítulo 3) e indican que la sección estudiada representa el intervalo entre 6800 y 5500 años cal AP. Los resultados del modelo de edad-profundidad realizado para PM2 se muestran en la figura 5.3 junto con el perfil estratigráfico y el espectro palinológico. 


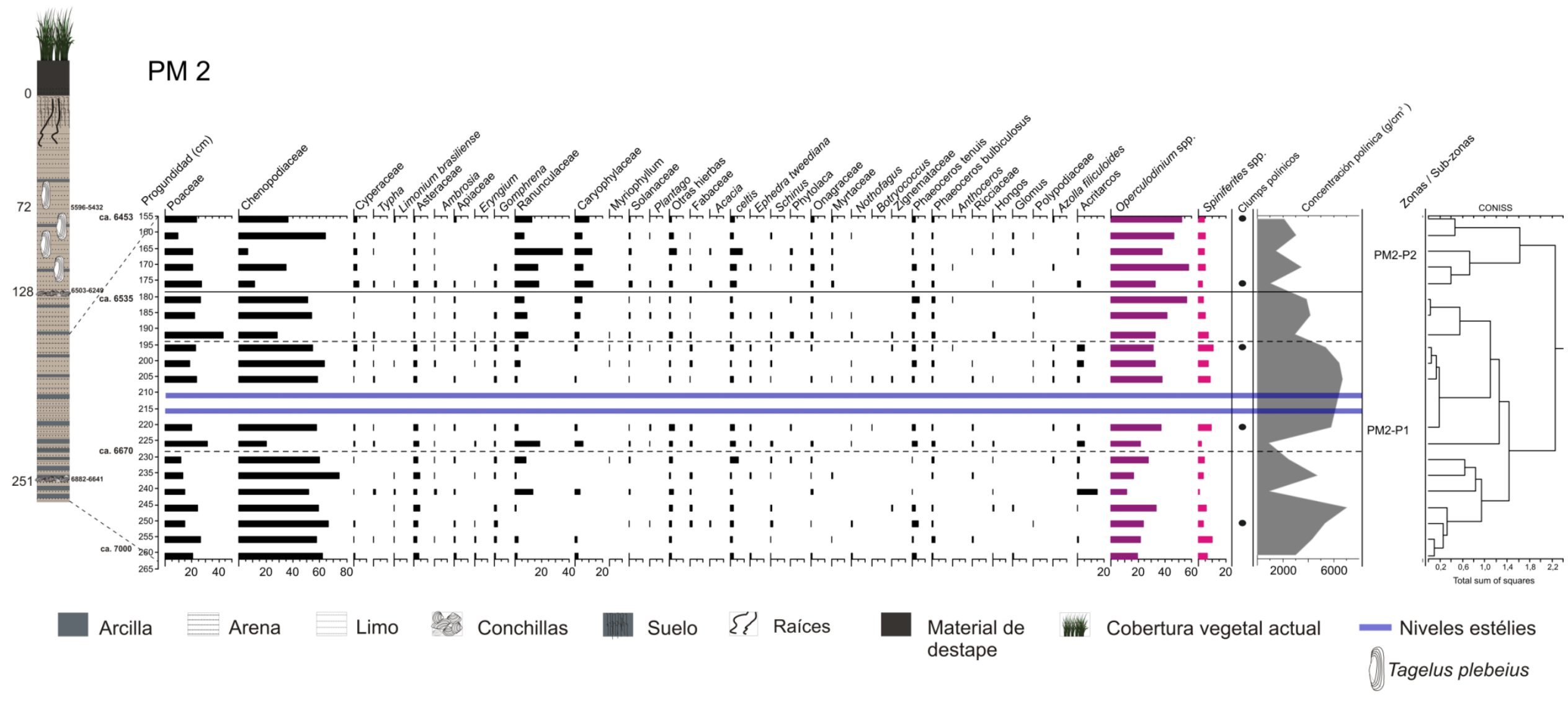


Figura 5.3. Diagrama polínico en porcentaje, concentración polínica total (granos $/ \mathrm{cm}^{3}$ ) resumido y análisis de agrupamiento (CA) de PM2. Perfil estratigráfico y edades radiocarbónicas de la secuencia sedimentaria PM2. Asteraceae incluye los tipos Baccaris, Senecio y Cichorioideae. Otras hierbas: Lamiaceae, Brassicaceae, Convolvulaceae, Geraniaceae, Malvaceae, Alternanthera. Arbustos árboles: Acacia, Ephedra tweediana, Fabaceae (Caesalpinioideae y Papilionoideae), Schinus, Celtis y Phytolacca. Algas coloniales: Botryococcus y Zignemataceae. Briofitas: Ricciaceae, Phaeoceros tenuis, P. bulbiculosus y Anthoceros. Hongos: Glomus y esporas undiff.

\subsubsection{3.-Análisis de Correspondencia sin tendencia (DCA).}

El ordenamiento espacial de los datos fósiles y actuales mediante el análisis de DCA (Figura 5.4) agrupa todas las muestras provenientes del PM2 en los cuadrantes derechos (inferior y superior), y presentan valores positivos en el eje 1. Este análisis indica que, la mayoría de las muestras fósiles, no presentan similitudes con aquellas de superficie a excepción de unos pocos niveles fósiles que poseen similitud con algunas muestras de la marisma media. Estas muestras fósiles corresponden a las $\mathrm{m}$ basales en el perfil estratigráfico (entre los niveles cm 261 y 231), que se ubican en el cuadrante superior derecho del gráfico bidimensional del DCA, están determinadas principalmente por las variables Limonium brasiliense y Spiniferites spp. (Figura 5.4).

Además, los niveles fósiles agrupadas en la zona PM2-P2 se ubican mayormente en el cuadrante inferior derecho y no presentan analogía con las muestras de superficie. Este grupo está caracterizado por las variables Operculodinium spp. y Phaeoceros (Figura 5.4).

\subsection{2.- Discusión}

\section{Comparación de muestras actuales y fósiles mediante análisis multivariado (DCA)}

Los espectros palinológicos (polen y PNP) de los niveles superiores de la secuencia $(155-186 \mathrm{~cm})$ no tienen similitudes con los espectros actuales. Esto puede ser debido a que el ambiente y la vegetación del pasado (6700-6500) no se desarrollan en la actualidad. 
La distribución de las muestras fósiles en el DCA refleja que los cambios paleoambientales son principalmente en salinidad del agua; pasando de un ambiente con moderada influencia de las mareas a otro de alta influencia mareal.

Esta ausencia de analogía con espectros modernos se relaciona con la alta cantidad de elementos acuáticos marinos, especialmente la alta proporción de dinoquistes, lo cual implica una mayor influencia marina que la actual vinculado posiblemente a ambientes abiertos. 


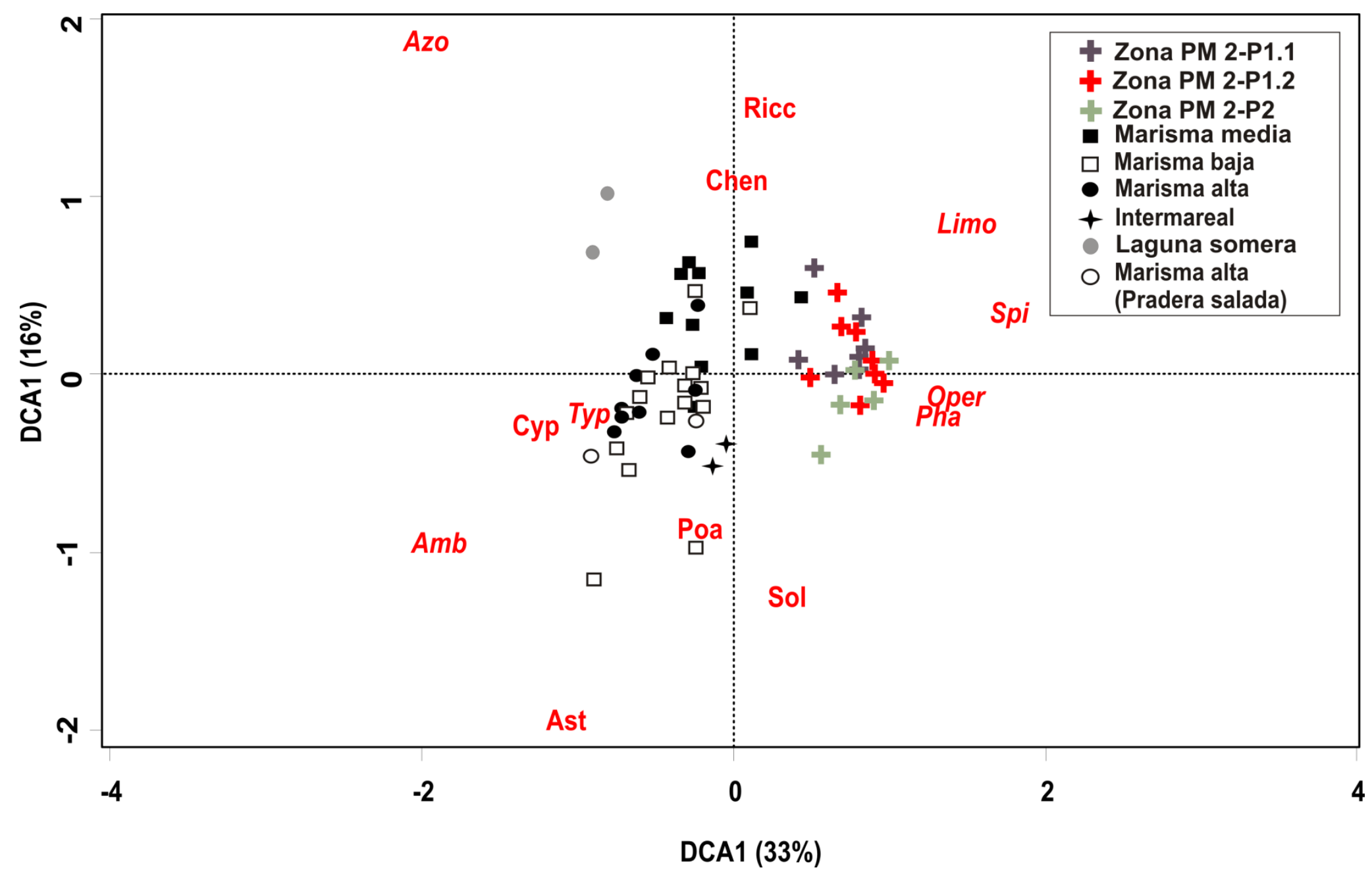


Figura 5.4. DCA de las muestras palinológicas de 40 muestras de superficie y 20 muestras fósiles de la secuencia PM1. Ordenamiento espacial de los 13 tipos palinológicos considerados para el análisis, a lo largo de los dos primeros ejes de ordenación. Referencias: Poa: Poaceae, Cheno: Chenopodiaceae, Limo: Limonium brasiliense, Cyp: Cyperaceae, Typ: Typha, Ast: Asteraceae, Amb: Ambrosia, Sol: Solanaceae, Pha: Phaeoceros, Ricc: Ricciaceae, Oper: Operculodinium spp., Spi: Spiniferites spp., Azo: Azolla filiculoides.

\section{Cambios de la vegetación y reconstrucción paleoambiental durante la fase transgresiva del nivel del mar en la actual franja costera del sector central de la Bahía Samborombón.}

El inicio de la transgresión marina Holocena que siguió al Último Máximo Glacial ocurrió hace 18000 a 20000 años AP (Violante et al., 2001) cuando el mar avanzó desde una posición de 100-120 m por debajo del nivel actual a una velocidad promedio de 1 cm/año. Comenzó invadiendo la actual plataforma con la generación, mediante procesos erosivos, de la superficie de transgresión o ravinement.

Luego de los 8000 años AP y con el mar en continuo ascenso, en el ámbito de la Bahía Samborombón se desarrollan extensas llanuras de mareas, playas, lagunas costeras (Violante et al., 2001; Fucks et al., 2010) que en la zona central de la Bahía constituyeron importantes depósitos agrupados bajo la unidad litoestratigráfica Mb. Destacamento Río Salado de la Formación Canal de las Escobas (Fucks et al., 2010).

Según las curvas del nivel relativo del mar realizadas por varios autores (e.g. Isla, 1989; Cavallotto et al., 2004; Prieto et al. (2017), entre otros) a 7000 años cal AP dicho nivel se situaba en una posición semejante al actual. En este contexto transgresivo es que comienza la depositación de la secuencia sedimentaria PM2 con un nivel relativo del mar de $\sim+3$ m (Prieto et al., 2017) a 6800 años cal AP. Los sedimentos de esta unidad fueron agrupados por Fucks et al. (2010) cómo Mb. Canal 18 de la misma unidad formacional Canal de las Escobas el cual ha sido interpretado por estos autores como llanuras de mareas en ambientes abiertos. Fechados sobre Tagelus plebeius registrados en esta unidad varían entre 6803-6372 años cal AP a 5596-5432 años cal AP según (Tabla 3.1 y Tabla 3.3, Capítulo 3). 
El registro multi-proxy de la secuencia sedimentaria PM2 permitió establecer los cambios ambientales entre 6800 y 5500 durante la etapa transgresiva del nivel del mar, los cuales se describen a continuación mediante intervalos cronológicos:

Con anterioridad a 6800 años cal AP y hasta 6670 años cal AP El registro polínico refleja el desarrollo de comunidades halófitas de marisma. Esta vegetación estaba caracterizada por Chenopodiaceae (probablemente representando a Sarcocornia perennis) y Poaceae (probablemente Sporobolus spp.), acompañadas por Asteraceae, Ranunculaceae, entre otras. S. perennis y Sporobolus spp. son especies pioneras en la colonización de ambientes de llanuras mareales debido a su tolerancia a ser cubiertas por agua salobre durante largos periodos de tiempo. La dominancia de Chenopodiaceae (hasta $70 \%$ ) junto con el registro de Limonium brasiliense estarían evidenciando un ambiente de marisma media a alta, con variaciones en la salinidad y exposición aérea en relación a la frecuencia y duración de las inundaciones de la zona por parte de las mareas en un ambiente de llanura de mareas abierto. Según el DCA, la asociación polínica registrada en este intervalo presenta leve similitud con aquellas de ambientes de marisma media desarrolladas en la actualidad (Figura 5.4).

El registro de los géneros arbóreos Celtis y Schinus, indica su presencia en el area con anterioridad al desarrollo de los cordones conchiles (ca. 5300), por lo cual podrían estar asociados a elevaciones del terreno como médanos o lunettes como los encontrados por Colado et al. (1995). Por otra parte, el registro de esporas de Ricciaceae podrían asociarse a cuerpos de agua someros en los alrededores/ cercanías de la marisma (Luengo et al., 2018). Los dinoquistes Operculodinium spp. y Spiniferites spp., junto con acritarcos, reflejan una significativa influencia de las mareas en un ambiente marino costero (Figura 5.3).

La presencia de sedimento arcillo-arenoso con estratificación paralela, pero con predominio de la fracción arcilla, refleja la alternancia de eventos de tracción y decantación sugiriendo la acción de las mareas en un ambiente de baja energía de llanura costera (Richiano et al., 2012). Además, las fluctuaciones en la concentración polínica total 
(desde 949 a 7058 granos $/ \mathrm{cm}^{3}$ ) registradas en este intervalo pueden deberse a esta alternancia en la litología (Figura 5.2) siendo más propicio para la preservación de los palinomorfos los sedimentos de textura fina.

El registro de un nivel de conchillas de pocos centímetros de espesor indica un evento de alta energía, probablemente un depósito de tormenta (6882-6641). El molusco dominante de esta asociación es Mactra isabelleana y el análisis de los atributos tafonómicos de las valvas sugieren un rápido enterramiento ya que la mayoría se preservaron enteras, unas pocas articuladas y además presentaron disposición caótica.

En resumen, con anterioridad a 6800 años cal AP y hasta 6670 años cal AP, el registro palinológico junto con las evidencias litológicas sugieren un ambiente estuárico de baja energía, influencia marina significativa y el desarrollo de una marisma media a alta, posiblemente abarcando gran extensión similar a la de la actualidad en la zona central de la Bahía; relacionado con la configuración topográfica del área. Según Prieto et al. (2017) durante este intervalo de tiempo, el nivel relativo del mar en el estuario del río de la Plata se encontraba en ascenso, alcanzando los $\sim+3 \mathrm{~m}$ a $\sim 6800$ años cal AP.

Entre 6670- 6535 años cal AP.

El registro muestra el aumento de Poaceae y un leve descenso de Chenopodiaceae y estaría evidenciando el pasaje de una marisma media a una marisma baja. El gradual incremento de Operculodinium spp. y Spiniferites spp. (hasta 40-60\%) indica la mayor influencia marina posiblemente vinculada a nuevas posiciones de la línea de costa como respuesta al aumento del nivel del mar que continúa en este periodo.

Según el DCA, esta asociación palinológica no presenta análogo moderno, lo que puede explicarse por tratarse de ambientes con mayor influencia marina que los actuales (Figuras 5.4). Los géneros palustres como Typha y Cyperacecae (e.g. Carex, Cyperus, Schoenoplectus), junto con los elementos acuáticos que aparecen en este intervalo, como Myriophyllum, A. filiculoides (fragmentos de másulas sin gloquídeos) y las algas coloniales Botryococcus y Zignemataceae, sugieren la influencia de agua dulce-salobre (Figura 5.3). Posiblemente, tanto los taxones palustres como las algas coloniales sean de origen 
alóctono, y hayan sido transportados desde cuerpos someros de agua dulce a salobre, establecidos en las cercanías como sucede actualmente en el ambiente de la marisma baja de Bahía Samborombón.

La concentración polínica total es baja y disminuye hacia el tope de este intervalo (de $\sim 6700$ a 3800 granos $/ \mathrm{cm}^{3}$ ) e incluye niveles estériles (Figura 5.3). Esto puede deberse, p or un lado ala granulometría (alternancia de capas areno-limosas con capas arcillosas) que evidencia la energía fluctuante en un ambiente bajo acción de las mareas, y por otro lado, la lejanía de la fuente productora polínica que se re-ordena hacia el oeste de la secuencia en respuesta a un nuevo cambio en la posición de la línea de costa como consecuencia del continuo aumento del nivel del mar.

En resumen, el cambio de una vegetación de marisma media a una de marisma baja está reflejado por el aumento de Poaceae, una leve disminución de Chenopodiaceae y el gradual incremento en las proporciones de los elementos marino-estuariales como Operculodinium spp. (Figura 5.3). Este ambiente transicional se debe a la creciente influencia de mareas en respuesta al aumento del nivel del mar que alcanza los +3 y +3.5 $m$ en el periodo 6670 -6535 años cal AP (Prieto et al., 2017). Este cambio en las comunidades halófitas ocurre a $\sim 10 \mathrm{~km}$ de la costa actual (Figura 5.2).

Entre 6535 a 6453 años cal AP.

En este intervalo continúa el predominio de una vegetación de marisma bajo significativa y creciente influencia marina, en las cercanías a un ambiente depositacional intermareal a submareal como reflejan las más altas proporciones de Operculodinium spp. a lo largo de toda la secuencia (Figura 5.3). $\quad$ Además, la gradual y constante disminución de la concentración polínica total estaría reflejando, por un lado la lejanía entre la fuente y el ambiente depositacional, vinculado al continuo aumento del nivel del mar cambiando la posición de la línea de costa hacia el Oeste. Por otro lado, un cambio en la energía del ambiente se refleja en la mayor proporción de arenas en la secuencia en detrimento de la fracción fina (arcillosa).

La vegetación halófita coexiste con comunidades de agua dulce como indicarían el aumento de Cyperaceae y las trazas de Typha representando comunidades como juncales 
(Figura 5.3), mientras que la creciente representación de Ranunculaceae en el espectro podría estar reflejando el desarrollo de comunidades herbáceas relacionadas a bosques de tala como indicaría la mayor representación de Celtis en el espectro.

A partir de 6453 años cal AP, el registro palinológico es escaso., y se destaca la abundancia de Tagelus plebeius con valvas articuladas en su mayoría y en posición de vida, que corresponden a asociaciones autóctonas preservadas in situ (Figura 3.17, Capítulo 3 y Figura 5.3). T. plebeius es una especie infaunal eurihalina que habita en los márgenes de estuarios o bahías, puede vivir en el rango que va desde $90 \mathrm{~cm}$ por sobre el nivel de mareas y $30 \mathrm{~cm}$ por debajo del mismo (Holland y Dean, 1977). Son excavadores profundos pudiendo alcanzar hasta $75-80 \mathrm{~cm}$ de profundidad, en ambientes donde la sedimentación es lenta, indicando mayor estabilidad (Holland y Dean, 1977). La presencia de estos moluscos estaría indicando ambientes de laguna costera o ambiente de estuarios de baja energía. Además, este registro coincide y es coherente con un periodo en el cual el nivel relativo del mar se encuentra estable.

Por encima del nivel de T. plebleius depósitos areno-limosos masivos sin restos de moluscos ni microfósiles podrían ser producto de los procesos de sobrelavado que se desarrollan por detrás de los cordones conchiles (Richiano et al., 2012), pero también podría ser el resultado del retrabajo de procesos eólicos, deflacionados de los cordones y médanos. Luego, el desarrollo de procesos pedogenéticos se evidencia por la presencia de un suelo en el techo de la secuencia con estructuras prismáticas a columnares, colores oscuros y presencia de raíces. Este suelo es cubierto por material de destape proveniente de la construcción del Canal 15 a principios del siglo XX (Figura 5.3). 


\subsection{3.-Conclusiones}

El análisis palinológico del sector central de Bahía Samborombón permitió establecer la evolución paleoambiental durante la fase transgresiva del nivel del mar en el Holoceno Medio, mostrando los cambios desde un ambiente de marisma media a alta bajo una significativa influencia mareal, a un ambiente submareal-intermareal desarrollado en extensa llanura de mareas en un ambiente abierto. Esta evolución se evidenció mediante:

Transición de una marisma media a alta, a una marisma media como una rápida respuesta de las comunidades vegetales a un cambio en la posición de la línea de costa como resultado del evento transgresivo durante el Holoceno medio.

El predominio de la fracción arenosa (gruesa) en el registro, hizo que no sea un buen archivo para establecer los cambios de la vegetación en base al registro palinológico.

El gradual aumento de los dinoquistes en particular de Operculodinium, hasta alcanzar los valores máximos a los 6400 indicando un aumento gradual de la influencia marina y aumento en la salinidad como consecuencia del continuo aumento del nivel del mar.

A partir del los 6400 el aumento en la granulometría indicaría un aumento en la energía del ambiente, y la consecuente esterilidad en el registro aunque las inferencias paleoambientales pueden establecerse por medio de otros registros proxy como las asociaciones de moluscos, litología, estructuras sedimentarias. 
5. 3.-PM1. Cambios ambientales durante los últimos 2700 años AP en la franja costera del sector central de la Bahía Samborombón.

\subsection{1.-Resultados}

\subsubsection{1.-Análisis palinológico}

Espectro palinológico actual de sedimentos superficiales de cuerpo de agua somero LEM 1 Y LEM 2 (Figura 5.5)

El espectro palinológico de las muestras superficiales del sitio LEM (LEM 1 Y 2) está representado por Chenopodiaceae ( 67-75\%), Poaceae (12-17\%), Cyperaceae y Asteraceae (3-5\%). Apiaceae junto con Ambrosia, Asteraceae, Typha, Solanaceae, Celtis presentan valores traza ( $\leq 5 \%)$. El helecho acuático $A$. filiculoides presenta valores entre 15 y $20 \%$. Se registran también microforaminíferos de pared orgánica $2 \%$. La concentración polínica es de 161130 y 81847 granos $/ \mathrm{cm}^{3}$. Se registran también hongos (hasta 3 \%), algas Botryococcus y Zignemataceae, y briofitas Ricciaceae con valores traza (Figura 5.5).

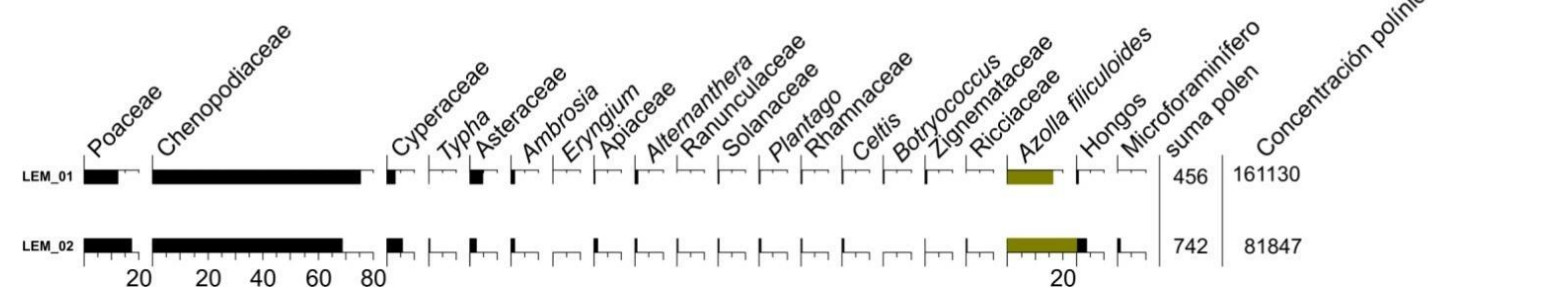

Figura 5.5. Diagrama polínico en porcentaje y concentración polínica total $\left(g r a n o s / \mathrm{cm}^{3}\right)$ de las muestras LEM 1 Y 2. 
PM1. Espectro palinológico de la secuencia sedimentaria (Figura 5.6)

Los resultados del análisis palinológico se presentan en gráficos de porcentaje y concentración polínica total (Figura 5.6). Las sumas totales variaron entre 563 y 2765 palinomorfos por $/ \mathrm{cm}^{3}$ y las sumas polínicas entre 234 y 803 granos de polen $/ \mathrm{cm}^{3}$. La concentración polínica total (granos/cm3) varió desde 4441 a 144653 a lo largo de todo el perfil.

El diagrama polínico mostró que las familias Chenopodiaceae y Poaceae son los taxa dominantes del registro alcanzando valores de $45 \%$ y $80 \%$ (Figura 5.6). Acompañan a estos taxones, Cyperaceae con valores de hasta $20 \%$ y Asteraceae con valores de $10 \%$, junto con Celtis sp. con valores de $\sim 5 \%$. En cuanto a los quistes de los dinoflagelados; Operculodinium spp. y Spiniferites spp.presentan los valores más altos en la base de la secuencia sedimentaria, con valores entre $\sim 15 \%$ y $60 \%$ respectivamente, pero mostrando una tendencia decreciente hacia el tope de la secuencia. Por el contrario, Azolla filiculoides muestra una tendencia a incrementar de base a techo con proporciones que alcanzan valores de $80 \%$ (Figura 5.6 ).

De acuerdo con el análisis de agrupamiento (CA) el espectro palinológico se divide en dos zonas PM1-P1 y PM1-P2 y tres sub-zonas PM1-P1.1a, PM1-P1.1b y PM1-P1.2 (Figura 5.6), las cuales se describen a continuación:

Zona PM1-P1 (117-30 cm).

Sub-zona PM1-P1.1a (117 - 97 cm): el espectro está caracterizado por Chenopodiaceae (ca. 55\%) y Poaceae (35\%), acompañados por Cyperaceae y Asteraceae y Typha con valores de entre 3-7\%, Celtis, Schinus, Ephedra tweediana con valores traza. Gloquidios de $A$. filiculoides con valores de $\leq 10 \%$; Phaeoceros spp. y Botryococcus presentan valores traza ( $\leq 5 \%)$, los dinoquistes Operculodinium spp. y Spiniferites spp. presentan los valores más altos de todo el perfil (60\% y $10 \%$, respectivamente). La 
concentración polínica varía de 4400 a 7000 granos $/ \mathrm{cm}^{3}$, alcanzando valores máximos de ca. 9000 granos $/ \mathrm{cm}^{3}$, presentando los valores mínimos de toda la secuencia sedimentaria.

Sub-zona PM1-P1.1b $(97-65 \mathrm{~cm})$ : el espectro está caracterizado por valores fluctuantes tanto de Chenopodiaceae como Poaceae (entre 40-50\% y 30-40\% respectivamente), acompañados por Cyperaceae y Asteraceae (3-7\% respectivamente), y Celtis, Schinus, Ephedra tweediana con valores traza $(\leq 5 \%)$. Limonium brasiliense se hace presente en esta sub-zona al igual que Myriophyllum, ambos con valores traza $(\leq 5 \%)$. $A$. filiculoides alcanza el $15 \%$ mientras que Phaeoceros spp., Anthoceros y el alga Botryococcus se registran como trazas ( $\leq 5 \%)$. Los valores de Operculodinium spp. varían entre $25-50 \%$ mientras que Spiniferites spp. fluctúa entre valores que van de 5 a $15 \%$. Hacia el final de la sub-zona se registran clumps polínicos de las familias Chenopodiaceae y Poaceae. La concentración polínica varía de 12000 a 17000 granos/cm³ y alcanza valores máximos de 30000 granos $/ \mathrm{cm}^{3}$.

Sub-zona PM1-P1.2 $(65-30 \mathrm{~cm})$ : el espectro palinológico está dominado por Chenopodiaceae, incrementando hacia el tope de la zona y con valores fluctuantes (5575\%). Poaceae disminuye al $15 \%$ con un pico de $35 \%$ cerca del nivel PM1 $50 \mathrm{~cm}$. Asteraceae incrementa ligeramente ( 10\%); acompañan Celtis , Schinus, Ephedra tweediana con valores ( $\leq 5 \%)$. Phaeoceros spp. con valores $\leq 5 \%$ y Ricciaceae se hace presente en esta sub-zona con valores traza. Se registran clumps polínicos de las familias Chenopodiaceae, Poaceae. Por otro lado A. filiculoides (másulas y gloquidios) alcanzan valores de 40-50\%, mientras que Operculodinium spp. y Spiniferites spp. muestran una tendencia decreciente gradual (a $10-15 \%$ y a $\leq 5 \%$ respectivamente). La concentración polínica aumenta de 17000 a 53000 granos $/ \mathrm{cm}^{3}$, 
Zona PM1.P2 (30-0 cm): Chenopodiaceae varía entre 35 y 75\% y Poaceae entre valores que van de 10 a 40\%. Cyperaceae y Ambrosia incrementan hacia la parte superior de la zona, alcanzando valores de $20 \%$ y $10 \%$ respectivamente. Acompañan Celtis (7\%), Schinus y Ephedra tweediana continúan con valores traza ( $\leq 5 \%)$. Es en esta subzona donde ocurre un gradual y notable aumento en las proporciones de A. filiculoides (másulas y gloquidios) alcanzando un $80 \%$. Se registraron numerosos clumps polínicos de las familias Chenopodiaceae, Poaceae, Asteraceae y del género Ambrosia. Operculodinium spp. y Spiniferites spp. disminuyen considerablemente, los primeros hasta $\leq 5 \%$ y los segundos a trazas. La concentración polínica varía entre los 56000 a 116150 granos $/ \mathrm{cm}^{3}$, mostrando los valores máximos a lo largo de toda la secuencia. 


\section{PM 1}

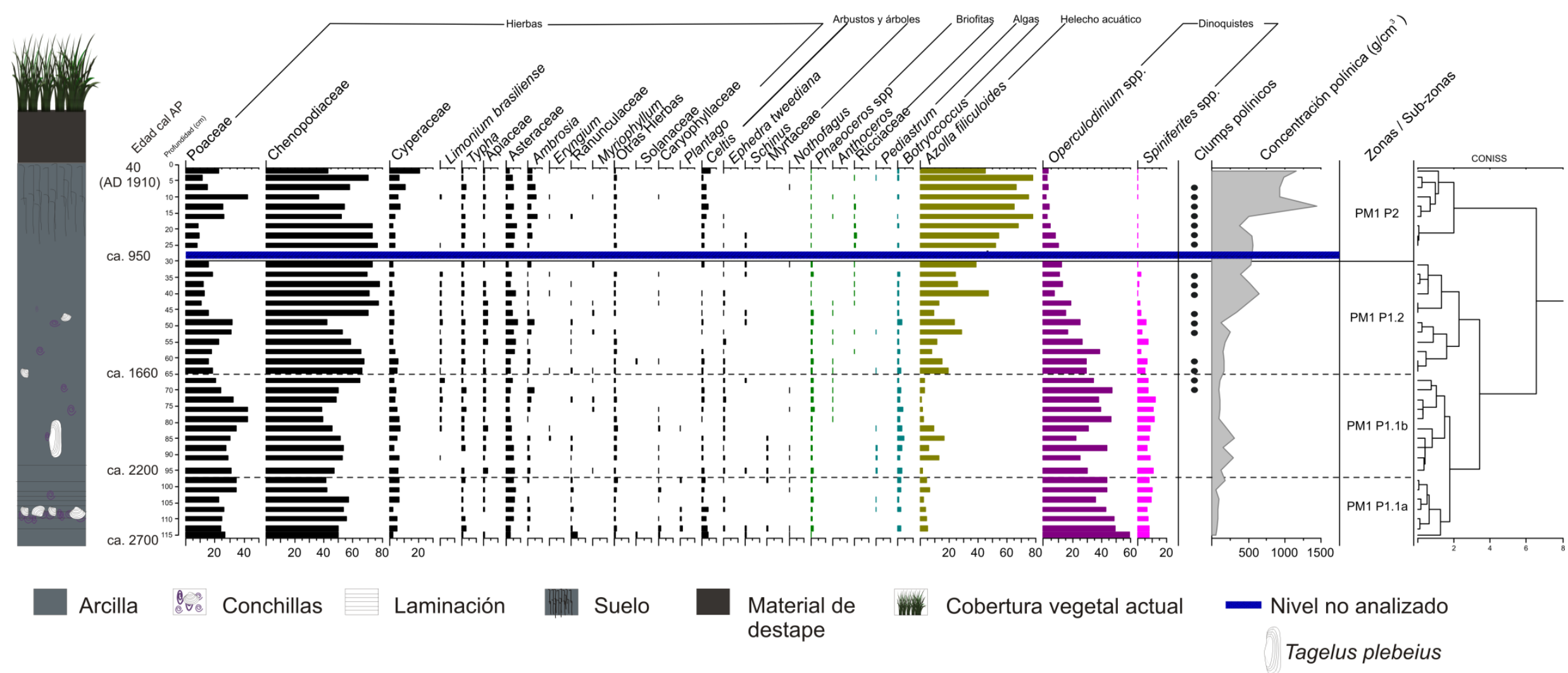

Figura 5.6. Diagrama polínico en porcentaje, concentración polínica total (granos $/ \mathrm{cm}^{3}$ ) y análisis de agrupamiento (CA) de PM1. Perfil estratigráfico y edades

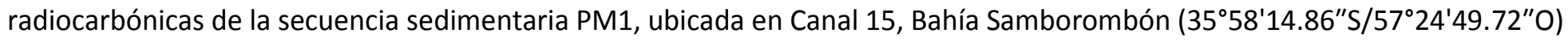




\subsubsection{1.-Cronología de la secuencia sedimentaria PM1.}

La cronología de la secuencia está basada en tres dataciones radiocarbónicas, dos sobre Mactra isabelleana y una sobre materia orgánica (Tabla 3.3, Capítulo 3) e indica que la sección estudiada representa los últimos 2700 años AP. Un modelo de edad profundidad para PM1 se muestra en la Figura 5.7.
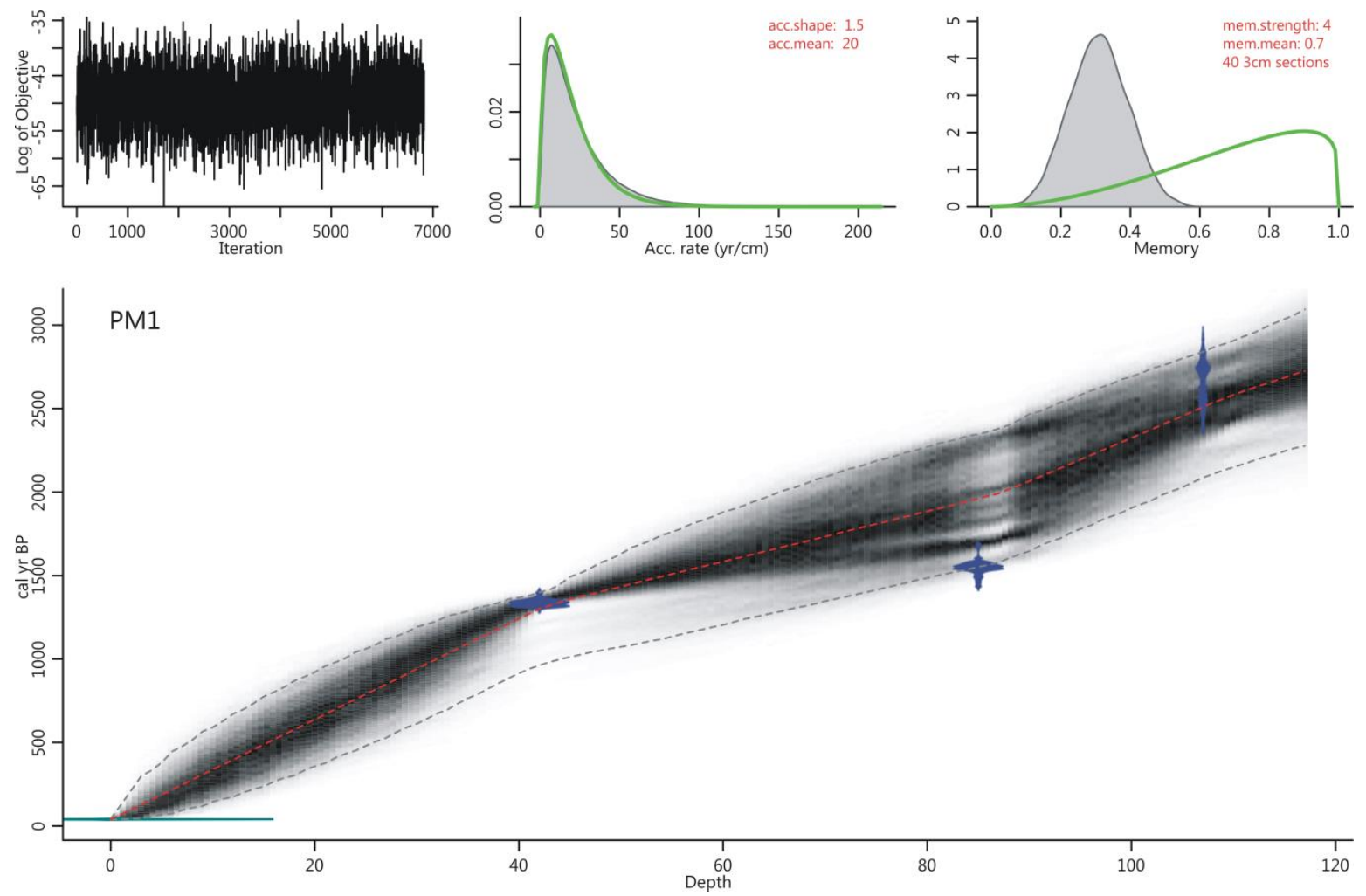

Figura 5. 7. Modelo de edad-profundidad de la secuencia PM1 realizado con el programa Bacon. Los paneles superiores representan las iteraciones de Markov Chain Monte Carlo (MCMC) (izquierda), anteriores (curvas verdes) y posteriores (histogramas grises) distribuciones de tasa de acumulación (panel central) y memoria $\mathrm{R}$ (panel derecho). El panel inferior muestra el modelo de profundidad de edad (gris) y las fechas calibradas ${ }^{14} \mathrm{C}$ (azul). Las líneas grises despojadas indican los intervalos de confianza del 95\%; la curva roja muestra el "mejor" ajuste en función de la edad promedio ponderada para cada profundidad. 


\subsubsection{3.-Análisis de Correspondencia sin tendencia (DCA)}

El ordenamiento de las muestras fósiles y actuales mediante el análisis DCA se muestra en la figura 5.8. Las muestras fósiles agrupadas en la subzona PM1-P1.1, caracterizadas por Operculodinium spp. y Spiniferites spp. (Figura 5.8.B), se ubican en los cuadrantes izquierdos del gráfico bidimensional, en el cual se puede observar que dichas muestras fósiles no presentan similitud con las muestras provenientes de ambientes actuales.

Las muestras fósiles agrupadas en la subzona PM1-P1.2 se dividen en dos grupos a lo largo del eje 1 (Figura 5.8.A). Un grupo se ubica en el cuadrante superior izquierdo junto con las muestras de la subzona PM1 y dos muestras actuales que representan la marisma media. El otro grupo se ubica en el cuadrante superior derecho y tienen similitud con muestras de la marisma media, caracterizadas por Chenopodiaceae (Figura 5.8.B).

Por último, las muestras fósiles agrupadas como PM1-P1.2, ubicadas en el cuadrante superior derecho, no tienen similitud con los ambiente actuales excepto con las que representan el ambiente del cuerpo de agua somero; el cual está determinado por Azolla filiculoides.

\subsection{2.- Discusión}

\section{Comparación de muestras actuales y fósiles mediante análisis multivariado (DCA)}

En el gráfico bidimensional (Figura 5.8) se observa la separación de las muestras fósiles del PM1 en dos grupos a lo largo del eje 1. Por un lado, se encuentran las muestras basales (entre 117- $46 \mathrm{~cm}$ ) con valores negativos en el eje 1; y por el otro, las muestras de niveles superiores hasta el tope de la secuencia $(43-0 \mathrm{~cm})$, con valores positivos en el eje 1.

El grupo de muestras con valores positivos del eje 1 (cuadrante derecho superior) corresponden a las agrupadas por el CA en la zona PM1-P2. 
La distribución de las muestras fósiles y actuales a lo largo del eje 1 refleja el gradiente de salinidad y sugiere que los cambios paleoambientales son principalmente en salinidad; pasando de un ambiente de influencia exclusivamente mareal a otro sin alcance de las mareas, en donde predomina la influencia de agua dulce.

A su vez, los resultados indican que las muestras fósiles de la zona PM1-1.1 no presentan análogo moderno mientras que un subgrupo de las muestras de la zona polínica PM1-1.2 tiene analogía con aquellas muestras de superficie que representan a las comunidades halófitas dominadas por Chenopodiaceae de la marisma media (Figura 5.8). Las muestras de la zona PM1-2 se agrupan en el espacio junto con la muestra LEM 2, correspondiente a un ambiente depositacional de laguna somera (Figura 5.8).

Una de las razones por las cuales el espectro palinológico de las muestras basales no tengan análogo moderno puede deberse que el ambiente y la vegetación de ese momento no se repite en la actualidad o que no fue relevado durante el desarrollo del modelo. Esta ausencia de analogía con espectros modernos se relaciona con la alta cantidad de elementos acuáticos marinos, especialmente la alta proporción de dinoquistes correspondiendo a un ambiente submareal-intermareal; lo cual implica una mayor influencia marina que la actual. 

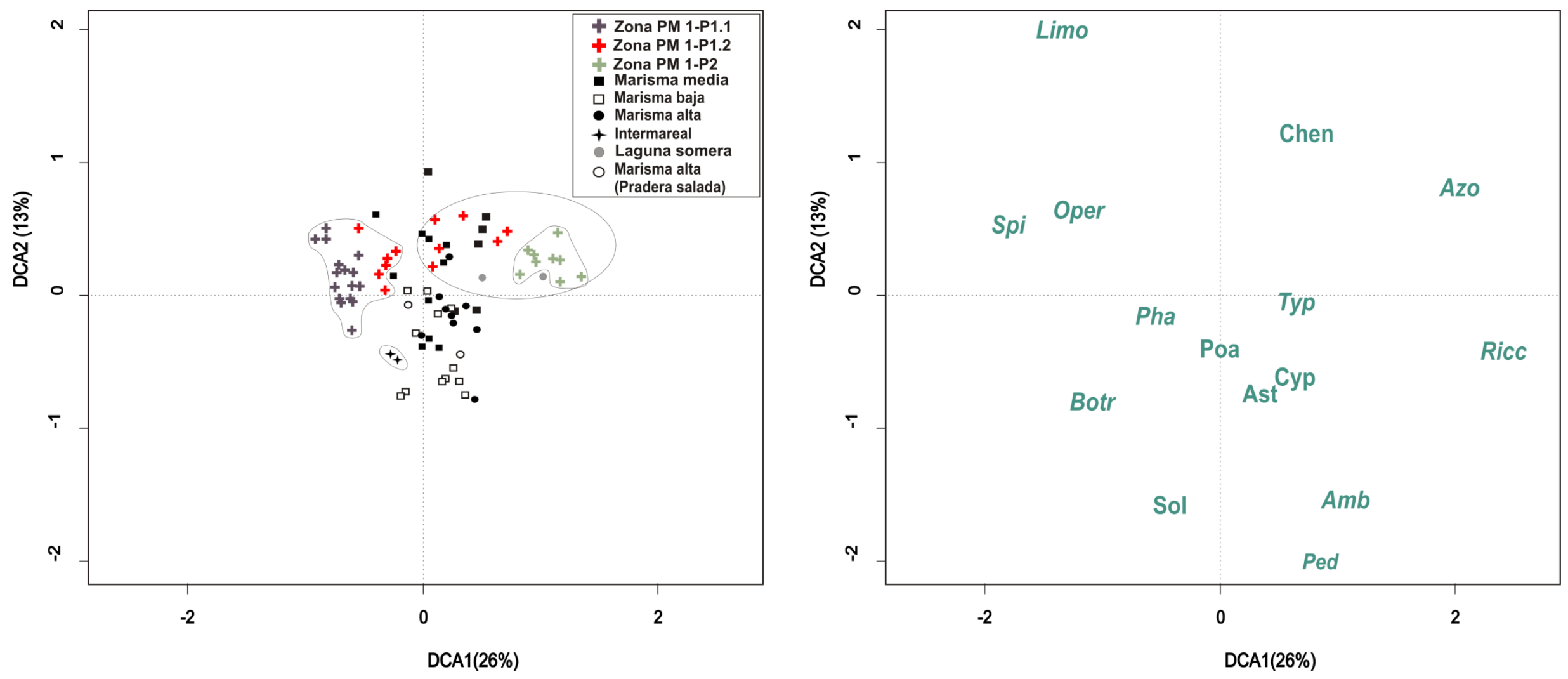

Figura 5.8. A- DCA de las muestras palinológicas de 40 muestras de superficie y 38 muestras fósiles de la secuencia PM1. B- Ordenamiento espacial de los 15 tipos palinológicos considerados para el análisis, a lo largo de los dos primeros ejes de ordenación. Referencias: Poa: Poaceae, Cheno: Chenopodiaceae, Limo: Limonium brasiliense, Cyp: Cyperaceae, Typ: Typha, Ast: Asteraceae, Amb: Ambrosia, Sol: Solanaceae, Ped: Pediastrum, Pha: Phaeoceros, Ricc: Riccia, Botr: Botriococcus, Oper: Operculodinium spp., Spi: Spiniferites spp., Azo: Azolla filiculoides. 
Cambios de la vegetación y reconstrucción paleoambiental durante los últimos 2700 años cal AP en la actual franja costera del sector central de la Bahía Samborombón

Después del máximo transgresivo Holoceno ( 6-5.5 ka), cuando el nivel relativo del mar alcanzó los $\sim+4 \mathrm{~m}$, comienza la fase regresiva del nivel del mar. Esto genera la constitución de diferentes ambientes como marismas y llanuras de mareas encerradas o parcialmente encerradas por el desarrollo de cordones de conchillas, desarrollados en la incipiente proto-Bahía Samborombón (Violante et al., 2001; 2004; Fucks et al., 2010). En la zona central de la Bahía los cordones regresivos que se agrupan bajo la unidad Mb. Cerro de la Gloria comenzaron a formarse durante los intervalos de tiempo de 5200-4900 años cal AP y 4600-4000 años cal AP (Tabla 3.1, Capítulo 3). Además, después de los 4000 años cal AP, la progradación costera ocurrió como resultado de un alto aporte de sedimentos finos provenientes de la descarga del Río de la Plata (Violante et al., 2001); éste fenómeno se ve reflejado en la creciente separación entre las sucesivas paleolíneas de costa que progradan hacia el Este (Figuras 3.7, Capítulo 3 y Figuras 5.9.A y 5.10). Además, de acuerdo a la evidencia geomorfológica y cronológica, a partir del periodo 3600-3338 cal AP y 2941-2726 tiene lugar la formación de cheniers aislados y desagregados en la zona Norte de la Bahía (Figura 3.4, Capítulo 3), asociados a paleolíneas de costa. Es en este contexto de progradación costera que comienza la depositacion de la secuencia PM1 (Figura 5.10.C), con un nivel relativo del mar de $\sim+2.5 \mathrm{~m}$ a los ca. 3000 años cal AP (Prieto et al., 2017).

El registro multi-proxy de la secuencia sedimentaria PM1 permitió la interpretación de varios escenarios ambientales durante la fase regresiva del nivel del mar del Holoceno Tardío, los cuales se describen a continuación en distintos lapsos de tiempo:

Durante el período 2700-1660 cal AP, la vegetación halófita de marisma predominaba en las cercanías de un ambiente de depositación intermareal-submareal en el actual sector costero, que, según el DCA no cuenta con un análogo moderno (Figura 5.8). Esta vegetación estaba caracterizada por Chenopodiaceae (probablemente 
Sarcocornia perennis) y Poaceae (probablemente Sporobolus spp.), acompañadas por Asteraceae (e.g. Baccharis, Ambrosia, entre otras). Por otra parte, el registro de Celtis, un género arbóreo, podría estar asociado a cordones de conchillas que se desarrollaban en las proximidades. Los géneros palustres como Typha y Cyperacecae (e.g. Carex, Cyperus, Schoenoplectus), junto con el helecho acuático $A$. filiculoides y las algas coloniales del género Botryococcus y Pediastrum, sugieren la influencia de agua dulce-salobre y alcalina (Figura 5.6).

Los dinoquistes Operculodinium spp. y Spiniferites spp. presentan los máximos porcentajes de todo el perfil reflejando una significativa influencia marina (Figura 5.12). El registro de foraminíferos se caracteriza por el predominio de la asociación de los géneros Elphidium y Ammonia (Luengo et al., 2018). El primero corresponde a organismos epifaunales habitando sustratos arenosos típicos de ambientes de plataforma y en profundidades que van de 0-50 m, también en ambientes salobres, marismas y lagunas costeras (Luengo et al., 2018). La asociación Elphidium-Ammonia se la ha registrado habitando ambientes de plataforma, aguas salobres a hipersalinas como en lagunas costeras (Murray, 2006) y ambientes de condiciones oligohalinas a mesohalinas, con salinidades que varían entre 5\% y $18 \%$ (Brewster-Wingard e Ishman, 1999). En Argentina, esta asociación se la ha registrado en ambientes estuáricos modernos (Calvo Marcilese, 2011; Calvo Marcilese et al., 2013), lagunas costeras (Márquez et al., 2016) y en planicies mareales al sur de la Bahía Samborombón (Laprida et al., 2011); también se la ha registrado en asociaciones de edad Holocena de ambientes de plataforma al sur de la zona de estudio (Laprida et al., 2007). Para la zona central de la Bahía Samborombón, el registro de Elphidium aff. poeyanum en asociación con Ammonia parkinsoniana estarían reflejando condiciones estuarinas en un ambiente marino costero de aguas poco profundas (Figura 5.9.A). Por otro lado, la presencia de dos especies infaunales pertenecientes al género Bolivina ( $B$. ordinaria y $B$. pseudoplicata) podría estar vinculada a un ambiente fangoso y de bajos niveles de oxígeno (Corliss y Chen, 1988). La alta abundancia de estos organismos durante este periodo probablemente se relacione con 
buenas condiciones para el desarrollo de los foraminíferos y una significativa influencia marina (Figuras 5.11 y 5.12 ).

Además, un nivel fosilífero de escasos centímetros, constituido por bivalvos y gastrópodos como: Mactra isabelleana, Heleobia australis, H. parchappii, Natica sp., estaría evidenciando posiblemente un episodio de tormenta en un ambiente intermareal. Análisis de los atributos tafonómicos realizados en ejemplares de Mactra isabelleana evidenciaron cierto grado de transporte y un importante grado de corrosión debido a la exposición de los restos, aunque sin llegar a producir un desgaste mecánico (fragmentación y pulido) de los mismos. Por encima de esta capa fosilífera, el registro de ejemplares de $T$. plebeius hallados con sus valvas articuladas y en posición de vida, junto con estructura sedimentaria de tipo laminar (alternancia de finas láminas de sedimento de tamaño limo a arcilloso) sugieren un ambiente estuarino de baja energía, submareal a intermareal (Tabla 3.2 y Figura 3.16, Capítulo 3).

Durante este periodo, hacia 2050 años cal AP, la presencia de Limonium brasiliense indica un ambiente de marisma media a alta, con variaciones en la salinidad y exposición aérea relacionados con la reducción en la frecuencia y duración de las inundaciones de la zona por parte de las mareas (Figura 5.6). La disminución de la influencia de las mareas se refleja en el escaso y disperso registro de conchillas de los géneros Heleobia y Mactra y de fragmentos biogénicos, todos de pequeño tamaño, junto con un cambio en la estructura sedimentaria pasando de laminar a masiva indicando posiblemente el mecanismo de pérdida de capacidad de transporte de las mareas al recorrer grandes distancias en una costa baja (Bértola, 1994) evidenciando además, la sucesión de ambientes producto de la progradación costera.

En resumen, para el intervalo de tiempo mencionado, el registro palinológico y de foraminíferos junto con las evidencias litológicas sugieren un ambiente de estuario con influencia marina significativa y con aporte de agua dulce; y el desarrollo/ surgimiento de una marisma madura/estable. Por otra parte, el cambio a un ambiente de marisma media a alta es evidenciado por la presencia de Limonium brasiliense y la gradual disminución de los dinoquistes y foraminíferos (Figuras 5.6 y 5.12). 
Durante este intervalo de tiempo, continúa la progradación costera evidenciado por la nueva posición de la línea de costa al norte de la bahía, con cheniers de edad 23442146 años cal AP (Tabla 3.3 y Figura 3.4, Capítulo 3 y Figura 5.10).

Entre los 1660-950 años cal AP el establecimiento de una marisma madura y estable es evidenciada por la dominancia de Chenopodiaceae de $70 \%$ (Figura 5.6). El gradual incremento de $A$. filiculoides (másulas, esporas y gloquidios), y de la briofita Ricciaceae en el registro, indican la presencia de cuerpos de agua someros en el área posiblemente vinculado a un alto aporte de agua dulce; esto sugiere la disminución de la salinidad indicada también por la tendencia a la disminución gradual de los dinoquistes (Figuras 5.6 y 5.12). El avance y desarrollo de la vegetación también es evidenciado por el aumento y alto contenido de materia orgánica en el sedimento fangoso (Tabla 3.2, Capítulo 3). La ausencia de restos de conchillas de moluscos (fragmentados o enteros) sugieren que este ambiente se desarrollaba en una marisma media a alta, ambiente supramareal, con alcance limitado por parte de las mareas, incapaz de transportar restos de moluscos. Por otro lado, dentro de este intervalo, el DCA permitió establecer con una mayor precisión el pasaje de las condiciones con poca influencia de las mareas a las de una marisma madura hacia 1400 años cal AP (Figura 5.8). El aumento de la concentración polínica total y la presencia de clumps de polen de Chenopodiaceae, Poaceae, a lo largo de casi todas las muestras que representan este intervalo, indican depositación in situ en un ambiente de baja energía.

En cuanto a las asociaciones de foraminíferos; la variación en la abundancia de Elphidium aff. poeyanum y Ammonia parkinsoniana reflejan variaciones en la salinidad (Figuras 5.11 y 5.12). Por otro lado, el incremento gradual de la influencia de agua dulce es sugerido por la baja/rara frecuencia de Bolivina y E. gunteri, por la ausencia de $E$. articulatum y Elphidium sp y por el drástico descenso de la abundancia y diversidad de foraminíferos, incluso hasta no registrarse a partir de 1110 cal AP (Figuras 5.10 y 5.13).

Los valores estandarizados de los dinoquistes cambian de positivo a negativo (Figura 5.13), sugiriendo condiciones desfavorables entre 1535 y 1520 años cal AP, lo cual puede vincularse a un mayor aporte de agua dulce y el consecuente y gradual descenso 
del nivel del mar. También, se observa esta fluctuación en los foraminíferos (tanto, positivos como negativos) reflejando condiciones de salinidad variable (Figura 5.13).

Los cambios micropaleontológicos junto con el desarrollo de nuevas paleolíneas de costa hacia el este, sugieren que la progradación costera fue dejando gradualmente ambientes aislados de la influencia de las mareas, aunque posiblemente puedan haber mantenido contacto por medio de canales de marea, como sugiere el registro de estas geoformas preservadas en el terreno (Figuras 5.9.B y 5.10.B-E). Además se desarrollaron de depósitos de cheniers cuyos espesores varían entre 1.3 y 1 m (Figuras 3.7 y 3.15 , Capítulo 3). Éstos posiblemente actuaron como barreras ante la acción de las mareas, generando el medio propicio para el desarrollo de los cuerpos de agua someros.

La progradación costera podría estar vinculada a los procesos que acompañan la caída del nivel del mar durante este período final del Holoceno; intensa sedimentación fluvio-estuarina, e intensa descarga sedimentaria en el río de La Plata proveniente del río Paraná (Cavallotto et al., 2004). Consecuentemente, estos procesos pueden haber favorecido el transporte y depositación de sedimentos finos a la zona de Bahía Samborombón; lo que provocó la formación, acreción y sucesión de ambientes desde intermareal a marismas a medida que continuaba el aporte sedimentario, interceptado y atrapado por la vegetación junto con la materia orgánica agregada a la superficie de la marisma, debido al crecimiento de raíces; todo lo cual conduce a una acumulación constante en el nivel superficial de la marisma.

Desde 950 a 40 años cal AP (AD 1910) continuó el predominio de una vegetación de marisma estable en coexistencia con comunidades de agua dulce desarrolladas en pequeños cuerpos de agua (Figuras 5.5 y 5.10.F). La salinidad disminuyó como lo evidencia la drástica disminución de dinoquistes hasta casi desaparecer, mientras aumenta de forma exponencial la representación de Azolla (más de 80\%) (Figura 5.10). El ordenamiento de las muestras en el DCA refleja el pasaje a condiciones ambientales netamente de agua dulce hacia 790 años cal AP (Figura 5.8).

A. filliculoides es una especie de amplia distribución, con hábitos flotantes o fijas a los márgenes de canales o estanques, con preferencia a aguas lénticas (Medeanic et al., 
2006). La casi absoluta desaparición de los dinoquistes y la ausencia de los microfósiles calcáreos evidencian la rara a nula frecuencia de las mareas extraordinarias y la gradual predominancia de condiciones de aguas salobres a dulces en un ambiente de marisma alta ubicada a $6 \mathrm{~km}$ de la costa actual (Figuras 5.11 y 5.12). A su vez, la buena preservación de los palinomorfos, en cuanto a la presencia de másulas completas y clumps polínicos de Chenopodiaceae, Poaceae, Asteraceae, Apiaceae, y Ambrosia sugieren un ambiente depositacional de baja energía y ausencia de transporte, es decir depositación in situ. El aumento en la concentración polínica total hacia el techo de la secuencia, o hacia el final de este intervalo de tiempo, puede estar relacionado con la cercanía de la fuente dentro de la marisma madura (Figura 5.9) y con el desarrollo del cuerpo de agua que actúa como trampa del polen.

Estos cuerpos de agua locales fueron progresivamente secándose a una distancia de aproximadamente $6 \mathrm{~km}$ de la presente línea de costa, posiblemente debido a cambios en el nivel freático en relación a la progradación costera y al descenso del nivel del mar, con la consecuente migración y desplazamiento de la marisma a una posición cercana a la costa. Luego, tuvieron lugar procesos pedogenéticos evidenciados por el desarrollo de un suelo estructurado en prismas (Fucks et al., 2010), presencia de raíces y alta concentración polínica total (Figura 5.6). Sobre ese suelo se desarrollaron comunidades azonales como pradera salada, espartillar y juncales en una marisma alta, sugerido por raíces y por el predominio de polen de Poaceae y Cyperaceae. Además, la concentración polínica total alcanza los $\sim 116150$ granos $/ \mathrm{cm}^{3}$ lo que es coherente con el ambiente de marisma alta. Posteriormente este suelo es cubierto por material de destape proveniente de la construcción de un canal artificial, Canal 15, a principios del siglo XX. 


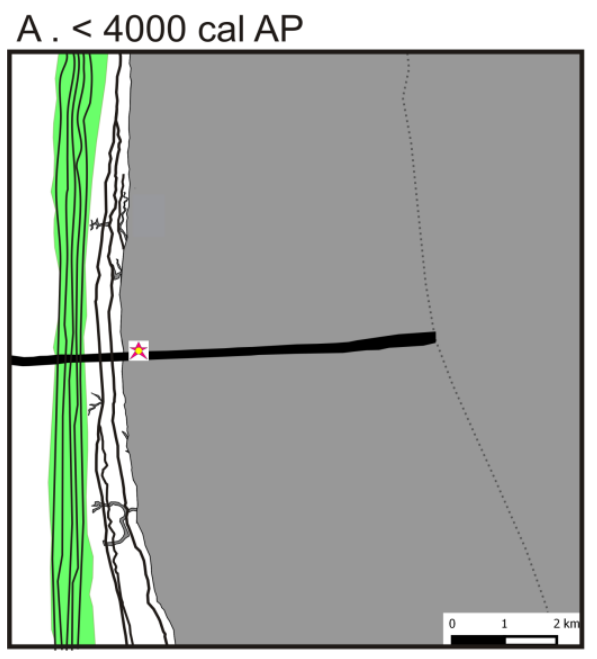

사 PM1

|III| Cordónes de conchillas
B. $<1660 \mathrm{cal}$ AP

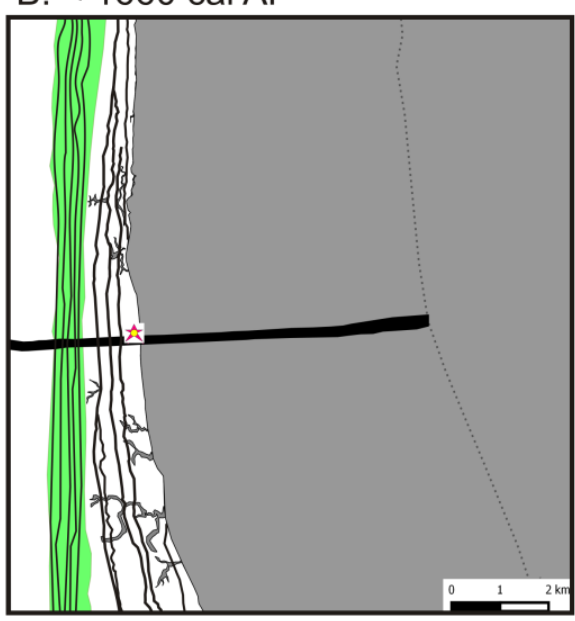

21 Canales de marea activos

Cuerpos de agua
C. Después de $\sim 950$ cal AP

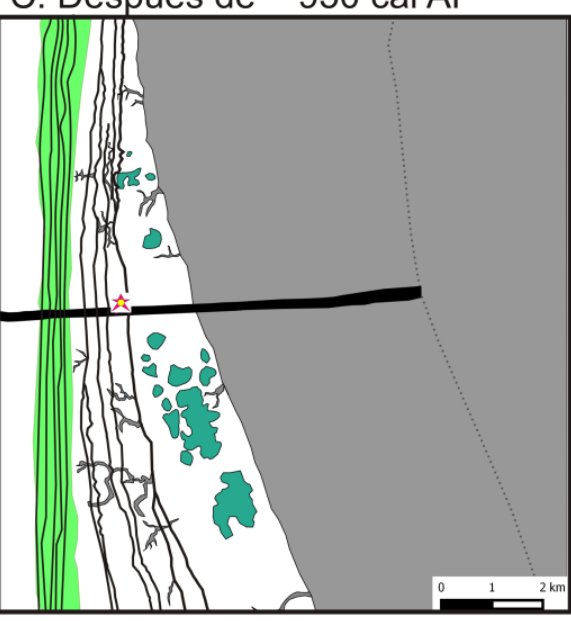

Canal 15

... Línea de costa actual

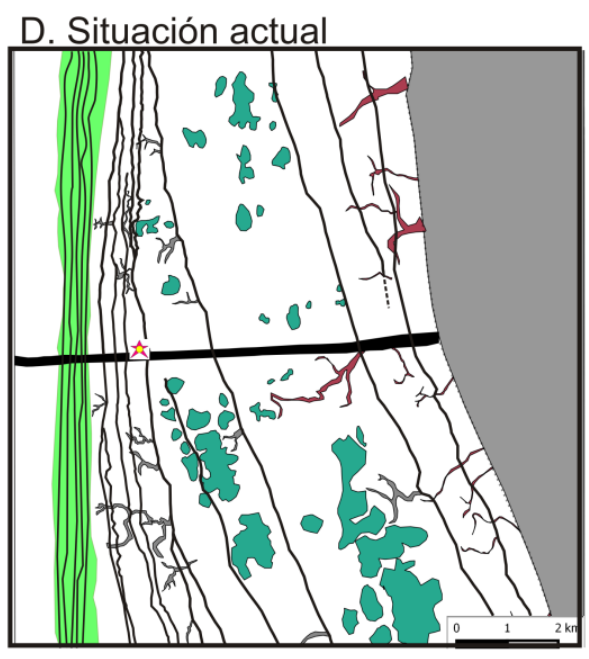

Paleolíneas de costa

Paleocanales de marea

Figura 5.9. Secuencia evolutiva de la planicie costera de la zona central de Bahía Samborombón construida mediante el mapeo de las geoformas reconocidas a travéz del uso de sensores remotos y marco cronológico basado en dataciones de secuencias sedimentarias y de depósitos de cheniers. 


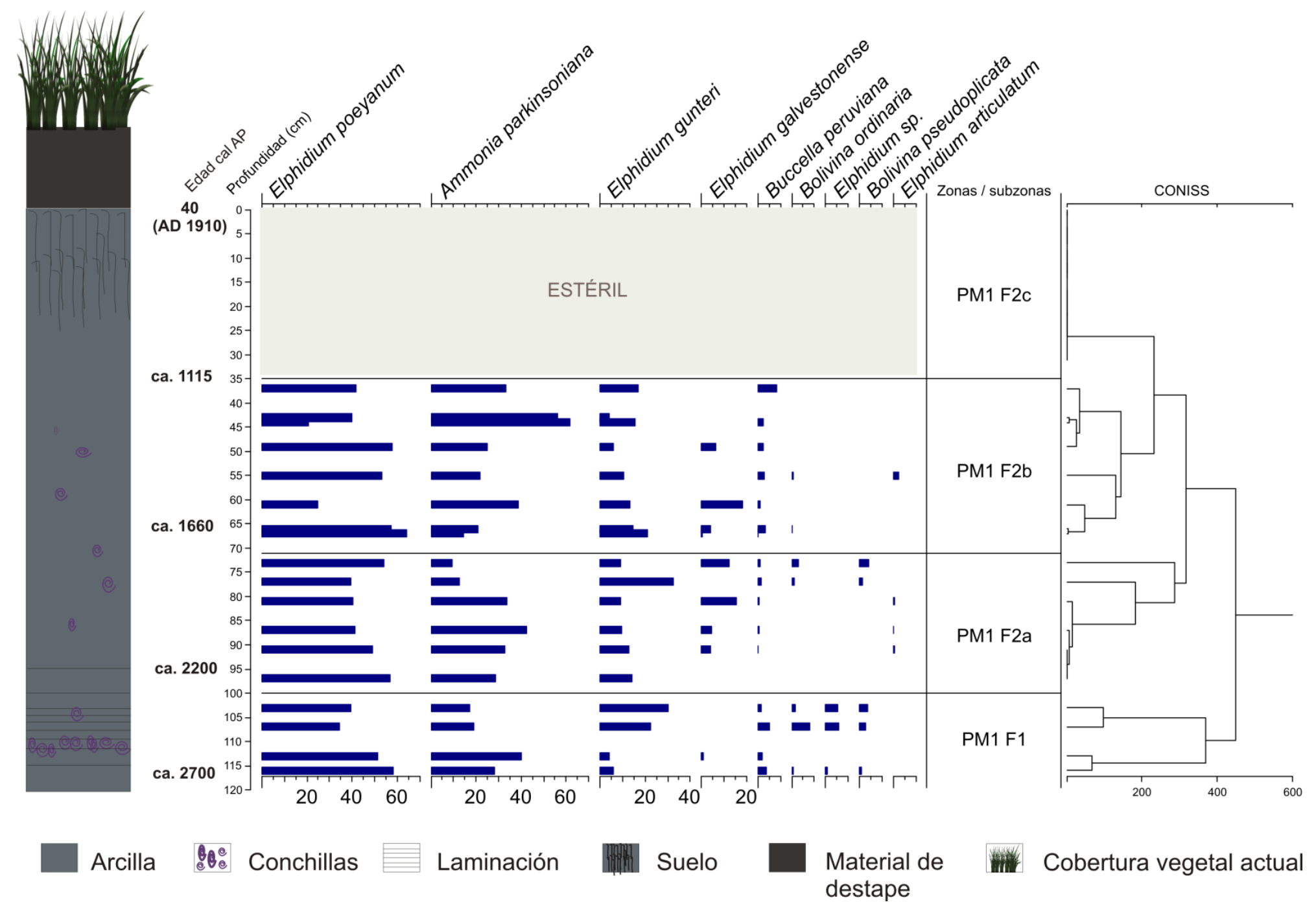

Figura 5.10. Distribución de las especies de foraminíferos de la sección PM1, Canal 15, Bahía Samborombón, con al menos 1\% de abundancia relativa. 


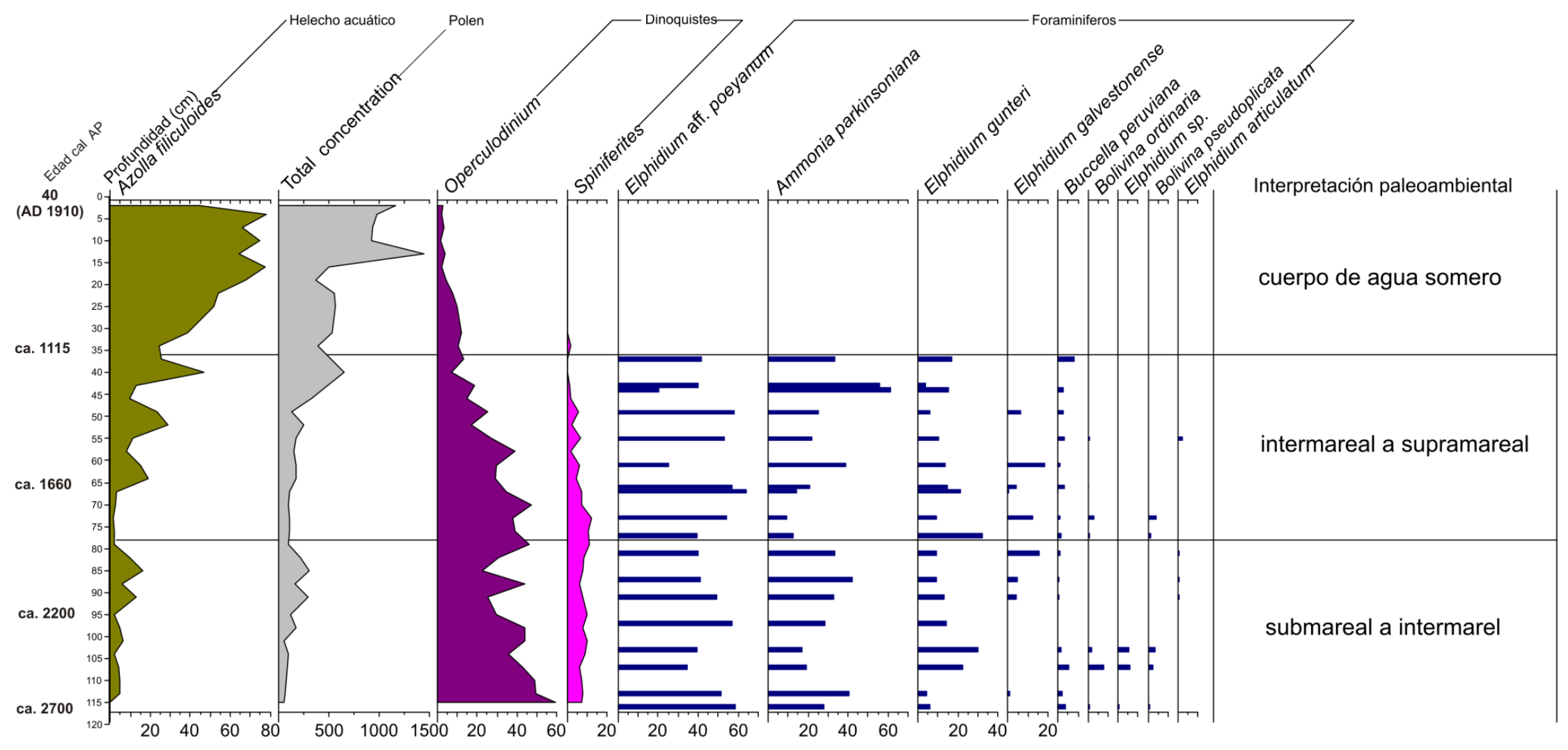

Figura 5.11. Resumen de zonas micropaleontológicas y paleoambientes inferidos a partir del análisis de la secuencia PM1. 


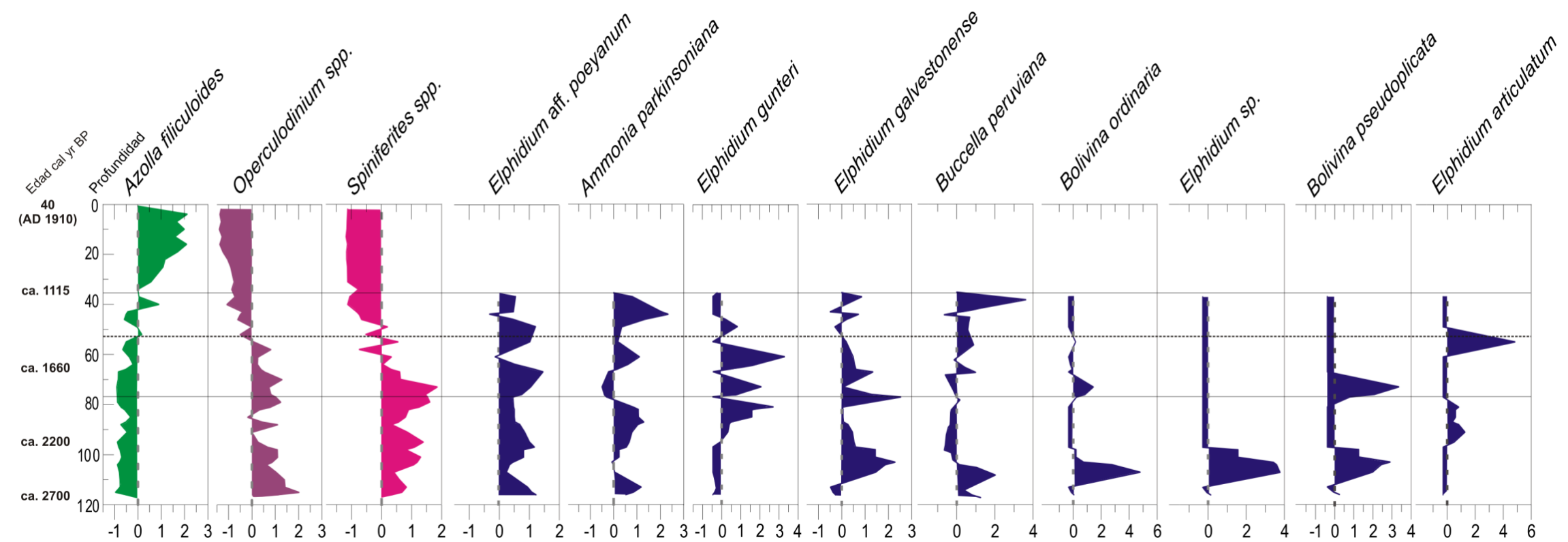

Figura 5. 12. Datos estandarizados de diferentes proxies analizados provenientes de la secuencia estratigráfica PM1. 

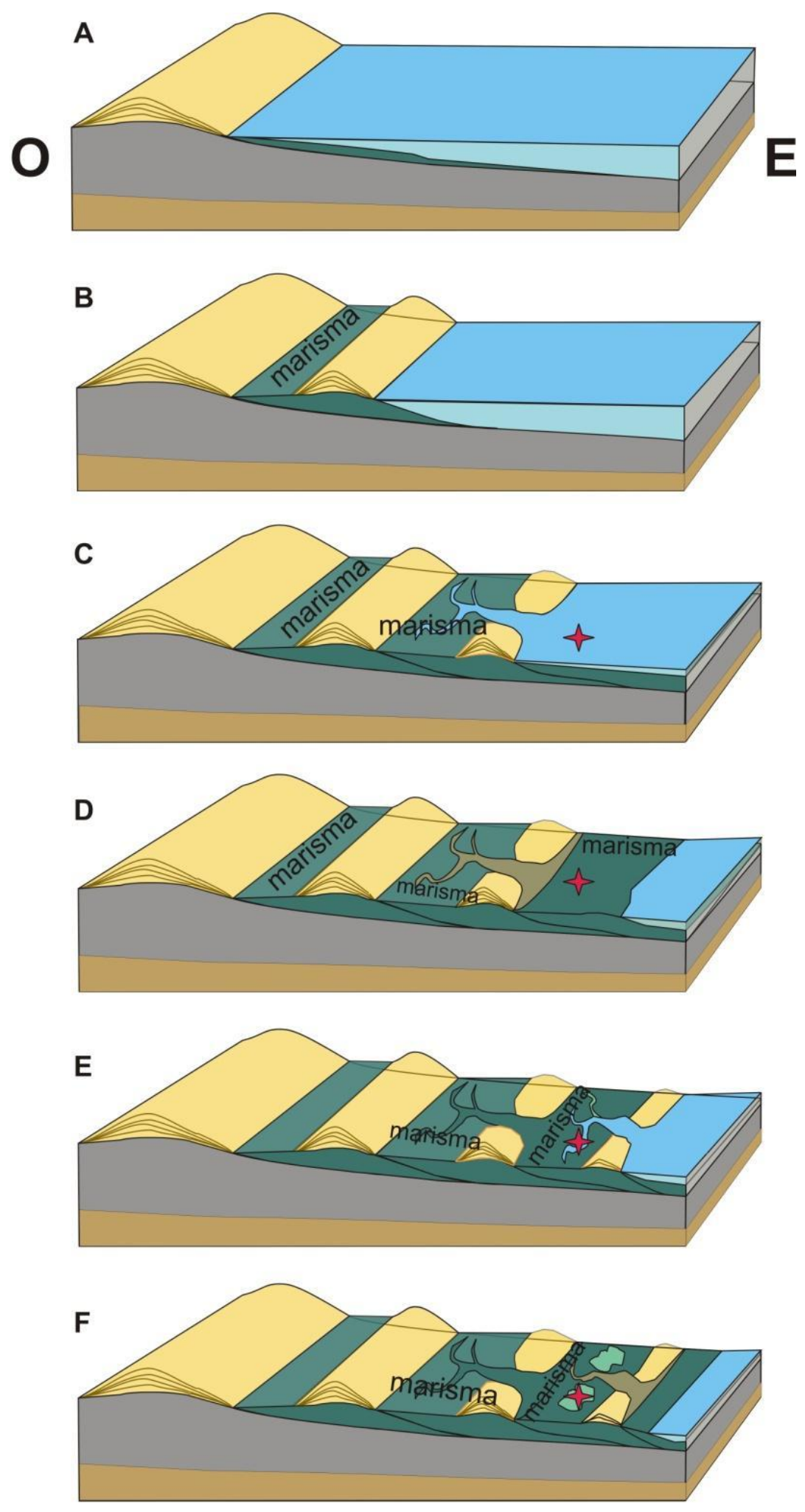

Loess Fango transgresivo $\quad$ Fango regresivo

Material bioclástico $\stackrel{\ngtr}{ } \mathrm{PM} 1$ 
Figura 5.13. Modelo de evolución geomorfológica. Esquema de la progradación costera con formación de cheniers, posterior al máximo transgresivo.

\subsection{3.- Conclusiones}

El análisis multi-proxy (geomorfológico, litológico y micro-paleontológico) del sector central de Bahía Samborombón permitió establecer la evolución paleoambiental durante la fase regresiva del nivel del mar en el Holoceno tardío, mostrando la evolución desde un ambiente submareal-intermareal, es decir bajo una influencia significativa de las mareas, a un ambiente supramareal con influencia de aguas salobres a dulces. Las evidencias de esta evolución son:

Una progradación costera de $\sim 5.7$ km durante los últimos 2700 años cal revelado por el reconocimiento de paleolíneas de costa, paleocanales de marea, cheniers. Además la cronología de estos depósitos apoyó su carácter regresivo.

Procesos de sucesión ecológica caracterizada por el reemplazo de vegetación típica de una marisma baja por comunidades vegetales típicas de una marisma alta en la que además, se desarrollaron comunidades vegetales de aguas dulces a salobres.

El gradual descenso de los dinoquistes y foraminíferos, estos últimos hasta desaparecer durante el último milenio, indicando un descenso gradual de la influencia marina y descenso de la salinidad.

Durante el último milenio, a medida que el nivel relativo del mar retrocedía, la forzante climática pudo visualizarse en el registro, dado el cese de la influencia marina. Esto permitió interpretar el registro de la señal climática, la cual indica un mayor régimen de precipitaciones que se pudo inferir por el aumento de los componentes acuáticos de agua dulce. 


\section{Capítulo 6}

\section{DISCUSIÓN GENERAL Y CONCLUSIONES}

\section{1.- Discusión General}

A continuación se presenta la reconstrucción paleoambiental, paleoclimática y de los cambios de la vegetación en la llanura costera del sector central de la Bahía Samborombón durante el Holoceno; esta reconstrucción está basada en el análisis de indicadores múltiples (o "multi-proxy" como polen, esporas, PNPs, foraminíferos y moluscos contenidos en los perfiles PM1 y PM2, junto con el análisis geomorfológico e información proveniente de otras perfiles etratigráficos estudiados previamente en este sector central de la bahía (sitios 1-4, Figura 6.1), consistentes en depósitos marinos Holocenos correspondientes al evento transgresivo-regresivo post-glacial (MIS 1).

Durante el intervalo 9000-7000 años cal AP a $30 \mathrm{~km}$ de la costa actual (Sitio 1, Figura 6.1) y en las cercanías a la actual cuenca del río Salado, se desarrollaron comunidades halófitas de pastizales salobres en marismas, similares a los que se desarrollan actualmente en la marisma media, ubicada en la franja costera de Bahía Samborombón (Vilanova y Prieto, 2012). Esta vegetación se desarrollaba en ambientes de llanuras de marea, playas y de lagunas costeras como evidencian también sedimentos intermareales y geoformas relictuales en superficie como canales de marea (Violante et al., 2001; Fucks et al., 2010). Además, el registro de conchillas de H. parchappii, girogonites de carófitas y valvas del ostrácodo Cyprideis salebrosa permitió establecer el desarrollo de cuerpos de agua alcalino-salobre a dulceacuícolas en el área de extensas Ilanuras de mareas que comenzaban a desarrollarse como respuesta al ascenso del nivel del mar durante la fase transgresiva que, a 7000 años AP, alcanzó una posición 
semejante al actual (Violante et al. 2001, Cavallotto y Violante, 2005, Prieto et al., 2017). Durante el intervalo 7000-5000 años cal AP, mientras ocurría el reemplazo de las comunidades halófitas de marisma media por comunidades de marisma baja a $30 \mathrm{~km}$ de la costa actual, a una distancia más cercana a la costa ( 10 km), (PM2, Figura 6.1) se desarrollaban comunidades de marisma media que fueron también reemplazadas posteriormente por las de marisma baja a 6670 años cal AP. Esta misma dinámica a diferente distancia de la línea de costa actual con un desfasaje temporal puede relacionarse con la configuración topográfica de este sector central de la bahía, que determinó que el mar ingresara y avanzara a través de los sectores más deprimidos adyacentes al actual curso del río Salado. Sin embargo, estas transiciones de una marisma media a una marisma baja en ambos sitios respondieron al mismo forzante, representado por el aumento del nivel del mar, que alcanzó el máximo transgresivo a los 6300-5600 (Prieto et al., 2017).

Con posterioridad a los 6300 cal años AP las evidencias litológicas y fosilíferas (asociaciones autóctonas de T. plebeius) en el zona media del sector central de la bahía (PM2) permitieron inferir la estabilidad ambiental como respuesta a la estabilidad del nivel del mar en $\sim+4 m$, entre 6000 y 5500 años cal AP (Prieto et al., 2017) y una línea de costa en posición intermedia entre la costa actual y la alcanzada durante el máximo transgresivo (Fucks et al 2010).

El registro de estas asociaciones de $T$. plebeius tiene una amplia distribución a lo largo de la zona central de Bahía Samborombón (e.g. 1. Perfil río Salado, 3.Sitio Ea. Rincón Grande, (Figini, 1992); 2. Sitio Los Molles, (Aldazabal, 2002); 4. Sitio Puesto Berrondo, (Fucks et al., 2007), Figura 6.1), evidenciando el ambiente de extensas llanuras de marea y generalmente con edades que coinciden con el periodo de estabilización del nivel del mar.

Luego del máximo transgresivo, cuando el mar comienza a estabilizarse, prevalece la progradación de cordones litorales hacia el este de la secuencia PM2, presentando edades de 5294-4843 y 4613-3979 años cal AP (Violante et al., 2001, Fucks et al., 2010, Richiano et al., 2012, entre otros). Estos cordones que fueron aislando los ambientes desarrollados por detrás (al Oeste) de la influencia de las olas y mareas se componen 
mayormente por moluscos (Mactra isabelleana) y representan ambientes de playas de alta energía. Las asociaciones faunísticas parautóctonas que constituyen estas barreras estarían indicando condiciones óptimas para la proliferación de las comunidades de moluscos bentónicos (mayor salinidad y mayor temperatura oceánica superficial) vinculado al Optimo Climático del Holoceno medio registrado para el área (Aguirre, 1993; Aguirre y Whatley, 1995; Richiano et al 2012).

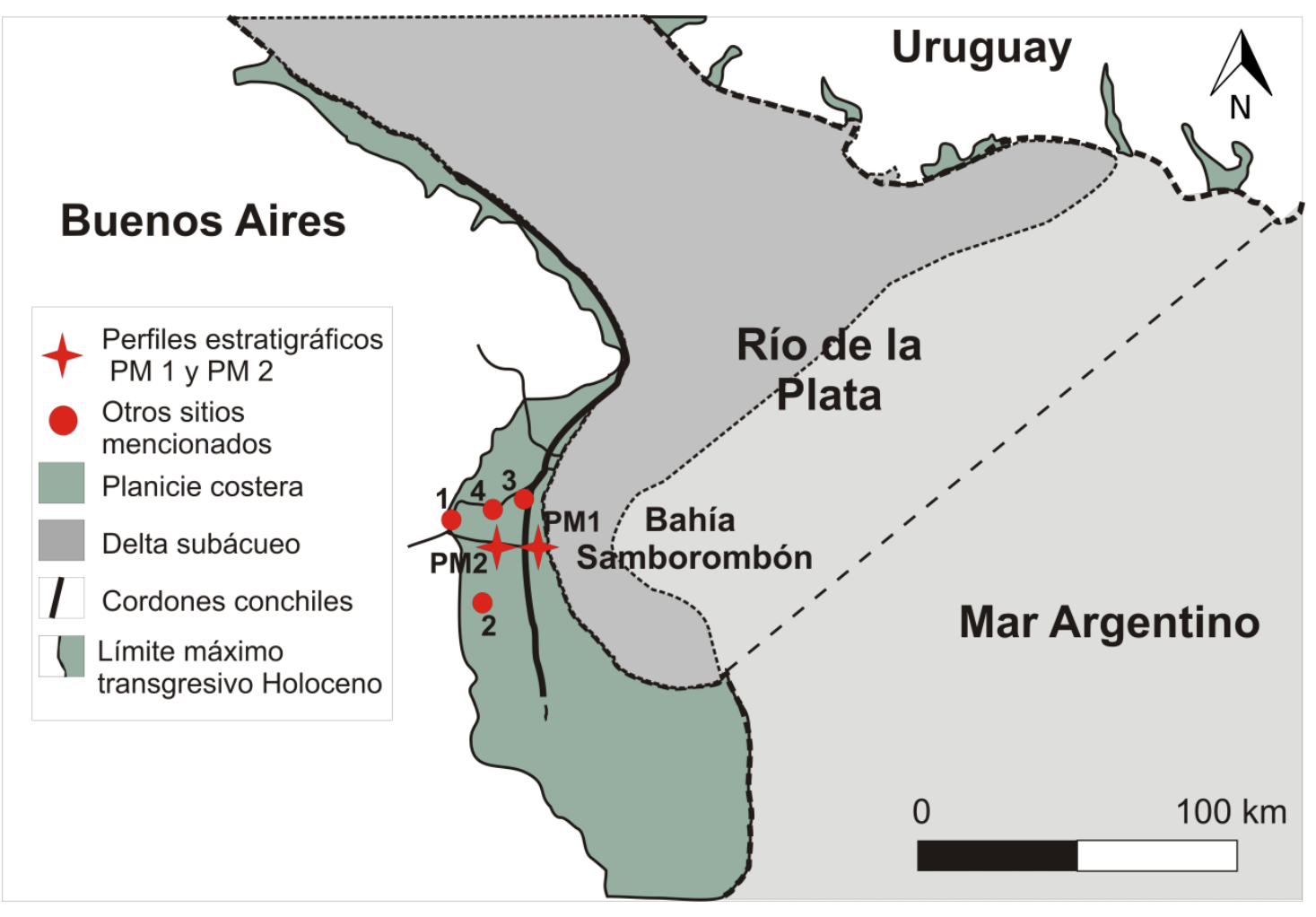

Figura 6. 1. Mapa de ubicación. Mapa geomorfológico regional, modificado de Cavallotto (2002), en donde se muestra la ubicación de las secuencias sedimentarias PM1 y PM2 (asteriscos rojos). Además, se señala la ubicación de otros sitios previamente estudiados por otros autores, en la llanura costera, y que se mencionan en la presente Tesis (círculos rojos): 1. Sitio RS (Vilanova y Prieto,2012); 2. Sitio Los Molles (Aldazabal,2002); 3. Sitio Ea. Rincón Grande,(Figini,1992); 4. Sitio Puesto Berrondo (Fucks, et al., 2007)

Durante el intervalo 5000-3000 años cal AP el único registro palinológico (1. Sitio RS, Figura 6.1) permitió inferir una transición gradual desde una marisma baja a una alta (Vilanova y Prieto, 2012) respondiendo a las tendencias de retroceso del nivel del mar (Violante et al., 2001). Además, en este sector se registró con posterioridad a los $\sim 4800$ 
años cal AP la disminución gradual de las condiciones estuáricas y un incremento en la influencia del río Salado (Vilanova y Prieto, 2012) como consecuencia del crecimiento de los cordones conchiles vinculado al descenso del nivel del mar (Violante et al., 2001). Con posterioridad a $\sim 4110 \pm 50$ años ${ }^{14} \mathrm{C}$ AP, hacia el este del sitio RS (4. Sitio Puesto Berrondo, Figura 6.1) la disminución de la influencia marina se ve reflejada por el desarrollo de ambientes fluvio-lacustres con evidencia de procesos pedogenéticos hacia los $3540 \pm 70{ }^{14} \mathrm{C}$ años AP (Fucks et al., 2007).

Durante el Holoceno tardío (últimos 3000 años), a medida que el nivel relativo del mar continúa en descenso (Prieto et al., 2017), ocurren cambios ambientales y geomorfológicos significativos en la franja costera de Bahía Samborombón que fueron conduciendo a la actual configuración ambiental. Además, las condiciones climáticas constituyeron otro forzante particularmente evidenciándose en el registro durante el último milenio. Según Gyllencreutz et al. (2010), el fenómeno del Niño (ENOS), que se estableció aproximadamente a 5000 años AP, habría aumentado llegando a su dinámica actual alrededor de 3000-2000 años AP. Esto causó un aumento de la descarga del río Paraná durante los años de El Niño y la extensión hacia el norte de la baja salinidad del río de la Plata a $25^{\circ} \mathrm{S}$ durante el fenómeno La Niña. Además, la intensificación del Sistema Monzónico Sudamericano durante el Holoceno tardío favoreció el trasporte de sedimentos al Atlántico Sur occidental. Ambos fenómenos generaron alto régimen de precipitaciones sobre la cuenca de drenaje del río de la Plata incrementando la descarga sedimentaria hacia el Atlántico Sur occidental (Razik et al., 2013).

Durante los últimos 3000 años, en el área del sitio PM1 (Figura 6.1) ocurrieron cambios en las condiciones ambientales y en las comunidades vegetales en relación con una intensa progradación costera, de $5.7 \mathrm{~km}$ hasta alcanzar su actual posición. Esta evolución geomorfológica se dio con alternancia de pulsos de acreción de sedimento fangoso/arcilloso y periodos de interrupción con formación de paleolíneas de costa y cheniers (Luengo et al., 2018). Entre 2700-1660 años cal AP la vegetación halófita de marisma se desarrollaba en las cercanías de un ambiente depositacional intermarealsubmareal con una línea de costa ubicada a $5.7 \mathrm{~km}$ de la costa actual mientras que a 30 
km de la costa actual (RS, Fig.1) se desarrollaban comunidades pertenecientes al pastizal pampeano, luego de que se produjera la transición de un ambiente de condiciones estuarinas a uno netamente fluvial evidenciado también por procesos pedogenéticos incipientes (Vilanova y Prieto, 2012). Estas diferencias en las condiciones ambientales responden a la distancia a la costa y a la configuración geomorfológica, ya que se encontraban constituidos los cordones generando así el aislamiento de las comunidades vegetales desarrolladas por detrás (hacia el oeste), en ambientes estabilizados mientras que el área de la localidad PM1 se encontraba sujeta a condiciones costeras dinámicas por su cercanía a la línea de costa (Luengo et al., 2018). Durante este periodo, y como respuesta a la continua progradación costera se estableció una marisma media, en respuesta al gradual descenso del nivel del mar (Luengo et al., 2018). Simultáneamente hacia el norte, donde tienen sus actuales desembocaduras los ríos Salado y Samborombón la progradación costera se manifestó por la presencia de cheniers que se evidencia por el comportamiento de los cursos de los ríos mencionados, que fueron provocando el abandono de los cauces por procesos de avulsión.

Entre 1660 y 950 años cal AP, como respuesta a la progradación costera, se establece el predominio de una vegetación de marisma alta coexistiendo con el desarrollo de comunidades vegetales de agua dulce en cuerpos de agua de escasa profundidad y aguas tranquilas localizadas en la zona central de Bahía Samborombón a 5.7 km de la actual línea de costa. A $\sim 30 \mathrm{~km}$ de la costa actual (Sitio RS, Figura 6.1), no hay registro palinológico con posterioridad a los 1560 años cal AP.

Durante el último milenio, desde 950 años cal AP hasta el presente, la disminución de la influencia marina hasta desaparecer a $5.7 \mathrm{~km}$ de la costa actual, el descenso del nivel del mar y la progradación de la franja costera permitieron la estabilización de las comunidades vegetales. Probablemente, durante este intervalo de tiempo, mientras el nivel del mar descendía hasta alcanzar su posición actual, la señal climática comenzó a notarse a través del desarrollo de un ambiente con aporte fluvial y el establecimiento de los cuerpos de agua en el humedal relacionados con un régimen de precipitación más alto y variable, con el consecuente descenso de la salinidad. El régimen 
de precipitaciones, posiblemente de mayor frecuencia pero de variable intensidad puede haber contribuido a la mayor descarga/ caudal de la pluma del Río de la Plata y del Río Salado provocando así un cambio a ambientes de menor salinidad, y el surgimiento de las condiciones ambientales actuales del humedal costero de Bahía Samborombón.

Es decir, la progradación costera junto con el descenso del nivel del mar, bajo condiciones hidroclimáticas variables pero más húmedas forjaron la configuración geomorfológica actual de Bahía Sambrorombón. El régimen de precipitaciones durante este tiempo ha sido asociado con la intensificación de SAMS y del fenómeno ENSO (Razik et al., 2013), lo cual se evidencia en el registro un vez que la influencia marina deja de superponerse a la señal climática. 


\section{2.- Conclusiones generales}

1- El análisis geomorfológico mediante el empleo de imágenes satelitales de alta resolución espacial y la aplicación de filtros y realces permitió el reconocimiento y mapeo de las geoformas en la llanura costera de la Bahía Samborombón tanto de origen litoral como fluvial. Se reconocieron 9-10 paleolíneas de costa, cheniers, paleocanales de marea, paleoespigas, paleocauces en el sector central de la Bahía Samborombón. Este análisis permitió, junto con la cronología de estos depósitos, generar un modelo de evolución geomorfológica e inferir una progradación costera de 5,7km en 3000 años AP.

2- El estudio de las asociaciones palinológicas de superficie permitió generar un análogo moderno que representa la vegetación de los ambientes mareales de Bahía Samborombón, incluyendo las zonas baja, media y alta de la marisma. Además, palinomorfos no polínicos como: dinoquistes, microforaminíferos, hongos, junto con la concentración polínica total contribuyeron en la diferenciación de los ambientes actuales, constituyendo, también, un buen análogo para interpretar secuencias polínicas fósiles de ambientes costeros cuya evolución está vinculada a los cambios del nivel del mar.

3- El análisis palinológico de las secuencias seleccionadas en sector continental de la Bahía Samborombón (PM1 Y PM2), permitió reconstruir los cambios de la vegetación y de los ambientes en relación a las fluctuaciones del nivel del mar a partir de la etapa final de la transgresión Holocena (MIS 1).

4- El número de muestras palinológicas resultó escaso para el Holoceno medio, esto se debió a la esterilidad de la secuencia vinculada principalmente a la granulometría no propicia para la preservación de los palinomorfos, aunque también vinculada a procesos naturales que pueden haber provocado la posterior pérdida de información (e.g. procesos eólicos). Sin embargo, la alta tasa de sedimentación registrada en PM2 hizo que el registro tuviera alta resolución ( 600 años en $\sim 150 \mathrm{~cm}$ ). 
5- La comunidades vegetales del Holoceno medio ( 7000- 6400) presentaron similitudes con las comunidades que se desarrollan actualmente en la franja costera de Bahía Samborombón y su evolución respondió al aumento acelerado del nivel relativo del mar durante la transgresión marina.

6- El estudio multi-proxy de la secuencia sedimentaria PM1 junto a análisis de las geoformas originadas durante el descenso del nivel del mar (Holoceno tardío) permitió reconstruir la historia de la vegetación y de las condiciones paleoambientales y además ampliar el conocimiento sobre el evento regresivo del mar para el sector central de la Bahia Samborombón.

7- Los registros palinológicos del Holoceno tardío (últimos 2700 años) mostraron una alta resolución temporal para las inferencias de los principales cambios de la vegetación en respuesta a la evolución geomorfológica durante la fase regresiva del nivel del mar y la variabilidad climática.

8- La comunidades vegetales del Holoceno tardío presentaron similitudes con las comunidades que se desarrollan actualmente en la franja costera de Bahía Samborombón, y su evolución respondió a la intensa progradación costera en relación a la evolución de sucesivas paleolíneas de costa con cheniers.

9- Se evidenciaron procesos de sucesión ecológica caracterizada por el reemplazo de vegetación típica de una marisma baja por comunidades vegetales típicas de una marisma alta a medida que la progradación continuó hasta alcanzar la posición actual, y en la que además se desarrollaron comunidades vegetales de aguas dulces a salobres.

10- El gradual descenso en las proporciones de dinoquistes y foraminíferos analizados en PM1, incluso estos últimos hasta desaparecer durante el último milenio, indican un descenso gradual de la influencia marina en relación al descenso del nivel del mar y por lo tanto el descenso de la salinidad. 
11- Durante el último milenio, la forzante climática pudo visualizarse en el registro dado el cese de la superposición de la influencia mareal en PM1. Esto permitió interpretar el registro de la señal climática, la cual indica un mayor régimen de precipitaciones que se pudo inferir por el aumento de los componentes acuáticos de agua dulce. 


\section{Capítulo 7}

\section{REFERENCIAS BIBLIOGRÁFICAS}

Adam, D. P. y Mehringer, P. J. 1975. Modern pollen surface samples-an analysis of subsamples. Journal of Research of the US Geological Survey, 3(6): 733-736.

Adam, P. 2002. Saltmarshes in a time of change.Environmental conservation, 29(1): 39-61.

Aguirre, M.L. 1993. Paleobiogeography of the Holocene molluscan fauna from northeastern Buenos Aires province, Argentina: its relation to coastal evolution and sea level changes. Palaeogeography, Palaeoclimatology, Palaeoecology, 102: 1-26.

Aguirre, M. L. y Whatley, R.C. 1995. Late Quaternary marginal marine deposits and palaeoenvironments from northeastern Buenos Aires province, Argentina: a review. Quaternary Science Reviews, 14: 223-254.

Aldalur, B. y Santamaría, M. 2002. Realce de imágenes: filtrado espacial. Revista de Teledetección, 17: 31-42.

Aldazabal, V. 2002. La ocupación humana en el sector centro oriental de la Pampa Deprimida, provincia de Buenos Aires, Argentina.

Ameghino, F. 1889. Contribución al conocimiento de los Mamíferos fósiles de la República Argentina. Actas de la Academia Nacional de Ciencias, VI. Córdoba.

Augustinus, P.G. 1989. Cheniers and chenier plains: a general introduction. Marine Geology, 90 (4) : 219-229.

Barros, V., Gonzalez, M., Liebmann, B. y Camilloni, I. 2000. Influence of the South Atlantic convergence zone and South Atlantic Sea surface temperature on interannual summer 
rainfall variability in Southeastern South America. Theoretical and Applied Climatology, 67 (3-4): 123-133.

Bértola, G. 1994. Geomorfología y sedimentología de los ambientes mareales de la Bahía Samborombón, provincia de Buenos Aires. Tesis Doctoral Inédita,Universidad Nacional de La Plata, Facultad de Ciencias Naturales y Museo. 153 pp.

Bértola, G., Cortizo, L. y Pastorino, S. 1998. Delimitación de ambientes costeros en la Bahía Samborombón mediante información satelitaria. V Jornadas Geológicas y Geofísicas Bonaerenses (Mar del Plata), Actas: 217-225.

Birks, H. J. B. y Birks, H. H. 1980. Quaternary Palaeoecology. University Park Press. Baltimore. $289 \mathrm{pp}$.

Blaauw, M. y Christen, J. A. 2011. Flexible paleoclimate age-depth models using an autoregressive gamma process. Bayesian analysis, 6 (3): 457-474.

Borel, C. M. 2007. Algas no silíceas y acritarcos de depósitos costeros holocenos en el Arroyo La Ballenera, Buenos Aires, Argentina. Ameghiniana, 44: 359-366

Borel, C.M., Guerstein, G.R. y Prieto, A.R. 2003. Palinomorfos acuáticos (algas y acritarcos) del Holoceno de la laguna Hinojales (Buenos Aires, Argentina): interpretación paleoecológica. Ameghiniana, 40: 514-531.

Bravard, A. 1857. Observaciones geológicas sobre diferentes terrenos de transporte en la hoya del Plata. Biblioteca diario La Prensa, Imprenta y Literatura Bernheim, Buenos Aires, 113: 80 pp.

Brewster-Wingard, G.L. y Ishman, S.E. 1999. Historical trends in salinity and substrate in central Florida Bay: paleoecological reconstruction using modern analogue data. Estuaries, 22:12-15. 
Cagnoni, M. 1999. Espartillares de la costa bonaerense de la República Argentina. Un caso de humedales costeros. En: A. I. Álvarez (Ed.): Tópicos sobre humedales subtropicales y templados de Sudamérica. UNESCO: pp. 51-67.

Calvo Marcilese, L. 2011. Sistemática y paleoecología de los Foraminifera (Protista) del Holoceno del área del estuario de Bahía Blanca, Argentina. Tesis Doctoral Inédita,Universidad Nacional de La Plata, Facultad de Ciencias Naturales y Museo. 255pp.

Calvo Marcilese, L., Pérez Panera, J.P., Cusminsky, G. y Gómez. E.A. 2013. Micropaleontological record of Holocene estuarine stages in the Bahía Blanca estuary, Argentina. Journal of South American Earth Sciences, 45: 147-159.

Carol, E., Mas-Pla, J. y Kruse, E. 2013. Interaction between continental and estuarine waters in the wetlands of the northern coastal plain of Samborombón Bay, Argentina.Applied Geochemistry, 34: 152-163.

Carter, R. W. G. y Woodroffe C. D. 1994. Coastal evolution: Late Quaternary shoreline morphodynamics. Cambridge UniversityPress. Cambridge. 517 pp.

Cavallotto, J.L. 1995. Evolución geomorfológica de la llanura costera ubicada en el margen sur del Río de la Plata. Tesis Doctoral Inédita, Universidad Nacional de La Plata, Facultad de Ciencias Naturales y Museo. 237pp.

Cavallotto, J.L. 2002. Evolución holocena de la llanura costera del margen sur del Río de la Plata. Revista de la Asociación Geológica Argentina, 57(4): 376-388.

Cavallotto, J.L., Violante, R.A. y Parker, G. 2004. Sea-level fluctuations during the last 8660 years in the de la Plata river (Argentina). Quaternary International, 114: 155-165.

Cavallotto, J.L. y Violante, R.A. 2005. Geología y Geomorfología del Río de la Plata. En: de Berrío, R.E., Etcheverry, M.F., Caballé, M.F., Liambias, E. (Eds.): Geología y Recursos 
Minerales de la Provincia de Buenos Aires, Relatorio del XVI Congreso Geológico Argentino, La Plata, pp. 237-254.

Codignotto, J.O. y Aguirre, M.L. 1993. Coastal evolution, changes in sea level and molluscan fauna in northeastern Argentina during the Late Quaternary. Marine Geology, 110: 163-173.

Colado, U, Figini, A. Fidalgo, F. y Fucks, E. 1995. Los depósitos marinos del Cenozoico superior aflorantes en la zona comprendida entre Punta Indio y el Río Samborombón, Provincia de Buenos Aires. $4^{\circ}$ Jornadas Geológicas y Geofísicas Bonaerenses, Actas 1: 151158, Junín.

Corliss, B.H. y Chen, C. 1988. Morphotype patterns of Norwegian Sea deep-sea benthic foraminifera and ecological implications. Geology, 16: 716-719.

Corrales-Zarauza, I., Rossell-Sanuy, J., Sánchez de la Torre, L. M., Vera-Torres, J., y VillasMinondo, L. 1977. Estratigrafía (Rueda): Madrid, España, 717 pp.

Darwin, C. 1846. Geology of the Voyage of the Beagle, Under the Command of Capt. Fitzroy, RN During the Years 1832 to 1836: III. Smith, Elder.

Davidson-Arnott, R. 2010. Introduction to coastal processes and geomorphology. Cambridge University Press.

Doering, A. 1882. Informe oficial de la Comisión científica agregada el Estado mayor general de la expedición al Río Negro (Patagonia), 3o parte, Geología.

D'Onofrio, E.E., Fiore, M.M.E., Pousa, J.L., 2008. Changes in the regime of storm surges at Buenos Aires, Argentina. Journal Coastal Research 24, 260-265.

d'Orbigny, A. 1842. Voyage dans l'Amerique meridional, III, Geologie, Paris. 
Dougherty, A. J. y Dickson, M. E. 2012. Sea level and storm control on the evolution of a chenier plain, Firth of Thames, New Zealand. Marine Geology, 307: 58-72.

Eliades, L. A., Ferreri, N. A., Bucsinszky, A. M. M., Saparrat, M. C. N. y Cabello, M. N. 2014. Microbiota alcalino-tolerante descomponedora de restos de Distichlis spicata (Poaceae) en suelos alcalinos de la provincia de Buenos Aires: habilidad enzimática. Lilloa, 51 (1): 4653.

Evans, G. 1965. Intertidal flat sediments and their environments of deposition in the Wash. Quarterly Journal of the Geological Society, 121(1-4): 209-240.

Exelis, V. I. S. 2013. ENVI 5.1. Exelis VIS: Boulder, CO, USA.

Faegri, K. y Iversen, J. 1989. Finding the grain. Laboratory technique. $4^{\circ}$ edition. En: K. Faegri, P.E Kalana and K. Krzywinski (Eds.):Textbook of Pollen Analysis. John Willey and Sons, Londres, pp. 69-90.

Fidalgo, F., Colado, U.R. y De Francesco, F.O. 1973. Sobre ingresiones marinas cuaternarias en los partidos de Castelli, Chascomús y Magdalena (Buenos Aires). V Congreso Geológico Argentino. Actas, 3: 227-240.

Fidalgo, F. 1979. Upper Pleistocene-Recent Marine Deposits in Northeastern Buenos Aires province (Argentina). Proceedings of the 1978 Internacional Symposium on Coastal Evolution in the Quaternary, 384-404, Sao Paulo, Brasil.

Fidalgo, R., Figini, A., Gómez, G., Carbonari, J. y Huarte, R. 1981. Dataciones radiocarbónicas en las Formaciones Las Escobas y Destacamento Río Salado, provincia de Buenos Aires. VII Congreso Geológico Argentino. Actas, 4: 43- 56.

Figini, A. J. 1992. Edades $14 \mathrm{C}$ de sedimentos marinos holocénicos de la provincia de Buenos Aires. Actas de las Terceras Jornadas Geológicas Bonaerenses, 1, 147-51. 
Fontana, S. L. 2005. Coastal dune vegetation and pollen representation in south Buenos Aires Province, Argentina. Journal of Biogeography, 32(4): 719-735.

Frenguelli, J. 1950. Rasgos generales de la morfología y la geología de la provincia de Buenos Aires. Laboratorio de Entrenamiento Multidisciplinario para la Investigación Tecnológica, La Plata. Serie 2 (30): 72 pp.

Frenguelli, J.1957. Neozoico. En Geografía de la República Argentina. Sociedad Argentina de Estudios Geográficos, GAEA. Tomo III.

Fucks, E., Aguirre, M.L., Schnack, E., Erra, G. y Ramos, N. 2007. Rasgos litológicos y fosilíferos de la Formación Pascua (Pleistoceno Tardío) en su localidad tipo, provincia de Buenos Aires. III Congreso Argentino de Cuaternario y Geomorfología. Actas, 2: 727-736.

Fucks, E., Schnack, E., y Aguirre, M. 2010. Nuevo Ordenamiento Estratigráfico de las Secuencias Marinas del Sector Continental de la Bahía Samborombón, Provincia de Buenos Aires. Revista de la Asociación Geológica Argentina, 67(1): 27-39.

García-Moreiras, I., Sánchez, J. M. y Sobrino, C. M. 2015. Modern pollen and non-pollen palynomorph assemblages of salt marsh and subtidal environments from the Ría de Vigo (NW Iberia). Review of Palaeobotany and Palynology, 219: 157-171.

Garreaud, R.D., Vuille, M., Compagnucci, R. y Marengo, J. 2009.Present-day South American climate. Palaeogeography, Palaeoclimatology, Palaeoecology, 281 (3-4): 180195.

Gómez, G. 1988. Secuencia vertical de edades 14-C de la Formación Las Escobas, en la localidad de Cerro de La Gloria, Bahía Samborombón, provincia de Buenos Aires, Argentina. 2 Jornadas Geológicas Bonaerenses. Bahía Blanca. Acta: 277-278.

Grill, S.C. y Guerstein, G.R. 1995. Estudio palinológico de sedimentos superficiales en el estuario de Bahía Blanca, Buenos Aires (Argentina). Polen, 7: 40-49. 
Grimm, E. 2004. Tilia software 2.0.2, Software.Illinois State Museum, Research and Collection Center, Springfield.

Grindrod, J. 1988. The palynology of Holocene mangrove and saltmarsh sediments, particularly in northern Australia. Review of Palaeobotany and Palynology, 55 (1-3): 229245.

Guerrero, R., Martos, P. y Lasta C. 1989. Observación directa de corrientes, vientos y mareas en Bahía Samborombón, modelo de circulación. Jornadas Nacionales de Ciencias del Mar: 88-89.

Guerrero, R., Acha, E., Framiñan, M. y Lasta, C. 1997. Physical oceanography of the Rio de la Plata Estuary, Argentina. Continental Shelf Research, 17: 727-742.

Guilderson, T.P., Burckle, L., Hemming, S., Peltier, W.R. 2000. Late Pleistocene sea level variations derived from the Argentine Shelf. Geochemistry GeophysicsGeosystems. An electronic journal of the Earth Sciences 1.

Gyllencreutz, R., Mahiques, M.M., Alves, D.V.P. y Wainer, I.K.C. 2010. Mid- to late Holocene paleoceanographic changes on the southeastern Brazilian shelf based on grain size records. The Holocene, 20: 863-875.

Hammer, Ø., Harper, D. A. T. y Ryan, P. D. 2001. PAST: Paleontological Statistics Software Package for Education and Data Analysis. Palaeontologia Electronica, 4 (1): 1-9.

Heusser, C.J. 1971. Pollen and spores of Chile: modern types of the Pteridophyta, Gymnospermae, Angiospermae. University of Arizona Press, Tucson. 167 pp.

Hogg, A.G., Hua, Q., Blackwell, P.G., Niu, M., Buck, C.E., Guilderson, T.P., Heaton, T.J., Palmer, J.G., Reimer, P.J., Reimer, R.W., Turney, C.S.M. y Zimmerman, S.R.H. 2013. SHCal13 Southern Hemisphere calibration, 0-50,000 years cal BP. Radiocarbon, 55: 18891903. 
Holland, A. F. y Dean, J. M. 1977. The Biology of the Stout Razor Clam Tagelus plebeius: I. Animal-Sediment Relationships, Feeding Mechanism, and Community Biology. Chesapeake Science, 18(1): 58-66.

Isacch, J. P., Costa, C. S. B., Rodríguez Gallego, L., Conde, D., Escapa, M., Gagliardini, D. A. e Iribarne, O.O. 2006. Distribution of saltmarsh plant communities associated with the environmental factors along a latitudinal gradient on the southwest Atlantic coast. Journal of Biogeography, 33 (5): 888-900.

Isla, F. I. 1989. Holocene sea level fluctuations in the southern hemisphere. Quaternary Science Review, 8: 359-368.

Lamb, H. 1984. Modern pollen spectra from Labrador. Journal of Ecology, 72: 37-60.

Laprida, C., y Bertels-Psotka, A. 2003. Benthic foraminifers and paleoecology of a Holocene shelly concentration, Salado Basin, Argentina. Geobios, 36 (5): 559-572.

Laprida, C., García-Chapori, N., Violante, R. y Compagnucci, R. 2007. Mid-Holocene evolution and paleoenvironments of the shoreface-offshore transition, north-eastern Argentina: New evidence based on benthic microfauna. Marine Geology, 240: 43-56.

Laprida, C., Chandler, D. D. E., Ramon-Mercau, J., Alvaro López, R. y Marcomini. S. 2011. Modern foraminifera from coastal settings in northern Argentina: implications for the paleoenvironmental interpretation of Mid Holocene littoral deposits. Revista Mexicana de Ciencias Geológicas, 28 (1): 45-64.

Luengo, M., Bernasconi, E., Vilanova, I. y Fucks, E. 2018. Past environmental changes during the Late Holocene sea-level fall (last $2.7 \mathrm{Ka}$ ) at Bahía Samborombón, NE coastal plain (Argentina). Journal of South American Earth Science, 85: 362 - 373. 
Mancini, M.V. 1989. Depositación del polen actual en el sur de Santa Cruz. Tesis Doctoral Inédita, Universidad Nacional de Mar del Plata, Facultad de Ciencias Exactas y Naturales. $124 \mathrm{pp}$.

Mancini, M. V. 1993. Recent pollen spectra from forest and steppe of South Argentina: a comparison with vegetation and climate data. Review of Palaeobotany and Palynology, 77 (1-2): 129-142.

Marcos, M. A. y Mancini, M. V. 2012. Modern pollen and vegetation relationships in Northeastern Patagonia (Golfo San Matías, Río Negro).Review of Palaeobotany and Palynology, 171: 19-26.

Márquez, M., Ferrero, L. y Cusminsky, G. 2016. Holocene palaeoenvironmental evolution of the Pampa coastal plain (Argentina) based on calcareous microfossils. Revista Brasilera Paleontológica, 19 (1): 25-40.

Markgraf, V. y D'Antoni, H.L. 1978. Pollen flora of Argentina. Modern spore and pollen types of Pteridophyta, Gymnospermae, and Angiospermae. Tucson, Arizona. Univ. Arizona Press. $208 \mathrm{pp}$.

Markgraf, V., D'Antoni, H. L. y Ager, T. A. 1981. Modern pollen dispersal in Argentina. Palynology, 5 (1): 43-63.

McBride, R. A., Taylor, M. J. y Byrnes, M. R. 2007. Coastal morphodynamics and ChenierPlain evolution in southwestern Louisiana, USA: a geomorphic model. Geomorphology, 88(3-4): 367-422.

Medeanic, S., Costa, C.S. B. y Corrêa, I.C. S. 2006. Os palinomorfos nas reconstruções paleoambientais: Azolla filiculoides Lam. os sedimentos holocênicos da Planície Costeira do Rio Grande do Sul. Gravel, 4: 49-61. 
Medeanic, S., Costa, C. S. y Diniz, D. 2016. Modern pollen-vegetation relationships in saltmarsh habitats along a salinity gradient of a fluvial estuary.Review of Palaeobotany and Palynology, 233: 67-76.

Mourelle, D. 2011. Relación polen-vegetación actual en Uruguay. Tesis de maestría Inédita,Universidad de la República (Uruguay), Facultad de Ciencias - PEDECIBA. 61 pp.

Mourelle, D. y Prieto, A.R. 2016. Pollen and spores from surface samples in the campos region of Uruguay and their paleoecological implications. Acta Botanica Brasilica, 30 (3): 351-370.

Mourelle, D., Prieto, A.R., Pérez, L., García-Rodríguez, F. y Borel, C.M. 2015. Mid and late Holocene multiproxy analysis of environmental changes linked to sea-level fluctuation and climate variability of the Río de la Plata estuary. Palaeogeography, Palaeoclimatology, Palaeoecology, 421: 75-88.

Mudie, P.J. y Harland, R. 1996. Aquatic Quaternary.En: Jansonius, J. and McGregor, D.C. (Eds.): Palynology: principles and applications. American Association of Stratigraphic Palynologists Foundation, 2: 843-877.

Murray, J. 2006. Ecology and Applications of Benthic Foraminfera. Cambridge University Press, Cambridge. 426 pp.

Otvos, E. G. 2000. Beach ridges-definitions and significance. Geomorphology, 32 (1-2): 83-108.

Otvos, E. G. y Price, W. A. 1979. Problems of chenier genesis and terminology-an overview. Marine Geology, 31(3-4): 251-263.

Parker, G., Violante, R., Paterlini, C. M., Costa I. P., Marcolini S. I. y Cavallotto J. L. 2008. Las Secuencias Depositacionales del Plioceno-Cuaternario en la Plataforma Submarina 
adyacente al Litoral del Este Bonaerense. Latin American journal of sedimentology and basin analysis. 15 (2): 105-124.

Prieto, A. 1989. Palinología de Empalme Querandíes, provincia de Buenos Aires. Un modelo paleoambiental para el Pleistoceno tardío-Holoceno. Tesis doctoral. Universidad Nacional de Mar del Plata.

Prieto, A. R. 1992. Dispersión polínica actual en relación con la vegetación en la estepa pampeana: primeros resultados. Publicación Electrónica de la Asociación Paleontológica Argentina, 2(1): 91-95.

Prieto, A. R. 1996. Late Quaternary vegetational and climatic changes in the Pampa grassland of Argentina. Quaternary Research, 45(1): 73-88.

Prieto, A.R. y Quattrocchio, M. 1993. Briofitas y Pteridofitas en sedimentos del Holoceno de la provincia de Buenos Aires, Argentina. Anales de la Asociación de Palinólogos de Lengua Española, 6: 17-37.

Prieto, A.R., Mourelle, D., Peltier, W. R., Drummond, R., Vilanova, I. y Ricci, L. 2017. Relative sea-level changes during the Holocene in the Río de la Plata, Argentina and Uruguay: A review. Quaternary International, 442: 35-49.

Razik, S., Chiessi, C., Romero, O. y von Dobeneck, T. 2013. Interaction of the South American Monsoon System and the Southern Westerly Wind Belt during the last 14 kyr.Palaeogeography, Palaeoclimatology, Palaeoecology, 374: 28-40.

Reimer, P.J., Bard, E., Bayliss, A., Beck, J.W., Blackwell, P.G., Bronk Ramsey, C., Buck, C.E., Cheng, H., Edwards, R.L., Friedrich, M., Grootes, P.M., Guilderson, T.P., Haflidason, H., Hajdas, I., Hatté, C., Heaton, T.J., Hoffman, D.L., Hogg, A.G., Hughen, K.A., Kaiser, K.F., Kromer, B., Manning, S.W., Niu, M., Reimer, R.W., Richards, D.A., Scott, E.M., Southon, J.R., Staff, R.A., Turney, C.S.M. y van der Plicht, J. 2013. IntCal13 and Marine13 radiocarbon age calibration curves 0-50,000 years cal BP. Radiocarbon 55 (4): 1869-1887. 
Richiano, S., Varela, A. N., D'Elia, L., Bilmes, A. y Aguirre, M. 2012. Evolución paleoambiental de cordones litorales holocenos durante una caída del nivel del mar en la Bahía Samborombón, Buenos Aires, Argentina. Latin American Journal of Sedimentology and Basin Analysis, 19(2): 105-124.

Roe, H. M. y van de Plassche, O. 2005. Modern pollen distribution in a Connecticut saltmarsh: implications for studies of sea-level change. Quaternary Science Reviews, 24 (18-19): 2030-2049.

R Core Team. 2013. R: a Language and Environment for Statistical Computing. R Foundation for Statistical Computing, Vienna, Austria.URL. http://www.Rproject.org/.

Schäbitz, F. 1989. Untersuchungenzumaktuellen Pollenniederschlag und zurholozänenKlima-und Vegetationsentwicklung in den Anden Nord-Neuquéns, Argentinien.Bamberger Geographische Schriften, 8: 1-131.

Schnack, E.J., Isla, F.I., De Francesco, F.O. y Fucks, E. 2005. Estratigrafía del Cuaternario Marino Tardío en la Provincia de Buenos Aires. XIV Congreso Geológico Argentino. Relatorio, Capitulo 10,159-182 pp.

Servicio de Hidrografía Naval. 2002. Derrotero Argentino. Parte I. Río de la Plata. Buenos Aires. Publ.H-201.

Servicio Meteorológico Nacional. 1986. Estadísticas meteorológicas, Periodo 1971-1980.

Servicio Meteorológico Nacional. 1989. Inundaciones, Sudestadas y Crecidas Repentinas. Boletín Informativo 2, 19 p.

Spalletti, L. 1981.Paleoambientes sedimentarios en secuencias silicoclásticas. Asociación Geológica Argentina, Serie B, 175 pp.

Stockmarr, J. 1971. Tablets with spores used in absolute pollen analysis. Pollen Spores, 13: 615-621. 
Stuiver, M. y Reimer, P.J. 1993. Extended 14C data base and revised CALIB $3.014 \mathrm{C}$ age calibration program. Radiocarbon, 35 (1): 215-230.

Stutz, S. y Prieto, A. 2003. Modern pollen and vegetation relationships in Mar Chiquita coastal lagoon area, southeastern Pampa grasslands,Argentina. Review of Paleobotany and Palynology, 126 (3-4):183-195.

Tonello, M. S. y Prieto, A. R. 2010. Tendencias climáticas para los pastizales pampeanos durante el Pleistoceno tardío-Holoceno: estimaciones cuantitativas basadas en secuencias polínicas fósiles. Ameghiniana, 47(4): 501-514.

Torretta, J. P. y Basilio, A. M. 2009. Dispersión polínica y éxito reproductivo de cuatro especies arbóreas de un bosque xerófito de Argentina. Revista de Biología Tropical, 57(12): 283-292.

Tricart, J. 1973. Geomorfología de la Pampa Deprimida. INTA, Colección Científica, 12: 202 pp. Buenos Aires.

Van Geel, B. 2002. Non-pollen palynomorphs. En Tracking environmental change using lake sediments. Springer, Dordrecht: 99-119 pp.

Vervoorst, F. B. 1967. Las Comunidades vegetales de la depresión del Salado: Provincia de Buenos Aires. Instituto Nacional de Tecnología Agropecuaria (INTA). 262 pp.

Vilanova, I. y Prieto, A.R. 2012. Historia de la Vegetación de Las Llanuras Costeras de la Bahía Samborombón ( 35, $5^{\circ}$ s), Argentina, desde 7800 14C Años. Ameghiniana, 49 (3): 303-318.

Violante, R.A. y Parker, G. 2000. El Holoceno en las regiones marinas y costeras del nordeste de la provincia de Buenos Aires. Revista de la Asociación Geológica Argentina 55 (4): 337-351. 
Violante, R.A. y Parker, G. 2004. The post-last glacial maximum transgression in the de la Plata River and adjacent inner continental shelf, Argentina. Quaternary International, 114: 167-181.

Violante, R. A., Parker, G. y Cavallotto, J.L. 2001. Evolución de las Ilanuras costeras del este bonaerense entre la bahía Samborombón y la laguna Mar Chiquita durante el Holoceno. Revista de la Asociación Geológica Argentina, 56(1): 51-66.

Violante, R. A., Parker, G., Cavallotto, J. L., y Marcolini, S. 1992. La secuencia depositacional del Holoceno en el Río de la Plata y la Plataforma del noreste bonaerense. Resumen, 4, 275-282.

Volpedo, A. V., Yunes Nuñez, T. y Fernández Cirelli, A. 2005. El humedal mixohalino de Bahía Samborombón: conservación y perspectivas. En: J. Peten y J. Cappato (Comp.): Humedales Fluviales de América del Sur. Haciaunmanejosustentable, pp. 89-110.

Wong M.K.M. y Hyde K.D. 2002. Fungal saprobes on standing grasses and sedges in a subtropical aquatic habitat. En: Hyde KD (Ed.): Fungi in marine environments. Hong Kong, Fungal Divers, pp. $195-212$.

www.ramsar.org

Yañez, A., Macluf, C.C., Mallo, A., Giudice, G.E., Pasarelli, L., Márquez, G.J., Ramos Giacosa, J.P., Morbelli, M.A., Piñeiro, M.R., Copello, M., Nitiu, D., Kelly, S., Quetglas, M. y San Martín, C. 2014. La colección de preparados palinológicos de la Cátedra de Palinología de la Facultad de Ciencias Naturales y Museo (FCNYM), Universidad Nacional de La Plata (UNLP), Buenos Aires, Argentina. Boletín de la Asociación Latinoamericana de Paleobotánica y Palinología, 14: 55-69

Zedler, J. B., Callaway, J. C., Desmond, J. S., Vivian-Smith, G., Williams, G. D., Sullivan, G. y Bradshaw, B. K. 1999. Californian salt-marsh vegetation: an improved model of spatial pattern. Ecosystems, 2 (1): 19-35. 